\title{
THE MYTHOLOGY OF THE GAP IN THE WORK OF JAMES K. BAXTER
}

By Greg Martin

A thesis submitted to the Victoria University of Wellington in fulfilment of the requirements for the degree of Doctor of Philosophy in New Zealand Literature

Victoria University of Wellington 


\begin{abstract}
In 1967, New Zealand poet James K. Baxter reflected on his beginning as a poet with the statement that "what happens is either meaningless to me, or else it is mythology' and that in his personal mythology 'first there was the gap, the void'. While the first of these comments has been frequently cited in connection to Baxter's work, few critics have taken its extreme implications seriously. This thesis also takes the second statement as crucial to understanding Baxter's creative process and the links his poetry makes between otherwise disparate experiences. These statements are a starting point for a study which maps out the consistencies and continuities underlying Baxter's vast literar output throughout his career as a poet. It considers Baxter's poetry alongside his published prose and unpublished papers in order to demonstrate the underlying patterns which characterise Baxter's output throughout his diverse career.
\end{abstract}

The thesis first develops a framework for identifying the presence of gaps in Baxter's writing, tracing a network of symbolic and mythic relationships that comprise his evolving personal mythology of the gap. Having established this framework, I show how Baxter's engagement with 'the gap' evolves throughout his work. The thesis demonstrates the significance of gaps not only as central motifs in Baxter's work, but as a crucial part of the poet's creative process. Baxter's purposeful approach to poetic mythologising relies on notions of absence, division and descent: the 'gaps' out of which poems emerge. These gaps simultaneously create and are created by the temporary 'mythologising self' at the centre of the creative process. This is the poet as creator, shaping 'chaos' into 'cosmos' through 
the use of ordering tools. In Baxter's case these include the consistent use of three main mythic paradigms which address the imperatives of desire created by these gaps. As well as this parallel with the pattern of creation myth, Baxter's creative process is suggestive of the mythic 'journey to the centre' which is in turn recurrent throughout his poetry. In applying the 'chaos-ordering-cosmos' framework to Baxter's mythology, I reveal the consistent elements of his work on the underlying level of myth, symbol, origins and method, thus opening up new possibilities in the critical response to his work. 


\section{Acknowledgements}

Thanks to my supervisors Peter Whiteford and Geoff Miles for their support, guidance, and patience. I would also like to thank Peter and Geoff for the opportunity to work with each of them, which has helped this work in various ways.

Thanks to Paul Millar for generously making resources available, for arranging access to the Baxter material at the Hocken Library, and for sharing his thoughts on chaos and the gap in Baxter's work.

Thanks to John Baxter for granting permission to view the Baxter archive at the Hocken Library.

Thanks to Victoria University of Wellington for financial support in the form of the Victoria University $\mathrm{PhD}$ and Submission Scholarships. I am also grateful to have received the Herbert Sutcliffe MA Scholarship.

Thanks to my family, especially to my parents David and Elaine, for the many ways in which they have encouraged and assisted me throughout my studies.

Finally, thanks to my partner Rachel Patrick for her unstinting support and vital assistance in proofreading, reference checking and project management. This thesis is dedicated to her, with gratitude and love. 


\section{Contents}

List of Abbreviations ......................................................................... vi

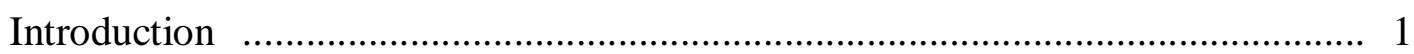

\section{Part One:}

Chapter One: The Mythology of the Gap ........................................................ 31

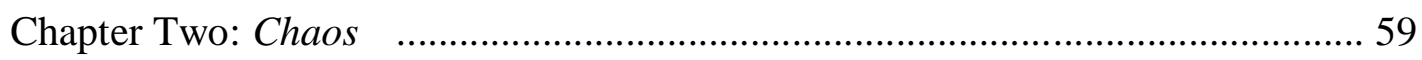

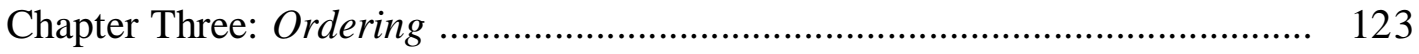

Chapter Four: Cosmos ....................................................................... 182

\section{Part Two:}

Chapter Five: 'Why the Central Horror? ' ......................................................... 216

Chapter Six: 'The time of turning darkness to sober light' ............................... 257

Chapter Seven: 'The Cold Hub' ................................................................... 288

Chapter Eight: 'To go forward like a man in the dark' ................................... 331

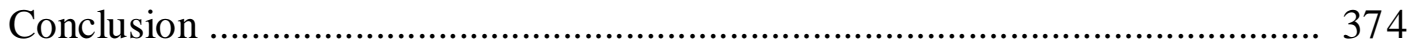

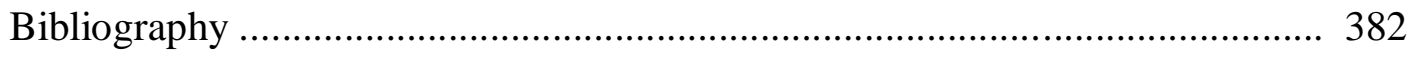




\section{List of Abbreviations}

$\begin{array}{ll}\text { CP } & \text { Collected Poems, James K. Baxter } \\ \text { CW } & \text { Collected Works, C. G. Jung } \\ \text { FA } & \text { The Fire and the Anvil } \\ \text { FC } & \text { The Flowering Cross } \\ \text { MH } & \text { The Man on the Horse } \\ \text { Muse } & \text { The Snake-Haired Muse } \\ \text { N } & \text { Baxter's manuscript notebooks, Hocken Library MS 704/1 to 704/28. } \\ \text { 'Notes' } & \text { 'Notes on the Education of a New Zealand Poet' (in MH) } \\ & \text { Collected Plays, James K. Baxter } \\ \text { Plays } & \text { Spark to a Waiting Fuse, by Paul Millar }\end{array}$




\section{Introduction}

There are always moments in history when an artist can reach out towards his country, towards his own people, and feel an answer, a response, something quite separate from the rattling noise of the business or the bureaucratic machine. At that moment an artist no longer has to fight his people: he is carried, lifted, strengthened by their genuine subconscious identification with his themes, as a boxer or a bullfighter is helped and strengthened by being at one with his audience. This is the marriage ceremony by which a myth is born. The myth may kill the man ... but one dies anyway. It is the secret hope of every artist to experience a moment of this kind. I cannot think it is likely to happen to any New Zealand artist that is, to an artist in the narrow sense of the word.

('Shots Around the Target' 2)

Since the death of James K. Baxter in 1972, just six years after voicing this 'secret hope', the mythology centred around this iconic poet has continued to flourish. As an artist Baxter, 'reached out towards his own people' through his voluminous writings - dozens of plays, articles and prose pieces as well as over 800 published poems spanning more than thirty years until his death at the age of forty-six. He remains a prominent figure in New Zealand's cultural landscape as possibly its most famous - and most widely recognised - poet. Yet when Baxter's 'own people' have reached back towards the artist it has tended to be firstly towards the poet as icon, seen through the lens of biographical narrative, rather than towards the mythopoeic art he created. It would seem that Baxter has become both more and 
less than an 'artist in the narrow sense of the word'. This thesis addresses the critical problems surrounding his work by examining the two key components of Baxter's personal 'mythology of the gap'. This approach enables a sustained appraisal of Baxter's creative process, while also highlighting the consistent and continuous elements of his poetry that have been overlooked as a result of the problematic emphasis on the 'myth' of Baxter.

A rich array of popular myth has become attached to the word Baxter, as the creative and destructive chaos of his private and public lives, along with his early death, have - (as Baxter once wrote of Hart Crane) - provided 'a whole generation of critics ... with an opportunity for myth-making' ('The Creative Mask', TFA 50). In the extended accounts found in the two major biographies, as well as in these abundant anecdotes, Baxter's life is generally divided into distinct phases based on his lifestyle as well as his literary output. ${ }^{1}$ Baxter's life-story is commonly read as an inevitable linear progression, starting with his upbringing as the son of a heroic conscientious objector and an academically accomplished and politically active mother. This leads into the distinct phases of his adult life: his literary beginnings as a precociously gifted 'natural' poet, the deeply conflicted years of his twenties mixing moralistic social commentary with literary skirmishes and 'bohemian' bouts of drinking and sexual indiscretion - and then the seemingly settled years as Baxter gave up alcohol, became a Catholic and cemented his status with the literary achievements of the mid 1960s. The twist in this narrative comes in the startling transformation of his last three years into 'Hemi' the bearded, barefoot founder of a commune at Jerusalem on the Whanganui River. In this phase, Baxter became a self-appointed spokesperson for those he perceived to be marginalised - especially

${ }^{1}$ Frank McKay's The Life of James K. Baxter (1990) and W.H. Oliver's James K. Baxter: A Portrait (1983). 
for the young and for Maori. This life-story has become central to the way that the poems are interpreted - very often these texts are simply taken to be a record of experience embedded with statements of belief.

At the same time as he publicised his 'secret hope' to be joined with his people, Baxter dismissed the likelihood of becoming a 'kiwi hero'. In 'Shots Around the Target' he challenged those attending the 1966 New Zealand Universities art festival with a dystopian view of 'mother New Zealand':

a society in which there is too much stupidity and emotional numbness; where it is extremely difficult for anyone to change, develop, grow up, break the pattern. She is determined to bear no children - that is, she won't allow any living acts or thoughts to survive inside her.

This reading of New Zealand presents a heady mixture of birth, sex and death, connection and separation, domesticity and disorder, sacrifice and exaltation which reflects the severe contours of Baxter's own personal mythology. It was on these extreme terms that Baxter felt called to struggle against his 'own people' while at the same time reaching out for connection with a tribe who were open to 'living acts or thoughts'. Having long been a legendary figure amongst the literary community, during the last three years of his life Baxter consistently spoke of having abandoned the artistic 'fight' for another, more socially active form of combat. In the process 'Hemi' became for many a living symbol of opposition to the 'majority culture' - a 
'kiwi hero' and a 'living myth'. ${ }^{2}$ Despite his assertion that James K. Baxter the poet was 'dead' the poetry of these final years is often considered to be amongst Baxter's best ${ }^{3}$. While the Hemi persona proved divisive and controversial during these years, the outpouring of grief and love towards Baxter after his death suggests a moment of celebration and acceptance which accorded with his 'secret hope'. The Dominion newspaper carried a full front-page headline simply stating: 'James K. Baxter: 1926 - 1972 - Friend'. Thus one might argue that the closest the artist came to a moment of unity with his people was during the tangihanga at Jerusalem which marked his death and celebrated his life, while in turn providing an enduring form for the 'Baxter myth'. The diversity of New Zealanders attending was considered a testament to the man and his life's work, while a survey of accounts of the proceedings during the tangi suggests that those attending found the experience to be inspirational, disconcerting, or a mixture of both. ${ }^{4}$ Some, such as Allen Curnow, expressed confusion over exactly who was being mourned - person, poet or prophet. ${ }^{5}$ Another prevalent response was a blend of profound loss with a faint hope that the unifying spectacle of Baxter's tangi might mark the beginning of something new within the culture as a whole.

Baxter's life and his poetry had already encouraged some to respond to him in the language of myth. After his death, mythologising was inevitably a common means to come to terms with what seemed to be a new cultural phenomenon. In this emotional climate, some interpreted Baxter's last 'act' in hopeful terms as a

\footnotetext{
${ }^{2}$ Baxter's friend James Bertram saw in his death 'an optimistic tragedy: if he lived by extremes, that was how it had to be. He lived his own myth, and by his poetry, his faith, and his vision of human brotherhood he had made it living for others' (Memorial 77).

${ }^{3}$ See for example Jerusalem Daybook (1971): 'The man called James K. Baxter, who is like a dead body in the ground, swells up and gives off a stink of words' (18).

${ }^{4}$ See The Double Rainbow 172-78, and James K. Baxter: A Memorial Volume.

${ }^{5}$ See Muse 251-53.
} 
revelation of another realm of possibility. As the centrepiece of the tangi, Baxter drew many Pakeha into the experience of a new ritual. In the space of silence and absence which his death created, it was possible for sympathisers to imagine Baxter in one last mythic role, as psychopomp standing at the threshold between two realms, guiding the spirit of the people towards a new era of openness and connection. This is reflected in a tribute by Baxter's friend, the novelist Maurice Shadbolt, whose earlier ambivalence towards the Hemi persona was overturned: 'I saw another New Zealand ... that was your last act ... To throw open the door ... and allow us a dazzling glimpse of the dream' (Memorial 32). Arguably, within the culture at large it is this 'Jerusalem' Baxter - 'Hemi' - combining public prominence and social activism with poetic mastery, which has been sealed by his early death and the ritual ceremony of his tangi as the icon at the centre of the dominant Baxter myth. Shadbolt's words suggest that for many of his contemporaries Baxter did indeed become in death more than an 'artist in the narrow sense of the word'; he became an iconic figure whose meaning would now be provided by the mythologising interpretations of others.

The extremes of iconolatry and iconoclasm have continued to inform 'popular' responses to Baxter. In 'Shots Around the Target' Baxter despairs of ever 'being one' with his people and suggests that in death he will remain beyond the pale, dissipating into an anonymous ghostly presence:

... perhaps in a hundred years from now I will still be haunting her sleep, like something lost, like a voice whose owner one cannot quite identify, slipping in between the TV and the tranquilizers. 
On the contrary, the name Baxter remains resonant within New Zealand culture, crossing over between literary culture and the wider culture. The emphasis on the later Baxter at the centre of these mythic stories has made the poet an 'icon' in the sense of a highly recognisable figure interpreted as representing distinctive qualities. Baxter's 'ghost' seems ever-present - if only as an image which can variously represent inspired creativity, non-conformity, calculating sophistry, a spiritual search for truth and brotherhood, or egotistical self-deception. Competing mythologies claim narrative possession of this polarising figure through a diversity of forms encompassing plays, films, poems, songs, a dance opera, memoirs, sociological studies and literary criticism. The image of 'Hemi' has remained visible - notably in a number of plays which exploit the theatrical possibilities of this conflicted character and highlight the generic aspects of Baxter's Jerusalem project as emblematic of a cultural moment, embodying the fusion of the earnest and the absurd which are commonly associated with the 'hippie' era. ${ }^{6}$ These creative responses affirm the 'fertile' ongoing relationship between the man and his people and arguably reflect a range of cultural needs which are not being met elsewhere - thus a popular myth emerges, utilising a suitable icon to address a cultural need.

However, the prominence of this public icon raises critical problems when the real or perceived 'difference' in the way that Baxter presented himself as a poet is repaid in kind by critics. In his opening address to the 1994 'James K. Baxter: Poet and Prophet' conference, Bill Manhire expressed a common concern that Baxter the poet was disappearing behind the mask of the 'prophet':

\footnotetext{
${ }^{6}$ Particularly Jerusalem, Jerusalem by Mike Riddell and Horseplay by Ken Duncum.
} 
It strikes me as perfectly possible that a serious devotional cult will grow up around him in the next twenty years. The next gathering that deals with James K. Baxter may well find itself putting the prophet before the poet. I can't say that I will be eager to attend.

('Stranger at the Ranchslider' 17)

While there is little evidence that a 'serious' cult has emerged in the intervening years, the extremes of iconolatry and iconoclasm have continued to inform the 'popular' response to Baxter. Writing weeks after Baxter's death, C. K. Stead expressed his appreciation for Baxter's later poetry at the same time as lamenting the 'haze of undiscriminating feeling' which then surrounded Baxter as a public figure:

to the young ... he has become a culture hero, and if his poems were much less remarkable than they are I suspect his youthful disciples would not know it and would admire them quite as much.

('Towards Jerusalem’ 9)

John Newton takes issue with this notion of Baxter as a 'cult' writer, considering this suggestion of 'an audience drawn to Baxter's writing by his person or his legend, and by implication engaging with the text itself in a partial, vestigial, or untutored way' to be based on a false elevation of another sort of reader. For Newton, also a poet and an academic: 
"cult" imposed as an academic label, patronises reader and poet alike. And in doing so it implies an erroneous distinction, blaming this ad hominem seduction on an unreliable readership; this closes down the more challenging thought that everyone, in fact, may read Baxter naively, the trained and the untrained reader alike, in as much as we all now encounter the text - at least to some extent - through the filter of Baxter's fame.

('By Writing and Example')

Newton notes that 'the photographic imagery associated with Jerusalem' has been particularly influential in shaping the response to Baxter as both poet and public figure. In these images, Baxter is frozen in place as an icon, a mythic figure whose appearance is read as a set of signs. The dominance of this image has ensured that Baxter's place in the culture has remained connected with the counterculture of the late 1960s and the 1970s, with various forms of religion and spirituality, and with the movement towards biculturalism which emerged in the last quarter of the $20^{\text {th }}$ century. ${ }^{7}$ In keeping with the tone of response popular at the time of his death, it appears that some readers continue to see Baxter as a totemic figure, a man of deep principles and spiritual insight and thus a worthy subject of reverence. While a formalised 'cult' has not emerged, there is a lingering perception that these sociopolitical and religious strands dictate simplified readings of Baxter's poetry for many 'untrained' by academic discipline; that he is read for the 'prophecy' rather than the poetry.

If the popular mythology surrounding Baxter and the fringes of 'cultish' devotion rely on naive or simplistic interpretations of the man at the centre of the myth, literary criticism has also often failed to go beyond the barrier of Baxter the icon. In

${ }^{7}$ See The Double Rainbow 7. 
a typically confrontational manner Baxter wrote in 1966 that the marriage ceremony of writer and community is 'only a preliminary to a further ceremony where he will be decapitated or emasculated or torn apart or disembowelled by those to whom he has joined himself' ('Thoughts of an Old Alligator' 8-9). If the 'myth' of Baxter has threatened to 'kill' anything, however, it is receptiveness towards the poetry itself, which seems for many to have become inseparable from the figure of the poet as prophet. Given the 'prophetic' position on display here, it is perhaps unsurprising that few critics have been willing or able to consider Baxter's work as a whole without feeling obliged to judge the merits of the man who inhabited these public roles. It seems possible that the response of literary critics has thus been shaped by Baxter's iconic stature in the culture at large, with the result that his poetry is rarely taken as the subject for serious extended analysis in itself. Thus the tendency towards partisan and partial responses to Baxter, and a notable preference for a tone of informality and irreverence in the literary discourse which is suggestive of the extent to which the artist has truly become iconic, a mythic figure himself rather than a creator of mythopoeic art. In Newton's words, as poet Baxter presents 'the paradox of a figure who is somehow too famous to write about' ('Example'). By treating Baxter as both more and less than an artist - whether responding in sympathy with or against the 'icon', many literary critics have overlooked the variousness, as well as the sum accomplishment of Baxter's lifetime of writing as demonstrated by the Collected Poems. As in the wider culture, Baxter has come to 'represent' views and beliefs which must be defended or attacked, rather than a poet like any other whose works can be engaged with critically and creatively.

In 1997 Paul Millar noted that Baxter criticism had failed to keep pace with posthumous publications of his verse as well as 'frequently fail[ing] to achieve 
balance' ('The Tension of Belief' 103). A large proportion of those writing about Baxter's poetry during his life and in the decades following his death had personal dealings with him. Thus critical responses have frequently blurred the lines between serious analysis, personal reminiscence and attacks on Baxter's character. In 1990 the Scottish poet and academic Alan Riach wrote that

one's reading of Baxter's work may be affected by whether one was personally offended by him. This is particularly important with Baxter, who offended more people than did most other New Zealand writers; and it is particularly important in New Zealand.

('James K. Baxter and the Dialect of the Tribe' 107)

Iain Sharp presents an example of the problematic blurring of the critical and personal modes in 'My Grudge against Baxter'. Sharp is refreshingly open in this humorous diatribe, in which he presents the origins of his own bias against including Baxter in a list of the 'ten best New Zealand poems'; eventually deciding against including Baxter despite 'popular opinion'. Sharp's discussion of the literary merit of Baxter's work in a popular magazine is problematic where it blurs the lines between critical analysis, humorous and self-deprecating reminiscence, moral judgment and open personal hostility:

Ah, the hell with it ... I'm sick of Baxter's histrionic presentation of himself as a sacred pariah. Since he was so determined to be an outcast, why don't I cast him out? Yeah, I'm going to kick him off my list altogether. 
Sharp makes it clear that his critical appraisal of the poetry had been shaped by two early encounters with 'Hemi', who was not the heroic figure he had hoped to meet but instead 'a cagey, self-conscious, manipulative ham actor.' Eventually the critic cannot resist the opportunity to label Baxter a 'sanctimonious bastard', using his own authority to exact critical revenge and snatch Baxter's poetic 'staff away from him and beat the bejasus out of him with it'.

In 'The Stranger at the Ranchslider' (1994) Manhire takes exception to some of the creative mythologising which has emerged as Baxter becomes more icon than artist. In the context of a conference devoted to Baxter as 'poet and prophet', ${ }^{9}$ where academics, 'devotees' and others engaged with a wide variety of notional Baxters, Manhire presented an informed analysis of the poetry before concluding by questioning Baxter's fitness for the role of prophet. Alluding to his own early encounters with Baxter, Manhire suggested that as a man, the poet 'struck me as a dangerous figure - someone who was partly responsible for the human problems to which he ministered' (19). However valid, this subjective response seems to contradict Manhire's earlier suggestion that 'the Baxter that we talk about now is a mythological figure of his own creation' (15).

In 'Tension of Belief' Millar suggests an approach to Baxter's apparent hypocrisy or duplicity which may prove more fruitful:

\footnotetext{
${ }^{8}$ See Muse, 17.

${ }^{9}$ See Journal of New Zealand Literature 13.
} 
the critical response should not be to castigate Baxter for his duplicity, nor should attempts be made to justify or excuse. Rather, understanding its origins should be a necessary pre-condition for approaching his poetry.

The focus on Baxter's mythopoeic mode of thought can perhaps shed some light on this apparent 'duplicity', without the need to either defend or attack the individual. Rather, what Baxter's extreme example can perhaps reveal is the relative strengths and weaknesses of this mythopoeic mode as a way of making meaning out of one's personal experience and the world one inhabits. The importance of this focus on 'origins' in Baxter's work cannot be overstated. In order to move the discourse forward, an emphasis on the methods underlying the material is vital in furthering a critical understanding of Baxter's work.

The defensive response to the 'popular' notion of Baxter as prophet is linked to trends within New Zealand literature which have seen the work marginalised while the 'image' remains central. Millar notes the 'curious possessiveness' amongst New Zealand's small literary community which has always influenced reception of Baxter's work, especially given the dominance of poets amongst these critics. A stance 'towards Baxter' as a type of poet and a type of man has come to be more important than a critical appreciation of his work. The desire to claim Baxter for one camp or another has been matched by an opposing tendency identified by Millar, where 'some of what passes for criticism is merely the new testing itself against the old, or the origins of the critique derive from the personal and philosophical differences that inevitably arise when one poet was as celebrated and controversial as Baxter' ('Tension' 124). The virtual absence of Baxter criticism 
from outside New Zealand has not helped this situation. Riach noted the 'cloud of prejudice and conventional cant' that surrounds Baxter's later poems in particular: 'Even now, myth and legend help to relegate any freshness of response and make it difficult to read the words there on the page' ('Dialect' 107). These shifting literary 'myths' have often obscured Baxter's work rather than illuminated it. In 1990, Riach suggested that as poet Baxter was often seen as a threat to the 'categories by which the local exigencies are measured. He is seen in a confused context; he is evicted from the tradition-structuring myths or wrested into them by violence' (111).

Curnow, generally seen as a poet both equal and opposite to Baxter, played a large part in determining the younger man's position within the New Zealand literary 'tradition' he attempted to create and shape. The mode of poetic expression was central to the debate over Baxter's work, with Curnow criticising Baxter for lacking the 'instinct for a reality prior to the poem' which could support rhetorical expression (Penguin Book of New Zealand Verse 62). Curnow had earlier tried to claim Baxter for his new local tradition. By including six poems from Baxter's first collection in his 1945 anthology before the work was even published, Curnow gave the young prodigy his entry into the literary spotlight, while at the same time expressing the belief that the young poet owed a 'debt' of influence to 'some older New Zealand poets' (A Book of New Zealand Verse 54). ${ }^{10}$

Curnow's paternal sense of disappointment in Baxter was still evident thirteen years after Baxter's death. In an interview with Harry Ricketts, he expressed a fear that the 'package - the poet and the poetry, the book in the hand, the poet acting the

\footnotetext{
${ }^{10}$ See chapter 6. In Spark Millar provides evidence suggesting Curnow was overstating this 'debt', perhaps as a result of Baxter's own comments (115).
} 
part, and dressed for it' diminished the popularity of poetry, rather than promoting it: 'so many of the public in these mass-media times are stopped short by that posturing image of the poet outside the tent - like the showman he calls out "now showing on the within", but they don't go in, or they don't stay long' (Talking About Ourselves 101). Thus Baxter is seen as representing an unfashionable, even embarrassing, romantic version of the role of writer in society. Manhire's comment that the Jerusalem Baxter confirmed a "whole set of standard prejudices, including those about the general uselessness of poets' ('World Famous in New Zealand' 7), while presented in a humorous manner, reflects this ongoing struggle over the status of the writer.

In contrast to this enduring strain of defensiveness, Curnow's erstwhile 'ally' C. K. Stead told Ricketts that he regretted his own support for this excessively personal response to Baxter:

Brasch and others would be dismissive, and I'd join in. What we should have been saying was, 'Well, Baxter may be an irritating person in all kinds of ways, but aren't we lucky to have someone so brilliant!' and it wasn't being said.

In 'After Bathing at Baxter's', Gregory O'Brien considers the struggle of the generation of poets following in his wake:

Because Baxter was such a singular prophet-like figure, towering in his brilliance, his idiosyncrasy, his rightness and his wrongness, no one was 
going to directly inherit the role or step into his shoes. He served to atomise New Zealand poetry, leaving a chaos or variousness in his wake. I suspect few younger poets would be comfortable with having the label BAXTER or BAXTERIAN stamped on any of their luggage, let alone on their person.

From this perspective the process of re-creating 'New Zealand poetry' out of the chaos left after Baxter's death is bound to be a defensive response to this 'towering' figure. This sense of a looming, monolithic presence might be one explanation for the continuing reluctance to engage with Baxter's work directly, as demonstrated by O'Brien's preferred creative approach, in which he threads his response to the poet into a personal narrative. Rather than attempt to re-evaluate and re-position the poetry through 'systematic and rigorous investigation', O'Brien chooses 'not to refer to - or reread - any of Baxter's writing ... I wanted to excavate the residue of "Baxter" inside myself, to find out exactly what was still there and how persuasive it was' (43).

In his own critical work, Baxter attempted to distance himself from the "personalist heresy of equating a writer and his work', suggesting that this type of literary 'Hero-worshipper' who 'confuses inextricably biographical detail and literary criticism' can be particularly 'dangerous' ('Criticism' 24). However, there is conflict between this view and Baxter's belief in the social function of the poet as someone who speaks the truth to the people. This becomes clear when Baxter's own idiosyncratic, mythologised reading of personal experience leads to a 'meaning' which is then applied to the world at large. Baxter habitually make this step from private emotion to universal 'truth' within the space of a line. Separating the poet 
and the poetry becomes increasingly difficult when this focus on personal experience is matched with a 'prophetic' tendency to pronounce on spiritual, political and social matters. Bill Manhire presents the objections of those who feel crowded out by this 'prophetic voice':

There is no conversation to be had with such a voice. It makes the word 'preaching' alliterate with the word 'precious'. ${ }^{11}$ It is seamless in its utterance. You listen, or you leave the room.

('Ranchslider' 11)

The resistance to Baxter's rhetorical methods, as well as his messages, has thus remained a common trend in the critical discourse, though other poets have more recently displayed a receptive attitude to Baxter's rhetorical tendencies. ${ }^{12}$ The apparent dominance of Baxter's voice has often obscured other notable aspects of his work such as his incredible productivity and the role that his 'mythologising' mode of writing and thinking played throughout the course of his life. In an early critique of the notion of a 'national' literature, Baxter praised Frank Sargeson's work above and beyond consideration for its 'local reality', since 'creation precedes classification' ('When the Wind Blows', Canta, 5/5/1948, 6). For Baxter, mythologising did not start and end with the composition of poetry, being fundamental to the way that he saw the world and lived his life. Rather than starting from a supposedly common shared experience of the local environment, for Baxter the 'reality prior to the poem' is emotional and spiritual, and the critical response to his work needs to take this into account.

\footnotetext{
${ }^{11}$ See 'Wild Bees', chapter 6.

${ }^{12}$ See for example Anna Jackson, ‘An Appealing Excess' 205-06.
} 
Curnow criticised Baxter for taking on the public persona of the poet too selfconsciously, meaning that his was an 'image much more impressively elevated in the public eye, a personal 'myth' very consciously projected by the poet'. Curnow added that 'one says it can't be helped, and maybe it's silly to wish it could have been' (Talking 101). To wish that it might have been otherwise is to imagine another poet. Indeed, Baxter seems to have been aware of the many of the obvious faults in his own poetic method as well as the faults of others. His own resistance to Curnow's 'literary fiction of the spiritual isolation of the New Zealander' (expressed privately in a letter to Curnow's 'ally' Charles Brasch) applies to his own work:

... The trouble with Allen as a critic and editor is that he is right within his frame of reference, but the frame of reference excludes the actual growingpoints of quite a number of other people, who are not really concerned whether they are New Zealanders or not.

(McKay 187-88)

Baxter's own 'frame of reference' inevitably also excludes 'growing-points' and reflects subjective inclinations which are consistently presented as universal truths. Yet the point at issue for critics now is whether they wish to address the distinctive features of Baxter's personal mythology - his frame of reference - as well as discovering that which links Baxter to a certain time, place and people, and beyond this, what if anything Baxter's mythologising might reveal the process of making meaning. If the reader disagrees with the 'meaning' extracted from Baxter's mythologising, one need not 'leave the room' if one still has an interest in the 
mythologising and what lies behind it. This is the fundamental approach taken by Miles, Davidson and Millar in The Snake-Haired Muse:

Baxter's use of classical myth needs to be taken seriously... far from being dispensable baggage, it lies close to the heart of his poetic project; and that criticisms made of it often rest on assumptions about poetry in New Zealand - what it is and what it should be - that are positively unhelpful in dealing with the kind of poetry that Baxter was trying to write.

In 'By Writing and Example' Newton argues that the attempt to separate the two parts of the 'Baxter effect' - the textual and the 'legendary' elements - by reading the poetry as distinct from the public figure has failed. Newton suggests that these two elements are both manifestations of Baxter's romanticism, which he sees as flowering in the late poetry and activism: 'the Hemi persona emerge[s], not at the cost of the poetry, but as an evolution of it'. Thus 'rather than try to uncouple the poems from the figure of their over-publicized author' Newton aims to 'consider the rhetorical continuities that bind the two together in the service of Baxter's romanticism'. This represents a new direction in attempting to deal with the 'Baxter effect' where the poetry and public life are inseparable. I would argue, however, that the emphasis on Baxter's romanticism as a consistent underlying element informing his work is problematic and that Baxter's 'romanticism' is not as stable and convinced as his readers might imagine. This thesis builds on earlier work ${ }^{13}$ to suggest that Baxter's 'rhetorical continuities' in positioning himself as a principled

${ }^{13}$ See for example Millar, 'The Tension of Belief'. 
'outsider' and implicitly or explicitly claiming an elevated status for the poet ${ }^{14}$ are strategies which relate to the ongoing, unresolved tensions which are reinforced through his creative process. The evidence supports Baxter tendency to present his writing as a necessity, an urge, a drive or a compulsion - not as a deliberately practiced 'deployment' of a poetic, as Newton has it. This thesis shows that Baxter's method relied on accessing and accentuating a sense of loss, absence and division, rather than being simply a means to expressing identity and beliefs. The chaotic mixture of elements in Baxter's writing and his character may perhaps be reinterpreted together in the light of a new focus on Baxter's method.

A list of the published critical studies which have dealt with Baxter's work in detail provides a suggestive contrast to the enduring prominence of Baxter's image. Three slim volumes appeared in the 1970s - John Weir's The Poetry of James K. Baxter (1970), Charles Doyle's 1976 monograph for the World Authors Series and Vincent O'Sullivan's monograph James K. Baxter (1976). ${ }^{15}$ A twenty-five year gap followed before Millar's work on Baxter's adolescent poetry in Spark to a Waiting Fuse and his collaboration with Geoffrey Miles and John Davidson on The SnakeHaired Muse. This exhaustive work focuses on Baxter's use of classical myth, covering not only the breadth of published material - poems, plays and prose - but also the enormous volume of unpublished work which is archived in libraries throughout the country. ${ }^{16}$

Other critics have tended to focus on isolated aspects of Baxter's work such as technical elements, literary and other influences. While this has produced much

\footnotetext{
${ }^{14}$ See O’Brien 20.

15 In addition to this, Frank McKay's 1989 biography The Life of James K. Baxter also includes a running commentary on Baxter's poetry. All references to Weir, O'Sullivan and McKay are from these texts unless otherwise stated.

${ }^{16}$ In particular the Hocken, Beaglehole and Macmillan Brown library collections.
} 
interesting work, the problems stemming from the large amount of published material, the divergent streams in Baxter's work - devotional and profane, high seriousness and humour - along with the persistent biographical focus in these responses means that often events in Baxter's life are read as the sole cause of these differing elements. This leads to critical gaps, where the range of Baxter's work is overlooked in favour of excessively subjective preferences. It has become a commonplace observation that Baxter is a poet 'whose circumference our reading does not seem able to reach' (Ian Wedde, The Penguin Book of New Zealand Verse, 1985, 44). This has led to a notable disparity between the plethora of short pieces on Baxter and the dearth of more 'systematic and rigorous investigations'. It is likely that the imposing bulk of the Collected Poems - which lends itself to dipping rather than immersion - has played a part in ensuring that 'our sense of his achievement is necessarily inconclusive. The full overhaul has yet to be done' ('Dialect' 104-5). This all means that fundamental aspects of Baxter's work are overlooked at the expense of an exclusive focus on the surface detail of literary form and social, political or religious content.

The focus on the surface level content of Baxter's work - the 'ideas', beliefs, historical events it contains - is one reason why there is a lack of awareness of the distinctive underlying features of his personal mythology. Reading Baxter's work as a personal mythology allows for the possibility of establishing connections on this underlying level - in Baxter's own terms, the 'subconscious' level of myth and symbol - which can highlight what Baxter was doing within his own mythological 'frame of reference'. My contention is that Baxter should indeed be positioned and evaluated in light of his work as a whole, rather than becoming the sum of his different parts. This holistic approach takes away some of the risk of projection 
which can be supported by selective reading, as sustained reading brings out the connections and underlying consistencies in Baxter's approach while also revealing the extent to which he imposed mythological meaning on his experience. This is firstly shown in Baxter's distinctive and relatively consistent symbolism, drawing heavily on natural processes and mythic patterns. The mythologising mode of thought which links these symbols quite directly with emotions and intuitive or non-rational, pre-articulate sensation then allows for the tracing of a network of meanings, as O'Sullivan outlines. What becomes clear is that Baxter's mythologising often applies the same patterns of symbolism and mythic structure to what might otherwise appear to be widely divergent 'surface' content. It is on this level of mythologising that Baxter is consistent, rather than in any presentation of rational argument. This explains the significant issues arising from the obvious sense in which, as Mark Williams notes, Baxter 'simplified various kinds of otherness' - notably women and Maori - for his own mythologising purposes ('James K. Baxter'. The Literary Encyclopedia). ${ }^{17}$

The critical response to Baxter needs to focus initially on establishing the things that Baxter does consistently, the material that he chooses to shape and the way that he shapes it. From this can emerge a picture of Baxter's creative endeavour which allows for informed criticism free from the personalist tendencies towards mythologising or demythologising the persona of the poet. Thus my work is an attempt at making connections between the various aspects of Baxter's work, where the divergent, inconsistent or seemingly paradoxical elements are illuminated by looking at what drove his thinking and the patterns and processes that he relied on

\footnotetext{
${ }^{17}$ See for example, Rachel McAlpine in Talking About Ourselves 40-41: 'When I read [Baxter] now, I think there's an enormous gulf between us ... It's like him being up on a high hill or up by the altar and everybody else is a long way away, at least I am ... when he turns on that voice...'
} 
to make meaning. This approach offers a chance to make these connections and mythologise Baxter more meaningfully.

In constructing a framework for reading Baxter's poetry, I am not attempting to present a 'definitive' interpretation of his work, nor to limit the frame of reference to the recurrent elements which I trace throughout this thesis. A few critics have previously claimed the discovery of a hitherto unknown 'key' to Baxter, based on some external influence which had shaped his work. Kai Jensen's 'The Drunkard and the Hag: James K. Baxter's use of Jung' and Trevor James's 'Baxter in the Labyrinth' are two notable examples of this search for a defining influence on Baxter's work. ${ }^{18}$ These two pieces present interesting perspectives on Baxter, and Jensen's argument that Jung is a major influence on Baxter's thinking is convincing, yet these pieces rely on a selective reading of Baxter's work which ignores or underplays the inconsistencies and conflicts which are most evident in Baxter's prose. Similarly, Weir's summary of Baxter's work accurately highlights the importance of a 'sense of loss' and the relationship to the narrative of 'The Fall', as well as the way in which Baxter's poetic mythologising functioned as a whole. Yet Weir reads the poet's development as a pilgrim's progress towards the establishment of a Christian philosophical framework which would finally end the 'search for order' that Weir claims was central to Baxter's mythologising. This reductionism was immediately challenged by Baxter's actions in abandoning (an outwardly) 'stable', orderly suburban, domestic life for his Jerusalem mission, which had happened between the writing of Weir's thesis and the publication of this work. Weir's own 'frame of reference' is quite clearly shown in the 1971 interview

\footnotetext{
${ }^{18}$ James's investigation into Baxter's symbolism reveals consistent patterns of imagery of the centre and the labyrinth. However, the limited selection, overlooking of Baxter's prose and dubious hunch regarding the supposedly 'definitive' influence of Cecil Day Lewis result in a significantly flawed argument.
} 
with Baxter, where the poet's emphasis on the fundamental sense of 'chaos' is consistently misread in privileging 'order'.

These readings again seek to impose a critical myth from outside. I am not approaching Baxter through the lens of a specific literary theory or philosophical context, nor am I aiming to place Baxter in relation to his peers in a New Zealand literary canon. My own approach is to seek to point out what Baxter does consistently, allowing the internal structuring elements of the work to emerge and utilising the critical tools developed by those who have read Baxter's work as a whole. Rather than reading from the personality to the poetry, the poems themselves, read as a whole, allow us to see what Baxter was consistently doing in 'making meaning'. Thus they also offer the possibility of making links between the various diverse elements of Baxter's character and life. This thesis is therefore not intended as a critical re-evaluation or an 'intervention' in Baxter's favour. ${ }^{19}$ Indeed, my focus on Baxter's creative process will make no direct consideration of notions of quality with respect to the poetry. Nor will I pay substantial attention to matters of literary form and influence, instead focusing on the machinations of the creative process which shaped the work.

This reading of the poems is supported by a thorough reading of Baxter's vast, uncollected prose. Commentators on Baxter's work have often ignored this vital evidence. I take a critical yet receptive approach to Baxter's comments on his own creative process, as they suggest his own sense of the origins of his work. My thesis builds from the twin claims about 'origins' which Baxter makes in the highly revealing prose piece 'Notes on the Education of a New Zealand Poet'. By focusing on 'the gap' and 'mythologising' as the two organising principles of Baxter's work,

${ }^{19}$ See Newton, 'By Writing and Example'. 
this thesis draws out the implications and assumptions which inform this creative process, demonstrating the ways in which Baxter's mythologising reflects the imperatives of desire which drove his poetic mythologising, particularly his enduring search for meaning, healing and identity.

In developing a framework with which to consider the consistent aspects within this variousness, a fruitful approach to Baxter's poetry has been suggested by the work of O’Sullivan and Millar. O'Sullivan points to the most consistent aspect of Baxter's writing, when evaluated as a whole, when he suggests that if Baxter's verse 'carries "one story and one story only" it is the story of his own personality exchanging unshaped experience for the form of myth' (9). ${ }^{20}$ In turn, the personal mythology he created is centred around the 'ubiquitous notions of the gap' that Millar highlighted in 'Hemi te Tutua'.

O'Sullivan's work points to another crucial yet often overlooked issue which underpins the tension around Baxter's cultural positioning. Notions of identity are brought into question whenever an individual seems to display such a range of divergent characteristics. The reader may feel

an odd discomfort when one part of the man so obviously appeals to us, and another part does not. Yet our preference ... well that quite clearly is our business, rather than Baxter's. If we continue to feel that what we deal with as we read him, or remember him, are two personalities rather than one, then that may be because most of us do not easily accommodate the notion that personality is perhaps a much more fluid thing than we like to believe ...

(Two Baxters 75)

\footnotetext{
${ }^{20}$ The reference is to Robert Graves' poem 'To Juan at the Winter Solstice'.
} 
This thesis argues that, rather than an assertion of identity and belief, Baxter's poetry is produced in an attempt to discover or construct that which appears to be lacking - meaning, healing and identity. While Baxter himself was critical of the tendency to worship cultural icons, for the Baxter 'iconolators' and 'iconoclasts' the poet's 'strong personality' and firm beliefs are often taken as the source of the poetry, reflecting the common tendency to search for a unitary centre or source for the work. In contrast to this supposition, Baxter consistently pointed to experiences of internal division, dissolution, negation and alienation as the source of his inspiration. The final years of his life present the paradox of the 'iconic' Hemi figure courting publicity and controversy on one hand while using his poetry to (amongst other things) attack his own attachment to the 'icon' of his personal identity:

It's a long time now

Since the great ikons fell down,

God, Mary, home, sex, poetry,

Whatever one uses as a bridge

To cross the river that only has one beach,

And even one's name is a way of saying -

'This gap inside a coat' ...

('The Ikons', 1971, CP 499) 
As Miles notes in his commentary on Nigel Brown's triptych Poet 3 Times, 'The Ikons' presents a typical paradox, where the claims to humble self-abnegation are brought into question even as they are written by the act of public selfmythologising ('Baxter as Icon'). Yet the concern over a sense of 'absence' is constant throughout Baxter's work, indeed it seems to be one of the driving factors which leads him to 'mythologise' so constantly.

While Baxter's mythologising comes out of a sense of lack, absence, division and uncertainty, it is also a product of his tendency to read reality through the mythic lens which developed as part of his poetic gift. Baxter sees the world through his own frame of reference, associating what is 'meaningful' with what he can 'mythologise' - and thus selecting and shaping those elements of his experience which relate to the meanings that have already been established. What Baxter's mythologising reflects, then, is the constant need to rediscover or recreate a sense of meaning, healing, and identity. Paradoxically, these are all threatened and affirmed by the focus on the gaps in his experience, which thus reshaped the 'mythologising self' in the process of the writing. Whatever else it is, the story of James K. Baxter is presented in his personal mythology as the lifelong engagement with 'the gap', which provides the starting point for the mythology and thus the origins of personal meaning and identity.

Thus in order to approach Baxter's work 'whole', we need to pay critical attention to his creative method as well as his material. This means addressing his 'mythologising' method directly, as well as understanding the ways in which Baxter utilised mythic forms. By analysing Baxter's mythologising method, critical tools can be forged which can be of use in reading the full range of his work. Weir's reading of Baxter's 'search for order' emphasised the importance of this method as a 
means to shaping the 'chaos' of personal experience. O'Sullivan notes the use of 'transference' in moving between myth and personal experience, thus making meaning and also shaping his life experience. He also addresses Baxter's purposeful use of mythopoeia as an attempt to make contact with the 'sources of order' and engaging with the shared communal past which informs his mythologising.

O'Sullivan notes Baxter's comments on 'the three great burdens [God] requires our souls to carry - great pain, great cold, great darkness' as a common starting point: 'One could set out from there and arrive at many places in Baxter's thought' (Two Baxters, 80-81). Elsewhere O'Sullivan discusses Baxter's use of the term nada in 'The Cold Hub', suggesting that this sense of emptiness and dissolution could serve to represent Baxter's underlying unity of belief on an 'existential' level. This mysterious centre of life and death can in this sense be considered the terminal point of Baxter's thought, where all aspects of his writing converge' (51). O’Sullivan's argument concerning a 'network of relationships' (Two Baxters 78) which illustrate the fundamental consistency underlying the complex elements of Baxter's thought is persuasive, though in my own work I use the term 'the gap' as the central point of Baxter's personal mythology. This follows from Baxter's own mythologised account in 'Notes' - however, I use this term in a way which serves to interrogate Baxter's practice rather than simply accepting the way that it is used in this 'tidied up' account.

Thus I will use Baxter's mythologising and the 'ubiquitous notions of the gap' which Millar identifies as the starting point for my own reading of the consistent elements in Baxter's personal mythology. Baxter's mythologising has been addressed often in the critical discourse, though few have gone as far as O'Sullivan in establishing the extent to which this mode of writing was also central to Baxter's 
thinking in his non-writing life. The recent work in The Snake-Haired Muse is aligned with O'Sullivan's view in stating that 'Baxter's essential mode of thought was mythic and symbolic' (18). This work greatly extends our understanding of Baxter's use of myth, in the process demonstrating how the 'mythic presences' in his writing were evident right throughout the changes of style, tone and form in his writing, and even the insistence on doing away with 'icons' in the later phase of his life.

My own work will also highlight the fundamental significance of Baxter's mythologising method in his quest for meaning. I will demonstrate that the ubiquitous notions of the gap relate not only to the symbolism and mythic structures that Baxter utilises in his poetry, but that these notions of the gap rely on a 'way of seeing', a lens which Baxter insists is his only way to him to access what is meaningful in relation to 'the gap'. While my approach relies heavily on the examination of Baxter's prose, and my readings are informed by Baxter's an awareness of the poet's stated intentions, I take a critical stance towards the claims presented in these texts. In particular, through the notion of the 'mythologising self' I draw out the implications and assumptions inherent within Baxter's method, tracing the creative strategies he employs and revealing his reliance on stances and lenses which effectively create the gaps in experience 'out of which poems emerge'.

I will trace Baxter's use of three broad 'types of gap' throughout the published poetry in order to establish the extent of their relevance to the full range of Baxter's personal mythology. The first of these gaps relates to the 'sense of grief' which Baxter claims to have been plagued by throughout his life, which is associated with absence, lack and loss. The second type of gap is space between opposing forces, 
the 'locus of tension' identified by Millar, which generates creative energy. The third type of gap is the experience of dissolution which is both threatening and fruitful, leading through a process of death and rebirth.

These gaps functioned as starting points for Baxter's process of mythopoeic ordering. The gap could be utilised by ways of seeing and being which allowed Baxter to enter the 'door of dissolution' that led to creation and regeneration. These three broad tendencies and strategies - both deliberate and compulsive - all become vital to Baxter's poetic practice - they are reasons to mythologise, the means to mythologising, and they give mythic structure to the work. It is not my contention that Baxter always and only deliberately employed these tools as a matter of conscious choice - and never came at his work by any other means. But when the work is surveyed en masse, a startling consistency is revealed in the amount of his work which relates to one or more of these three 'starting points'. Thus I compare Baxter's creative process to the traditional structure of creation myth, which progresses from chaos to cosmos through the ordering intelligence of a divine authority. This comparison reveals the workings of Baxter's creative process, in which the godlike 'mythologising self' creates gaps through rejection, distancing and dissolution of the ordinary world and the self who inhabits it. By moving towards this state of 'chaos', the mythologising self asserts its own authority over the mythological world or 'cosmos' which is created, using the ordering tools of symbol and myth to make mythology out of 'meaningless' experience.

In taking this approach I aim to provide tools for reading Baxter's method as much as his material, establishing a critical framework which will enable new connections to be made across his writing as a whole. This will allow for readings which incorporate awareness of the scope of the work and a sense of its consistent and 
distinctive aspects, as well as potentially opening up new areas for critical engagement by suggesting concerns and methods Baxter shares in common with other writers and thinkers.

The thesis is divided into two sections of four chapters. In chapters one to four I establish the basis for my critical framework for reading Baxter's work. I make a reading of 'Notes' so as to highlight the relationship between the two central elements of Baxter's work. A reading of the notebook poem 'Cosmos' shows that the 'mythologising self' occupies a central position in the creative process, creating and exploiting the gap in order to transform 'chaos' to 'cosmos'. I then demonstrate the relevance of the 'Chaos-Ordering-Cosmos' framework. In chapter two I distinguish three different 'types of gap' and show how these function as 'starting points' in Baxter's mythologising, which centres on the confrontation with chaos. In chapter three I explain Baxter's practice of mythologising as an 'ordering' process which makes mythological meaning by applying tools and structures to the "chaotic material' accessed via the gap. In chapter four I explain how Baxter's poetic personal mythology relates to 'cosmos', in the sense of a network of connected parts which is 'harmonious' on the level of method and material.

In chapters five to eight I divide Baxter's poetic output into chronological segments (1941-48, 1948-58, 1958-68, 1968-72) and apply my framework for interpreting Baxter's poetry. In these readings I demonstrates the consistent starting points and ordering tools which construct poems out of the 'chaos' of experience. Thus I demonstrate the network of meanings or 'cosmos' that the consistent presence of these two elements produces. 


\section{Chapter One: The Mythology of the Gap}

What happens is either meaningless to me, or else it is mythology.

... as in all good mythologies - first there was the gap, the void.

('Notes' 122)

These two statements are the starting point for a study of the consistent elements in Baxter's work. The first has become Baxter's 'most famous and resonant statement about myth' which 'virtually every critic writing about his work feels compelled to quote' (Muse, 24). Despite its familiarity this statement is rarely considered in the context of other revealing comments made in 'Notes'. Indeed, Baxter was on the whole typically forthcoming about his poetic method, yet few have considered the relevance of this claim and to what extent it is supported by evidence elsewhere in his work.

Baxter's second statement, that in his personal mythology 'the gap' preceded the creation, has been overlooked by many critics despite occurring on the same page of 'Notes' and clearly relating to the earlier 'meaningless or mythology' claim. What does Baxter really mean when he claims that in his personal mythology 'first there was the gap'? An extended reading of the first section of 'Notes' demonstrates that - at least at this point in the mid 1960s - Baxter considered the mythologising habit and notions of 'the gap' to be intertwined as fundamental elements of his 
poetic process. In this chapter I present the basis for my own approach to Baxter's work, which examines the relationship between 'the gap' and mythologising in relation to the 'chaos-ordering-cosmos' structure commonly found in creation myths.

Taking the two quotations above as my starting point, I consider the links between Baxter's practice of 'mythologising' and notions of 'the gap', exploring the implications of Baxter's 'mythology of the gap' beyond the poet's own assessment of his creative process and focusing on 'what happens' in and around the gap. I demonstrate that these notions of 'the gap' link a wide range of key concerns, the flexible nature of the term allowing Baxter to connect these interests in a network of meanings within his personal mythology. After establishing the interdependence of mythologising and 'the gap' in relation to Baxter's quest for the poetic 'voice', I outline my own framework for engaging with Baxter's 'mythology' through a reading of the unpublished manuscript poem 'Cosmos' (written at the age of 14). This poem demonstrates the 'chaos-ordering-cosmos' progression at the centre of Baxter's mythology of the gap as well as the nature of the momentary 'mythologising self' that occupies a position analogous to the creator god.

Baxter's second claim complicates the otherwise conventional notion of a 'personal mythology' based on one's life experience. Only in Paul Millar's work have these notions of 'the gap' been considered in relation to the whole of Baxter's personal mythology and his poetic method, shedding light on the places where the poems 'come from'. ${ }^{1}$ Aside from the critical problem of 'competing mythologies' outlined in the introduction and the tendency to ignore Baxter's prose, this critical lacuna

\footnotetext{
${ }^{1}$ Particularly in "Hemi te Tutua / Jim the Nobody: The "Gap" and the "Void" in the Poetry of James K. Baxter'.
} 
may also be the result of the elusive and paradoxical characteristics of 'the gap' itself. A gap is by definition an 'absence' and therefore less noticeable than the 'presences' in Baxter's work. Many of the 'gaps' in Baxter's mythology are evident through their effect on the surrounding material. Another reason for this oversight could be that the term 'the gap' is largely missing from Baxter's earlier work, with the majority of references to 'the gap' or 'gaps' coming from the early 1960s onwards, at which point Baxter's published poetry stretched back two decades. Yet even the clear evidence of the centrality of notions of 'the gap' in Baxter's later writing has been almost entirely overlooked, generally in favour of biographical, aesthetic or ideological components. For these reasons, earlier commentators tended to either privilege the presences in Baxter's work over the gaps, or to address the context of specific 'gaps' in isolation, consequently missing the network of connections which place the gap at the centre of Baxter's personal mythology.

In September 1963, four years before the publication of 'Notes' with its claim for the fundamental significance of the gap, Baxter wrote the first poem of the 'Pig Island Letters' sequence (1963, CP 276-85), dedicated to Maurice Shadbolt. This poem provides perhaps the most prominent reference to 'the gap' in Baxter's poetry and stems from a period in which 'the gap' becomes a common term within the mythology. Thus the scholarly response to this poem can be used to illustrate a common critical oversight regarding the fundamental importance of the gap in Baxter's work, stemming from a partial approach which ignores connections between the poems. Weir claims that Baxter's movement towards Christianity as a 'positive philosophical structure' (1970: 50) led to the discovery of a 'pattern of meaning through loss and suffering' (52). However Weir does not connect notions of 'the gap' to this pattern of meaning. He interprets 'the gap' in this poem as 
relating to Baxter's view of 'the polarities of life and death' inherent in 'the sexual liaison' (41). While sex is undoubtedly an important element in the poem, Weir's emphasis on a sexual context means that his interpretation is overly narrow:

If the sexual act is a form of dying, it is one of the curious ambivalences of Baxter's writing that its deprivation is also regarded as a death - death in a minor key. The not-yet-dead may be freed from the tensions of active sexuality, but they have not found the ultimate release. This is what is meant by the opening poem in the title sequence.

Doyle (1976) identifies a number of the 'complex connotations' of the gap in this poem: 'the unbridgeable distance between oneself and other, the actual world itself, and one's own disconnectedness, and even an arrival at the humbling experience of middle age' (79). He also points to the sense of destitution in Baxter's work and the importance of his later 'acceptance of death' as the 'center of his existence' [sic]. However, he does not compare these associations with Baxter's own assessment of the fundamental importance of the gap, stressing instead the difference between the poet's earlier tendency to lament 'man's loss of the capacity to float untutored on the waters of Chaos' and his later 'acceptance of that loss and a search for comradeship in loss' (116).

While Doyle and Weir make relevant observations on the associations between the gap and death, sex and destitution, neither makes the connection between this poem and Baxter's claim that 'first there was the gap, the void'. This failure to consider the wider significance of the network of associations running throughout Baxter's 
mythology has been a common oversight. In his insightful commentary on the 'Pig Island Letters' sequence, McKay (1990) connects notions of 'the gap' to Baxter's pervasive sense of inner conflict and the awareness of loss and death, (196-97). However, in the specific context of the first letter, McKay focuses on the association of the gap with the mental 'menopause' Baxter mentions in relation to middle age and creative sterility. McKay's biographical focus means that his interpretation is directed by 'prophetic' elements:

'Wives in the kitchen cease to smile as we go / Into the gap itself ...' extends the meaning of the 'gap' to include death, and indicates Baxter's awareness that even in dying he would be creating a spectacle.

Though McKay asserts the importance of the gap, he follows the same 'chronological' line of thinking as Weir and Doyle in suggesting that 'the notion of the "gap" is crucial to the later Baxter' (196). These interpretations overlook the range of contexts in which Baxter employs an otherwise generic spatial term. They also ignore Baxter's claims about the relationship between 'the gap' and the 'moment of art'. Millar argues convincingly that, when various synonymous notions of the gap are considered, an evolving network of meanings is revealed which demonstrates that 'the notion is equally crucial to the earlier Baxter' ('Tutua'). Within Baxter's mythology the gap can and does relate to all of the areas of experience considered above, but it also relates to virtually any experience that engenders poems. Baxter's claim that the gap comes 'first' suggests that his use of the term in these two apparently contrasting ways - as 'menopause' and as entrance 
to a threatening yet fruitful realm - may tell us something about his mythologising method and the relationship between experience and 'mythic' art form. The specific context / s of 'the gap' in 'Pig Island Letters' 1 - sex, death, middle age, creative 'sterility' - are only one layer of meaning, a starting point. Beyond this, the dynamic, functional nature of the gap in this poem indicates that what links these gaps is their connection to the creation of poems. I return to 'Pig Island Letters' 1 in chapter four to demonstrate the value of using the 'chaos-ordering-cosmos' framework to connect Baxter's mythologising and these notions of the gap.

The $O E D$ defines a gap as a breach, break, split, or space between; a pause; a hole or chasm; an opening; a distance between individuals or groups of people; a gash or wound; a breach or wider divergence in character or sympathies; the act of bridging a gap, creating access or passage. Explaining Baxter's use of this term presents a challenge since he employs it in a number of different, often apparently paradoxical ways, utilising many of its various spatial and dynamic connotations. 'Ubiquitous notions of the gap' are at the centre of a 'complex symbolism' ('Tutua') which Baxter uses to represent the inner experiences and patterns associated with the mysterious place or state where poems come from. Baxter uses the various connotations of this term, and synonymous notions, consistently throughout his writing - what links the diverse 'gaps' is not the thematic or conceptual 'content', but the function of the gap. The gap is where 'what happens' becomes either 'meaningless' or 'mythology'.

The first section of 'Notes' (121-28 in The Man on the Horse) deals with Baxter's 'beginnings' as a poet. ${ }^{2}$ To use Baxter's own description, this is a 'tidied up' version of his growth as a poet, one in which he makes the claim for an underlying

\footnotetext{
${ }^{2}$ The original title of this piece as published in Landfall 75 (September 1965): 237-40.
} 
consistency in his poetic method and material centred around diverse notions of 'the gap'. Baxter describes a range of conditioning factors which initially led to the forming of a mythopoeic (myth-making) 'habit' and the birth of the poetic voice. Prior to the 'meaningless or ... mythology' claim, Baxter establishes these 'beginnings' in relation to intense inner experiences and an awareness of loss, suffering and mortality. Death, dissolution and threatening depths are all invoked immediately; the origins of the mythologising habit 'tied up in a bundle somewhere near the beginning of the track' are analogous to 'the dead cat in a bag floating and tugged at by eels on the surface of the black bottomless river hole' near his childhood home.

Having started in this abject manner, Baxter draws attention to the subjective and 'artificial' nature of his own account of childhood experience: 'all mental reconstructions of those early events seem likely to be false - not deliberate lies, but an improvised and artificial childhood tidied up for others to look at'. Thus Baxter acknowledges that in looking back at his development as a poet, a range of factors such as memory, myth and emotion, along with notions of his role and identity as a writer, are all tightly bundled together in the process of mythologising. The writer more or less deliberately selects certain events and experiences from an unreliable memory in order to construct a 'meaningful' mythopoeic narrative. Baxter claims that the events of 'the day before yesterday ... might as well be the day before Noah's Flood' - unless they can be mythologised, the details of everyday life are washed away. He asserts that while 'objectively' he knows that his childhood was happy, subjectively 'a sense of grief has attached itself to my early life'. This retrospective 'attachment' of an emotional meaning is associated with the 'sense of having been pounded all over with a club by invisible adversaries' which has 'been 
with me as long as I can remember'. This suffering belongs to the experienced older self who is looking back.

Baxter acknowledges the danger of turning this grief into a 'grievance' held against external adversaries. Instead he states that this sense of suffering and alienation is 'probably the universal condition of the human race' only influencing the poemmaking habit in that 'it may determine the gloomy tone of my verse'. Thus he attempts to pre-empt criticism of this highly subjective account of his own life while simultaneously suggesting that this intense emotional experience is a 'universal' occurrence. Baxter seeks to distinguish between the subjective 'sense of having been pounded by invisible adversaries' and his belief in the fundamental underlying reality of the Fall. This seemingly unfounded 'sense of grief - even at times a sense of grievance ... helped me to write poems'. Baxter adds that the 'poems sprang out of a quarrel with the status quo', which was both painful and productive. From these observations, Baxter speculates that this tension, grief and resistance all related to one fundamental disjunction: 'it could be that at the root of it all was no more than an early perception of that state that theologians call Original Sin'. Here the Christian doctrine of Original Sin and - by implication - the Biblical story of the Fall are invoked as the explanation for the 'grief' which in turn assists the creative process. The 'sense of grief' is somehow permanently a part of the poet's inner reality - stemming from an ontological gap which equally pertains to the rest of humanity. Thus Baxter moves quickly from personal emotions to his interpretation of the myth of the Fall and traditional theological doctrines which give that story a 'universal' significance. In the stories Baxter inhabited during his adolescent reading, the process of identification and integration allowed him to occupy the hero's place by shifting details while retaining the underlying pattern. 
Once this process of exchange was complete, 'there I was in the centre of the tale'. Similarly, in this personal myth, the story of the Fall is compared with the pattern of experience, revealing a common underlying 'plot' linking a personal story to universal truth.

Baxter then attempts to demonstrate the link between these three factors - the emotion of 'grief' and the tendency towards a sense of grievance; the 'state that theologians call Original Sin'; and the mythologising habit - through the example of an 'alcoholic grave-digging friend'. This typically Baxterian outsider tells the poet as they watch the delinquent 'milkbar cowboys' that he took 'the wrong turn around the cabbage tree ... a long time ago; and since then I've not been able to change it'. Distance is opened up by looking back, and grief is 'attached' to the past and the actions of a flawed, ignorant self. This unspecified primal crime is mythologised as a fall from grace, the source of an endless grief, an irrevocable wrong which forever fixes the plot of the personal myth which makes one's life meaningful.

It is in this context of intense subjective experiences - both emotional and spiritual - and an acknowledgement of the 'artificial' nature of one's own personal mythology that Baxter adds:

He was mythologising his life; and that's what a writer does. The trouble is, I can't demythologise it. What happens is either meaningless to me, or else it is mythology. 
In context, this statement reveals a degree of ambivalence which is often ignored by those who feel compelled to quote the resonant final line. Rather than a proud declaration of intent, Baxter's mythopoeic mode of operation is simply 'what a writer does'; a habit which also causes 'trouble'. In this mythologising process, the events of one's own life can be made meaningful by turning them into a story, a 'myth'. As Baxter has already acknowledged, this myth is 'false' in an important ('objective') sense. Yet he believes that it can be meaningful because it connects the subjective, emotional experiences of the individual to deeper truths which lie below the surface of ordinary awareness. This mode of mythological thinking could thus give the prevailing, otherwise unfounded 'grief' a meaning. However, beyond this Baxter is claiming that for him there is no separation between this mythological mode of making meaning, vital for the poem-writing habit, and the rest of his life. At the age of forty he is well aware of the trouble which comes from this tendency, particularly when taken to the extremes of a 'meaningless or mythology' dichotomy. If experience is only 'meaningful' when seen through the lens of one's own 'artificial' personal myth, then not only one's own inner life, but also the shifting complexities of human relationships and social and political events are likely to be either negated as 'meaningless' or 'mythologised' and reshaped in a way which tends to fit one's own pre-existing views and needs. Baxter thus points towards a valid and persistent criticism of his work as reflecting too strongly the shape of his own personal 'frame of reference'.

Baxter follows this bold claim with an extract from 'Letter to Robert Burns' (1963, CP 289-91) which he slyly presents as the 'exact mythological record of my birth', establishing his credentials as a 'born poet' at odds with the social order. In this account his birth is hastened when his mother - a 'professor's daughter' clearly at a 
loss in nature - is frightened by a cow. The vulnerable newborn poet is then menaced by the instruments of the social order in the form of a Plunket nurse with a pair of scissors - but apparently remains intact thanks to the fright caused by the mythological 'fact' that poets are 'born with three balls'. Thus it is the 'fertility' of the poet which keeps him whole and free from society's influence.

While acknowledging the importance of his parents as 'two strong influences' on his development as a poet, Baxter believes that he 'broke out in words' while someone else in the same place, under the same external influences would not have. This 'tidied up' account has a ready-made answer to the obvious question: 'How did it come about? Well - as in all good mythologies - first there was the gap, the void'. Baxter reproduces a fragment called 'Before the Creation' - written at the age of fourteen - as an example of his own early awareness of the originating gap that is found in all 'good mythologies'. His selection of this poem clearly links notions of the gap with the mythic paradigm of 'creation', where new worlds emerge and take shape out of the fertile emptiness of 'chaos, / the abyss of space, / the deep Ginungagap'. The reference to this poem twenty-six years after writing it is intended to support Baxter's theory on the origins of his poem-writing habit; before he could create he had to confront 'chaos' and thus the gap came 'first'.

The remainder of this section of 'Notes' presents a variety of seemingly distinct and diverse gaps which led to the young poet 'breaking out in words'. The 'sense of difference, of a gap ... between myself and other people' relates to the differences between the two sides of his own family, the wider division between 'socialistpacifists' such as the Baxters and the rest of the country during a time of war, and more emotively - the abuse experienced at school as a member of a 'conchie' family. As Millar has noted, this sense of division and alienation simultaneously 
allowed for the time and space in which to develop as a poet (Spark 88). The experiences of alienation and abuse eventually brought forth the creative voice; creating 'a gap in which the poems were able to grow'.

For Baxter, the poems were also the product of a mysterious process of inspiration. He describes his first poem, written at the age of seven, as 'no doubt significant, if not in its form or content, at least in the way I approached the writing of it'. The young boy found a gap when he climbed 'up to a hole in a hill above the sea' and 'fell into the attitude of listening out of which poems may rise' ${ }^{3}$ Baxter claims that this mysterious and uncertain process remained central to his poetic method: 'I don't think my methods of composition have changed much since that time. The daimon has always to be invoked; and there is no certainty that he will answer the invitation'. This descent into the depths and the invocation of the poetic voice became increasingly necessary during puberty as a way to deal with a sense of isolation and internal division. When Baxter returned to New Zealand from two years in England and Europe at the age thirteen he 'fell into the habit of poemwriting with a vengeance'. Soon after this fall 'the door opened into some kind of cellar of the subconscious mind', a threatening realm which was also a source of creativity, 'peace and wisdom'. Baxter looks back at his adolescent experience as a struggle for survival in a lifeless 'space between' with 'no tools to deal with the central anguish'. In the meantime, 'all I could do was wait it out', exploring the inner world while enduring the long painful 'pause' before adult life could begin.

Baxter describes this early poetry as a response to the threat of the 'adolescent abyss'. A combination of factors provoked a sense of urgency, the need for some

\footnotetext{
${ }^{3}$ It is possible that Baxter's later experience at Quaker schools may have also influenced this 'listening' habit.
} 
sort of response or respite. As well as the specific difficulties arising from being the son of a prominent conscientious objector, the would-be poet experienced pressure to 'accept the Calvinist ethos' of 'Mother New Zealand', the voice of the status quo which was 'buried in the backyard': 'work is good; sex is evil; do what you're told and you'll be alright; don't dig too deep into yourself'. Preserving distance from the influence of this sterile social order was difficult while he lacked the tools and 'experience to contradict them and forge against' those pressuring him.

Baxter notes the importance of three texts which guided his development in relation to poetry, politics and psychology and thus helped him to develop the skills to 'forge against' the status quo. ${ }^{4}$ However, he summarises his mythological account by reaffirming the primacy of experience over ideas: 'the negative aspects of my growth' were 'in the long run the most help to me as a writer'. The learning which resulted from various experiences of grief, suffering and alienation was more valuable than anything gained from books as it helped to '[temper] the axe of intellect'.

Baxter closes 'Notes' with a further statement of belief: 'A writer cannot avoid the task of exploring and understanding the private hell which lies just below the threshold of his own mind'. It is this territory below the threshold which gives meaning to the mythologising. Baxter then extends this claim to a more universal application: 'I doubt if [the writer] can begin to understand the threefold aspect of the modern world - monotony, atrocity, anarchy - if he has not first done this'. Thus Baxter asserts that awareness of the gaps in one's own life leads to a

\footnotetext{
4 These were 'John Lehmann's Penguin survey, New Writing in Europe ... a sloppily written anarchist tract by Ethel Mannin, called Bread and Roses ... Carl Jung's Modern Man in Search of a Soul ... These three books were each helpful to me in quite different ways'.
} 
confrontation with chaos which is the foundation of understanding as well as creativity.

This network of gaps suggests a retrospective, highly 'mythologised' view of the poet's progress. Baxter gives an account of his growth as a poet which presents the 'mythologising' habit as inextricably bound to notions of a fundamental 'gap' which is the source of poems through experiences of loss, conflict and dissolution. These experiences were varied and otherwise apparently unrelated - from the sense of alienation which he experienced as a member of a 'conchie' family, to the prevailing 'sense of grief' which had no apparent cause but which he later considered to be an intimation of 'Original Sin', to the experience of sitting alone in a small cleft in a hill and hearing the sound of the waves echoing below, feeling one's sense of self dissolve until another 'voice' gave poetic utterance. In turn the gap is symbolised by absences and spaces between and mythologised by narratives of grief, alienation and dissolution. In Baxter's view the poems 'came out of' experiences such as pervasive grief, the adolescent abyss or desert, a 'quarrel' or dissociation between groups, a 'fall' or descent. These personal experiences of gaps reveal a 'universal' meaning when they were mythologised and these 'negative aspects' became a defining feature of Baxter's poetry. Other aspects of experience are not as creatively productive and become effectively 'meaningless', which is one explanation for their omission from his personal mythology. ${ }^{5}$

Baxter's urgent desire to preserve and foster creativity is vital to understanding his mythologising mode of thought and attitude to the gap. The respite which Baxter hoped to find through the 'poem-writing habit' meant that from the beginning this mythologising was a purposeful quest for transformation. O'Sullivan asserts that ${ }^{5}$ See Millar, Spark 24-28, for a discussion of this in relation to Baxter's friend Noel Ginn. 
'everything that Baxter wrote has about it a strong sense of the necessary in psychological terms' ('Urgently Creating a Past', 94-95). The poems were driven by a desire to 'fill' or 'bridge' the gap, yet paradoxically continuing contact with these gaps was essential for the creation of poems. By observing the conditions preceding creation Baxter came to believe that the 'negative aspects' of experience were intrinsically linked to inspiration. Thus he searched for the places and states out of which poems might arise.

Baxter's prolific poem-writing habit is suggestive of the desire for personal transformation which, Timothy Clark argues, informs the writer's search for inspiration. Clark contends that for 'Romantic and Post-Romantic writers the image of the writer as hero, sage, or prophet, or as an initiate into mysteries of creativity, becomes the compelling way of presenting what is undergone in the space of composition'. In this 'space' the writer can enact a 'fantasy of identification with an image of control ... which serves to deny and repress a sense of fragmentation and powerlessness' (30). Baxter acknowledged that the urgency behind his poetry was related to the belief that the poem was the product of a larger quest. The gap between chaotic experience and meaningful mythology is bridged by the poem and the mythologising self, its author:

The poet begins with the desire for wisdom, for a changing of his being, and ends with a poem on his hands which may be no more than a record of the search. 
I will use the term 'the mythologising self' to stand for the momentary self who creates and is created by the poems through the exchange which transforms 'chaos' into 'cosmos'. This self is the author of Baxter's mythology, analogous to the creator god who establishes cosmos out of chaos through a process of ordering. The mythologising self exerts its authority over personal experience by taking up the voice, thoughts or eye of 'God', revealing the pattern within the chaos. Yet the 'chaotic conditions' which bring forth creation are also the product of this process through the implied destruction, annihilation or dissolution of the world as perceived by the 'ordinary' self. This process places the 'mythologising self' in a position of authority over the self who experiences events in the world. It was this intoxicating sense of control and authority which first drew Baxter into the habit of mythologising as an adolescent, where the 'meaning' of personal experience could be reinterpreted and reshaped according to the imperatives of desire. This term does not denote a distinct, separate constant self responsible for all of Baxter's varied writings, but the notional, temporary figure at the centre of the dynamic creative process - the poet at work in the space of composition.

While the purpose of a collective mythology is traditionally to explain the world, to affirm identity, or to provide a sense of harmony and cohesion, in a personal mythology this is complicated by the doubling of reader / writer. In considering a wide range of theories of inspiration, including writer's accounts of 'inspiration', Clark points to the recurrent tendency to situate 'the act of composition as a space of division, rupture or possibility between the mundane subjectivity of the writer and alternative and usually unforseeable modes of being or subjectivity'. Clark considers this 'crisis of subjectivity' to be a distinctive feature of the writing process, arguing that 'composition may work through self-reading (or, of course, 
self-listening), or, more precisely, through the unanticipated effects that arise from moving between writing as act and reading as openness to possibility' (11). In this sense, the self at the centre of Baxter's mythologising is both subject and author, reader and writer in the process of 'self-reading' Clark characterises as 'splitminded'. From this perspective, the 'messages' and the 'messengers' in Baxter's poetry carry the imprint of the 'recipients', and the imperatives of desire effectively create the voice of the poet out of the gap:

...There has to be some distance. The 'I' of the poem is not the autobiographical ' $\mathrm{I}$ ', it is a dramatic ' $\mathrm{I}$ '. The poem is a dramatic device which one uses. People mistake the capital 'I' of the poem (either the poet or the reader) for the personal 'I' ... that doesn't make a poem: it's a dramatic 'I'.

('Interview' 242)

This notion of 'distance' is a key element of the creative process which overturns the mundane subjectivity of the 'personal I' in favour of the 'greater I'. O'Sullivan suggests that the desire for transformation is the most consistent aspect of Baxter's writing - if his verse "carries "one story and one story only" it is the story of his own personality exchanging unshaped experience for the form of myth' (9). In turn, the personal mythology Baxter created is centred around the 'ubiquitous notions of the gap' highlighted by Millar. This is because the gaps provided the space in which this exchange could occur, where the ordinary self could be exchanged for the self who writes poems, and the meaningless world exchanged for meaningful mythology. In the gap the poet becomes one with the 'daimon', the voice of 
creativity, wisdom and authority, the one with the power to 'forge' a vision to set against the sterile social order. The poem itself is a 'gap' in the sense that it is the space where 'what happens' is made meaningful, the space of composition where creation is brought forth out of absence and material is arranged into a 'harmonious' cosmos of parts.

While Baxter generally associates his poetry with the desire to access meaning and healing, the search for an acceptable identity also informs the creative process. For Baxter, to write poetry was - especially in his earlier life - to take on the cherished role of the 'Poet' and thus affirm a fragile sense of identity, an ideal self associated with wisdom, authority and creative mastery. Baxter wrote that 'it does not seem that a man can be an artist without also being a narcissist - that is, without creating a fictitious self more powerful, knowledgeable, and loveable than, in fact, he is' ('Symbolism' 62). While this might refer to some of the 'figures of the self' which he utilises, the 'fictitious self' Baxter speaks of here is also the creator, the possessor of the poetic voice which is explicit or implicit in the poem at a level above the characters found within it. Though he considered himself a 'born' poet, this identity was fragile and threatened, a momentary self which must be constantly recreated through the poetic process. The act of mythologising, the 'moment of art' creates this authoritative self - who can 'never stay'. Baxter later suggested that the mythologising habit could be attributed to a solitary adolescence, in which the imperatives of desire create the voice of the poet: 
You talk to an imaginary companion - that would be the psychological cause: to fill that solitude with another voice - two people, yourself and yourself as poet. There was an Irishman who said his writing was a conversation between the older man and the younger man inside himself. ${ }^{6}$ Artists populate their solitude.

('Interview' 241)

This fictitious other self is a creation, yet as the voice of the 'daimon' it is also in a sense the creator of the poem. Richard Hugo writes that the '[poetic] voice is usually something that grows out of stance. It has to do with how strong a person's urge is to reject the self and to create another self in its place' (qtd in Creating Another Self, 1). This process of rejection and re-creation is central to understanding Baxter's poetic 'stances', which on the most fundamental level functioned to ensure that the poems continued to emerge out of the gap. Baxter's urge to reject the ordinary self and exchange it for a 'mythologising self' remained central regardless of the various 'phases' which he passed through. The persistence of this 'voice' can be seen in the final poems where the mythologising self is 'Hemi te Tutua', the 'nobody' who continues to write long after the (poetic) statement that the poet 'James K. Baxter must die'.

The creative process thus relies on the right 'place' being found and the right 'attitude' of mind established. The poet is the one who is willing to go into the gap, or to adopt the 'stance' which provides the perspective and position out of which poems come. The 'position' of the mythologising self thus creates gaps as well as 'discovering' them. Baxter's mythologising is also the product of his ability to create the gaps 'in which the poems were able to grow' through 'mythological'

\footnotetext{
${ }^{6}$ See W.B. Yeats's 'A Dialogue of Self and Soul'.
} 
ways of seeing and being. Thus while Baxter suggests that his poems are responses to pre-existing, 'universal' gaps, his mythologising is dependent on finding and facing these gaps. The mythologising self brings a sense of 'meaning and harmony' through the 'moment of art' which links the personal to the universal through mythology. Yet it is this self who also 'attaches' grief to past experience, reinforces divisions, and rejects the ordinary self. This is another sense in which Baxter's mythologising caused him trouble.

Baxter's mythological thinking provided the tools for creating cosmos out of chaos, a shorthand of symbols and mythic patterns which he utilised to go into and come out of the gap where the poems originated. Baxter's symbols and myths are, as O'Sullivan suggests, 'signposts' marking the places where transformative experiences - and thus further poems - could be found (51). Once the right 'tools' were developed, these 'places' of creation could be discovered through the repetition of mythopoeic processes. Millar and O’Sullivan both identify the double nature of the gap as 'tomb' and 'womb' as vital to an understanding of Baxter's work, and this relationship between death and rebirth is also crucial to an understanding of Baxter's poetic process and its emphasis on birth and death. As O'Sullivan notes, Baxter speaks of his poems as 'the end result' of a process (6), as the record of a discovery or an event. Baxter's fascination with, and dependence on, the process of creation led him to a preoccupation with 'birth, death, procreation and so on ... one has to give them their true names ... This can be done with mythology' (Interview with Peter Bland, 1966). For Baxter the 'true mythological names' of these experiences linked the individual to universal patterns and paradigms which structure life and death. The exchange which takes place in the 
gap transforms these personal experiences and their 'universal', mythological significance is revealed.

'Notes' reveals the relationship between the gap and mythologising as the components of a continual, urgent creative process shaped by a desire for transformation. The mythology is in this sense a record of the places where inspiration is accessed - the aesthetic, mythologising shaping of the 'material' is the more conscious work of ordering which follows this initial moment of discovery. If creation and transformation rely on the establishment of the space in which poems can grow - a 'womb' which fills with the poem - then it follows that clearing this space requires a disconnection, an emptying or a ritual sacrifice.

Two mythic paradigms which are prevalent throughout Baxter's personal mythology are the 'primal crime' paradigm - typified by the Judaeo-Christian myth of the Fall - and the 'fertility' paradigm, centring on the sacrificial quest of the hero, particularly as found in the story of Christ's passion, death and resurrection. These mythic structures are tools which Baxter uses to mythologise experience and connect the personal to the universal. Beyond these two explanatory mythic structures, however, Baxter's creative process - and by extension his views and actions - is shaped by the paradigm of 'creation'.

Creation myths generally divide into two categories, creation ex nihilo or ex materia. As in some versions of the creation myth paradigm, such as the Genesis story, Baxter's mythopoeic process points to both of these aspects of creation, with the poems emerging out of the empty space of 'the gap, the void', while also depending on the mythical rearrangement of the 'chaotic' material of his own life for their substance. Baxter's mythologising can be understood in relation to the three 
phases of creation. The 'starting point' for the poem is a gap, which comes 'first'. By creating or discovering a gap through ways of being and seeing, Baxter encounters the threatening and fertile chaos out of which creation emerges. The material of the poem is shaped by ordering tools, through myth, symbol and the aesthetic and technical instruments of the poet. The finished product is a cosmos in the sense that pattern, meaning and 'harmony' has been established out of the chaotic state.

In the work that follows I use the 'chaos-ordering-cosmos' structure of creation myth to discuss the consistent elements in Baxter's work and the relationship between the gap and mythologising. At the centre of this creative process is the mythologising self, the author of this 'moment of art', the one who transforms chaos to cosmos and is implicit within the process of 'exchange'. Thus the mythologising self is the creator 'god' of the mythopoeic cosmos, maintaining authority over meaning, defining the terms of reality and communicating messages.

\section{'Cosmos'}

The notebook poem 'Cosmos', also written at the age of fourteen, embodies the 'chaos-ordering-cosmos' process which informs Baxter's work, demonstrating the role of the momentary 'mythologising self' at the creative centre of the poem. In Clark's terms, the poet here represents an experience of initiation into the 'mysteries of creation' and the ecstatic, 'intoxicating' sense of control and authority which accompany the restoration of 'Meaning' and 'Harmony' to the (personal) cosmos: 
I raised the veil of human consciousness

And glowed, a naked fire of living thought,

Within the vast abyss of outer space.

And fiery round me shone the rolling spheres

Where all was flaming chaos; then I passed

Far out of our atomic universe

To the abyssmal [sic] depths of emptiness

That dwarf the nightly vistas of all Time

To nothingness in far eternity.

Infinite was I, and could not comprehend

The timeless cosmic wonder of it all:

My spirit shrank and flinched there in fear

For all was cold, and there was naught of Life

And thought was nothing. Then, a flash of light,

A thunderbolt of flame and all was bright

Before my mental eyes; and then I heard

A mystic song that swelled from out the void:

The song of spheres that moved upon their way

In splendid harmony and silent sound;

The song of earth, the song of mighty hills

And deep, unfathomed ocean vastnesses;

Of every flower, of every singing bird;

The song of human hearts that rose above 
The pain and discord of our earthly lives

On swings of harmony. I saw that all

Within this mighty universe is full

With innate thoughtfulness and harmony:

And there for one brief [moment] I perceived

The Meaning of all things. The cosmos seemed

No place of chaos or of discord then

But one great heart of golden Unity.

(N1. 46)

This poem gives an example of how mythologising and notions of 'the gap' are interdependent. By creating a gap of distance and emptiness, the mythologising self engenders the 'moment of art' which is implicitly shaped by the imperatives of desire. The poem charts the progression from 'Chaos' to 'Cosmos' which occurs through the creation of space and the mental attitude which orders experience. The gaps are retrospectively made meaningful; to get to the starting point requires implicit mythologising, as the chaotic, discordant and meaningless world is annihilated, rejected and reordered before the mythologising self can begin to speak. The knowing voice of the mythologising self looks back at a sequence of events following from an initial act of will which affirms its mythopoeic authority: 'I raised the veil of human consciousness'.

The cosmic vision that unfolds in the poem has its origins in this initial rejection ordinary 'human consciousness' is denied and negated in favour of another way of seeing and being, with its overtones of romantic inspiration, where one can burn 
with a greater intensity, glowing as 'a naked fire of living thought'. This can only happen 'within the vast abyss of outer space' - a gap in which poems could grow where the isolated self confronts the profound reality that is otherwise shielded by the 'veil of human consciousness'. In this chaotic space, the unshaped material remains threatening and perversely disordered, the limits of the merely 'atomic universe' are left behind as the poet flees into the 'abyssmal depths of emptiness ... To nothingness in far eternity'. The vastness of this vision entirely overwhelms the poet's ability to describe this experience, as this descent entails an apotheosis which is paradoxically a humbling: 'Infinite was I, and could not comprehend / The timeless cosmic wonder of it all'.

This is the point of complete division between mythologising and other modes of meaning. The mythologising self, the 'I' of the poem, has been further elevated to godlike status while at the same time the ordinary modes of rational 'comprehension' have been abandoned, ordinary 'human consciousness' cannot cross the threshold of this other embryonic universe. At this point of crossing over, the ordinary self's experience of suffering, loss, dissolution and despair reaches its peak: 'My spirit shrank and flinched there in fear / For all was cold, and there was naught of Life / And thought was nothing'. To assume the position of the 'infinite I' requires the sacrifice of ordinary modes of being and the identity attached to them. In Baxter's words twenty-six years later, the 'myth may kill the man ... but one dies anyway'. The shedding of this ordinary self brings 'a flash of light', an illumination which signifies new life, an inspiration which makes all bright 'before my mental eyes' and invokes 'a mystic song that swelled from out the void'. This is 'the song of spheres that moved upon their way / In splendid harmony and silent sound'. This silent song is a sacred truth which must be translated and voiced by the 
mythologising self, who finds in it the harmonious connection underlying the seemingly discordant variety of life: 'earth ... mighty hills ... deep, unfathomed ocean vastness ... every flower ... every singing bird'. This is also the unifying basis of 'the song of human hearts that rose above / The pain and discord of our earthly lives / On swings of harmony'. The song brings transcendence and an escape from suffering and division into a momentary vision of paradise. From the 'abyssmal depths' this song has carried the mythologising self to the heights of ecstatic rapture and mystical perception, culminating in 'one brief moment' in which is 'perceived / The Meaning of all things'. This temporary enlightenment completes the desired transformation: 'the cosmos seemed / No place of chaos or of discord then / But one great heart of golden Unity'.

The overwhelming insistence of this juvenile piece provides a clue as to the poet's motivation. The indecisiveness of 'seemed' reveals the uncertainty that drives this poem into Romantic cliché. This is not a vision of a future social utopia, reflecting instead the poet's desperate desire to discover a path back to a time before there was a need to search for 'harmony', 'unity' and 'meaning'. The poet sees himself as an initiate engaged in a secret quest for a change of being, pursuing an esoteric discipline in his poetic laboratory while developing the tools to transform loneliness, despair and alienation. Thus the process of composition is itself glorified here, along with the mythologising self who has heard the cosmic 'song'. Through the heroic endeavour of the poet, this threatening chaos is momentarily replaced by 'Harmony', where the poet experiences a sense of meaning, healing, identity which affirms the authority of the mythologising self. This experience of immersion in the primordial 'chaos' is seemingly available at will - the powerful affirmation of the 'great heart of golden unity' is accessible at any time. This engagement with chaos 
turns distance, threat, coldness and meaninglessness into an affirmation of the creative mind and the ability to discover order within the world. The poem exalts the (momentarily) 'infinite I' who is able to discover order within the threatening chaos of the world far beyond and deep within. Creating poetry is thus analogous to the act of world creation and Baxter - not for the last time -appears to equate himself with God.

Yet this poem also reinforces the transient nature of the 'moment of art'. If the experience of transcendence and unity with all of creation that is described here actually lasted, there would be no need to write a poem, sing a song, or affirm the value of a moment in time by simply 'raising the veil'. The world that the poet returns to is, presumably, unchanged in an objective sense. The same 'meaningless' material which threatened to consume the poet must be continually dissolved and reshaped so that the sense of meaning, healing and identity can be found once again. It is the mythologising self who must be reborn again and again from out of this process of destruction and creation.

As 'Cosmos' demonstrates, the act of mythologising is a creative response to the poet's pervasive sense of 'chaos', seen as the absence of a fruitful meaning and order, but this relies on an act of distancing, dismemberment or dissolution. Baxter's mythologising is driven by a desire for personal meaning, healing and identity through the process of setting the world in order and the role of the poet as master of the 'subjective disciplines' of art and contemplation. In this process the starting point of chaos and the process of ordering are interdependent, as the 'gaps in experience' and the mythological 'meaning and order' which seems to explain these gaps become an habitual 'frame of reference' which imposes a pattern on Baxter's experience and his work. 
The poems are the product of a momentary 'voice' as well as the shaping tools which the poet employs. Reading Baxter's poetry as the product of this momentary, mythologising self, provides the possibility of avoiding the influence of the competing mythologies which have tended to shape criticism of the work. Rather than a biographical reading of Baxter's poems as a historical record of experience, my thesis traces the journey of this mythologising self by charting the evolution of the personal mythology which is the product of the poetic voice. Rather than purporting to exactly represent the complex process of creation as it occurred in relation to thousands of individual poems, this framework provides a set of critical tools for interpreting Baxter's work and making connections between the poems in terms of origin and structure.

In the following chapters I expand on the three iterative, concurrent stages in the mythopoeic process to show how Baxter's mythology was created and shaped by a network of gaps. 


\section{Chapter Two: Chaos}

You get cunning: you learn to use the gaps in experience ...

('Interview' 245)

... when you are dealing with the world you tend to see it as Chaos ... the multiple Chaos as it appears to the human mind - perhaps to the eye of God it is not Chaos at all, but to us it looks like Chaos.

('Interview' 242)

This chapter focuses on the first part of Baxter's creative process, where inspiration is found below, beneath, behind, beyond what is 'ordinary', in the state of 'chaos'. In chapter one I outlined Baxter's account of his development as a poet in 'Notes', which suggests that the poems came from the gaps in experience, and that these gaps were universal, pre-existing conditions. The gap came 'first' in Baxter's mythologising process because it allowed him to recreate these chaotic conditions and access the 'space' and the 'material' required for the production of poetry. In this chapter I explore the implications of Baxter's claims and consider processes which are implied in the discovery of these gaps. Baxter's urgent quest for meaning, healing and identity meant that he utilised certain ways of seeing and being to effectively create gaps and thus access the chaotic conditions preceding creation. These ways of seeing and being imply a 'heroic quest' which the poet undertakes, via these gaps, to the starting point for creation, chaos. I illustrate the extent to 
which this search for a 'starting point' shaped Baxter's personal mythology in terms of his poetic method and material, and present a range of Baxter's accounts of experiences which led to the moment of art, where chaos gives birth to a new world and in the process affirms the authority of the mythologising self.

Baxter's poetic mythology is the collected record of the moments of 'breakthrough', of finding the 'places' where inspiration is accessed, where the mythologising self is brought to life. Baxter implied that whatever could not be incorporated into this mythology was essentially 'meaningless' to him. What he did mythologise, consistently, were experiences of absence, separation and dissolution. These were the starting points which provided Baxter with a reliable source of creative inspiration. Although Baxter claims that the gaps 'came first', in practice these elements of the creative process are not sequential, the poet's experiences are always shaped by what he brings to them. Thus the 'ordering' tools of myth are always implicitly or explicitly influential in the first part of the creative process. 'Chaos' is meaningless unless or until it becomes 'mythology', and the mythic paradigms, figures, and structures through which Baxter made meaning informed the 'discovery' of the gaps. The ongoing urge to create meant that Baxter developed a dependence on these modes of relation which ultimately structured his mythology and thus all aspects of his life and writing.

\section{Odin}

In describing his resistance to formal education during his teenage years, Baxter writes in the second part of 'Notes': 
I was already unconsciously erecting my defences around that core of primitive experience, that ineducable self which I like to call a dinosaur's egg. Unfortunately the abstract analytical processes which the schools were able to offer me - and ram down my throat, if necessary - have the sideeffect of neutralising this kind of experience and making it inaccessible to the conscious mind.

The kind of education Baxter sought would be found outside the classroom, and would involve different processes which promoted rather than neutralised these other perspectives and types of experience. Baxter notes a number of sources for this other learning, including his early exposure to myth:

Among my books at home there were one or two of Norse and Greek mythology. I became the companion of Odin and Thor and Jason and Ulysses. That was an indispensable education.

Odin's story was one of the many Norse myths contained in The Heroes of Asgard. This popular collection of tales from Norse mythology, aimed at a young audience, clearly captured Baxter's imagination. ${ }^{1}$ From heroes such as Odin Baxter learnt the ‘indispensable lessons' of mythic or 'sacred' patterns which were set in opposition to that which was rammed down his throat at school. Thus he identified

\footnotetext{
${ }^{1}$ Baxter had Millicent's copy of the Heroes of Asgard, probably the 1893 second edition, which included an extended introduction omitted from the 1930 edition.
} 
two types of learning which seem to be mutually exclusive - the first being the discovery of a sacred pattern in natural events; the second the acquisition of the lens of abstract thought, which sees nothing sacred in heaven or on middle earth.

(ibid)

In this somewhat circular approach to discovering meaning, the 'sacred pattern in natural events' revealed the mysterious cycles of creation and fertility and provided a 'lens' which could reveal the mythology within meaningless experience. The poem 'Cosmos' demonstrates that, along with the creation and fertility paradigms, Baxter's attitude towards his poetic vocation embodies elements of the heroic quest found in these myths. Hero myths such as Odin's quest for wisdom gave form to Baxter's own nascent desire for sacred meaning, healing and identity. Thus the mythic paradigm of the hero's quest, which Baxter pointed to as a formative 'lesson', usefully demonstrates an important thread in his mythology. Odin's journey, which contains elements from a range of mythic paradigms, parallels the active part of Baxter's creative process, the search for transformation which takes one to the edge of 'creation'. This is where the eye of wisdom is acquired and the poet chooses to seek out and confront chaos in order to experience a 'change of being' and replace the profane with the sacred.

In the story presented in The Heroes of Asgard (59-66), Odin is driven by an urgent need to embark on a quest for wisdom, strength and nobility. The process of growth and learning involves experiences of separation, initiation and dissolution which are the archetypal or 'sacred' patterns embedded in hero myth. Each stage of Odin's quest centres around one of the three types of gap Baxter identifies in 'Notes': 
absence and grief, discord and suffering, dissolution. In his search for that which is lacking Odin wanders alone

through trackless uninhabited woods, up silent mountains, over the lonely ocean, until he reached that strange, mysterious meeting-place of sea and sky. There, brooding over the waters like a grey sea fog, sat Mimer, guardian of the well where wit and wisdom lie hidden.

'Mimer', the misty embodiment of memory, is the intermediary who grants access to this source of wisdom by providing awareness of that which has been lost. To gain this sense of direction, however, Odin must stand in the place between sea and sky, the 'mysterious meeting-place' of opposing forces, and accept dismemberment. In his desire for the 'great treasure ... which many have sought before', Odin accepts the sacrifice of his right eye in exchange for 'a draught of the fathomless deep'. This act of devotion and courage brings access to the 'fountain of wisdom', an 'inward light' which begins 'springing up within him'.

For Odin, this new source of wisdom brings an awareness of "what it was necessary for him to do in order to become a really noble Asa [god] ... to push on to the extreme edge of the earth itself', and peer into the abysmal depths of Niflheim. The hero is driven to the very edge of the known world on this next stage of his quest, 'over ice-bound seas, through twilight, fog, and snow, right onward in the face of winds that were like swords; until he came into the unknown lands', full of 'sad unfinished shapes ... drifting up and down'. This is 'the end of all creation', and soon Odin reaches Niflheim, at the 'earth's extreme edge, where, lying down and leaning over from its last cold peak, he looked into the gulf below'. Suspended in 
the abyss, Odin initially perceives 'only empty darkness; but, after hanging there three nights and days, his eye fell on one of Yggdrasil's mighty stems'. This is the world-tree that stands at the centre of the Norse universe, with its roots extending through the various levels of the cosmos. Odin then discerns the root of evil and suffering where 'Nidhogg the envious serpent, and his brood of poisonous diseases' threaten the life-giving qualities of the world-tree. After this Odin encounters ghosts who arise from 'Nastrong, the Shore of Corpses' and all the 'shapeless, nameless ills' which surround the 'boiling cauldron of evil'. Eventually after nine nights and days exposed to this horror Odin returns to the world 'more wise ... than when he came'. The narrator of Keary's account finishes by wondering whether it is 'not always thus that wisdom and strength come to us weeping?'

The key elements of Baxter's creative process are all present in this myth - the sense of loss and absence which sparks the 'quest', the discord and anarchy which requires reconciliation and healing, and the experience of dissolution and regeneration which brings forth new life and wisdom. Similarly, the stances and positions which enable the process of 'exchange' of the ordinary self for the mythologising self are all implied - Odin endures distancing, rejection, sacrificial dismemberment, horror and dissolution because of the wisdom and integrity on offer at the end of this process.

\section{'Before the Creation'}

'Before the Creation' (1940) - which was written 'after reading The Heroes of Asgard' - shows Baxter's early fascination with the conditions preceding creation, 
and demonstrates that at fourteen he was already beginning to draw on notions of chaos and the gap as the 'starting point' for poems.

Long, long ago, ere e'en the world was made,

Was naught but chaos, the abyss of space,

The deep Ginungagap - on one side lay

Cold Niflheim, home of frosts and gloomy mists,

And in it was the cauldron Hvergelmir,

The source of twelve great rivers of strange waves

That flowed into the space and chaos far

To freeze therein; while to the south there was

The red abode of Muspelheim,

The glowing home of the eternal fires.

('Notes' 122-23)

Within this mythic framework, creation is natural, cyclical and seasonal; an eternally recurring process. Chaos is where form becomes emptiness and emptiness becomes form, where the tension of opposing forces destroys and recreates life. Paradoxically, even though in this timeless space there is 'naught but chaos', the primordial ginungagap has structural characteristics. The abyss of space is surrounded by opposing poles of ice and fire which seem to pre-date creation. Time, causality and agency are thus blurred and fluid within the chaos of the ginungagap, which is both a space and a material state. As with the seasonal cycle which plays a central role in the mythology of the gap, creation or regeneration only 
occurs after a process of waiting for the thaws of spring, much as Baxter 'waited out' his adolescence. Within the unshaped space-matter of primordial chaos, which is both the first state of the universe and the abyss itself, the process of bringing opposites together sparks creation and allows the life-giving waters to flow.

This gap is the 'locus of tension' or 'central absence' Millar identifies as present in Baxter's work from the early stages of his poetic development.

The locus of tension - that place where poems come from - is then developed as a potent, constantly changing, symbol ... Whatever [the symbol] is, at its centre stands a paradoxical absence that generates poems, and which eventually comes to be referred to, simply, as the gap.

('Tutua')

The teenage poet's interest in the conditions preceding creation is emphasised by the fact that in this poem he neglects to mention the results of the creation or any of the creatures or heroes that follow this brief moment. ${ }^{2}$ Unlike 'Cosmos', in this fragment there is no heroic mythologising self at the centre of the 'myth' and the chaotic conditions of the ginungagap seem about to beget the cosmos of their own accord. However, if the production of this fragment is connected to the story of Odin - which Baxter read at the same time - the 'lesson' which is revealed by both of these mythic patterns elucidates Baxter's creative process.

For the ordinary self to 'become' a poet and access the desired meaning and healing, these conditions would therefore need to be reproduced - repeatedly - in the laboratory in the 'fuggy room at the top of the stairs' ('A Family Photograph,

${ }^{2}$ See also Muse 40-41. 
1939', CP 237). Here Baxter identifies absence, extreme polarities and threatening energies as the treacherous yet fruitful conditions which could consistently engender the necessary 'exchange' of the ordinary for the sacred. The poet as mythologising self is the 'hero' who chooses to undertake the quest for meaning and wisdom, finding the way to the ginungagap, the source of creation and regeneration, the place where chaos becomes cosmos. By facing chaos in this heroic manner, the poet is invested with the wisdom, integrity and godlike authority of the mythologising self.

\section{Definitions of Chaos}

In 'Before the Creation' Baxter describes the ginungagap as a turbulent void, a chaos out of which will emerge the renewed cosmos. This Norse term - the source of the English word 'gap' - shares characteristics with 'chaos'. The English term 'chaos' carries connotations of a 'gaping void, chasm, abyss' or 'infinite darkness', as well as "the "formless void" of primordial matter, great deep, abyss out of which the cosmos or order of the universe was evolved' $(O E D)$. As well as being a 'space between', an absence, or a void, the English usage also carries older Latin and Greek connotations of 'the first state of the universe', the prima materia or primal substance associated with creative potentiality and a belief in a common origin on a cellular level. It is this analogical association with 'creation' which has often linked such connotations of chaos with the symbolism of the womb, an otherwise 'empty space' which can harbour and bring forth new life. Chaos as 'abyss' or 'void' is also an 'empty space' evoking loss, death, disconnection and meaninglessness, an absence of order or a descent into a state of anarchy. Thus the connotations which are most common in modern English: 'a state resembling that of primitive chaos'; 
'anything where the parts are undistinguished - a confused mass or mixture, a conglomeration of parts or elements without order or connexion' $(O E D)$. Baxter's personal mythology abounds in descriptions of such extreme, chaotic conditions, where a lack of order leads to anarchy and suffering. In his view, these are the essential conditions which are embedded in the world following the Fall; thus the experiences of loss, conflict, dissolution are a reminder of this fundamental state and the urge to restore the original cosmos.

In the cosmogonic cycle, creation requires the 'death' of the old world to create the conditions for the renewal of life and the beginning of a new world. Similarly, in Baxter's creative process, the 'exchange' which transforms chaos to cosmos requires the death of the ordinary self in order for the mythologising self to be reborn. Thus the descent to the deathly realm of the underworld is one of Baxter's most commonly utilised mythic paradigms. If the key characteristic of chaos is the absence of order or cosmos, then the poet as hero-creator is the one who must restore this cosmos by making a journey to the extreme edge or the depths, and discerning there the roots of order. This journey takes one 'in' to chaos via the gaps of loss, dismemberment and dissolution. In Baxter's mythology of the gap the 'underworld' and the 'grave' signify, simultaneously, locations and states of being which are below the surface of ordinary awareness. Miles connects Baxter's enduring obsession with death to notions of chaos through the mythopoeic treatment of death and the underworld (Muse 215-46). Interpretation of this underworld symbolism is 'complicated by Baxter's characteristic doubleness. Like a number of key motifs in Baxter's personal mythology ... Hades has two contradictory values, negative and positive' (220). Miles sees Baxter's mature poetry as 'increasingly shaped by the tension between negative and positive values 
of death' as a process which is both desired and feared (215). This 'characteristic doubleness' is also evident in the notions of 'chaos' in Baxter's work. Chaos can be - alternately or simultaneously - 'empty space' and potent matter, terrifying and fruitful, personal and universal. It is only by confronting chaos and death directly that the process of transformation can begin. Thus the poet's search for 'the terrifying but regenerative chaos out of which every island and myth rises, and into which it returns' ('Symbolism', TFA 58) becomes an all-encompassing quest for transformation.

\section{'Debased or Drowned'}

In a 1971 interview Weir quoted Baxter's poem 'The Waves' - 'The waves do not debase / Or drown what shares their fluid motion' (1963, CP 286-88) - and questioned Baxter on the sense of 'a fundamental anarchy' which 'seems to rest at the centre of your way of life' ('Interview' 248). The previous year Weir had written that 'the whole of Baxter's life and thus his writing has been a search for order' (19). This position is evident in his persistent assumption that Baxter must privilege the safety and stability of 'order' over chaos. Baxter's response shows his identification with the sacred patterns which centred around 'chaos':

One may seem at times to be debased or drowned, but then one comes up again like the dolphin. Perhaps this is Grace, I don't know. But I think that what is expressed there is the fundamental anarchy at the heart not of a way of life chosen but of life itself not chosen. It is there, anyway, at the heart of every man's life. The horror of moving into that area of fundamental anarchy is the horror that the writer has to overcome, and any man who has courage who's not a writer ... because it's like that tohu and bohu, the 
Chaos at the beginning of the world when the Holy Spirit moved on that Chaos. That Chaos is inside the human heart. We are in the process of being created: we are not fully-formed creatures. And this anarchy is very painful to us, perhaps the most painful thing in the world - to know that one is a heap of Chaos being made into something. ${ }^{3}$

('Interview' 248-49)

Here Baxter links the sacred pattern of loss, initiation and return with the creation paradigm. The same law applies on both the microcosmic and the macrocosmic level, where the writer's task is essentially the same as the spiritual quest and where the macrocosmic 'Creation' is mirrored by the writer's efforts to continue creating. Like Odin, the writer is shaped by the quest in which he - or 'any man' interested in truth - must make a heroic journey into 'that area of fundamental anarchy', overcoming one's horror and courageously subjecting oneself to the painful process of transformation. The hero travels to Niflheim, the edge of creation, and exposes himself to the horrors of that state in which one 'may seem debased or drowned' but which is in fact 'the centre of man's heart', a primal nature shared with the ginungagap. Thus even though this state of anarchy is horrific and degrading, ultimately Baxter claims that his ambition is to be "that chaos and void on which $\mathrm{Te}$ Wairua Tapu ${ }^{4}$ can rest' (JD 28). This reflects Baxter's belief, which evolved over time, that man is, himself a 'heap of Chaos' perpetually forged and reforged into his true, original state.

The fluidity of chaos is a quality which appealed to Baxter's imagination, and the traditional association with the threatening and healing properties of water is found

\footnotetext{
${ }^{3}$ Ellipsis in original.

${ }^{4}$ The Holy Spirit.
} 
throughout his work, beginning with the first two poems recorded in the manuscript notebooks, 'The Stream' and 'The Waterfall'. The healing and insight which Odin accesses at the well is also represented by a spring, and this imagery of running water - as in the weirs running through the first of the 'Pig Island Letters' - is persistent throughout Baxter's mythology. In the Genesis story, creation occurs when the formless and empty ('tohu wa bohu') space is transformed by 'the spirit of God' which 'moved over the waters' (Genesis 1:2). In this view, to 'be chaos' is to choose to allow the ordering intelligence of God - the Holy Spirit - to shape one's life. While chaos and death are terrifying to the ordinary self, they are essential conditions for the manifestation of the mythologising self. The origins of the obvious dualities in Baxter's writing (and life) can thus be understood in relation to this process of exchange. This later, explicitly Christian terminology fits with the underlying 'existential' framework which informs Baxter's work from the beginning.

In Baxter's creation process this cycle is continual as new life emerges out of the three gaps. His poetry continually emerges out of the formless, empty, dark space, or the chaotic material shaped by the inspiration of a mysterious ordering intelligence. In this view, when one opens oneself to this chaotic state, inspiration arises and the poetic 'myths' which emerge from the depths reflect the same creative order that is responsible for the existence of 'islands' and the 'shaping' of man. In writing, as in life, this process is painful because it involves the inner experiences of being broken, debased, wounded or 'drowned' yet the danger and suffering guarantees the value of what 'comes up', the self who is remade in the image of the creator. On these terms, returning to the destructive and creative conditions of the ginungagap is a heroic form of death which brings the 
mythologising self to life. Baxter's later openness to this chaos contrasts with his early desire for sacred order, reflecting the lifelong journey towards a position where the poet identifies with, rather than fights, chaos.

Rather than a single, definitive act of creation, this ongoing 'evolution' revolves around the choices which man makes, on a journey which mirrors the cycle of traditional cosmologies. Just as in Norse mythology the world is always moving from creation to destruction, so in this personal version of the Christian framework the individual moves from creation through debasement and destruction into the restoration of new life. The ginungagap is the state which follows from the Ragnarok - for the new creation, the old gods must die. The ordinary self or the worldly authorities must be overcome in order for the mythologising self and cosmos to be restored. In this view to 'become chaos' is the first step in the process of 'co-creation', finishing the 'unfinished shapes' by allowing them to align with the sacred patterns embedded in creation. ${ }^{6}$

In 'Thoughts of an Old Alligator' (1966 [first version]) Baxter stated that for the God he believed in 'motives are important ... in my view of it God is not a moralist; $\mathrm{He}$ is primarily a Creator who loves what He has made, and as far as we share in that creative love we fulfil our human destiny' (8). Thus man fulfils God's will if he

5 Baxter tentatively presented the idea of 'evolutionary' co-creation in a letter defending Pierre Teilhard de Chardin's theories:

... (de Chardin) believed like other Catholics that God created the world - the point at issue is how the world was created. I too believe (though not with the absolute certainty pertaining to defined faith) that God created and creates the world by means of an evolutionary process - to put it metaphorically, that He is a democratic rather than an autocratic Ruler, allowing some degree of self-determination to his subjects ...

(Undated letter, Hocken MS - 0739 / 023)

\footnotetext{
${ }^{6}$ See for example 'Choice of Belief': 'We continually deify our ideas and make idols of them' (7).
} 
has the right 'motives' and manifests creative love, regardless of the moral codes which are used to interpret this will. These elements of loss, 'sacrifice', death and resurrection clearly relate Baxter's creative process to other facets of his Christian faith. However these two aspects of Baxter's life are not separate but reflect the primary, fundamental 'quest' for meaning and harmony through an alignment with sacred patterns. Therefore in this larger quest for renewal and truth man must learn from his suffering and loss and be 'hollowed out' and broken down before he can be truly honest and speak with authority. Within the world of Baxter's personal mythology, the mythologising self takes this role, transforming the ordinary into the mythical and sacred through ways of seeing and being which destroy the fallen world and recreate cosmos.

\section{The Quest for the Sacred}

In the early stages of Baxter's quest poetry and psychology were more directly influential than religion in shaping Baxter's search for meaning and harmony. Baxter singles out Jung's Modern Man in Search of a Soul as a formative influence. Like Odin, Jung's 'modern man'

stands upon a peak, or at the very edge of the world, the abyss of the future before him, above him the heavens, and below him the whole of mankind with a history that disappears in primeval mists 
This man is engaged on a heroic inner quest, with the objective of becoming 'conscious to a superlative degree'. Thus with 'every step forward' this solitary man tears himself 'loose from the maternal womb of unconsciousness in which the mass of men dwells' ('The Spiritual Problem of Modern Man', $C W$ Vol 10, 75). Jung writes of the chaotic cultural conditions facing modern man in the first half of the twentieth century, suggesting that they reveal an urgent need to look into the depths of being and reconnect with a neglected mode of being. The common man

protects himself with the shield of science and the armour of reason. His enlightenment is born of fear; in the day-time he believes in an ordered cosmos, and tries to maintain this faith against the fear of chaos that besets him at night... is not ... [the "psyche"] ... a door that opens upon the human world from a world beyond, now and again allowing strange and unseizable potencies to act upon man and to remove him, as if upon the wings of night, from the level of common humanity to that of a more personal vocation?

(Modern Man 166)

In order to 'raise the veil' of ordinary consciousness and see with another eye the poet would have to open the door into this 'world beyond'. This became the basis of Baxter's personal vocation which he consistently saw in terms of a shift away from the ordinary 'level of common humanity'. This returns us to the process of 'exchange' which rejects the ordinary in favour of the quest for transformation and access to a 'sacred' way of seeing and being. Baxter's enduring view was that life in New Zealand was becoming 'progressively more meaningless', with modern man lacking the tools to address the 'deep sense of isolation and malaise, of 
meaninglessness which explodes inward and produces those symptoms which go by the name of neurosis and psychosis' ('Choice of Belief' 1). In this space created by the absence of meaning, a new way of seeing is required. Thus if Baxter tended to 'see the world as chaos', it was at least partly because of his belief that this rejection of a constructed order was a necessary first step towards discovering sacred or mythological meaning:

To make works of art one has to be prepared to set aside the objective lens and endure the unrectored chaos of life until such time as it takes a mythical shape.

('Baxter: the human being is object and subject' 21)

As O'Sullivan has pointed out, Baxter's mythic mode of thinking also resembles Mircea Eliade's notional homo religiosus. Influenced by Jung's theories, Eliade suggested that modern man was losing access to a sacred way of being which had always functioned alongside the 'profane' operations of ordinary life.

homo religiosus always believes that there is an absolute reality, the sacred, which transcends this world but manifests itself in this world, thereby sanctifying it and making it real. He further believes that life has a sacred origin and that human existence realises all of its potentialities in proportion as it is religious - that is, participates in reality.

(The Sacred and the Profane 202) 
While there is no evidence that Baxter read Eliade, he consistently wrote (and acted) from a mythical perspective which reflected the priorities of Eliade's notional religious man. In O’Sullivan's view

Baxter did not use myth as most writers do, for resonance or illustration, for proposing a more than personal significance, or for opening up the ramifications of tradition, but because there was never any question of another way but the mythic being available to him. He could no more not think mythically than he could stop talking, or believe that his life was not being acted out on a cosmic stage.

(Two Baxters 76)

Yet taking up this 'mythic' stance was a continual choice which involved a rejection of one way of being in favour of another. This is the perspective reflected in the polarities of Baxter's 'meaningless or mythology' dichotomy. Writing in the middle of the twentieth century, Eliade expressed the view that

the completely profane world, the wholly desacralized cosmos, is a recent discovery in the history of the human spirit ... desacralization pervades the entire experience of the nonreligious man of modern societies and that, in consequence, he finds it increasingly difficult to rediscover the existential dimensions of religious man in the archaic societies.

('When the Sacred Manifests Itself', Eliade Reader 20)

Eliade's religious man searches for sacred places and states in which he can overturn the meaninglessness of 'profane' history and enter 'sacred time', which 
'appears under the paradoxical aspect of a circular time, reversible and recoverable, a sort of eternal mythical present that is periodically reintegrated by means of rites' ('Profane Duration and Sacred Time', Eliade Reader, 219). This resembles Baxter's similarly dualistic view, which emphasised the loss of the 'sacred' as a modern phenomenon and the 'abyss' between the sacred and the profane as (in Eliade's terms) 'the two modalities of experience'. Thus, like homo religiosus, Baxter developed strategies which actively encouraged the sacred to manifest in the world. In Eliade's view, a hero like Odin or the modern poet 'finishes the work of creation' through the repetition of this pattern and the rediscovery of sacred time and space.

The gods created man and the world, the culture heroes completed the Creation, and the history of all these divine and semi-divine works is preserved in the myths. By reactualising sacred history, by imitating the divine behaviour, man puts and keeps himself close to the gods - that is, the real and the significant.

(The Sacred and the Profane 202)

While Eliade's homo religiosus reflects the sense of a loss of collective order anchored in a shared mythological framework, Baxter's quest is first and foremost for the establishment of personal meaning and harmony, considering everything which could not be reshaped as mythology to be 'meaningless to me'. Baxter's use of myth and ritual reflect this urge to 'reactualise sacred history' by imitating the gods and aligning his life with the structure of the sacred patterns, thus transforming the world and making it personally 'meaningful'. Baxter writes that profane time is meaningless to him, 'the day before yesterday ... might as well be the day before 
Noah's Flood' ('Notes' 121). As in Baxter's creative process, the ritualistic repetition of the 'cosmogonic myth' is for Eliade's archaic man a tool which enables a 'return to the original time, the therapeutic purpose of which is to begin life once again, a symbolic rebirth'. Thus life can be recreated through symbolic repetition of the cosmogony ... the paradigmatic model for all creation' ('Regeneration through Return to the Time of Origins', Reader, 225). Eliade considered a great modern poet to be one who 'discovers the world as though he were present at the cosmogonic moment, contemporaneous with the first day of Creation. From a certain point of view, we may say that every great poet is remaking the world, for he is trying to see it as if there were no Time, no History' ('The Myths of the Modern World', Eliade Reader, 213).

By reinforcing the sense of a dichotomy between the sacred and the profane, Baxter maintained a dualism which set his quest in opposition to the cultural status quo. By facing chaos the hero rejects or dissolves the false reality of the profane world and returns to the original state, where cosmos emerged out of chaos, thus renewing the creation and in Baxter's terms reversing the Fall. Baxter shares with Eliade an emphasis on the Fall as a mythic explanation for the human condition, as well as a template with which to interpret the ongoing process of disconnection from 'the sacred'. In Baxter's view, New Zealand's 'secular Calvinist ethos' cut man off from the sacred to the extent that it 'civilised' him:

The Calvinist thesis that the Fall is absolute and the natural man totally depraved has led, by devious byways, to a kind of idolatry - a deep reliance, torn still by an anguish of uncertainty, on the civilising influence of education, culture and the power of the State - as if these could eradicate the 
turbulence of the passions and put in their place an abstract social benevolence. Yet the equation never quite works out. Modern Western man resembles the Norse god Odin, who went to the secret well which lay in the roots of Yggdrasil, the tree of life, and demanded some of the water to drink, so that he would have the power of wisdom and foreknowledge. The guardian of the well demanded that he should tear out his right eye and give it to him before he could drink the water. Odin did so, and achieved knowledge at the cost of partial blindness - an image, I think, of the loss of the religious and aesthetic vision.

('Conversation' 21)

Here Baxter employs the mythic image of Odin's dismemberment to demonstrate the exact opposite experience - the loss of the sacred vision or eye of God through the attainment of 'knowledge'. 7 This use of the mythic pattern reflects Baxter's own view of the Fall as the fundamental, mysterious reality at the root of man's 'universal' condition of ignorance, imperfection and mortality. Yggdrasil, the lifegiving tree, is continually threatened by the serpent Nidhogg, here manifest as the ignorance of man, whose desire for control and authority always comes at a loss. In his quest for 'knowledge' (rather than wisdom), this 'secular Calvinist' Odin has made the wrong bargain and lost access to the sacred. Thus for Baxter it became necessary to break down the social patterns in order to discover the sacred patterns behind this form of civilised 'idolatry'.

\footnotetext{
${ }^{7}$ This tendency to use mythic patterns to express opposing positions is clearly demonstrated by The Snake-Haired Muse.

${ }^{8}$ See 'World' 179.
} 


\section{The Gap in the Hoardings}

From an early age Baxter believed that to restore what was lost, one must find the creative chaos at the centre and thus manifest the mythologising self. To do this one must enter (or create) gaps. By his early twenties, Baxter considered this mythologising mode to be the primary purpose of the poet and the means to restoring 'vitality' to modern life. Addressing the Literary Society of Victoria University College in 1949 ('Why Writers Stop Writing', 26-27) Baxter explains the need to go beyond, beneath, and behind the ordinary surfaces of life. The central concern of this talk was the effort to preserve the 'vitality of the creative impulse' which was threatened when 'the periods of incubation necessary for sustained and organic themes cannot be afforded'. Poets needed the space and time in which poems could grow. The traditional notion of creative 'incubation' here is a clear link to the gap as the 'menopause of the mind' and the imagery of fertility and sterility in the first of the 'Pig Island Letters'.

For Baxter the true writers, however, were unable to stop: 'Those whom the Muse has once visited are haunted for the rest of their lives'. Beyond practical issues Baxter saw 'a deeper cause of sterility' threatening this productive relationship with the Muse:

In composition a writer's struggle, above and beyond his technical problems, is to rouse himself from that sleep which he normally calls waking, and see motives, moods and situations, with a naked intensity.

To keep the mythologising self alive and exchange the 'sleep' of the ordinary self for the 'naked intensity' which the mythologising self experiences in 'Cosmos', one 
needed to confront chaos rather than becoming lost in the artificial world man constructs for himself. Baxter suggests that this process is dependent on a 'true world-view' which provides the 'naked glare of insight' and is 'accompanied always by an awareness of moral conflict'. This necessary act of remembrance is obstructed by the falseness of the popular culture:

... awareness of moral conflict is not over-popular with us. From every hoarding the gigantic moronic faces stare at us, over their Kruschen Salts or electoral slogans, telling us that a little more money, a little more 'love', an iron tonic, the right name marked on the voting paper - and the line will be clear at last, put on steam for Paradise-on-Earth. In the gaps between the hoardings children still find jungles, and grown-ups disturbing memories or jagged guilt; but the gaps are closing. We are in danger of forgetting what we mean to ourselves.

Thus Baxter rejects a superficial 'advertising view' of human nature (27) in favour of the awareness of 'conflict', 'memories' and 'guilt' which may lead to emotional dismemberment but like Mimer's guidance can also help us to remember 'what we mean to ourselves' and to see again the suffering, horror and anarchy which stems from loss and dismemberment. In a modern landscape the quest for wisdom and strength requires the search for these 'gaps between the hoardings', points of entry into another realm of meaning where one may gaze into the abyss of memory, fear and guilt, and discern the roots of order and the source of creation. This heroic quest begins when that which is valued as most precious by the tribe is threatened or lost. The rejection of a false order frees the writer to explore the gaps in search of the 
wisdom and vitality beyond. To do this, the culture must be broken apart, the superficial illusion of meaning, harmony and identity must be rejected in favour of what is found below. Thus Baxter claimed that the 'material of every good poem is in some sense forbidden' ('Criticism', 32), whether this related to the 'fundamental anarchy' of one's personal life, social taboos or spiritual insights. In Baxter's poetry there is often a sense that the allure of the 'forbidden' is seen as guarantee of this 'universal' value. This was a challenge to the poet's 'honesty' and the courage to face this demand was a characteristic of the mythologising self:

To save (in a purely aesthetic sense) his soul, a poet must be more honest than his everyday cowardly or jocular self. Agonies, desires, and dilemmas which the housewifely mind has cast out on the rubbish-heap must be unearthed and exposed to the sun; with those sexual, aggressive, and anarchistic motives which enter uneasily the drawing-room of verse, being accustomed to darker lodging, yet provide the power that makes the poem live. Before they can be admitted, a poet has to struggle at the door with his own butler conscience

To save (or find) his soul, the honest poet must face this anarchy at its roots, confronting and mastering the forces which otherwise led to destruction. Thus Baxter wrote that in the 'Age of Destitution' the 'wounds like craters in the body of humanity lead honest writers to a separateness, a habit of serupulous objectivity ${ }^{9}$ not trusting the way of looking at life that have allowed these things to happen' ('Further Notes', 1967, 21). This sense of separateness and a deliberate distancing defines Baxter's thinking, rather than a devotion to 'scrupulous objectivity'.

\footnotetext{
${ }^{9}$ Strikethrough in original.
} 
Whether it was vitality, love, the sacred or creativity which was sought, Baxter's 'private war' against the status quo continued. Baxter's distrust of the 'ways of looking at life' led to the 'meaningless or mythology' dichotomy.

\section{Using the Gaps in Experience}

Like Odin using memory to draw from the depths of the well of wisdom or travelling to the edge of creation and perceiving the roots of order with his wisdom eye, the poet must find the right place and the right attitude. To develop and grow as a poet, Baxter told Weir that 'you get cunning: you learn to use the gaps in experience and develop new styles to cope with a different situation' (245). Like Ulysses, Odin and other heroes, the poet must devise strategies for dealing with new situations, and use the gaps in experience to initiate the process of transformation. The gaps opened up the space where - momentarily - what was separated could be reconciled, what was lost could be found and restored, and where the desired transformation could occur. Not only did Baxter 'use' the gaps in experience, he actively initiated these experiences in order to create gaps. Thus these new styles Baxter referred to were not only aesthetic, but also mythic - over time Baxter identified with and utilised different parts of the mythic patterns and processes which shaped his personal mythology.

The tendency to harness the habits of his own thinking for creative purposes seems to have begun at an early stage. At the height of the Second World War the sixteenyear-old Baxter told his friend Noel Ginn that he longed to get away from New Zealand: 
My heart's desire — or almost — is to visit Europe after this bloody chaos has subsided. I don't know why. Perhaps youthful desire for excitement. Perhaps the obvious sparsity [sic] of intelligence among N.Z.ers—excluding you and a good few, who don't appear the typical New Zealand products.

(22/01/1943, Spark 187)

Baxter acknowledges that this reading of New Zealand as a cultural and intellectual desert may be unfair: 'I may be too hard on them. They may know intellect for what it's worth. But if I start thinking that way I won't write any more poetry' (ibid). The desire to return to Europe rarely raised its head in later years, and the emphasis here on 'intellect' seems to contradict Baxter's preferred type of learning. Yet aside from the possibility that the adolescent Baxter is employing an idiosyncratic use of the term, this is also an example of the primacy of Baxter's strategic approach to experience - what matters here is finding the right place and the right stance. Thinking in this way created the state out of which poems emerged, and this creation was pre-eminent.

Clearly Baxter already saw creation as dependent on a cultivated attitude of opposition towards the social order, and the preservation of distance from the mainstream: he had to remain in opposition to 'the status quo' in order to maintain the space 'in which the poem could grow'. The war would end but the 'bloody chaos' would need to continue if the poet was to continue writing. In this way, Baxter manipulated inner and outer experience to fit with the conditions that produce poems. Thus from the beginning Baxter's thinking - and his poetry - was shaped by the imperatives of his quest, rather than the poetry being a receptacle for fixed views. He relied on extreme readings, ways of seeing the world which 
identified and extended the 'gaps' and thus brought the mythologising self back to life.

Baxter's views and his actions were both shaped by this overriding quest and the need to confront chaos via the gap. In 1968 Baxter reviewed his relationship with 'the Muse' as an ongoing negotiation between the need to preserve creative vitality and the need to maintain order in one's personal life. He claimed that the urge towards a degree of domestic order had threatened this relationship: 'in my time I had already done all the wrong things. I had made a strenuous effort to remain married. I had got off the booze before it gave me a wet brain. I had reduced my late adolescent adulteries ...' However, Baxter claimed that he had developed the means to counter these problematic developments: 'I had learned cunningly to twist the Muse's arm' ('Burns Fellowship' 244). Like the hero engaged in his quest, the poet must discover a range of strategies to overcome obstacles in the way of that which is desired. Baxter's strategies involved ways of seeing and being which were designed to maintain the connection to the Muse's realm of chaos and creation.

The creative energies of the chaotic realm could be accessed by discovering the right place and the right state of mind and the strategies which had proved successful previously could be consistently utilised to 'locate' that which was desired. Thus in 1965 Baxter listed some of the 'places' where he had been able to consistently locate this creative inspiration:

There is a spot in the arena to which the fighting bull returns (a different spot for each bull) and from which he comes out more assured and formidable. For me it was once the beaches of the place I grew up in; then 
the pub; and latterly perhaps the hour of death which one looks forward to. If this spot is correctly located one can generally go on writing.

(Critic 211)

This meant that Baxter's tendency to read experience mythically in terms of loss, suffering, alienation, and dissolution was reinforced by the 'necessity' of poetic creation. It also meant that the experience of the gap - which enabled one to see the truth of human life as well as to create - could be somewhat 'manufactured' through certain practices and activities such as 'natural contemplation', 'saturnalian' indulgence in alcohol or sex, bohemian 'destitution' or religious ritual which led to the state out of which poems emerged. In Baxter's later terms, the common link between these diverse experiences was the belief that, in order to access 'grace', one must first become 'debased'. Thus Baxter explains his 'profanity' as a necessary strategy in the search for the sacred.

In 1967 Baxter wrote that, in contrast to the 'Calvinist' vision of the depravity of the natural man, he preferred the possibility that 'as the Catholic thinkers have always taught, the Fall was not complete, and the natural man, though wounded, is still the earth lamp who holds the oil of grace' ('Conversation' 21). Modern man can still access some form of 'grace' via this primitive mode of being; Odin can drink from the well if he is prepared to make the sacrificial exchange.

The 'primitive' self is however problematic in the social environment of the common man, rebelliously resisting the 'sterile order' in his desire for Eden. For Baxter, this explained the 'delinquents' he sees in the milk bar: 
I suggest that it is impossible for a poet or novelist to write well unless they regard such people as their difficult alter egoes, emblematic of the natural man, the living proof that no temporal order is ever satisfactory; and to this extent a writer is obliged to be Bohemian in thought, not moralising but mythologising, rediscovering his or her own buried natural self.

('Conversation' 22)

Mythologising is thus the process of 'digging deep', an incorporation of the 'buried natural self' which promises the possibility of wholeness, and a way to affirm the belief that 'no temporal order is ever satisfactory' (ibid). Yet this anarchic self is at odds with not only the sterile social order but also the imperatives of domestic and familial order and stability. At this point in the mid-1960s, Baxter sees both the 'bourgeois family man' (20) and the 'natural man' as only 'half' men, and this is persistent conflict. The struggle between these two modalities is illustrated by Horse, ${ }^{10}$ Baxter's posthumously published novel, which presents a retrospective account of the transition from his 'pagan' phase to the orthodox Christian faith he advocates in 'Why Writers Stop Writing'. The central character is Timothy Harold Glass, Baxter's 'Pig Island version of natural man' ('Conversation' 21) whose 'real' identity is 'Horse'. The 'tenets of the Horse religion' - though constructed at a remove of more than fifteen years and with tongue (somewhat) in cheek - reveal the connection between Baxter's exaltation of the 'primitive' and his desire for the 'sacred'. The young man's growth is an ongoing lesson in where and how to reclaim the 'eye of God' by entering sacred time and space:

\footnotetext{
${ }^{10}$ Started in India in 1958-59, completed in 1962 and published in 1985. This novel was originally intended to parallel the labours of Heracles ('Conversation' 17). See Muse (129-32).
} 
Surrounding Horse, not made by him, existed the sky, the earth, the sea, and other less clearly defined creatures ... By contact with the world of substance Horse had access to a sacred power ... This power adhered to particular places and particular people. In his childhood Horse had experienced its manifestations on certain cliff-faces and on the banks of creeks ... His father conveyed it strongly, by the capable strength of his hands, and by the smell of burnt gum-leaves he often carried on his person. As the primitive paradise of childhood fell apart, Horse had been led by meditation and example to look for the signs of this power in women.

Baxter's tragi-comic alter ego demonstrates the ways in which the 'world of substance' provides a 'door' into the space of composition, when he rather callously utilises his sexual relationship with Fern to access the sacred power:

... the mythical identification with all things living was achieved. Horse did not use a condom ... He had visited the holy place several times since then, alone, and each time had received the germinal image of a new poem.

In contrast to Horse, Timothy is essentially a mere mask, a 'good son' who relies on Horse's courage to deal with the difficulties of real life and who disappears when the sacred is accessed: 'At that moment it seemed as if Timothy Harold Glass, the ghost in trousers, ${ }^{11}$ had dissolved in thin air, and only Horse was left alive' (12). As noted in the first chapter of Snake-Haired Muse, the Jungian polarities of the ego and the 'Shadow' are inverted in this formulation, as the ordinary self is rejected.

\footnotetext{
${ }^{11}$ Baxter's original title.
} 
This is the 'ghost' who haunts 'Horse' as he attempts to retain his 'true identity' as a primitive. Horse possesses the 'naked glare of insight' and the vitality of the primitive, 'the redhot stovesitter'. Timothy is the false self 'with his hands over his ears, blinking and frozen' (8). Baxter tends to favour the other pole of this duality the anarchic natural man who is still able to access the sacred.

Here, the destruction of the self is associated with freedom from the mundane horror of profane time and entry into the sacred. Yet as Baxter himself suggests in Horse these modes were bound up with less lofty personal desires. In an early response to Baxter's 'duplicity', Robert Chapman noted 'a sense in which $\mathrm{Mr}$ Baxter as a romantic wants both the personal enjoyment of chaos and the poetical duty of restoring order' (qtd in Doyle 68). Baxter's embrace of chaos took many forms, and the duplicity which seems to be at the heart of his life story is arguably a reflection of the trouble which ensues when an individual retains the personal authority of 'mythic' interpretation over their own actions. A piece written for the Canterbury student magazine in 1948 entitled 'Saturnalia' (Canta 7/7/48) demonstrates this habit of destroying and restoring order on the microcosmic level of personal behaviour. Here the mythic paradigm of descent and regeneration connects seemingly incongruous areas of Baxter's life, allowing him to interpret his social life as an escape from 'Time' through the pathways of alcohol and sex. Baxter extols the virtues of the ancient Roman festival of Saturnalia, reinterpreted as a 'three-day, five-day, eight-day bash'. This spell of 'complete and dazzling freedom' serves as an antidote to the constraints of modern life because 'we, with our thousand restrictions and things-to-be done, need a drug' to transform experience and bring back to life 'the spirit of the times' which would restore the feeling of freedom that 'children have ... quite often - young children, anyway'. 
This destructive process is complete when 'we can say with Rimbaud: "By a road of perils my weakness led me to the borders of Cimmeria, land of whirlwinds and darkness", This place of absolute desolation and abject despair is reached by shaking off the 'overcoat' of one's socially adjusted self. There 'we find our true self, seemingly a complete stranger, forgotten since the earliest childhood. And having danced there and dived in the blinding pool, we come to life again, sick but filled with a strange peace and vigour'.

The process of rejection and mythic reconstruction presented in juvenile form in the poem 'Cosmos' was also central to Baxter's social commentary and world view. The 'growth' of the poet depended on the death, destruction, dissolution or diminishment of the ordinary self, and similarly the poet must be prepared to leave behind 'the tribal womb or matrix from which the individual emerges on his dangerous journey towards self-knowledge' ('Man' 101). The need to break social patterns and replace them with mythical or sacred patterns is persistent throughout Baxter's prose as well as his poetry. This 'rebellion of artists against the social patterns of their time ... is the inevitable accompaniment of their growth towards maturity' ('Mask' 52). The work of the artist or contemplative carries heroic implications embodied by the titan Prometheus, interpreted as 'the principle of rebellious energy in man that enlarges our order by breaking it and allowing it to reform in another pattern - an energy that our way of life dismembers and disregards.' ('Notes' 154). Baxter sees this form of mythologising as an assertion of 'an individual vision, a task which runs counter to the ordinary citizen's very real horror of freedom' ('Mask' 51). The need to 'believe in the possibility of a fruitful freedom' persisted, despite Baxter's habitually pessimistic view of the human condition. It was only through 'freedom' that man - and society - could be shaped 
through the process of exchange and the choice which led to growth. Thus Baxter quotes Wallace Fowlie who wrote of Rimbaud that he 'opposed conventionality through a deep principle of changing his being' ('Mask' 54). The poem is an assertion of godlike authority over personal reality, and this process relied on the 'freedom ... to put into words the shape of the world inside me' ('Notes' 150):

The secret joy in the act, say of smashing the windows of an empty house, and the joy in that act of choice which lies at the core of the creation of an art form, sprang from the same root (though one act is fruitful and the other demonic) - It is I who choose to do this.

('Mask' 52)

Baxter's creation myth relies on the space and material in which to shape or perceive cosmos, and thus creative ordering requires the right stance which gives the poet the 'eye' of God. This involved an embrace of 'that level of hardship or awareness of moral chaos where the soul is too destitute to be able to lie to itself' ('On Possessing the Burns Fellowship' 17). Awareness of moral conflict and suffering revealed man's essential nature and opened the way to both creativity and authenticity. In his interview with Weir, Baxter explicates the declaration that 'the poem is a plank across the lion's den' ('Pig Island Letters' 9, CP 282) by emphasising the importance of contact with this chaos. Rather than privileging order, as Weir suggests, Baxter contends that

One has to be pretty close to the fire, I think, pretty close to this position of Chaos. The nearer you are to it and can survive the better. One critic of my 
verse, a sympathetic critic, said that I was like a man who worked very close to the bull, a bullfighter. You almost get grazed by the horns. Perhaps you do. Perhaps the blood is helpful that goes into the poem.

('Interview' 243)

In this later approach, the 'blood' of experience gives the poem vitality and the 'wounds' endured in life are not covered over by the beauty of the poem. Baxter told Weir that

'Pig Island Letters', that actual sequence, is more Dionysiac [sic] - the blood-from-the-wound type-of-thing. There is a certain breakdown of form that occurs, but there is an advantage of spontaneity, I think, and in authenticity. I wanted that: just someone speaking authentically ... aesthetics is necessary: to have a form, a way of approaching things. One needs the form. When one begins to idolise the form or the artistic experience ... this is where the danger comes in, a sort of idolatry.

('Interview' 244-45)

This 'authentic' speech relies on breaking down forms, rather than applying or maintaining a fixed order. The 'positive philosophical structure' Weir sees as the basis of Baxter's later poetry is for the poet a set of tools for ordering chaos rather than permanently transforming it. Baxter values fluidity rather than structure - thus the poems are a temporary 'shaping' and the 'myths' return to the sea. 


\section{The Three Types of Gap}

Having established that the same basic process is central to Baxter's creative method - utilising notions of the gap as the starting point for mythologising - we can break the process down further to consider the different 'entry' points or types of gap which correspond to the characteristics of the ginungagap. Baxter uses a sense of 'grief', loss, lack or absence to generate a creative response which is based around the explicit or implicit desire for that which is 'missing'. He uses the tension between 'myself and other people', 'myself and the status quo', and internal tensions to generate creative responses which highlight the need for reconciliation and healing, for a 'compensatory' shift, or to simply highlight a perceived injustice. He uses the experience of 'dissolution' - whether deliberately engendered through various practices and rituals, or through the horrors of 'monotony, atrocity and anarchy' to suggest the existence of a universal realm of wisdom and creativity below the surface of ordinary life. These three approaches are both deliberate and compulsive. Through constant practice, they become vital to Baxter's poetic method - they are reasons to mythologise, the means to mythologising, and they give mythic structure to the work. While it is difficult to ascertain the workings of the complex processes of composition, the poetry reveals a notable consistency on the level of 'starting points' which extends across the range of Baxter's work in terms of both time and content. Each of the following types of gap can be seen as relating to the mythic paradigms Baxter utilised most consistently - the primal crime of disobedience and loss, the suffering, dismemberment and initiation of the hero and the cycle of death and renewal which requires sacrifice and dissolution. 
O empty! what shall fill

The gap, or cure

That ache not to be banished?

('Cressida: A Lyric Sequence’, 7, 1951, CP 105-06)

The starting point in Odin's quest is an awareness that something is missing or lost. This takes him to Mimer's well, where this vague intimation is confirmed and his quest is validated. One of the dominant strains of Baxter's personal mythology is the pervasive pain of absence which leads to the creation of 'songs of grief'. Much of Baxter's poetry was initiated by a desire to 'fill' the space left by the desired 'presence'. The nature and identity of this presence constantly shifted and evolved, yet a sense of loneliness and grief remained constant in Baxter's work. Weir noted that there "is a sense in which the words "poetry of loss" apply to almost all that Baxter has written' (63). Millar goes further in suggesting that Baxter's early sense of grief may have provided him with the initial impetus to mythologise (Spark 24). In 'Notes' the mythic paradigm of 'the Fall' linked diverse experiences which shared this starting point of 'loss'. In this process the mythologising self fills the gap with song and momentarily restores connection to that which is lost. To reach this 'starting point', however, Baxter must first dismiss 'what is' in favour of what is absent, using the tools of memory and imagination.

The sense of loss, absence or lack applied to a wide range of postulated presences, the 'shape' of which could only be known through the imagination which reaches out towards them. At the centre of this sense of loss is the awareness that human life is imperfect and impermanent and that the desired conditions for harmony and 
'creative love' often seemed inaccessible. This in turn led to a grief which stemmed from man's ability to imagine life without these negative aspects - as what it could be rather than what it is or ordinarily appears to be. Thus the imagination becomes a substitute for the creator, providing tools for restoration and remembrance, and possibilities for that which might 'fill' the gap. Baxter's songs of grief required an imaginative awareness of that which has been lost. This absence defined the role of the poet who:

Will never be content this side of the grave, for the spirit of turbulence in his heart will reject every custom, law and institution, asking from man and nature an impossible harmony. Yet his songs are the fruit of that harmony, which he knows best by the pain of absence. He will always jerk against your yoke; and you will always find him hard to bear.

(Numbers 6, March 1957, 8)

Baxter insists on the lack of harmony in man and nature and at the same time is unwilling or incapable of reconciling himself to this state. The poems are almost always a rejection of 'what is' in favour of that which once was or could be. Baxter utilised experiences of loss as a means to imaginatively restore various absent 'shapes'. Behind each of these forms of loss was the prevailing sense of disconnection, fragility and the lack of a sustaining, creative love. He retained a strong emotional connection with the 'ghost' of his first lover nearly twenty years after the relationship had ended, noting in 1968 that on his return to Dunedin he once again 'wrestled with the ghost of an ancient mistress who came back to haunt 
me, and got a number of written lectures and some grim, dry poems out of the encounter' ('Fellowship' 244-45). ${ }^{12}$

Baxter's sense of a 'gap between' himself and others - and the empty landscape of his early poems - is suggestive of an absence which threatens to devour the isolated and vulnerable adolescent. ${ }^{13}$ In 'Notes' Baxter writes that during this time he hoped that poetry might bridge the interpersonal gaps, imagining

a secret tribe of friends and lovers who waited, guns and poems and contraceptives in their hands, to welcome my coming of age. The experience had some of the force of a religious conversion; and more important, I had the sense of a possible audience for my own verse ...

In 'Conversation with an Ancestor' the awareness of mortality and the inevitability of personal and interpersonal loss is the cause of Baxter's search for a tribe which mirrors his search for connection and meaning through the creation of poetry:

For me it is not death itself but the knowledge of death that makes me reach out to the tribe that no longer exists. As I have done time after time in imagination, looking for some fragment of the lost unity on which to build a poem, but now for a different reason, I go along the river track towards that gully where the clan built their houses ...

\footnotetext{
${ }^{12}$ See 'Words to Lay a Strong Ghost' (1966, CP 356-64).

${ }^{13}$ See Muse, 41.
} 
Baxter had searched for this sense of 'primitive order' amongst the remnants of his own 'tribal' background as the descendant of Highland Scots who had been forced off their land by the Clearances. This was the 'readymade myth' ('Recent' 3) of wholeness and loss which the 'ancestral face' evoked for the young Baxter as he heard tales of his ancestors and visited sites in Scotland as young boy. ${ }^{14}$ In this view, Baxter's ancestors had been spurred by loss of land and lifestyle to travel to the far end of the world in the hope of establishing a 'new Eden' (Dunedin) in Otago. Looking back to these pioneering ancestors, provided another lens:

I have seen inwardly my first ancestors in this country, those Gaelicspeaking men and women, descending with their bullock drays and baggage to cross the mouth of what is now the Brighton river; near to sunset, when the black and red of the sky intimated a new thing, a radical loss and a radical beginning; and the earth lay before them, for that one moment of history, as a primitive and sacred Bride, unentered and unexploited. Those people, whose bones are in our cemeteries, are the only tribe I know of; and though they are scattered and lost, their unfulfilled intention of charity, peace and a survival that is more than self-preservation, burns like radium in the cells of my body; and perhaps a fragment of their intention is fulfilled in me, because of my works of art, the poems that are a permanent sign of contradiction in a world where the pound note and the lens of the analytical Western mind are the only things held sacred. I stand then as a tribesman left over from the dissolution of the tribes.

('Conversation' 12)

This gap connects Baxter's poetic and religious views, as the condition of absence is bound to the creative process of restoration and connection with what is 'lost'.

\footnotetext{
${ }^{14}$ See McKay 1-3.
} 
Absence and emptiness are thus not indicators of an eternal void but the characteristics which signify the mysterious fruitfulness of the creative God. In Horse Baxter has his middle aged alter ego Grummett tell the eponymous hero that this awareness of absence is - paradoxically - the first step towards true knowledge of God: 'one knows Him by His absence, perhaps'. After this revelation 'Horse, having drunk at the holy fountain, felt it was time to go' (118-19).

This pervasive absence, alternately threatening and fruitful, is the starting point for the construction of meaningful mythology which transforms the 'mystery' of the gap in accordance with the imperatives of desire:

... Evil is the absence of good ... the absence of flesh on a man's face can be a very hideous ulcered wound ... the absence of ground in the middle of a footpath can be a hole twenty feet deep that you fall into, and break your neck ... the absence of life can turn a man into a corpse ... absence of honesty can ruin all communication ... the absence of courage makes it impossible for a man to be a loyal friend ... the absence of love and justice among nations can mean the end of life on the surface of the globe.

Absence can be a very terrible thing - or, if you like, a very terrible nothing.

The Christian believes that the being we call Christ is himself the response of God to the absence of love and truth among men. God's response to evil is to overcome it with good ...

... He puts his arms round the dead soul and brings it to life. This is what we call the mystery of redemption. 
The absence of that which is desired leads to suffering and eventually to songs of grief. Baxter's God is also commonly absent or unbearably distant. This quality of absence reflects the essential characteristics of 'chaos' which is the source of 'cosmos'. God is the 'answer' to the apparent absence of that which is desired, and conversely this absence is an indicator of God's manifest 'shape', in the form of Christ. An 'absent' God is thus the perfect 'other' - the unknown source of meaning, and healing and the answer to 'problems of identity' which plagued Baxter. This mysterious, absent God could be personally interpreted, with absence and silence providing the 'answers'. The 'God' at the centre of Baxter's mythology is thus the source of restoration, healing and transformation through the intermediary role of the mythologising self.

The second type of gap which shapes Baxter's mythology is the 'space between' groups or elements. Baxter characteristically insists on dividing the world into opposing, conflicting forces, occupying the central space between forces in order to bring them together and produce healing through the meeting of fire and ice. In identifying and inhabiting these opposing positions, Baxter generated the 'tension of belief' which he felt provided the 'edge' in his poems which gave them 'blood' and thus kept them vital. Millar demonstrates how Baxter's self-professed 'quarrel with the status quo' led at an early age to the instinctive formulation of 'the model that would inform his verse for the remainder of his life'. This is

a paradigm in which polarities (the tribe versus modern society, wisdom versus knowledge, and man versus woman, etc) generate tensions that produce poetry ... Baxter works with polarities that are alternately individual 
and universal: with the opposing poles being either himself and "the status quo", or "myself and other people". The creative tension occurs in the former antithetical pairing as a quarrel out of which "the poems sprang", and in the latter, as a sense of difference that creates a gap "in which the poems are able to grow".

('Tutua')

This came about through Baxter's early discovery that he could utilise the 'tension' between the poet and the 'status quo' - and later, internal tensions - to create poetry. This oppositional mythologising relied on a range of stances and lenses, with the constant reinforcement of a sense of alienation, division and separation.

Notions of the gap as a 'space between' allowed Baxter to utilise the space and tension which was created by 'incomplete' relationships. As with the other types of gap, this is underpinned by the comparison with an imagined harmony. Any suffering caused by these incomplete relationships could be interpreted as a reminder of the essential characteristics of the fallen world. The poems then 'sprang' from this experience of conflict and tension. The two aspects of the gap are evident in these differing notions of a 'space between'. The gap which the writer senses or maintains between himself and 'other people' or 'the status quo' allows the preservation of the 'space in which poems can grow'. Locating the gap between opposing forces allows the writer to access the creative energy generated by the tension between. Thus Baxter was simultaneously drawn to distance himself from the perceived 'majority culture' at the same time as remaining connected to the experience of this tension which was caused by the conflict between various social, natural, psychological or supernatural forces. 
Standing in the way of the quest to 'become' a poet was the prevailing social order in all its visible and invisible forms. Baxter believed that the 'Calvinist ethos' remained firmly embedded in New Zealand culture below the surface 'like the bones of a dinosaur buried in a suburban garden plot'. In 'Notes' he writes that as a teenager the real 'danger' came from within: 'I could not fight these chiefly inward pressures'. By insisting upon a rigidly interpreted moral ordering which saw on one side these prohibitive injunctions as central to the culture around him, and on the other some ill-defined alternative, Baxter reified an internal division which various 'external' factors had apparently opened up. Looking back in 'Notes' at the age of forty, he does not disagree or expand on this simplistic binarism which relies on extremely subjective (at times self-serving) interpretations of unseen motives. He simply notes that at the time 'I lacked the experience to contradict them and forge against them'. Thus he reveals one of the strongest motivations for his poetic output - to 'forge' or create against the order he perceives to threaten his identity. So he had to 'wait it out' while practicing his oppositional art in preparation for the time when that dominant order could be publicly challenged. Typically, Baxter saw this process as (virtually) universal:

nearly every capable writer in this country whom I have met has passed through a time of radical revolt, of cutting the apron strings of the social nursery, and that their later balance, if they achieve it, includes a direct knowledge of those aspects of human nature which a neo-Calvinist would ignore or repudiate. They work continually with two sides of the life of man - the instinctive and the social, the wild and the domestic, the passionate and the rational - and their art is the fruit of this radical tension. 
This gap tends to be associated with a more immediate, visceral form of suffering than the gap of absence. This is the space where great opposing forces threaten like the Plunket nurse in 'Notes' - to dismember the potential for life, love and creativity. Thus this 'gap between' is synonymous with wounds and with crucifixion, as in the notebook poem which Baxter refers to in 'Notes'.

Baxter's claim in 'Notes' that he had always felt beset by 'invisible adversaries' suggests the early development of the role of the scapegoat. Eventually this preexisting sense of conflict and threat took form in the schoolyard bullying of his adolescence. Baxter continued to search for these adversaries throughout his life, perhaps because the sense of conflict which ensued confirmed an essential element of his identity as an outsider. From the beginning, Baxter's identity was shaped by the experience of being an outsider, with the principles cherished by his parents and the 'pacifist church' set against the authorities of the 'status quo'. Throughout his life Baxter was tempted by the idea of a retreat to the 'wilderness' as a way of escaping the status quo. As O'Sullivan writes, Baxter's notion of the 'wilderness' is thus associated with the gap which is maintained in order to preserve 'integrity'. Baxter's sense of separation was a feeling 'he identified with integrity, rebellion, and in imaginative terms, with what he called "the wilderness". Variously, the enemies were convention, authority, and balancing it emblematically, "the city"" (20).

In 1951 Baxter gave an address to the New Zealand Writers' Conference in which he stated the belief that 'one of the functions of artists in a community is to provide a healthy and permanent element of rebellion; not to become a species of civil servant' ('Recent' 9). Thus while Baxter often resisted the 'prophetic' roles that he 
felt compelled to fill, he also presented this experience as an opportunity to occupy the locus of tension and work to 'transform' both self and society:

The typical dilemma of the modern poet is one of divided aims. A man who is working as a schoolteacher, a tradesman, or a government official in a society which he knows to be unjust, cannot dare to think clearly on moral issues; for the society is part of his physical and even psychological security. If he breaks with the society and departs into the Wilderness in customary Romantic style, then he loses brotherhood with all but similar outcasts. What Justice demands is something more difficult - that he should remain as a cell of good living in a corrupt society, and in this situation by writing and example attempt to change it. He will thus and only thus escape the isolation of the Romantic.

('Recent' 11)

The 'divided aims' of the poet are exacerbated by the mythologising habit which relied on black and white moral judgements to give clarity and 'psychological security'. Baxter preserved a distance from 'the city', from the 'authorities' and from the emergent notion of a distinctive 'national' literature. He harvested the tension created between his desire for 'freedom' and the increasingly urgent need for both spiritual and domestic order. The 'space' maintained between oneself and the 'Unjust City' is necessary to preserve the 'gap in which poems can grow'. Yet contact with society was also seen as essential for the writing of meaningful poetry. These two notions of a 'space between', with the poet situated either at the margins or at the locus of tension, provided Baxter with much creative inspiration while also shaping his opinions and 'public' actions. Baxter told Weir in 1967: 
What I have feared most in life is never some inward or outward pain, but the situation of being trapped in domesticity, in normality, in that segment of life which others no doubt quite properly find satisfying; I have feared it because it might choke up in me the double source of fantasy and truth.

(McKay 224)

Reconciling himself to 'that portion of life which for most people is normally satisfying' would therefore effectively 'kill' the mythologising self.

Baxter's identity was defined by his identification of, and opposition to, a shifting 'other'. Baxter saw self-marginalisation as a creatively and spiritually necessary act. Yet the 'divided aims' of the poet which are implicit in this distancing also shape Baxter's social commentary and criticism. Baxter spoke of a 'private war' against the 'devil of acedia', the spiritual sterility which he persistently identified as the determining force in New Zealand society and culture ('Conversation' 16-17). The primary battleground for this war was in fact Baxter's own mind, and he turned on many of his own perceived weaknesses and attachments with a fervour approaching hysteria. For example, he worked as a 'species of civil servant' for School Publications while constantly attacking 'bureaucrats'; he had a range of roles in the education system - teaching at primary, secondary and tertiary level - yet was especially vociferous in his attacks on the education system. ${ }^{15}$

As Millar has highlighted (Muse 42-45), the intensity of Baxter's rejection of the education system is undoubtedly linked to his feelings about the two sides of his family, which become mythologised as polar opposites reflecting the two similarly divergent 'types of learning', 'mythos' and 'logos'. Baxter's adoption of Maori

\footnotetext{
${ }^{15}$ See 'Notes' 128-37, 'Poetry and Education' and 'Shots'.
} 
culture in the last years of his life was also informed by this dualistic, oppositional mode of thought, and spurred by this sense of a pervasive lack within Pakeha culture and the need for a 'radical beginning'. While it would be wrong to argue that Baxter had no genuine interest in understanding Maori culture on its own terms, it appears that the strength of his feeling towards it was proportionate to the degree to which he saw it as diametrically opposed to Pakeha culture. Baxter contrasted the fruitful 'primitive order' of the former with the sterility of the Pakeha 'secular Calvinist' ethos. Thus the word 'Maori' becomes in Baxter's last writings an adjective denoting 'spiritual' qualities which reflect the imperatives of his own idiosyncratic quest. $^{16}$

Earlier Baxter had pointed to this role of the mysterious 'other' in reshaping and transforming the self: 'the work of most artists is convulsed about some mystery other than themselves, whether it be God, the natural world, or the life of their fellow-beings' ('Mask' 36). Fallen man's desire for a connection with this 'other' was the source of constant tension and thus

... Poetry is concerned with a living centre, and a ... suffering ... which rises from incomplete relationship, whether with the natural world, with God, or with one's fellow creatures.

('World' 181)

The third type of gap is the space of dissolution and regeneration in which the process of exchange is initiated and opposites are able to be brought together. Unlike the other two types of gap, Baxter generally acknowledges his own role in

${ }^{16}$ See O'Sullivan 52. 
creating this space through acts of self-emptying and setting aside ordinary modes of perception and behaviour. Baxter considered the artist's discipline to be based on 'natural contemplation' rather than - like a monk - 'supernatural' contemplation. The artist's 'job is to be useless and creative':

resembling by analogy the apparently useless exercises of the Trappist monk ... whose real work is an endless struggle in silence to find in the abyss of his own soul the source of holiness and the meaning of creation ... Especially in the modern world of noise, falseness, staleness and repetition, it seems to me a vital necessity that there should be monks, who will not accept a second hand version of God; and equally that there should be artists, though their work is one of natural contemplation, not supernatural the difficult gaining of a first hand intuition into things and the relation between things, which, as Aquinas tells us, constitutes the creation.

('Conversation' 11)

This contemplative faculty functions as another kind of 'gap in the hoardings', taking the poet through to the forgotten realm that is man's true inheritance. In 'Poetry and Education' Baxter describes an experience while roaming the countryside near Brighton, waiting outside a 'broken-down house

for an hour at least, without moving, and felt my mind go to the edge of some precipice of great sorrow and great joy - like an entry into a kingdom well known, remembered, and then wholly forgotten - something that had not happened to me for a long time ... 
This entry into another space, a 'kingdom' which reflects man's true nature, is the difficult work which requires the right stance and the right place, assisted by myth, symbol, ritual, and the therapeutic processes of Jungian psychology. Baxter's descriptions of the creative process often resemble Jung's therapeutic process of the 'bringing together of opposites for the production of a third: the transcendent function' ('The Transcendent Function', $C W$ Vol 8, 87). The ego and the unconscious - represented by the 'shadow' or another archetypal figure - can be brought together in a 'dialogue' which produces healing, wisdom and growth. Jung writes of cases in which patients found it

very simple to note down the "other" voice in writing and to answer its statements from the standpoint of the ego. It is exactly as if a dialogue were taking place between two human beings with equal rights

Jung describes the double nature of 'the anthropoid and archaic man' who is encountered in this process.

on the one hand, his supposedly uninhibited world of instinct and, on the other, his often misunderstood world of spiritual ideas, who, compensating and correcting our one-sidedness, emerges from the darkness and shows us how and where we have deviated from the basic pattern and crippled ourselves psychically. 
In Baxter's mythology this process turns on the division between 'natural man' and the 'bourgeois family man', both of whom are 'debased' in contrasting ways. In a discussion of the difficulties faced by artists who must balance priorities and principles, Baxter returns to the Horse/Timothy Harold Glass division ('Conversation' 17-19). Baxter makes the revealing claim that of these two alter egos it is in fact Timothy who is 'my shadow, my enemy, my monster: the public person who would destroy if he could whatever gifts I possess'. Instead it is 'my collaborator, my schizophrenic twin, who has always provided me with poems'. This primitive anarchic self has 'done the suffering and I have done the writing'. To ensure the survival of this self, the bourgeois self must enter the gap and 'visit the cellblock in the basement of my mind where he still lives, incorrigible, ineducable, unemployable'. This ritual descent is necessary for the continuation of the mythologising habit which provides meaning, healing and identity. This prisoner is Baxter's personal version of natural man, a connection to the 'primitive' chaos which is the source of both creativity and spiritual truth:

through the bars he will pass me a message written on the back of a tobacco packet. Something like this -

'Look out, you bloody fool! What will happen if I die? I'll tell you. One by one you're going to lose your sex, your art and your sense of humour ... I am It; and you can't do without me...'

Or it might be the beginning of a poem that he hands me, in exchange for a crude joke and a cigar: something cryptic which I have to unravel, three or 
four words perhaps. Recently he gave me the phrase - Suffer the autumn of the succubus - and I was able to build a poem round it ... ${ }^{17}$

This unlikely source of inspiration is a version of the 'daimon', a messenger connecting the ordinary self with the living centre. Characteristically, Baxter has it both ways - denigrating the self who presents the poems while also pointing out the 'depths' from which the poetry has emerged. The poet faces the abyss and the debased self, but it is the palpable presence of this chaos which also guarantees the 'authenticity', and even the 'authority' of this voice and the messages that it brings. Baxter presents this process as a 'descent' to the living centre, a katabasis to the heart of the horror which is also the source of meaning and harmony. Through courageously bringing this material to the surface and shaping it, the 'ordinary' self is transformed - momentarily - into the wise, heroic mythologising self with the power to discover 'cosmos'.

In Jung's model, this ongoing relationship of dialogue

represents the transcendent function of opposites. The confrontation of the two positions generates a tension charged with energy and creates a living, third thing - not a logical still-birth in accordance with the principle tertium non datur but a movement out of the suspension between opposites, a living birth that leads to a new level of being, a new situation. The transcendent function manifests itself as a quality of conjoined opposites. So long as these

\footnotetext{
$\overline{{ }^{17} \text { See 'The Succubus' (CP 330-31). }}$
} 
are kept apart - naturally for the purpose of avoiding conflict - they do not function and remain inert.

('The Transcendent Function' 90)

Baxter's 'therapeutic' approach is based on his belief in this process as a tool for accessing meaning, healing and identity. The purpose of bringing opposites together is to allow the waters to flow, in Jung's words freeing 'consciousness lost and obstinately stuck in one-sidedness' by confronting it with 'the image of instinctive wholeness and freedom' (ibid).

Baxter's poems are 'convulsed' around the mystery of otherness, shaped by stances towards experience which reveal or create gaps through which this 'instinctive wholeness and freedom' might be experienced. The 'poet' is the temporary self with the power to provide that which is desired by the ordinary self by becoming joined to the 'daimon', the voice of the other self. Baxter believed that the 'voice' of this other self is discovered in the gap, and the inspiration which is accessed is attributed to various sources - 'the Muse', the 'earth', archetypal and mythic figures, the 'wounds' of the suffering self, Mary, Christ or God. The common factor amongst this chorus is that this 'other' voice only appears when the ordinary self is empty or absent.

Baxter's mythopoeic depictions of women reflect the belief that many of the greatest mysteries of life - sex, birth and death - were related at the archetypal level to the 'otherness' of the female. These depictions of women are thus shaped by the role that they played in his 'quest'. Women teach 'lessons' or become 'obstructions' and are associated with gaps which lead to suffering or joy, growth and learning, 
constriction and escape. On this symbolic level women provided an 'entry' into another way of being, or else prevented such movement and growth by 'trapping' the male in the 'womb' of domesticity in a 'retreat from self-knowledge'. Thus women in Baxter's poetry tend to be present as either the agents of a stifling secular Calvinist 'normality' - the servants of the 'kitchen god'18 - or else as dangerous embodiments of the 'goddesses' of sex, death and inspiration. Baxter affirms the existence of a gap between the sexes in his reading of Burns' 'Tam o' Shanter', where the symbolism of gates and breaches indicates 'the melancholy dimension of distance between the independent male and his wife, who is also very much a mother figure, from whom his actual mode of being isolates him' ('Man’ 100).

The women in Baxter's work can usefully be considered as representations of the various attributes of the primary Jungian archetype of 'the anima'. This is the 'other' to the male's ego-self, the mysterious figure who initiates the male into the realm of the psyche and holds out the possibility of a 'secret order' within the disorder of the unconscious. In Baxter's words:

The anima changes shape according to the motives of those who approach her - a violent man will see her as a wolf; a sensual man, as a temptress; a Puritan, either not at all, or as a poisonous reptile; a saint, as a helpless child who needs to be looked after; a poet, as his difficult Muse ...

\footnotetext{
18 ،... The kitchen god embodies the crude, unshaped conscience of the tribe... pre-eminently a god of safety ... he ... can tempt any man ... to retreat from the area of self-knowledge and go back to the pieties of childhood... The trouble is, though, that returning, one becomes not a child but a schizophrene ...' ('Virgin' 73).
} 
Thus the female figures in this personal mythology are defined by their different roles, evolving through each stage of the journey to self-knowledge and effectively inverting the poet-hero's conscious attitude. In facing the 'negative side' of the anima, the hero is drawn towards death and dissolution, with the ultimate result being growth through suffering: 'The experience of the destructive power of the anima is the most terrifying event the conscious mind may have to endure in the journey to self-knowledge' (119). In her guise as 'snake-haired muse' the anima is a terrifying Medusa who relates equally to sex and death, fear and desire, dissolution and regeneration, the womb and the tomb. ${ }^{19}$ She is a creature of this chaotic realm, a potent figure whose energy and message Baxter aims to 'reflect' through his art.

Baxter interprets the dance described in 'Tam o' Shanter' as the 'dance of life' which

is also, if not a dance of death, at least a dance in the jaws of the grave. The dancers are not young women but grim hags. They signify the decay of female sexuality into a malicious energy that belongs partly to the grave. The dance exhibits the inevitable loss of fertility and innocence. The bonnie lass conceals the potential hag, the witch who will harm and destroy the sexuality of man if she is able. This cruel dialectic is mediaeval ... I think it corresponds to a genuine subjective reality

For the poet the snake-haired muse is the Medusa who slays the ordinary self. Baxter equates this figure with the anima a number of times: 'that mysterious

\footnotetext{
${ }^{19}$ See Muse chapter 1.
} 
archetype who has been called variously Venus, Cybele, Artemis ... patroness of witches, the goddess of the underworld' (116). Baxter's own relationship with the Muse is implied in his commentary on 'Tam o' Shanter': 'When Burns speaks of "my Muse", it is actually the daimon, the semi-conscious power of control over his medium, which he refers to'. ${ }^{20}$ It is this 'power of control' which continually brings the poet back to the chaotic state: 'the anima represents, to my mind, all that is notself. She cannot be constructed; she has to be discovered' ('Man' 116-17). Baxter learnt to 'twist the Muse's arm' by manufacturing the conditions in which the 'daimon' could be discovered.

For Baxter, the voice of the 'other' emerges from, and shows the way to, the 'buried kingdom', the living centre. O'Sullivan highlights the 'central pattern' in Baxter's mythology, associated with this process of exchange and the sacred patterns which structure

the seasonal cycle and the rites $d u$ passage ... at the core of most mythologies. The journey towards or through the secret door, the gates, the tomb, the maze, and the return not to a new world so much as to the old seen as if for the first time - these proliferate in Baxter's work, as do the figures of regenerated return, whether as Orpheus or Ulysses or Persephone or Christ ... I believe that Baxter did not use the myth of separation, death, and rebirth, with its usual attributes of autumn, winter, and spring, of departure and return, in a way analogous to any other modern poet, but that in fact he identified with it ...

\footnotetext{
${ }^{20}$ See McNeill, 'Baxter's Burns'.
} 
This is a vital point in considering Baxter's use of myth. Baxter did not merely identify with the characters in mythic stories, he identified with the pattern and structure which the story embodied. As O'Sullivan indicates, Baxter's use of these three gaps is suggestive of the 'monomyth' outlined by Joseph Campbell, in which mythic patterns of separation, initiation, dissolution and return are connected to form a supposedly 'universal' superstructure common to all mythologies, a mythological map of the journey to the centre also found within single myths such as Odin's quest. O'Sullivan writes that in poems such as 'The Cave' (1948, CP 69)

... the ancient seasonal myth of leaving light for darkness, of returning back to light, is not simply a device. It is the structure of the poem. For this kingdom is more than the grave, more than the obscure centre of self or the depth of experience. Here is the promise of death as the second womb. One remembers that to have order one must have repetition, and repetition is the basis of this cyclic myth.

This imagery reflects Baxter's lifelong dependence on strategies and rituals of 'descent' as a way to access inspiration:

the major features are unvarying - that sequence of entry to where the usual conditions of life do not obtain, the agony of entombment or the quiescence of the womb, and with luck the emergence with renewed wisdom or strength 
In O'Sullivan's view, this process represents the 'inception and birth of poetry itself, the reassembling of scattered or even disagreeable elements in life into something new and healthy'. It is also the place where 'the ground of one's own being is merged with that of the communal past' and the poetic mind 'touches the source of order' (8). Mythologically, this is Yggdrasil, the world-tree at the intersection of heaven, earth and hell, and also the place where the hero-poet discerns the roots of order amidst the dissolution of chaos. Eliade writes that, in the 'sacred, mythic geography' of 'primitive man', the centre 'constitutes the point of intersection' between Heaven, Earth and Hell' which provides the possibility of a 'break-through on to another plane' (Images and Symbols 39-40). For homo religiosus, rituals of dissolution provided

... the intuition of a certain mode of being, but also the comprehension of the "place" of that mode of being in the continuation of the World and the human condition.

... [as a result of these] initiatory rites involving a regressus ad uterum ... man believes himself able to start a new existence ... [these] ceremonies intended, periodically, to restore the primordial "Chaos" in order to regenerate the World and human society ...

('What the Symbols "Reveal"', Eliade Reader 135)

In 'The Cave' the ordinary self is taken into the chaos of the centre and sacrificed so that the mythologising self can return with the poem. Although death is tempting, the poet pushes on and emerges into the 'dazzling daylight', transfigured with the light of meaning and harmony, an experience which takes mythical shape as the poem itself. 


\section{The Hollow Place}

In Theories of Inspiration Timothy Clark argues that 'Romanticism exalted creativity as the object of a new mythology'. This mythology presented accounts of personal experience which involved "the "liberation" of a supposedly truer or deeper self from out of the pressures of convention ... false thinking and inauthenticity'. Clark considers these romantic myths of inspiration to be 'in effect ... secularized versions of religious conversion narratives ...' (5). Baxter's poem 'The Hollow Place' (1962, CP 251-52) presents a mythologised account of a sudden and definitive 'breakthrough' into another realm, a 'sacred event' in which the poet is initiated into his vocation at the point where the mythologising self is first brought to life or 'liberated'.

On the most literal level the poet - like Odin - finds the source of wisdom and healing in a desolate, unfertile environment - 'on the waste low headland' - and in the space between - 'Below the road, above the plunging sea'. The seven year old hero can only access this space by climbing 'round the crumbling face / Where flax bushes precariously / Gave something to grip'. When the place is reached the transformation begins to take place, the young hero can now 'stand / Alive in the hollow place / That meant ...' The poet feints as if to reveal the significance of the place, but first he 'must describe it' in order to fully re-enter the space:

a bent cleft

In limestone rock above a pool

Of fluttering scum; bushes to the left,

And an overhang. 
In Baxter's mythology of the gap this 'cleft' is the entrance to the womb of the earth mother who gives protection and controls fertility, as well as the cave of descent, the tomb of dissolution and the entrance to the underworld. Inside 'the passage was dark and cool', and there the questing hero is 'hidden from any eye / Not acquainted'. Thus he has become fully absorbed in a secret realm where the air is 'Tainted by some odour as if the earth sweated / In primeval sleep'.

This is when 'the gap, the void' first revealed its significance, when the heroic poet first experienced the process of natural contemplation which led to dissolution and regeneration, and the godlike voice of the mythologising self: 'I did nothing there; / There was nothing to do but listen to some greater I / Whose language was silence'. Later the poet will translate this message into a poem; here, however, the primary concern is with the healing power of the hollow place: 'Again and again I came / And was healed of the daftness, the demon in the head / And the black knot in the thighs, by a silence that / Accepted all'. The gap provides the answer to the problems of suffering and identity, but unlike the child the middle aged poet knows that this process must be continually repeated, until a new humility is learnt:

... would come again,

My coat of words worn very thin,

Knocking, as if lame,

With a dry stick on the dumb

Door of the ground, and crying out:

Open, mother open. Let me in. 
Baxter told Peter Bland that this hollow place

... is the womb, it is the place of death and birth, it's the place where God speaks to me and what have you. I dig into what I know. This is what a particular human being feels about a particular place and probably there is a religious element in it, something about a 'greater I' ... probably a Hindu ${ }^{21}$ would understand this very well ...

('Interview with James K. Baxter')

Here, the boundaries between the ordinary self and the 'greater I', self and God are blurred. While it is God who speaks in the 'empty' space, the material is dug out of 'what I know'. Elsewhere, Baxter suggests that the 'gap between myself and other people' was the cause for his discovery of the hollow place.

It was probably some sense of depression, or a failure to hold my end up in the battle to avoid getting beaten up or educated, that took me at the age of seven ... [to] a kind of seat in the rock, at the top of a steep slope of grass above a cliff ... I did not realise it was the Delphic cave. But in this solitude the sound of the breakers on the rocks below had a hypnotic effect; and for the first time I heard that voice inside my head - not in the head, in the mind - that makes my poems for me ...

('Further Notes' 4-5)

In the hollow place the voice emerges out of the right place and stance, it is the object of a quest which implies isolation and initiation. The 'attitude of listening' in a sense creates the voice, and the immediate circumstances of the poet's life are

${ }^{21}$ See chapter 7. 
given a 'response' which matches urgent needs. The rock is the throne of the mythologising self who has authority within the space of composition and its voice provides the 'solution' to the problems of the ordinary self. This proves its power.

Baxter's claims for spiritual authority derived from his access to the voices from 'below' rather than above. Elsewhere this is the 'daimon' or the 'dark spirit' of the gap which 'must always be invoked'. It is for this voice that Baxter 'listens' in the hollow place - though often the message seems to be passed on from other intermediaries, archetypal figures. Various messengers are invoked throughout Baxter's mythology. Both traditional and personal, these figures convey messages that are considered reminders of the primitive order and the sacred pattern which is obscured by the profane modern world.

These mythologised accounts of the same experience also show how the three 'types' of gap outlined above are often present simultaneously. Here there is a 'gap between myself and other people' in the form of the (probable) conflict which sent the young would-be poet out walking on his own; there is an intimation of the gap of 'loss', implied by the hint of a coming threat to the 'childhood paradise' in this experience of conflict; there is also the gap as the point of access and the initiatory space of transformation, where the entry into another realm leads to the gaining of wisdom, healing, creative energy, and a positive identity which transforms the significance of isolation.

Compared to 'Cosmos', the conclusion of this poem presents a humbling experience rather than an ecstatic apotheosis; yet in both cases the access to secret knowledge affirms the authority of the mythologising self and thus the true identity of the poet. The voice that emerges from the depths is endowed with 'real 
knowledge' because it is distinct from the poet's 'ordinary condition', an inspired mythologising which elevates the personal to the universal. The ritual of dissolution invests the poet with the authority of the Muse, the 'not-self', the earth mother, or alternately with the masculine voice of the 'greater I'. Myths, like islands, emerge from this sea as the spirit of inspiration hovers over the waters of chaos, providing for the possibility of continued, sustained life.

Baxter wrote in 1963 that 'poets record the messages that rise out of a hole in the ground' ('Poetry and Education', 1). Despite his increasingly ambivalent comments regarding the importance of the poet and the extent of his own ignorance, Baxter's mythopoeia is informed by the belief in the 'sacred' possibilities of the poetic role. The 'act of faith' allows for a fruitful connection with the mysterious 'other' and access to the material out of which meaning can be shaped. Baxter described this as the matrix of a poem:

By this term I refer to the primal substance of a poem, non-verbal, which the verbal structure of a poem reflects; not its overt meaning, but its secret incandescence, its point of contact with the world of Thou. ${ }^{22}$

('Mask' 37)

This is the point of transformation, where the 'ordinary' world is rejected in favour of a mythologised landscape, a world which in turn affirms the significance and authority of the mythologising self at its centre. It is the intoxication of this dynamic that brings Baxter to the point where personal mythology and spiritual authority are conflated. The sense of 'integrity' and authority which Baxter desired remained

\footnotetext{
${ }^{22}$ A phrase Baxter appropriated from Martin Buber.
} 
central to his insistence on the value of personal mythology at the expense of the 'meaningless' or 'chaotic' ordinary world. Yet the claims made for the 'objective' validity of that which is discovered through the 'subjective disciplines' are based on a faith in the authority of the materials accessed through self-emptying, passing through the low door of dissolution rather than the elevation suggested in 'Cosmos'. Baxter repeatedly denies personal authority while affirming the validity and merit of the 'messages' he gains access to:

There have been a good many times when I have felt that my own poetry was valueless, because a great deal of it embodied private sexual fantasy or alcoholic depression. But the particular kind of private material my life was giving me to use didn't really matter much. If I was standing on the rock of real knowledge when I wrote, then the poems would be significant for other people; and in some cases I had been standing on the rock.

('World' 180)

The poem lies between the unknowing and knowing selves, it is a record of the process whereby the unknowing self is taken into the gap, 'sacrificed' and returns to the surface with the meaning, healing and identity renewed. The ordinary self is debased and drowned, yet by journeying to the depths or the extreme edge of creation, he comes to the place of dissolution and regeneration, healing and wisdom: 
when I see the waves breaking on the rocks, I know that I stand on the edge of another sea whose reality will, if I let it, enter and suffuse my mind and heal me of the blindness and dumbness which is my ordinary condition ...

For Baxter, by entering this sea of chaos one is opened up to an extraordinary condition in which meaning, healing and identity are renewed and the mythopoeic 'island' which surfaces embodies the will of the creator. The voice is the instrument which is used to direct the ordering process. To the extent that this process is 'true' to the initial inspiration or message, the poem is 'meaningful'. This voice only emerges in response to the conditions which are conducive to creation - thus Baxter's poetic mythology is not an 'accurate' objective reflection of the whole of his experience, but a record of the places where, in his terms, he managed to 'breakthrough' to this extraordinary state and manifest the mythologising self.

Baxter utilised the three types of gap to initiate the heroic confrontation with chaos which he considered to be necessary for authentic art. This encounter with chaos involved grief, suffering and dissolution, yet out of this process came the renewal of the self and the tools with which to transform chaos to cosmos. In the following chapter I outline the ordering aspect of the creation process, in which the poet shapes the 'mythical' material accessed via the gap. This process relies on ordering tools which structure experience and impose a pre-ordained pattern on the chaos. 


\section{Chapter Three: Ordering}

Confronted with the aboriginal chaos of existence, man has a choice of two ways in which he can give it meaning and order - either by the objective disciplines of science and morality, or by the subjective disciplines of art and contemplation ...

('Object and Subject' 21)

In a very faint and limited way, I believe He allows us to think His thoughts after Him ...

(Six Faces, 'Love Creating Love')

In this chapter I consider the mythopoeic ordering process which Baxter utilised in his attempt to give 'meaning and order' to 'the chaos of existence' through the 'subjective disciplines of art and contemplation'. The mythographer Robert Segal asserts that 'what unites study of myth across disciplines are the questions ... of origin, function, and subject matter. By "origin" is meant why and how myth arises. By "function" is meant why and how myth persists' (2). In this chapter I consider the origin, function and content of Baxter's mythologising in relation to the process of 'ordering' chaos. Segal claims that 'the answer to the why of origin and function is usually a need, which myth arises to fulfil and lasts by continuing to fulfil' (Ibid). 
Baxter describes the mythologising process as the discovery and elaboration of a 'sacred pattern' contained within experience that transforms chaos to the cosmos of a personal mythology which in a 'faint and limited way' subjectively mirrors the truth about man, nature and God. Baxter's enduring attitude to mythopoeia is reflected in the notebook poem 'Truth', written during the same period as 'Before the Creation' and 'Cosmos'. The tools to discover meaning and harmony came not from 'the the chequered page of history' but the voice of the mountains, the place 'Where torrents rumble to the rocky plain', 'the unbounded firmament', or where nebulae

Circle unceasingly, for only there

Can thought of God chaos to cosmos turn,

While life incarnate from the furnace glare Springs ...

('Truth', N 2.128) ${ }^{1}$

In creation myth, chaos is transformed into cosmos by the ordering process which establishes the authority of the creator god. In the Genesis story, God transforms the dark and empty waste of chaos into an ordered cosmos by both creating and modifying the conditions which could sustain life. Through the supernatural ordering of the divine fiat, the chaos becomes a cosmos in accordance with the will of the creator. God establishes the natural laws which - in Baxter's view - are revealed as 'sacred patterns' and can be embodied in mythic paradigms.

${ }^{1}$ See Muse 220. 
Rather than a search for a static 'order', Baxter's quest was for the experience of meaning and harmony which came momentarily through the application of ordering tools such as myth, symbol and ritual. Baxter utilised symbol and myth, archetypal figures and patterns gathered from a range of traditional mythologies and belief systems, as well as Jungian psychology and poetry. In this chapter, I look at the three main mythic paradigms Baxter relies on to make meaning out of experience, and how these correspond to the three types of gap discussed in chapter two. These mythic structures shaped Baxter's experience, the dramatic roles he inhabited, and determined the significance of the 'meaning' presented in these texts and acts. Following this I consider the 'trouble' which arose out of Baxter's mythic thinking, which structured experience according to patterns and plots and often veered towards the extremism of mythic 'perfection' rather than the openness of 'possibility'.

The work of ordering is the other half of the 'moment of art' which elaborates on the message received in the confrontation with chaos. Thus through the process of art and contemplation, the poet - like Odin - is able to 'intuit' the creation in a secondary manner, and (as with Eliade's ideal poet) take a special place as an intermediary assisting with the 'remaking' of the world, as Baxter told himself in a private note: 'You are Adam, and you have the gift of naming the creation' ('Rules for (One) Catholic Writer'). The initial impetus or inspiration found through the confrontation with chaos has a force which directs the poet towards the completion of the poem: 'when I write, I do, not my own will, but the will of my poems - that is, I try to serve most scrupulously some spiritual event which my life proposes to me, of which the shape is not yet defined' ('Belief' 47). Thus - as in Baxter's later desire to 'be Chaos' so that he might be shaped by the Holy Spirit - the space of 
composition is a place where agency and authority are theoretically relinquished. Yet the act of ordering is a creative act of choice which reflects the 'imperatives of desire' which drive the creator, and the confusion of agency and authority in this process creates trouble where the purposes of Baxter's poetry occasionally contradict each other.

Laurence Coupe, in discussing the special status of romance within the literary cosmology implied by Northrop Frye's archetypal criticism, states that this mode 'represents the power of the human mind to construct a cosmos according to the imperatives of desire' (156-57). Baxter's endless desire for cosmos, to find meaning and harmony in response to 'the gaps in experience', is the quest which drives his mythopoeic ordering. In Baxter's mythology, personal imperatives of desire direct the construction of cosmos, through the momentary, mythologising self that oversees the process of creation. Just as mythic paradigms shape Baxter's gaps, so his ordering is shaped by the conditions which impel him to write. Ordering is set against the enduring conditions of chaos: absence, disconnection, discord and dissolution.

In the underlying approach to mythopoeia which informs Baxter's mythologising, the godlike authority of the poet over meaning is derived from the origins in the confrontation with chaos, as well as the efficacy of the ordering tools brought to bear on the material. Baxter told Weir that, faced with this chaos, the poet, like the scientist, 'gives it an intellectual order ... The poem is not more subjective; it's just a different style... And the myth is the form that the poet uses to crystallise experience' ('Interview' 242-43). Myth transforms the meaning of experience by condensing life to the core components which reveal the laws embedded in creation. Thus the artist must be prepared to 'endure the unrectored chaos until it takes the 
shape of myth' ('Object and Subject' 21). This is the process of 'exchange' which O'Sullivan highlighted, where Baxter continually moves back and forth from the chaos of meaningless experience to the harmony and meaning of cosmos via the ordering tools of myth, pattern and symbol. Thus the use of a mythic lens provides a semblance of the cosmic 'eye of God', by discovering and communicating sacred order. While Baxter writes of a 'choice' between the 'objective' and 'subjective' modes for making meaning and order, it is clear that (by 1967, at least) his own mythologising habit was so firmly ingrained that he expressed regret at the 'trouble' caused by his inability to 'demythologise'. This subjective mythopoeic mode which 'utilised gaps' became so familiar to Baxter that later it is a foregone conclusion that the world will 'appear as chaos'. Baxter chooses mythic 'learning' because it allows for the possibility of discerning 'meaning and order' and thinking ('in a limited way') the thoughts of God; the 'objective' mode is ultimately worthless to the poet because this lens is incapable of perceiving the sacred.

\section{Two Types Of Learning}

The 'two types of learning' Baxter contrasts in 'Notes' relate to the divergence between the Greek terms mythos and logos, which both originally meant 'speech' or 'word'. Coupe traces the development of the opposition between these two terms, which over time were generally taken to be separate and contrasting, signifying opposing modes of discovering or making meaning (10). The mythos of the poets was a way to find universal and spiritual significance in a sequence of specific events. Thus in Aristotle's Poetics, mythos is privileged over the bare facts of logos: 'poetry ... is a more philosophical and a higher thing than history, for poetry tends to express the universal, history the particular' (54). Rather than looking to logos 
and the 'chequered page of history', for Baxter truth and wisdom was found in the processes of nature and the mysteries of creation, as communicated through myth and symbol. The 'particular' events of Baxter's life are mythologised and imbued with significance by the poet himself: 'I consider that poets must have something of the attitude of the imaginative historian' ('Recent' 12). Thus the poet confirms personal authority even where the mythopoeic 'legends' created forge the 'unofficial and real history of the country' ('Mask' 48).

Paul Ricoeur interprets Aristotle's use of the mythos as including the notion of 'emplotment', where selected events and experiences are connected and linked to an initial cause. These events embody a truth which can only be communicated in this higher form of expression. Mythos is, in Ricoeur's terms, an 'integrative operation' which finds a hidden significance in a selected sequence of events. This work of ordering is an operation of the will which constantly reaffirms the authority of the creator over the material of life, and thus the mythologising self who is the god at the centre of the cosmos. Baxter often claims that if this ordering comes out of contemplation it reflects the imperatives of the creator god, alongside, or instead of the poet's personal imperatives. This leads to the characteristic conflation of personal and universal, 'artificial' myth and sacred truth, which is evident in 'Notes'.

\section{Literary Influences}

Baxter's mythologising was more than simply a literary method, it was a chosen way of seeing and being which was fundamental to his development as a poet. While Baxter suggests in 'Notes' (122-23) that he was born a poet, a number of 
factors influenced the type of thinking which shaped both his poems and the course of his life. Literary influences, particularly those derived from the Romantics, shaped not only the content and form of Baxter's poetry, but also the construction and rhetorical positioning of the mythologising self at the centre of the creative process. In Spark to a Waiting Fuse and The Snake-Haired Muse Millar traces the evolution of Baxter's mythopoeic ordering, particularly those developed through his adolescent experimentation and imitation in his manuscript notebooks. ${ }^{2}$ The notebooks remained Baxter's laboratory, a free space in which he could test poetic formulae, shape his views and sharpen his tools for dealing with the gaps in experience. The adolescent Baxter advised Ginn to follow his own method of 'shaping and reshaping' poems, 'not to a standard, but till an intuitional dissatisfaction is satisfied' (03/06/1944, Spark 361). It was this 'dissatisfaction' which must be attended to, patiently discovering the 'shape' which could best draw out the significance of the 'mythological core' (Spark 376).

Millar traces Baxter's typical 'convergence of the individual and the mythical' to 'the adolescent Baxter's close observation of the writing of Archie's pacifist memoir We Will Not Cease (Muse 46). Archie remained one of Baxter's treasured 'agents of progress and instruction' (45), someone who had the authority to speak because he had faced chaos, providing the model for Baxter's own inner quest. The influence of Archie in shaping Baxter's mythologising tastes has been amply demonstrated by Spark and Muse. Millar discusses the 'mountainous figures' who dominated Baxter's early life, concluding that 'his father was, and remained, the most mountainous of all the individuals who influenced him' (Spark 86). Baxter had 'absorbed the Romantic poets' from Archie at a young age ('Notes' 122), and his

${ }^{2}$ See Spark 23. 
poetry retained the common romantic emphasis on the experiences of the suffering individual at the centre of the poem, set apart from the social order and attempting to rediscover a sense of the sacred which is lost or threatened. As Millar notes, Baxter's juvenile attitude to myth was connected to his "prevailing notion that poetry is of the old world, opposed to war and mechanised modernity' (Muse 53). Thus Baxter considered himself destined to become a cultural hero, restoring fruitful order in the modern wilderness, telling Ginn that 'the rôle of a prophet is a delectable one' (14/03/1943, Spark 200). The desire to be extraordinary, to embody the creative heroism of Prometheus or Odin, thus shaped his view of the poet's vocation from an early age.

Millar notes that 'as well as the work of poets Baxter heard his father recite, in these early years Archie Baxter's own poetry was a powerful influence' (Muse 48). It seems likely that any poetic voice the seven the year old may have heard in his head would have been modelled on Archie's recitations. Baxter later praised Archie's poem 'Spirits of Harmony, Music, and Love' ${ }^{3}$ for its 'vatic and inspirational' mode (Aspects 8-9). ${ }^{4}$ This Shelleyan song of creation begins:

In the elemental chaos

When the worlds were in the making,

None could rule nor disobey us,

We were there in all partaking ...

\footnotetext{
${ }^{3}$ In Spark 544.

${ }^{4}$ See Muse, 48.
} 
Baxter acknowledges that: 'Under this kind of stimulus it was not strange that I too should want to write', thus linking these various influences to the discovery of the 'voice in my head' and the inspiration for his first poem ('Further Notes' 3-5). Baxter's comments on this poem may be a sign of the influence on his own mythopoeic ordering and the creative processes represented in the structure of the poem. Millar argues that this poem is 'certainly linked with Baxter's earliest attempt at incorporating myth into poetry, by describing chaos in 'Before the Creation', with a developing view of myth as a set of universal symbols suitable for discovering some form of order out of experience' (49). The parallels between this fragment of creation myth and poems such as 'Before the Creation' and 'Cosmos' and 'Truth' are apparent.

For Baxter, this mythopoeic form of ordering provided the means to affirming an identity calibrated to his father's ideals, as well as responding to the imperatives of his own quest. As Millar notes, Burns provided a model for this creative resistance and the sense that the poet could himself come to embody myths (Muse 46), forging a personal mythology in opposition to the sterility of the social order. Poems such as Burns's 'Tam o' Shanter' thus had an abiding influence on Baxter's use of mythopoeic tools to contradict 'secular Calvinism' by constructing the alternative 'cosmos' of the hero-creator:

... I received the story at an age when the reactions all belong to the heart, and one distinguishes, as it were, warmth from cold, light from darkness. 
Similarly, Baxter explained his enduring attachment to Burns' 'bawdry' by suggesting that it signified 'a deeper attempt to reintegrate the sexual impulse as part of a unified personal cosmos' ('Man' 97). This cosmos is defined in accordance with the moral and aesthetic intentions of the mythologising self, which establishes its authority through the continual act of mythopoeic (re)ordering. Baxter's poetry remained anchored in this contradictory mode, mythologising 'the struggle of the natural man' against the status quo (ibid).

Baxter's literary borrowings are shaped by his 'lifelong habit', noted by Millar, 'of plucking from every system of thought or belief he encountered only those elements that meshed with his personal convictions, practices or mythology' (Muse 41). Millar argues that 'of the Romantics, Blake seems to have had the most enduring influence on the young Baxter' (Spark 106). The merging of sacred and social visions found in Blake's poetry reflected Baxter's own imperatives, as did the creation of a mythology which was both personal and prophetic. In this prophetic mode the poet's vision addresses the need for social justice as well as expressing gnostic 'profundities' (Spark 204).

In 1967 Baxter expressed this desire for meaning and harmony through a 'unity of the imagination' in terms borrowed from Coleridge: 'art depends on some such power of double vision: one expresses through an artistic medium, at one and the same time, selected portions of objective reality and a subjective pattern which these are able to signify' ('Man' 99). Through this approach 
The poem is a combination of realist and mythical components, and thus (I think) more fully real as a reflection of the meaning of existence than either a medical report or a dream sequence.

('Object and Subject' 21)

This bringing together of experience and myth, of intuition and knowledge is a 'double vision' which 'is precisely the power of the imagination of which Coleridge has spoken' ('Man' 99). Coleridge writes of the 'Imagination' as a natural mode of perception and creativity which mirrors the supernatural:

The primary imagination I hold to be the living power and prime agent of all human perception, and as a repetition in the finite mind of the eternal act of creation in the infinite I AM. The secondary I consider as an echo of the former, co-existing with the conscious will, yet still as identical with the primary in the kind of its agency, and differing only in degree, and in the mode of its operation.

(Biographia Literaria, Chapter XIII)

This borrowing from Coleridge reflects the ways in which Baxter's mythologising method was informed by his early study of the Romantics, as well as the spiritual preoccupations which are ever-present in his sense of the poet's role. Baxter adapts these traditional notions of the sacred role of the imagination, suggesting that through the imagination the poet is able to think God's thoughts in a 'secondary' manner, to echo and even share in God's 'creative love' through the act of mythopoeia. Baxter's version of this 'double vision' brings mythos and logos, 
meaning and experience together, yet his 'trouble' is partly because the experience is already shaped by 'myth' and the imperatives of desire. Baxter's early and enduring tendency to value mythos over and above logos is revealed in his response to the dream sequence discussed in the following chapter. Baxter also drew from this ideal of the 'double vision' in his prose, which in its vivid idiosyncrasy reflects his sporadic attempts to express 'practical issues in a unity of the imagination' ('Notes’ 132).

Where Blake's mythological system emerged out the fear of being 'enslaved by another man's', for many of Baxter's contemporaries in the first half of the twentieth century, it was the apparent absence of a tradition which drove them towards personal ordering. Baxter's poetry can be compared with the functional use of myth which is one of the key threads of literary modernism. This aspect of modernism is often interpreted as a response to a pervasive sense of accelerated (and often catastrophic) change in the first half of the twentieth century, as well as the loss of the 'certainty' which once came from traditional forms of belief. ${ }^{5}$ Baxter describes this elsewhere as the burden of "modern man (so objective in his orientation)' who is unaware of his disconnection but yet still plagued by a sense of emptiness, a gap: 'We carry the wildernesses we have made deep inside us' ('Object and Subject' 21). In Baxter's mythologising, the pattern discerned in personal experience is matched with the pattern of myth, yet in most cases this method does not lead to an extended mythical parallel in the manner championed by Eliot in his famous essay on 'Ulysses, Order and Myth'. Rather than 'manipulating a continuous parallel between contemporaneity and antiquity' (177) by conscious design, Baxter is concerned with momentary experiences of loss and restoration,

\footnotetext{
${ }^{5}$ See 'Symbolism' 52 and 'Choice of Belief'.
} 
suffering and healing, ignorance and revelation, disintegration and wholeness. W.H. Auden expresses a similar position to Baxter with respect to myth and the poet's need for a mythical framework in

a society in which men are no longer supported by tradition without being aware of it, and in which, therefore, every individual who wishes to bring order and coherence into the stream of sensations, emotions, and ideas entering his consciousness, from without and within, is forced to do deliberately for himself what in previous ages had been done for him by family, custom, church, and state, namely the choice of the principles and presuppositions in terms of which he can make sense of his experience.

('Yeats as an Example' 191-92)

In light of this view the poet must choose the tools with which to shape a personal mythology out of the materials of his own life, yet he returns to this fluid experience as the basis of his reality. The fragments of tradition which remain available and effective are thus utilised as a way to process experience and discover order and meaning within it. Despite his early - and ongoing - reservations regarding orthodox Christianity Baxter, like Jung and Auden, saw this tradition as a framework which still held out the possibility of bringing meaning to modern life through the symbols, myths and rituals which were modern man's 'inheritance'.

\section{The Function of Myth}

While Baxter's poetic technique and his views on form continued to evolve, absorbing new elements from other contemporary models, the function which his 
own poetry served remained anchored in the personal quest for integrity, truth and meaning amongst the diverse conditions of his own time. Despite his early training in the poet's vocation, and his comparatively conservative approach to form, Baxter increasingly downplayed the aesthetic value of poetry. He told Weir in 1967 that 'there are two kinds of poem I write - those that have a kernel of actual experiential knowledge; and those that grow from mental dryness and the wish to write a poem' (The Bone Chanter 5). ${ }^{6}$ If the poems contained this kernel of actual experiential knowledge, a 'fragmentary intuition' about the nature of self, of society, of nature or God, he returned to them until they were given a satisfying 'mythical shape' which in turn affirmed the authority of the mythologising self. ${ }^{7}$ Over time the thrill of this 'inner' ordering was increasingly tempered by the sense of responsibility to the chaotic world which the poet shares with his readers. Thus the technical developments in Baxter's use of form related to the approach behind the poems and 'the new styles' which follow from 'the gaps in experience'.

Baxter wrote that his earliest poetry was influenced by the subconscious hope that his mythopoeic ordering might reshape the 'objective' world. In 1955 Baxter acknowledged that when he was young he had 'looked on the processes of art as a kind of magic which could change the laws under which we live; just as many men secretly look on science as a similar kind of magic' ('World' 179). In the fifth section of 'Notes' Baxter looks back at his late teens as a time when

\footnotetext{
${ }^{6}$ 'Most of the poems I start are brought to some kind of final shape; but the number I would consider full and truly formed poems would be at most one in ten'.

7 ، ... artists ... must endeavour to communicate their own fragmentary intuition of what is true - an intuition which often runs counter to the popular climate of opinion' ('Choice of Belief' 1).
} 
It seemed to me the world couldn't go on the way it was going. There was a secret switch, almost within reach of anyone's hand, that would change the raw, tangled lives in a moment to real love and creative joy.

While he lost this juvenile hope for 'objective' transformation, as an artist he retained the "early image of himself as important - capable of learning the secret of the universe; possessing a magic that rearranges, not, it is true, the laws of nature, but the inner world of symbols' ('Symbolism' 62). Thus for Baxter, the real value of the poem lay in what it did or might do, the hope that somehow it might address the 'desire for wisdom, for a changing of his being' (63).

In 1967 Baxter wrote that the purpose of his poetry was

therapeutic, a bringing to the surface of those events in one's own experience or the experience of the tribe which have been pushed underground - deaths and births, crises, initiations, violations and reconciliations.

('Virgin' 67)

Despite changes in technique and attitude, Baxter was consistent in recording moments of crisis and breakthrough. The mythopoeic record of these moments of breakthrough is considered useful to the extent that over time it can map out the inner and outer spaces where a 'change of being' was more or less achieved. 
I see two habits of thought among ... those who are just beginning to think and perhaps write. On the one hand they turn to private symbolism, quarrying in their own natures for some spring of life $^{8}$ positive archetype to set against the society made of iron and excreta which they are obliged to inhabit - looking for the natural image, the private rhythm - and they also endeavour from time to time to hold up a mirror to the inhuman pattern of public events, as Perseus held up a shield to the Gorgon. The inward and the outward road may lead eventually to the same destination. I prefer poems that are ill-made but reflect something that has actually happened to poems that are well-made but reflect little or nothing.

('Further Notes' 21)

Thus 'poems are produced in response to innumerable situations' and utilise different ordering tools, 'but, while it may begin at a personal level, a good poem generally enlarges to a statement about problems and situations common to all men' ('Criticism' 23). The 'artist's job is ... to maintain a relation to the living centre'. While this 'need' is 'common to all men, an artist has a special way of performing the common labour, and the fruits of his labour are of a special kind' ('World' 178). Thus the artist is engaged in an endeavour which is both universal and unique, and the clash between the 'therapeutic', 'aesthetic' and 'prophetic' aspects of Baxter's approach are apparent in this position.

\section{Mythologising Tools}

These various intentions were all expressed through the consistent application of the set of ordering tools Baxter developed in his adolescence. Each poem is a way of dealing with an event or a problem, comparing and connecting experiences through

\footnotetext{
${ }^{8}$ Strikethrough in original.
} 
an evolving network of symbol and myth. This process utilises mythic structures and figures as parallels which convey the 'spiritual life in mythical form', transforming the personal into the universal. In 1968 Baxter explained the use of Greek myths in his later plays:

I think I brought with me to the theatre a subconscious certainty that the Greek myths and legends are never out-of-date since they form that mythical stratum in the mind of modern man which enables him from time to time to make a pattern out of the chaos of his experience.

(Plays 334)

While Baxter's 'subconscious certainty' of the effectiveness of myth was the product of his long-established mythologising habit it was also supported by his early and ongoing interest in Jungian psychology. For Jung, myth was an essential tool for discovering meaning which in turn promoted psychological health. Jung also saw myth as a response to an urgent need:

The need for mythic statements is satisfied when we frame a view of the world which adequately explains the meaning of human experience in the cosmos, a view which springs from our psychic wholeness, from the cooperation between conscious and unconscious.

(Memories, Dreams, Reflections 340)

From this perspective, mythopoeic ordering offered the possibility of bringing together the disparate - chaotic - elements of personal experience and connecting 
them to form a personal mythology which transformed chaos into cosmos. Thus Baxter suggested in 1967 that he 'would probably never read or write a line of verse if I did not feel that works of art helped me, and might help others, to become more integrated' ('Virgin' 68). Jung remained an influence throughout Baxter's life, providing a functional approach to myth as a tool which could meet modern man's urgent need for meaning. Jung posited the existence of a 'collective unconscious', a 'universal homogenous substratum whose homogeneity extends into a world-wide identity or similarity of myths' (Psychological Types 624). This theory undoubtedly informs Baxter's notion of a 'mythical stratum' in the mind of modern man. ${ }^{9}$ For both Jung and Baxter, this was an enduring and functional part of the psyche which persisted despite - and at times in opposition to - the material advantages of logical thinking. In Jung's view:

one can withhold the material content of primitive myths from a child but not take from him the need for mythology, and still less his ability to manufacture it for himself. One could almost say that if all the world's traditions were cut off at a single blow, the whole of mythology and the whole history of religion would start all over again with the next generation ... Enlightenment avails nothing, it merely destroys a transitory manifestation, but not the creative impulse.

('Two Kinds of Thinking', $C W$ Vol 5, 25)

This mythic way of 'manufacturing' meaning was central to Baxter's quest for transformation; as with the child and 'primitive', the poet's mythopoeic ordering is the creative response to chaos. As Miles notes, 'the ordinary Kiwi bloke' who takes

\footnotetext{
${ }^{9}$ See also ‘Symbolism' 56.
} 
'the wrong turn round the cabbage tree' in 'Notes' demonstrates Baxter's belief that 'mythologising one's life as a way of making sense of it is a natural, spontaneous, instinctive human process' (Muse 124). In this view, mythologising isn't just 'what a writer does', it is an essential part of man's nature.

This process of integration brought the possibility of 'cosmos' on a personal level. When the various faculties of the self were all brought to bear on an experience, the possibility of wholeness was present: 'Through art the whole nature of man, intellect, feeling, sensation and intuition rises to meet a new occasion: a work of art is a record of that strange meeting' ('World' 181). Baxter lists the four faculties of the self which Jungian psychology seeks to balance to bring integration between the conscious and the unconscious sides of the whole 'Self'. In Jung's work, this process of integration or 'individuation' works towards a goal of personal, microcosmic harmony which brings into effect the 'transcendent function' where all elements of man's nature are balanced. As demonstrated in chapter two, Baxter's creative processes often mirrored this therapeutic model of integration where the poem is the product of the union between the prisoner/shadow and the poet/ego, and harmony comes out of the balancing of opposing 'faculties' or modes of being.

For Baxter, the 'crises, violations and reconciliations of the spiritual life' could only be understood and dealt with once they had a 'meaning', having been connected to a pattern or plot which linked the individual to the collective experience of humanity. A personal mythology in the Jungian sense ${ }^{10}$ represents the 'journey to self-knowledge' Baxter refers to in 'The Man on the Horse', a quest through the inner landscape of archetypes for the 'spring of life'. For Jung this journey leads through the various stages of understanding, encountering the ego, shadow, anima

${ }^{10}$ Dreams, Memories, Reflections 3. 
on the road towards the 'Self', the archetype which occupies the central position in the psyche and holds a godlike status.

Baxter's desire for 'meaning and order' was not primarily an intellectual pursuit but a quest driven by a visceral, enduring sense of 'chaos', reinforced by cultivated ways of seeing and being. Poetry provided the possibility of transforming the 'negative aspects of experience' into meaningful mythology, a process which restored, however faintly and momentarily, the sense of harmony and authority which he craved. This 'moment of art' could 'never stay', the cosmic sense of 'Meaning' and 'Harmony' which the poet conjures being only an intimation of the final meaning and healing which lies beyond understanding. Thus the 'cosmos' of Baxter's personal mythology is not the representation of a fixed order or a record of experience but an evolving mythological system which represents the moments of 'breakthrough'.

The distinction between order and ordering in relation to Baxter's use of myth can be demonstrated by considering two problematic critical responses to his personal mythology. In 'The Drunkard and the Hag' Kai Jensen establishes Baxter's early exposure to Jung and his ongoing use of key concepts such as the archetypes and the collective unconscious, as well as some of the similarities between Baxter's symbolic network and the archetypal figures and patterns central to Jungian psychology. Yet in his enthusiasm to overturn an apparent bias against the view of Baxter as a 'psychological writer' (rather than a primarily religious or literary one), Jensen overstates this influence in asserting that Baxter 'constructed himself and his writings after the theories' of Jung (226). The claim that Baxter systematically 'constructed' a Jungian self and a mythology to match is demonstrably inaccurate with regards to Baxter's selective approach to systems of thought and belief (nor, I 
would suggest, does this prescriptive approach seem true to the spirit of Jung's endeavour). Despite these reservations regarding Jensen's argument, the parallels he details are only the tip of the iceberg. Baxter saw in Jungian psychology a set of tools which he could utilise to discover order for himself within the chaos of the psyche, and to shape what he discovered there into a mythology which reflected personal experience. ${ }^{11}$ Yet while Baxter's 'therapeutic' approach shared many of the features of Jung's process of 'individuation' leading to the manifestation of the 'Self', he tended to emphasise momentary experiences of cosmos rather than the attainment of lasting 'harmony'. As with the poetic influences described above, Jung's theories were valued because they provided tools and methods which were functional, allowing the poet to engage with the 'chaos', and validating the view of the heroic individual on a modern quest.

The mixed purposes of Baxter's mythologising also contradict Jensen's view of a programmatic application of Jungian theory. One particular point of difference with Jung's project of individuation was Baxter's relentless insistence on the effect of the 'Fall' on man's capacity to make meaning out of experience and establish the internal balance and harmony which was the goal of Jungian psychology. In 1968 Baxter told readers of The Tablet that

I have often thought that the greatest single limitation which has come to the human race as a result of the Fall of Man is that none of us truly understand the meaning of our own lives. At times we catch glimpses of meaning in the pattern; but most of the time we simply have to trust that there is a meaning and that this is known to God. But when the process of Fall has finally been reversed - when earthly life, death, purgation, have come to an end, and we

\footnotetext{
${ }^{11}$ See chapter 4.
} 
are received into the Fatherland of Heaven - then God will give us His own knowledge, and we will see our lives and the lives of others as wholly meaningful.

('Heaven', FC 159)

For Baxter, ignorance of the 'true' meaning of life is itself a reflection of the truth of the Fall, a paradox which denies rational logos while at the same time affirming the prophetic authority of the mythologising self.

Weir's The Poetry of James K. Baxter provides another example of an emphasis on order and structure, rather than ordering and fluidity, in interpreting Baxter's mythologising. Weir structures his work to convey Baxter's gradual 'search for order' through a progression of methods and states - nature, poetry, myth and religion. While I would agree that Baxter's quest involved a 'search' amongst these different fields, it is evident that Weir's own religious imperatives influence his interpretation of Baxter's journey.

In the course of his long search for order in life Baxter has finally embraced a religion which has at its heart a suffering God. In Christianity he has found a dogmatic centre for his awareness of the nature of fallen man; he has also discovered a pledge of renewal.

While Baxter's Christian faith was a crucial shaping factor in his mythology, it should also be remembered that by the time he became a committed Christian, the habit of ordering 'deliberately for himself' was firmly established through myth, 
poetry and fragments of other systems such as Jungian psychology. Writing in the second half of the 1960s, Weir follows Baxter's own suggestion in stating that 'the poem is a kind of safety-valve', a way of ordering this chaos which will remove the danger of moral transgressions (17). Yet in their later interview Baxter corrected Weir on this point, insisting on the primacy of 'chaos' and the creative fruitfulness of the 'blood' which comes from the 'wound' of chaotic experience. Weir also believes that in Baxter's poetry 'even when ... formal patterns are not apparent, a mythology (in the sense of a schema of general truth) is still present in his writing, imposing meaning and order on the chaos of the events of everyday life' (18). This notion of a mythology as a 'schema of general truth' which precedes the poem is a problematic one for Baxter, as any fixed order obstructs the creative state of 'chaos' out of which emerges a cosmos mirroring the 'creative love' of God. In Baxter's ideal approach - if not always in his execution - the centre of his mythology is not 'dogmatic' and fixed but fluid and 'chaotic', moving between form and emptiness. Thus critics such as Weir and Jensen have imposed their own imperatives in selecting evidence to support the notion of a formal 'order' behind Baxter's work, while overlooking the consistent processes which are fundamental to his mythologising. It is not a static order which Baxter seeks, but the tools with which he may repeatedly initiate an ordering operation which momentarily creates the experience of cosmos.

For Baxter, the link between poetry, myth, psychology and religion is the desire for the sacred. Ultimately he saw each of these forms of ordering as dependent on an 'act of faith' which was the only response to the relentless desire for the transformation of 'chaos'. While he remained sceptical of 'objective' forms of order, in his impatience to exchange meaninglessness and discord for the meaning 
and harmony of 'God's knowledge', Baxter searched for some form of 'certainty' though poetry, myth and other forms of ordering where 'glimpses of meaning in the pattern' might be revealed. Thus Baxter interpreted Christ's 'silence' on the matter of art as an encouragement to test spiritual knowledge:

Art involves a fortunate area of spiritual knowledge, or if you like, an intellectual universe, where the flames of necessity that permeate all other areas of human experience become a shining, not a burning ... I think Our Lord left art to us as our playground, a specifically human area in which we could try to achieve self-knowledge, however painful, knowledge of the creation, however fragmentary, and even knowledge of Him, however incomplete, without the devastating weight of moral imperative ...

('Belief' 42-43)

Baxter returned to the 'places' where the meaning and harmony of cosmos had been experienced, and to the tools which had enabled him to discover or create patterns which led him to this experience. In his own view, these patterns emerged out of dissolution and chaos, rather than through the construction of knowledge and weighing of evidence. Thus Baxter described his conversion to Christianity as founded not on belief but the modern abyss of scepticism ${ }^{12}$ and (for Catholic readers) he described his conversion from Anglicanism as stemming from this epistemological issue:

... suddenly I realized that if I were to live for a thousand years and sift evidence night and day, I could never ... reach certainty, since the study of

${ }^{12}$ McKay 160. 
history cannot tell us the entirely true inner meaning of events. The Protestants asked me to accede to a reasoned and possible opinion; or rather, perhaps, to add my own variant of possible opinion to theirs ... the Catholics asked me to believe. And I could see the only possible certainty on matters which lay beyond the reach of human reason must come from belief. And in that instant I bowed my head to the Magisterium and I believed.

('Faith', FC 10)

Baxter's desire for 'certainty' and access to 'true inner meaning' beyond man's limited rational powers meant that the objective modes were often seen as a threat to what mattered most. In response to this, Baxter exercised his 'choice of belief' because the alternative was unacceptable to him: 'I choose to believe that He did give authority to his Church. Otherwise this world would be a desert and a mockery in which truth cannot be obtained about the things that concern us to the roots of our beings' (ibid). Jung considered 'the rupture between faith and knowledge' to be a 'symptom of the split consciousness which is so characteristic of the mental disorder of our day' ( $C W$ Vol 10, 285). In Jung's view, by the first half of the twentieth century the contrast of modes which this 'gulf' had 'opened out' had become 'so enormous that one is obliged to speak of the incommensurability of these two categories and their way of looking at the world' (216). Baxter saw his own Christian faith in similar terms, as a way to overcome 'split consciousness', to bring the sacred back into modern experience, and to go against the 'godlike' authority of the 'objective' disciplines.

Both Jung and Baxter saw religion as an ideal way for modern man to stay connected to the living centre, providing the tools of myth and ritual which allowed 
for internal transformation. However, unlike Jung, Baxter seems less interested in bringing faith and knowledge together than in the pursuit of the sacred, which in effect came at the expense of the profane or 'meaningless' ordinary experience, and his attitude to reason and logic reflects and maintains this division. Baxter believed that 'reality is indecipherable by logical and geometric method' ('Object and Subject' 21), thus knowledge derived from rational analysis - or 'logos' - was only useful if one had gone 'through a tunnel, an anguish of scepticism, in which doubts concerning the stability of the universe cease to be academic and become personal' ('Alligator' [second version] 3), thus suggesting the possibility of gaps ('tunnels') which transform merely theoretical knowledge into the wisdom of experience. Baxter writes in 'Notes' of the 'spiritual bombshelter' which provided a rebellious young man with a sheltering space constructed from the work of those who 'worked it out by feel' (130). This was the 'experiential' basis which justified his selective borrowings from other systems of knowledge - whether Jungian psychology, Christianity, Maori beliefs, eastern religions or Marxism - and incorporated them into his mythology. Thus Baxter says of his Marian devotion, 'where one has found pure water flowing from the rock, one will return again and again to drink'('Faith' 9-10). As demonstrated in chapter two, Baxter consistently employs this imagery of the 'rock' and the healing water to indicate the place where chaos is transformed into cosmos.

In two places I can find God without hindrance - before the Blessed Sacrament in a Catholic church; and at the heart of an A.A. meeting, when 
the quiet, irresistible force of the Holy Spirit wells up in the hearts of those who are standing together on the same rock of reality ...

('The Church and the Alcoholic', FC 33)

The alcoholic's recovery is thus described as a quest for the true source of replenishment, the spring of life:

The road of recovery, however, is almost always rocky. Something of the terrible dryness of active alcoholism lingers in the inner lives of recovering alcoholics - we have, I think a spiritual landscape of rock and water ... There is always the fresh shock of joy and discovery when, after a long dry trek, we find the river flowing and the waterhole brimming over.

Thus, like the alcoholic's therapeutic communion or the poet's 'hollow place', the Church is for Baxter a sacred place where one stands on the rock of experiential knowledge and finds the spring of life, the well of wisdom and truth. It is because of the meaning and harmony which he claimed to access through these ordering rituals of communion and self-emptying that Baxter - uncharacteristically accepted the authority of 'the Magisterium': 'The Church moves like a boat upstream; she moves against the Fall' ('Letters to a Priest' - 2nd Series - 12). This external, 'objective' order only gives 'certainty' through the 'subjective' mode, with the mythologising self implicitly involved in connecting personal experience to a collective set of myths and rituals, tools which give access to the experience of cosmos. 
These various poetic, psychological and religious influences each shaped and affirmed Baxter's later 'certainty' in the value of myths. The myths and symbols Baxter develops throughout his poetry are intended to function as signposts leading to the lost 'kingdom' revealed in natural contemplation. Baxter's 'natural man' is 'the fallen Adam who remembers, as if in a dream, his first state. He endorses the dying words of Dylan Thomas: "I want to go back to the Garden of Eden"" ('Conversation' 20). This self is still able to connect to Eden through the power of myth, symbol and ritual to recreate a semblance of what has been lost. Baxter describes the ritual act of dissolution elsewhere as 'a primitive form of prayer' ('Middle Age' 172), an expression of the desire to return to Eden through an act which has the same purpose as 'bowing to the Magisterium'. The vision of the unfallen Eden is central to Baxter's poetry as the imaginative space which his mythologising seeks to rediscover. Just as the Church is a 'ship' which takes one back across the gap to the other shore and communion with God, so myth and symbol are tools and 'ikons' which help the natural man to momentarily restore the ‘incomplete relationships' with man, nature and God.

\section{Symbol and Metaphor}

In Baxter's personal mythology symbols and mythic references perform the role of signposts and guides on the journey towards the centre. In Classical Mythology in English Literature, Geoffrey Miles writes that such literary borrowings from myth depend on cultural context and thus 'the language or code of mythology is not a fixed one' (4). As shown in chapter two by the contrasting use of Odin, Baxter's use of certain figures and mythic patterns depends on the context and the stance which is being adopted towards the other. Within Baxter's mythology, as with the literary 
phases Miles charts, 'the mythic images may remain stable and simple, but the interpretation of the stories shifts from period to period' (ibid). Thus reading Baxter's consistent use of mythic structures enables us to chart the changes in his relationship with the notions of the gap which are central to these personal myths. The Snake-Haired Muse shows how Baxter's use of classical myth evolved and persisted throughout his writing, effectively demonstrating that these myths were far from decoration but the tools which Baxter used to forge mythopoeic meaning out of his own experience.

Through memory and contemplation Baxter actively maintained a connection to his personal childhood 'Eden' and thus the symbolic landscape which directed him back to the 'living centre':

More than half the images that recur in my poems are connected with early memories of the Brighton township, river, hills, and seacoast - especially the seacoast.

Sitting down to write in a room in Wellington, again and again my mind would make an imaginary journey over the neck of the Big Rock, across the mouth of the Brighton River, and wander round the domain, or up to the boathouse, or along the sandhills, or out to the fishing rocks ...

('On Returning to Dunedin' 4)

Through an act of natural contemplation, the poet could discover an order which can be placed in opposition to the unsatisfactory temporal order which masks the gaps. Despite the subjective nature of the process described above, Baxter claimed that 
natural contemplation is by its very function agnostic, depending on images provided by the senses; and I place the testament of sand and the parables of rock ... humble, obscure communications from nature... in contradiction to the works of lucre and boredom by which man continually poisons the waters of his own soul.

('Conversation' 26)

This process of 'natural contemplation' aligns with Jung's views on this link between nature, myth and the unconscious, as expressed in the influential essay 'Archetypes of the Collective Unconscious', where the notion of an essential, authentic inner self at odds with the modern world is proposed:

... Primitive man impresses us so strongly with his subjectivity that we should really have guessed long ago that myths refer to something psychic. His knowledge of nature is essentially the language and outer dress of an unconscious psychic process ... the psyche contains all the images that have ever given rise to myths, and ... our unconscious is an acting and suffering subject with an inner drama which primitive man discovers, by means of analogy, in the processes of nature both great and small.

In this view, myths which take their form from the patterns of nature are 'symbolic expressions of the inner, unconscious drama of the psyche which becomes accessible to man's unconscious by way of projection - that is, mirrored in the events of nature' (ibid). Thus for Baxter myths represent the events of the 'spiritual life', figured as a journey through a landscape of wonder and terror, guided by myth 
and ritual. Baxter followed Jung's thinking regarding the archetypes found in imagination, dreams, myths and art, seeing them as agents of instruction and signposts on an inner journey. According to Jung:

There are as many archetypes as there are typical situations in life. Endless repetition has engraved these experiences into our psychic constitution, not in the forms of images filled with content, but at first only as forms without content, representing merely the possibility of a certain type of perception and action. When a situation occurs which corresponds to a given archetype, that archetype becomes activated and a compulsiveness appears, which, like an instinctual drive, gains its way against all reason and will, or else produces a conflict of pathological dimensions, that is to say, a neurosis.

('The Concept of the Collective Unconscious', $C W$ Vol 9, Part 1, 48)

Reading Jung had presented the teenage Baxter with the "possibility that my subconscious might contain sources of peace and wisdom as well as ghosts, werewolves, hags, demons, and the various zoo of the living dead who crowded round my bed at night' ('Notes' 127). ${ }^{13}$ Baxter's repetitive symbolic patterns and mythic paradigms function as a mythological map of this inner landscape, reflecting the 'permanent subjective realities' ('Man' 99) he confronted in the depths of the psyche. These threatening figures were transformed into guides to the spiritual life and Baxter, like, Jung, claimed to communicate with them regularly.

Baxter writes of the 'core' of the poem as a 'sacred event' which is 'beyond the artist and his material' which stands 'above, behind, or inside the work' ('Conversation' 13). In Baxter's view this core elevates the poem above the

${ }^{13}$ See 'Mother and Son' (1966, CP 369-70). 
boundaries of mere art and offers the possibility of shattering the 'brittle and exhausted world where only the lens, the instrument of intellectual analysis, is regarded as sacred'. The bullish poet writes that critics 'would have to become contemplatives' to appreciate this sacred dimension of his work ('Ancestor' 13). Elsewhere he describes this core as the 'significance of a poem, that quality which governs all others', which is otherwise 'hard to grasp and harder to analyse' is given form through the shifting images of the poem until the mind is able to integrate the core message: 'Like the seagod Proteus, [the significance] takes a thousand shapes - a forest fire, a bull, a serpent, a water-spout, a running river - and one has to grasp it through every change till it delivers up its identity' (35).

Baxter's mythical thinking identified similar patterns rather than distinguishing details. The specific gaps are thus connected to a network of meanings which links individual and momentary experience to universal truths. The 'space' identified is removed from its specific context and read as evidence of a pattern or paradigm. The same underlying relationships and characteristics are at work beneath the surface, where only symbol and myth are able to convey these universal truths. The emotional and spiritual material which appears to be chaotic eventually reveals a 'mythical shape'. Through Baxter's use of symbolism and myth he connects these 'intuitions and associations' into a network of relationships which has the intended purpose of guiding the reader to where the poet has been, back through the door into the darkness of the gap.

Baxter's simplified 'plots' reflect the practice of 'natural contemplation' as well as the mythologising habit which divided 'good and bad, light and darkness' so irrevocably. The artist's act of contemplation provides the space where experience, pattern and mythical shape are brought together and eventually merge into the 
'roots of a poem where art form and suffered reality coalesce' ('Symbolism' 57). Using symbolism to express these mysterious experiences of the gap was the most effective way to represent this ineffable reality, and the point of exchange where chaos becomes cosmos. Thus the symbol is

... a door opening upon the dark - upon a world of intuitions and associations of which the poet himself is hardly conscious. It is the nature of symbolism to be ambiguous. Yet certain patterns of symbolism can be more or less accurately determined.

The patterns in Baxter's work can thus be seen as the product of his quest, the record of his search presented in symbol and myth. This consistent symbolic network reflects Baxter's belief in a unity of experience underlying the 'surface'. Baxter's 'exchange' of meaningless, chaotic experience for mythopoeic cosmos relies on the process which O'Sullivan calls 'transference', in which 'any event may become a symbol, any relationship may put one in mind of similar relationships, so all that they carry may be transferred to one's own' (6). Thus a part of the mythic 'pattern' may be taken to imply the whole, where personal experience of a similar event to that found in myth may encourage the poet to 'spontaneously' or deliberately draw a parallel between life and myth so that a pattern below the detail can be presented in mythic form and thus reinterpreted personally by others as pertaining to the details of their own lives - thus the 'catharsis' when a 'shape' is discovered that also takes away the sense of 'isolation'. As a result of this approach 
and mode of thought, Baxter does not 'draw a boundary between what is merely personal, and what is significant on a larger scale' (ibid).

Baxter wrote that

while metaphor reflects those inward events of which the poet is clearly conscious, and involves a conscious mode of thought and manipulation of words, a symbol reflects the stirring of massive intuitions inaccessible to reason, frequently obscure to the poet himself, and only comprehended by those readers who are similarly moved.

('Criticism' 20)

Metaphor brings together apparently discrete elements in a unity of their essential or archetypal qualities. O'Sullivan writes that when Baxter claims that 'what happens is either meaningless to me, or else it is mythology', he is stating that 'for him at least, metaphor is the only worthwhile instrument of knowledge'. In such a poet, the 'metaphorical gift can ... set up a network of relationships where none were thought to exist. In the hands of a good writer, a seemingly gratuitous and temporary linking can be strengthened by aptness and repetition into a pattern, and a pattern implies both permanence, and remembering one's way' (Two Baxters 78). Baxter's reliance on a network of images to convey 'certain experiences or feelings - pictures, one might say, for our emotions' (ibid) again reflects the consistency of his 'starting points' and the transformative intention of his mythologising. 


\section{Three Mythic Paradigms}

Baxter's 'personal myths' were 'mental reconstructions' of experience which brought subjective experience into alignment with the patterns, plots and paradigms of myth. 'Man' is at the centre of the poems as both 'object and subject', the experiences of the individual are universal and universal experiences structure the life of the individual. As in Baxter's view every 'good mythology' originates from the gap, so every good poem or play 'embodies a myth, whether or not the myth is recognisable by the audience' ('Some Notes' 21). In this process it is not the familiar reference points, heroic figures, mythic settings, which are important but the structure of myth, the underlying 'pattern' which allows the audience to connect the work to their own experience. O'Sullivan points out that consistent application of mythic paradigms 'give shape to Baxter's imaginative drift' (Two Baxters 77) over the course of his lifetime. Baxter utilises three main mythic paradigms or types of myth to 'translate' the meaning of the gaps in experience. In this ideal an 'archetypal' problem is presented and (at least partially) resolved, and thus the myths chart the poet's progress through each stage of life. These motifs link the three types of gap into an overarching, continually evolving mythology which echoes the 'monomythic' pattern which Joseph Campbell asserted as the underlying universal structure of all mythologies. ${ }^{14}$

The first mythic paradigm explains the mystery of loss:

... the sense of some almost fatal wound inflicted - the sense, above all, that Love, or God, or one's own soul, are dying - this experience is all but universal for the human race. And a writer can hardly write for the multitude

${ }^{14}$ See O’Sullivan 6. 
unless he or she has been burnt by it ... The point is - at least for a writer's purpose - that he or she recognises inwardly what a child recognises only outwardly - the mystery that theologians have called the Fall of Man. The experience presents a hurdle. Either the writer stops writing; or else writes as if the Fall had not occurred ... dead work, sentimental work - or else begins to write truthful poems about the Fall.

(New Zealand Listener 19/02/1965)

What was 'dying' was not entirely clear, yet for Baxter the emotional intensity of the experience guaranteed its significance. For Baxter, the myth of the Fall comes to explain this mystery, yet he is careful here to suggest that the myth follows the experiences. That which is threatened or already absent is in each case meaningful and this 'all but universal' perspective creates a stance from which the writer can shape work which is connected to the living centre. This view encouraged Baxter to identify and emphasise personal experiences of loss and to accumulate from the natural landscape the 'symbols of fruitful grief' ('Virgin' 77) which provided much of the consistent imagery of his poems. These expressions of desire and disappointment gave form to the prevailing 'sense of grief' which was 'at the root' of Baxter's various gaps. ${ }^{15}$ The absence of some essential source of harmony was the cause of grief. Despite the ubiquitous presence of the 'hoardings', nothing could make up for the absence of the 'Paradise' which was lost. This would explain something of Baxter's relentless insistence on the primacy of loss and his search for further examples of loss, absence and lack. As with Odin's dismemberment and insight, in this view of human nature, it is where we are 'wounded' by life that we can perceive the truth. For Baxter 'remembering' suffering - both personal and

15 'Notes', see chapter 1. 
'universal' - becomes a matter of necessity and a central aspect of his personal quest for wisdom and strength. The Fall is a story which embodies this 'mystery' at the centre of human existence. Without this mythic paradigm, the 'meaning' of loss remained obscure: 'The heart of man lacks a fixed season/ Except to know loss and not know the reason' ('Traveller's Litany' 2, 1954, CP 140). Thus good writing could come from the ability to connect a variety of personal losses to awareness of this 'mystery'.

The Fall becomes the centre of Baxter's mythological 'cosmos', connecting the various strands of experience and providing an explanation for the troubling aspects of life. Any new experience could ultimately be related to this single mythic template and the various gaps are linked by this underlying mystery.

...the vision of a perfect knowledge, of an undivided love, and a sense of dereliction at its unfulfilment, are the constant subject-matter of poetry; and to dismiss them as meaningless is to dismiss the strongest aspirations of which men are capable, almost to deny their humanity. If we had not intuition that the Fall had occurred, then indeed the Fall would be complete.

('Symbolism’ 63)

This 'intuition' is crucial, as it gives the impetus for the quest which leads eventually to restoration and redemption. Patterns could be perceived by looking back at experience with the distance of time and elevation of perspective. For Baxter, this applied to personal experience: the 'child's nightmare', the reflections on his adolescence and youth, dwelling on the difficult aspects of past experience as well as more diffuse sense of 'ancestral' and 'communal' memory. This provided 
wisdom by presenting the universal truth of 'loss', which was behind the various specific experiences.

The sense of a fall from the natural or instinctive gracefulness of childhood into the monstrous confusion of adolescence provided Baxter's entry point into this definitive aspect of his personal mythology. The Fall gave an explanation for loss, absence and lack which was seen as the source of his inchoate 'sense of grief'. This process started with puberty at which point, as Millar suggests,

the projection of 'the Chaos of the world', onto the fixed screen of a mythologised childhood becomes a device through which order, however fragmentary, is discerned and meaning, however limited, discovered.

(Spark 45-46)

Looking back at the loss of childhood's 'primitive joy' provided Baxter with a mythic screen which could be compared with the present. Thus the 'gloomy tone' pervasive throughout Baxter's work was established in his early poetry, epitomised by his grief for the lost childhood world, which reveals the larger loss of the 'bay that never was', reminding the twenty year old that there was 'no meaning now but loss' (1946, CP 44-5).

This screen allows for the projection of all positive value elsewhere - whatever is can only be a reflection or a distortion of that which could or should be - whatever is desired is lost or exists in 'paradise' on the other side of the gap. Eden is the impossible standard which stands behind Baxter's work. Anything less than cosmic harmony can potentially be considered 'chaos'. Looking back to these 'origins' 
provided Baxter with a reliable source of creative energy and poetic material. That which has been 'lost' and is now absent could be imagined based on what seems to be lacking: 'Water must / Exist (they say) to answer thirst" ${ }^{16}$ ('The Town Under the Sea', 1962, CP 253). Thus when Horse tells the poet Grummet that 'God never seems to be quite real' his wise older friend tells him that one may know God 'by His absence perhaps' (118).

Despite the pervasive grief over the loss of the 'city of instinctive wisdom" ${ }^{17}$, Baxter had criticised the 'belief in Idyllic Man' and 'that a return to a simple life would make us good' as early as 1952 ('Choice of Belief'). In romantic fables the unconditioned individual existed free from corruption by civilisation:

This I would call the belief in Idyllic Man. There are some factors make [sic] this view a plausible one ... But always Idyllic Man is somewhere over the horizon - five hundred years ago, another country, another race, with the glamour of distance - especially in the childhood of the author. He is a dream figure, a little less than living; generally an excuse to blame our environment for our vices and our distress. He is not, in fact, a being capable of moral choice.

The fable of Idyllic Man has its value, if only as an alternative to the logic of the anthill ....

The figure of 'Idyllic' - or 'natural' man - persisted within Baxter's mythology despite these reservations, though as seen in chapter two the 'anarchic' qualities of

\footnotetext{
${ }^{16}$ See John 4:13-14.

${ }^{17}$ See chapter 6.
} 
this primitive figure were one of the key motivating factors in determining Baxter's 'choice of belief'. This drew him towards the 'view that man is a moral being whose suffering proceeds from his denial of the Light of conscience within him; and that this denial is universal among men. This I would call the Tragic View'. From this perspective - after the denial of the various other flawed 'views' Baxter presents in 'Choice of Belief' - the only response available is to 'have the courage to look hard at the cancers of the world and share the physical and spiritual suffering of others. In shared suffering, I believe, lies the regeneration of man'. Thus he urged his audience not 'to look on the Crucifixion of Christ as a single horrible event, terrible to contemplate but unique', but to consider this as an ongoing process of suffering which stems from the denial of man's connection to one another and to God, and thus the creative love embodied in the figure of Christ (7).

Suffering is a reminder of that which is lacking in the world and because of God's absence or distance, Adam must journey back through the eye of the needle to the source of meaning in order to connect to the sacred and thus be 'real' in the sense Eliade describes. The suffering on this journey shapes the man from 'chaos' into something resembling (by analogy) Christ, the god-man who bridges the gap between the 'Father' and fallen humanity.

The second mythic paradigm transforms the meaning of suffering and alienation, translating this as the process of initiation and shaping by which the hero progresses on his path towards redemption or the object of desire. In Baxter's terms, this is where the desire to reverse the Fall and restore the fullness of Creation is equated with the dissolution and self-sacrifice of Christ as the redeemer of fallen man: 
a total peace is inaccessible because of the radical human deficiencies darkness of the intellect, instability of the will, disorder of the passions ... To become Adam in paradise one has to go the long way home, back through the eye of the needle, through the gap at the centre of the soul. It takes a lifetime. What makes the journey bearable is that one travels always in company.

Because God is, we are able to be.

$(J D 55)$

The figures most commonly employed to symbolise this second type of gap were Christ and Prometheus, those who endured suffering and dismemberment for the sake of others. Christ represented the suffering undergone by a heroic outsider, or by one who stands in the space between irreconcilable opposing forces. Prometheus remained a more ambivalent figure, a representative of man's disobedience towards the divine order in searching for knowledge, but also one who endures eternal punishment for having brought man closer to the gods. Prometheus represents the urge to 'break the pattern' as well as man's desire to claim the authority of God, and this rebelliousness is the cause of suffering as well as insight.

In 'Notes', Baxter points to an early poem as indicative of the suffering of the adolescent caught between opposing forces and enduring a painful wait for freedom.

I, Prometheus, under a sky of stone

Bare brain and entrails to the objective sand blast,

Eyes fettered, seeing sky and rock only, 
Here wait, endure, sans even the hate

Of enemy or love of lover,

The legions of the stone futurity,

The crowding of the birds of memory ....

Prometheus voices his suffering, baring 'brain and entrails to the objective sand blast'. The awkward phrasing highlights the significance of 'objective' here; with his 'eyes fettered' the magic 'switch' cannot be flicked and Prometheus cannot transform the rock into the place of meaning and harmony. Baxter's later interpretation of the poem notes that 'the words are well enough put together ... but they say only that life is an arid secular crucifixion between a tormenting past and stonelike future; it isn't quite enough to make a poem out of' ('Notes' 126). The crucifixion is only worthwhile and fruitful if an act of faith, a sacrifice which is taken up on behalf of others. Christ is in this sense the heroic god-man who leads the fallen from loss to redemption, through rejection of the false view, suffering, sacrifice and death.

The centre of meaning (or 'the Sacred') is the seemingly absent God, 'the Reality behind all created phenomena' (Six Faces, 'Love and Suffering') which is denied by those who endure a secular crucifixion on 'Calvary Street' ${ }^{18}$ For Baxter, the way to actively seek out this meaningful reality is through imitating the self-emptying of Christ 'the Crucified One, who is behind all subjective and objective reality' ('Virgin' 74) and shows the door or gap which leads back to the Creator. Thus the

\footnotetext{
${ }^{18}$ See chapter 6.
} 
answer is to identify with and enter into the mythic pattern as scapegoat and sacrificial victim in the belief that this opens the door to the centre:

... You are the heart and the meaning of all meaning. To die in your company is better than to be brought to Heaven. If I wince and complain every hour of my life, it is not me but my idiot brother, my second self .... This is the only place where I can be I, by being not I but the other I was born to be.

As in the poem 'Cosmos', the approach to the heart of meaning thus requires the sacrificial jettisoning of the ordinary self in order to become the mythologising self, where God and man seem to meet in the voice of the 'greater I'.

The third of the major mythic paradigms is the pattern of descent and return which completes the hero's journey and restores the world to its original state of harmony. This central mythic pattern is repeated throughout Baxter's poetry, where the imagery of cave, tomb, womb, cliff, and sea is consistently employed to mark the places of 'entry' to another realm of seeing and being. This paradigms leads to the 'central pattern' of imagery O'Sullivan noted, describing it as the 'most important paradigm in Baxter's work':

... there is no important aspect of living or dying which cannot find at some point its appropriate station. Baxter has variously resorted to it to declare his feelings on childhood, adolescence, sex, society, death, and religion. It seems to me that there is nothing else like his use of this pervading imagery 
in New Zealand writing, and probably little enough that is so consistent in any twentieth century poet's collected work.

Myths of descent transform the meaning of dissolution and death as an entry into another, more meaningful, real or sacred realm of being. The journey to the 'underworld' provides access to the voice of wisdom and a vision of the living centre. Baxter makes use of various myths of descent, including those featuring figures from classical myth such as Odysseus, Orpheus ${ }^{19}$ and Persephone, and from other mythologies - particularly the figure of Maui and his attempt to outwit Hinenui-te-po, the goddess of night and death. The figure of the 'earth mother' is also central through the recurring pattern of begging for healing, intercession or shelter in the 'womb', as in 'The Hollow Place'.

The symbolism of the cave and the descent into the 'underworld' carries a range of potential associations in Baxter's mythology. 'The Cave' transforms an experience of entering and exiting a hollow place into a myth of descent and return which embodies the sacred pattern of death and regeneration. The basic movement of the poem presents a transition from one realm to another, followed by a regenerated return, embodying the pattern of Campbell's archetypal 'monomyth'. Miles writes that this poem embodies the idea of the descent to Hades as a psychological journey', part of a series of poems which present this same mythological pattern (Muse 233). The imagery of rock and water signifies the closeness to the mysterious living centre and the cosmos which is experienced there: 'a rivulet / Beyond the

\footnotetext{
19 'Orpheus has one song only: that which he sings in Hades to rescue his soul, Eurydice, from the chasm of non-being and causality' (Critic 164).
} 
rock door running in the dark. / Where it sprang from in the heart of the hill / No one could tell'. Ultimately this paradigm becomes the centre of Baxter's 'theology of kenosis', where in imitation of Christ the self is 'emptied' to open up space for 'God and one's neighbour'. ${ }^{20}$

\section{'Trouble'}

In 'Notes' Baxter expresses regret at his inability to 'demythologise'. The ingrained ordering habit caused him trouble in both his life and his art, as the mythologising self's assertion of authority over past experience also shaped and structured the 'ordinary' present. In Segal's terms, Baxter's poems emerged to meet a specific need, yet they continued to appear because the mythologising habit affirmed the authority of the mythologising self. Coupe, in clarifying Kenneth Burke's use of the term 'perfectionism' in relation to myth, writes that 'both making myths and reading myths imply a drive towards completion, an insistence on seeing things through to as near their full development as is practicable' (7). Coupe describes 'two opposed theories of the interpretation of myth':

... One assumes the perspective of perfection, translating narrative into the terms of truth, mythos into logos. The other sees myth as a matter of permanent possibility, trusting in the ongoing power of mythos itself. One is bound to a hierarchy; the other is open to a horizon.

\footnotetext{
${ }^{20}$ See chapter 8 .
} 
Despite his reservations, in effect Baxter's 'intuitional dissatisfaction' often drove him towards the perspective of 'perfection' rather than 'possibility'. In considering the latter position, Coupe follows Paul Ricoeur in suggesting that

myth may imply a hierarchy, but it also implies a horizon: it is "a disclosure of unprecedented worlds, an opening on to other possible worlds which transcends the established limits of our actual world" (Ricoeur 1991: 490). In other words, while myth may be paradigmatic, and while it may imply a given social and cosmic order, or perfection, it also carries with it a promise of another mode of existence entirely, a possible way of being just beyond the present time and place. It is not only foundational (as in fertility and creation narratives), but also liberating (as in deliverance and in many heroic and literary narratives).

The question becomes 'liberation' from what? If myth embodies or represents 'liberation' it must to some degree be opposed to that which oppresses the self, and for Baxter, this is the 'meaningless', non-mythological, profane world. This is the extremism which is also implicit in Eliade's dichotomy of the sacred and the profane. In his desire for 'certainty' in his mythic ordering, Baxter emphasises paradigm and perfection over possibility. The desire for hierarchy, completion and order which is evident in the work of a modernist poet such as T. S. Eliot is thus present in a different form in Baxter's mythology. Coupe expresses concern at the links between this tendency and the imposition of mythos as logos or divine truth, paraphrasing Burke, for whom mythologising is both a blessing and a curse: 
... a blessing because it allows us to conceive of the 'perfect' season ... the 'perfection' of myth. It is a curse because it also allows us to conceive of the 'perfect' victim or scapegoat, and so the 'perfection' of sacrifice ... the drive towards completion and unity can create not only powerfully imaginative stories, but also systematic violence. Myth may imply totality, but 'perfectionism' is to be resisted where it becomes totalitarian.

While Baxter consistently resorts to the extreme position wherein he accepts that 'the myth may kill the man', in 'Literature and Belief' he expresses the desire to retain the creative possibilities of an 'agnostic' approach:

... that mood of creative scepticism regarding everything Divine and human, that playground attitude, that quality of 'As If', that suspension of belief and disbelief, which is the only possible basis of the curious conscious and subconscious condition from which works of art emerge ...

(MH 58)

Yet the tendency towards 'perfectionism' inherent in Baxter's mythologising is revealed in his view of the artist's intermediary role, as he manages to affirm both the independence of the artist and the sacred truth of the pattern that he deciphers. 'All art is agnostic' through

... the nature of the act of natural contemplation that precedes and contains a work of art. A Catholic artist, like a Catholic scientist, must not go beyond the natural evidence that his life and the world proposes ... he obscurely serves God by an implicit act of trust that $\mathrm{He}$ is present in a hidden way in 
the hearts of all men and in the natural creation. Theology interprets what is given; art discovers in each unique event, however imperfectly, the pattern of the hidden One; but it cannot presuppose the nature of the pattern; each work is a new discovery.

Here Baxter sees the role of the poet as important as an unofficial intermediary whose 'implicit act of trust' presupposes that God is 'present in a hidden way in the hearts of all men and in the natural creation'. Thus though each work is claimed as a 'new discovery' of the 'pattern of the hidden One'. This presupposition limits the 'possibilities' of mythopoeia to the extent that the source of all meaning at the core of each 'pattern' is ultimately God as the 'hidden one'. While this creative approach appears to cede authority to the Church to the extent that it 'serves God', by implication it effectively reinvests authority in the role of the poet as an intermediary, a messenger passing between realms or standing above personal experience.

The confusion or conflation of the 'sacred' with the merely 'mythical' is evident in Baxter's varied claims regarding the role of the poet. In a private note from around 1960, he advised himself to "look for what Hopkins called the "inscape" - the unique hieroglyphic ... God has planted for your eye and heart in His visible ... Creation ... a good poem can be made by reporting this inscape only' ('Advice for (One) Catholic Writer'). Thus, though Baxter also advised himself to 'ditch the Church's chart when you take up the pen' his poetry was already shaped by the 'sacred' implications of his method. 
The conflict between the differing purposes of art persisted in Baxter's life. The 'aesthetic' and 'understanding' approaches contrasted by Jung make different use of the 'material' which is accessed within the psyche. ${ }^{21}$ While the former approach gives up any emphasis on 'meaning', the latter edges towards 'prophetic' art in its claims for insight into the state of the collective, as well as the personal, unconscious. Similarly, Baxter seems to have wavered over the limits of the artists' 'spiritual knowledge'. While he consistently denies the special status of the poet on the one hand - particularly when addressing writers - he also has an obvious tendency towards prophetic proclamations. In Baxter's correspondence with Weir, his creativity is the 'double source of fantasy and truth'. Thus by his own appraisal Baxter moves between these connotations of mythos and logos. In part, this confusion or elision is the result of the differing purposes which engender the poems, the gaps appearing at times to be purely personal and at others to be collective.

While Baxter distances himself from the prophetic mode in 'The Virgin and the Temptress', he reveals an anxiety over some of his own shortcomings as a poet in confessing that he retains a 'concealed weakness of sympathy for the prophetic attitude'. The 'schizoid' dynamic informing this mode of poetry, where life is divided into the sacred and the profane, meaningless or mythology, is considered: 'the main danger is that the prophetic themes lack substance - too much is repudiated, too much is set aside' (66). This criticism could often be applied to Baxter's own work, a recurrent tendency demonstrated by the extreme example of 'Cosmos' where the disconnected reality of the poem revolves entirely around the speaker's inner 'spiritual' experiences. At a young age Baxter was already aware of

21 'The Transcendent Function', 84-88. 
this tendency to 'cast my own feelings on the exterior universe', though he believed that he had learnt to 'melt' this projected material and let the 'process of discovery [begin] again' (Spark 301). I would suggest that, in the creative process where agency and causality are blurred, there is a sense in which Baxter's primary audience is the 'ordinary' self, which the mythologising self wants to guide through the gap and into the regenerative chaos in the process of exchange. This also seems to be the case in his prose 'advice', where personal problems, often of quite a specific nature, are projected onto the culture. ${ }^{22}$

Baxter wrote that the 'cathartic' potential of a poem relied on the possibility of identification with the self at the centre of the poem. This self 'is a projection of complex associations in the poet's mind, and the poem enables the reader to make the same projection' ('Mask' 42) as the universal archetype is 'triggered'. This process determines the successes and failures of the 'therapeutic' mode of art, where an imbalance between subjective, emotive content or tone and the 'objective' experiences and realities invoked or inferred can lead the reader to be excluded by the personal imperatives of the poet. The imperatives of desire which also shape the poem do not allow the reader to make the same project, hence the common criticism that Baxter leaves 'no room' for other views or voices. Baxter's mythology is the product of a mind urgently seeking to impose an order or favoured meaning on the threatening and unsatisfactory world of 'chaos'. Is the pattern imposed or discovered, meaning dredged with 'scrupulous objectivity' or imprinted at will? This issue is a key feature of the relationship between 'the gap' and mythologising, chaos and ordering. While Baxter often affirms the partial, imperfect and secondary nature of the poet's work, at times the line between the claims of 'natural' and

${ }^{22}$ See for example 'Shots', 'Poetry and Education', 'Why Writers Stop Writing', 'Choice of Belief', 'The Virgin and the Temptress'. 
'supernatural' contemplation are blurred and the mythologising self assumes a godlike status. Yet each poem contains by implication the 'world-view' of the poet and the imperatives of desire which shape the search for meaning and order. Baxter's conscious agenda is present in the poem regardless of notions of inspiration and the voice of the 'other' self. The authority over the mythology rests with the poet, the imperatives of desire shape the 'myths' which are, however, considered 'universal' when written 'from the rock of knowledge'.

While in his later poetry Baxter rejected the tendency to shape his poems into the 'perfect round', ${ }^{23}$ his identification with the sacred patterns at the centre of the mythology became even stronger in the last years of his life, informed by the 'mystical view'

... that life is a kind of code language, by which monotony, anarchy, or atrocity, those all-too-familiar features of the human condition, are in truth the strange caresses of an all-knowing, all-loving Father.

(New Zealand Listener 28/10/1966)

The true self is forged through this process which reveals the sacred patterns as the centre of man's reality. This approach contains an element of the 'gnosticism' Baxter attributed to Blake. The 'true inner meaning' of any experience was ultimately anchored in the 'hidden One', while at the same time the poet could claim the authority to 'subjectively' interpret experience in terms which placed this God at the centre of every pattern or plot. The 'messages' which the poet is given access to amount to a mythological 'cosmos' which reveals ('faintly') the true

23 'Interview' 245. 
nature of creation and the purpose of man's existence. When such works of personal mythology become public works of art, they enter into a relationship with readers that challenges the caveat of 'subjective' interpretation. The mythological pattern becomes a prophetic 'code': 'No man has ever been able /To dodge what's written in code on the night sky / Over our heads - "Adam, I love you. Stand / Up and walk!"' ('Letter to Peter Olds [2]', 1972, CP 578-81). Thus Baxter is drawn back to his 'weakness' for the prophetic mode even as he continues to affirm the role of poetry as 'therapy' and its status as only a 'secondary' form of creation.

The network of relationships connecting these notions of the gap was more meaningful than the particular details of each emotional or 'spiritual event'. Thus patterns and plots could be discerned where for others they might not exist. As Millar notes, 'the elements [Baxter] valued in people's lives were those that connected individuals to a wider mythical landscape of human experience. Where others may not recognise, or place importance on, such connections, Baxter relied on them to provide the essential structure of his art' (Spark 25). The specific aspects of a group's or a person's character and identity were only valued if they could be connected to a larger pattern which revealed a mythological meaning. In this sense, for Baxter as for Aristotle, character comes second to 'plot'. In Millar's words, 'If there is a fault in thinking mythologically, it is that experiences and relationships that do not fit preferred designs ... are discarded'. This applies to Baxter's personal life as well as his poetry, and explains his 'occasional tendency towards selective recall' (ibid). In effect, the test of the 'meaning' of an experience within Baxter's mythology was whether it could eventually be crystallised into the form of personal myth. The changes in Baxter's method and material were intended to meet these changing needs and respond to gaps in experience which came in new forms. What 
is not mythological is repudiated - this becomes troublesome where the mythological thinking strikes up against the complexities of human life, outside the realm of the poetic mythology. The details of life are lost in flood, only returning from the sea of chaos if they wash up reshaped into myth.

Baxter himself warned against the 'propagandist intention, imposing a pattern on experience rather than searching for the pattern which lies, unknown... under the surface rubble of events' ('Belief' 46). Whether the pattern was 'discovered' or merely 'imposed' determined a poem's value. The pattern could itself become a 'lens' narrowing the 'frame of reference' and crystallising the chaotic world to the shape of myth. Baxter's reliance on the gaps for his creative starting point suggests that this is a crucial point for critical analysis. Baxter's 'starting points' are already mythologised as familiar modes of seeing and being which structure experience in the present as well as shaping the past. Thus what the poet 'sees' is determined by the patterns that he has already seen.

This crystallisation process involves - either consciously or unconsciously - the breaking down of experience into components from which a pattern is selected or discovered. While Baxter's use of 'plot' is determined by the patterns he considered archetypal or universal, this process is however highly selective, rejecting the complexity of experience for the patterns which address the imperatives of desire. As Baxter says himself in 'Notes', these myths are 'tidied up ... artificial ... mental reconstructions'. Through the destruction and recreation of this selective process the mythologising self asserts its authority. The process of 'crystallisation' thus implicitly or explicitly includes the extremist, essentialist tendency of 'perfectionism'. Baxter fastens onto the 'mythological facts' of his past experience, while leaving the remainder of his personal history to become 'meaningless'. 
Baxter's tendency to represent whole groups of individuals according to their symbolic place within his own personal mythology of the gap is also evident in much of his social commentary and literary criticism. Baxter was characteristically candid about his mythologising 'trouble' with regards to women, wryly noting in 1965 that he had struggled to come to terms with the 'news' passed on by his friend Louis Johnson that 'women were also people' (Critic 211). Yet the following year he typically implies his own oppositional credentials and the possession of the eye of wisdom, even as he tentatively comes to terms with this news:

The great wall of mutual ignorance between the sexes which is perhaps the strongest single negative factor in our society has been broken down a little.

... leaving a gap through which the wisest can now look and recognise each other as human beings.

('Returning' 4)

Baxter's 'advice' is here directly addressed to his own personal 'learning' and the instruction of his 'ordinary' self.

For Baxter, the paradigm of the 'primal crime' explained all forms of loss and distance, even on the level of literary criticism. He took issue with 'Curnow's literary fiction of the spiritual isolation of the New Zealander' as a pervading reality in the cultural unconscious of the nation. In Baxter's view, this was simply an unconscious application of a deeply embedded sacred pattern: 
[t]he myth of colonial isolation and inferiority seems to be connected broadly to the theological concept of the Fall of Man - the immigration of our ancestors was, as it were, a second Fall, a departure from a Garden of Eden situated somewhere in Victorian England. Like other myths of inferiority ... the loss of self-confidence is insidious: no labour of intellect or will can ever really bridge the predetermined gap.

(Aspects 19)

McKay writes that Baxter was opposed to Puritanism because the Puritan 'imagination was dialectical', it 'exalted the rational and distrusted the instinctive. Baxter's imagination was analogical' (202). While I agree that Baxter's imagination was analogical - finding correspondences between seemingly disparate events, searching for recurring patterns and plots - I would add that a key part of this analogical process was Baxter's own form of dualistic or dialectical imagination. As O'Sullivan notes, this mythologising mode of thought means that 'any single disagreeable fact in New Zealand society becomes emblematic of a total way of life; any sinner, like Bunyan's Christian, carries the crammed sack of fallen man' (37). Thus in the persistent 'struggle of the natural man' which marked his mythologising, Baxter often reverted to a form of 'inverted Calvinism', which pitted the natural man in opposition to the 'bourgeois' elect. Baxter's role as social critic is frequently compromised by the tendency to impose this pattern, so that he reduces the complexity of modern life to a simple 'social dialectic'. In this formulation, the 'perennial battle' between 'the bourgeois family man - ape in an overcoat, donkey with a crown of thorns' ('Conversation' 20) and the 'forgotten' natural man reflects his own dialectic of the sacred and the profane, mythology or meaninglessness. This stance allowed for the ordering of the mythopoeic universe, 
establishing an evolving system of signs which placed value on the human world as well as the natural, yet it limited Baxter's capacity to present more 'complex practical issues' convincingly. This divisive tendency creates the fruitful tension which leads to poems, yet it also simplifies matters as it strengthens the emotional affect. O'Sullivan notes that objections to this mode of thought can be addressed by the straightforward defence 'that the man is writing poetry' and that for Baxter 'mere fact ... is nothing without the mythological mind'. The psychological need that O'Sullivan identifies means that the 'poet's mind imposes pattern, otherwise living is confusion' (38).

Jerome Bruner argues that 'eventually the culturally shaped cognitive and linguistic processes that guide the self-telling of life narratives achieve the power to structure perceptual experience, to organize memory, to segment and purpose - and build the very 'events" of a life' (694). One could suggest that for Baxter something like this happened at a young age, and that this is the root of his complaint that after thirty years of creating poetry, 'the trouble is, I can't demythologise'. Bruner argues that 'the ways of telling and the ways of conceptualizing that go with them become so habitual that they finally become recipes for structuring experience itself, for laying down routes into memory, for not only guiding the life narrative up to the present but directing it into the future' (708). Thus Baxter's desire for meaning dictates the limits of the mythological meanings in his poetry - the 'possibilities' are narrowed by the purpose.

The inability to 'demythologise' caused Baxter 'trouble' in his ordinary life as well as in his writings. Over time the poetic persona or voice, the public persona and the private life all merge and are essentially incorporated into the mythology, under the direction of the mythologising self. In 'The Creative Mask' Baxter writes that the 
'I' of the poem is a 'projection of complex associations'. By 'not permanently committing to any one attitude' the poet attempts to portray the 'total vision' of man's experience. The persona allows the poet to perform his role of commenting on an aspect of experience and is not a representation of a permanently committed attitude. Similarly, 'in ordinary life each man plays many parts ... The self which a man unconsciously assumes in a given situation is a kind of tribal mask, for which the psychological term is persona' (48-49). The dramatic role provides the possibility of replacing the mask of the social self with the mask of outcast, scapegoat, jester at the centre of a ritual drama. This is a crystallisation of identity, much as the poetry crystallises experience into the shape of myth: 'Without the dramatic role, life is experienced as chaos' (Plays 336). This applies to formal experience of ritual, such as the Catholic Mass or the performance of a play. For Baxter it also applies to the role of the poet - both in the structured setting of a reading and in the more general sense of living the myth. This tendency is taken to its apogee in the Jerusalem period, when Baxter consciously (and rather gleefully) takes on the task of becoming a walking symbol, with his bare feet, beard and derelict appearance, a sign of contradiction and opposition to the status quo. I would argue that the dramatic roles which Baxter took up were not indicative of a surplus of 'personality', but stemmed from the sense - reinforced by the mythologising - of the emptiness of the ordinary self and the 'meaningless' world it inhabits. This was the root of Baxter's 'problem of identity', another issue which he never resolved, leading to one of his numerous suggested epitaphs: 'He was too much troubled / By his own absurdity' ('Poem for Colin' 29, 1969, CP 469).

In 1954 Baxter wrote that 
The kind of persona a poet may assume depends on many factors - the society in which he lives, his own frustrations, his religious and ideological background. In Shakespeare's The Tempest ... and in Goethe's Faust, the poet becomes master magician; in the work of Rimbaud and Hart Crane, hobo and outcast, the scapegoat taking upon himself the burden of tribal guilt. Where tradition is strong, an Apollonian role is most probable. The poet tries to remain unmoved and subjugate his images to a formal order... Many poets, however, in the sterile order of modern civilization take on a Dionysia (sic) persona and submerge themselves in the flux of sensation and primitive mysticism ......

('Mask' 49)

Here Baxter addresses his own personal dilemma, contrasting the approach taken by a local poet like Curnow with a more 'romantic' perspective which emphasises the need for contact with chaos. This contrast between rhetorical 'Apollonian' intentions and the chaotic freedom of the 'Dionysian' was also played out in Baxter's poetry. The public 'persona' of the poet for the most part align with the latter position and created the pervasive Baxter myth.

In Baxter's view of the mythologising process, myth gives a 'form' to the poem, links personal and universal experience, gives a structure for the 'momentary' inspiration or 'harmony', meaning, suggested after the experience of chaos. Yet these myths, patterns and symbols also become 'ways in', structuring experience and shaping 'what happens'. The mythological or sacred pattern is imposed on experience and identity - the ordinary self is the 'subject' of the mythology which becomes an object at the mercy of the mythologising self. Eventually Baxter defines and inhabits his own mythology and accepts the extreme terms of a bargain he has himself laid down - to sacrifice his ordinary life entirely to the meaning of the 
mythology of the gap. The final 'persona' Baxter adopted was an expression of his desire to 'be that chaos' and at least partially submerge himself in the 'primitive mysticism' of the natural man while acting out a sacrificial drama as Hemi te tutua. As in the poem 'Cosmos', to make this movement and approach the heart of meaning required the sacrificial jettisoning of the ordinary self. This is the pattern which lies behind Baxter's imitation of Christ, a crystallisation of identity into a shape resembling that of the god-man who restores, reconciles, and renews life through the pattern of his life and death.

Baxter's mythology of the gap is the product of the creative ordering which shapes the material of 'chaos' into a poetic approximation of the harmony of 'cosmos'. In this mythologising process he continually reaffirms the reasons for his reliance on mythological 'learning' which discovers the 'sacred' within ordinary experience. Baxter's ordering involves the crystallisation of experience into the 'mythical shape' which gives it 'meaning'. In doing this he 'repudiates' whatever does not fit his preferred designs, and continually rediscovers evidence of the same 'patterns' underlying the diversity and complexity of the 'chaotic' non-mythological world. Thus Baxter's personal mythology presents the repetitive elaboration of three main mythic paradigms of loss, alienation and dissolution. In the following chapter I make an extended reading of two texts to demonstrate the ways in which this consistent focus on familiar 'starting points' and the employment of the same mythic tools leads to an approximation of a 'unified personal cosmos' in Baxter's writings, this cosmos evolves over time, yet continues to be defined by ubiquitous notions of the gap and the practice of mythologising. 


\section{Chapter Four: Cosmos}

It seems to me often that each poem is part of a larger subconscious corpus of personal myth, like an island above the sea, but joined underwater to other islands. Each poem is thus part of the big single poem I am always writing to let God know I still exist ...

(The Bone Chanter 5)

Baxter's collected poetry is a personal mythology that charts the evolution of the 'unified personal cosmos' which he attempted to shape out of the chaotic material of his life. From this perspective, each poem is connected to the others through its origins in the "terrifying but regenerative chaos out of which every island and myth rises, and into which it returns', as well as through the consistent practice of using myth and symbol to order this material. The term 'cosmos' carries connotations of 'order, ornament, world or universe' as well as denoting an 'ordered and harmonious system' of 'ideas, existences', that which 'constitutes the sum-total of "experience" $(O E D)$. Baxter's poetic mythology can be considered a personal 'cosmos' in the sense that it is an artificial mythopoeic 'world' which aims to show the sum total of the poet's experience and to arrange these experiences into a 'harmonious system'. The created cosmos can be interpreted as bearing the hallmarks of the ordering intelligence, and Baxter's personal mythology is in this sense a reflection of the 'shape' of his mind and the evolving framework which structured both art and life. 
'Cosmos' can also be defined as 'the opposite of chaos'; Baxter's personal mythology is in this sense the product of his habit of identifying and transforming 'chaos' through the use of ordering tools, a process which is continually refined as the cosmos is 'reforged'. Therefore these three components are not sequential stages of creation but recurring and interdependent components. Baxter's personal mythology was constantly remade and reshaped by the creation of further poems which dealt with new experiences and reflected shifts in thinking and lifestyle throughout the course of his writing life. The major ordering features of this cosmos, however, remained largely fixed in place and thus Baxter's vision of an 'objective' cosmos can be inferred from the contours of this subjective, personal mythology and the consistent use of similar patterns to shape the chaotic material of his experience into mythical form. The poems are, individually, 'records of the search' for transformation, they are 'reports' or 'charts' which map 'the spiritual country in which we live - ragged, mountainous, and by reason of the Fall frequently inaccessible' (Critic 165). Each poem builds on the earlier 'reports' to construct a world with its own meaning and harmony out of what has been learnt: 'I know only a little about the world; and most of it is somewhere in the poems I have written' ('World' 178). Thus for Baxter, 'a poem with true significance is a microcosm which contains by implication the author's central view of the world and human nature' ('Criticism' 27). The poems were connected by various formal factors, such as the use of symbol and myth, as well as the poetic voice and the experiences of the questing hero at the centre of the mythology. The starting points are determined in conjunction with the imperatives of desire, and the use of ordering tools also represent implicitly or explicitly the poet's 'view of the world and human nature'. 
In this chapter I give two examples of the mythologising process from extended texts which were each conceived in a short space of time, one a discussion of an unpublished dream sequence from 1947, the other a reading of one of Baxter's most notable poetic sequences from 1963. Extended analysis of these two sequences suggests the extent to which, at any given point in his writing life, Baxter was attempting to bring together the different aspects of his experience in a 'unified personal cosmos'.

\section{Dream Sequence}

The series of dream notes which Baxter typed up in 1947 are an early example of his enduring belief - 'with some aid from psychology' - that 'the events of a dream, though not objectively real, may shed light on the nature of man' and assist the urgent quest for meaning ('Man' 99). In this view dreams - though insubstantial and mysterious - contained meaning, and in the urgency of his quest Baxter followed Jung's dictum that 'the least of things with a meaning is worth more in life than the greatest of things without it' (Modern Man 67). Baxter shared similar views to Jung on the similarities between the dream and the work of art; both have therapeutic value and can be used to chart the inner world of archetypal symbols. Baxter's attitude to the value of dreams appears have varied depending on his immediate circumstances, but their relation to his quest is clearly evident in the significance he placed on his 'Jerusalem' dream-vision and in Horse, where Baxter uses a dream sequence to conclude one stage of the title character's journey to selfknowledge, including material which is very similar to the dreams found in the following sequence (119-21). 
In late 1947 Baxter was in contact with Grete Christeller, a psychoanalyst based in Christchurch who had trained with Jung. Baxter later stated that his intention in moving to Christchurch the following year though 'ostensibly to begin a second Varsity career', was 'actually to visit a Jungian psychiatrist' ('Essay on the Higher Learning' 62). It is possible that the typescript may have been prepared by a third party from handwritten notes. This would account for a number of question marks and a carelessness uncharacteristic of Baxter's early manuscripts. The typescript states that these dreams were recorded 'after being drunk about 2 days ...leaving me in a mentally indigestible position, as if lost in a desert or being frozen to death' (Hocken MS 0975/151, 'Notes on Baxter's dreams'). Baxter presents 'Mrs Christeller' with an incredibly intense and vivid dream sequence with a selfconscious sense of drama, providing her with assistance in interpreting the symbolism of the dreams and noting at the end:

All the dreams seem to be unusually vivid and important. I am as it were taking heaven by storm. I thought you might be interested in this series, for I imagine one does not often find the dream and its analysis occurring on the same level.

These notes present a fascinating insight into Baxter's personal sense of an inner journey towards contact with the mysterious 'centre' of meaning. The sequence of dream-experiences suggests a fluid continuity between otherwise disconnected scenes - just as the sequence moves from the stratosphere to the centre of the earth. The dream notes read almost like a consciously crafted elaboration of Jungian psychological elements and Baxter clearly interprets these dreams in relation to the 
key archetypes. The mythologising self is at the centre of this fluid chaos, in the form of the conscious ordering intelligence applied to the material, as well as the apparent ability to interpret the dreams from within the sleeping state. Yet regardless of the mediated nature of this material, Baxter's notes provide evidence that the contours of the personal mythology found in the poetry are directly related to the private process of 're-membering' and working in the 'abyss of his own soul' to discover the connections between things and the source of creation. The images, patterns and dynamics at work in these notes give a taste of the inner world which directed what O'Sullivan calls the 'imaginative drift' of Baxter's mind.

Baxter's dream sequence was recorded while he retained an early, more unbridled enthusiasm for Jungian psychology as a set of tools with which he might take Heaven by storm and flick the magic switch of transformation. A significant parallel is found in Jung's extended reading of a dream sequence in 'Psychology and Alchemy' where he connects the images and figures in an anonymous patient's dreams to many recurrent mythological motifs and patterns. Jung concludes by suggesting that

What is particularly noteworthy here is the consistent development of the central symbol. We can hardly help feeling that the unconscious process moves spiral-wise round a centre, gradually getting closer, while the characteristics of the centre grow more and more distinct. Or perhaps we could put it the other way round and say that the centre - itself virtually unknowable - acts like a magnet on the disparate materials and processes of the unconscious and gradually captures them as in a crystal lattice ... if the process is allowed to take its course ... then the centre symbol, constantly 
renewing itself, will steadily and consistently force its way through the apparent chaos of the personal psyche and its dramatic entanglements.

('Dream Symbolism in Relation to Alchemy, $C W$ Vol 12, Part 1, 325)

Baxter's sequence presents a similar process, leading to a minor revelation at the 'centre' which restores a sense of meaning and harmony. The sequence is divided into twelve parts, with the first part revealing the chaotic state of the dream world. The ordering laws of nature have been overwhelmed and the dreamer is 'high up in the air, in a town rather like Dunedin' and is able to 'swim through the air'. Rather than any sense of joy or exhilaration at this potential, the lack of gravity brings feelings of alienation and a fear of banishment: 'My remoteness from other people makes me very lonely and chilled. I am frightened that I will float away from the warm, rich world, and be frozen against the stars'. This 'gap between myself and other people' mirrors Baxter's prevailing beliefs regarding the isolation of the artist, as well as the vast empty space evoked in 'Cosmos' and in 'Pig Island Letters (1)' as 'the solid night where drunks fear the icy firmament'. Thus the chaotic state of absence and discord is revealed, driving the dreamer to embark on his quest for cosmos.

While still suspended in this state, the dreamer is faced with images of wild weather and seas, which are linked with momentary scenes evoking guilt, conflict and the fear of separation and alienation. When the dreamer does descend 'from the air to the street' he is immediately 'surrounded by brutal jeering faces'. He becomes the scapegoat who resists the moment of sacrificial 'exchange': 'There is a scaffold prepared with what I conclude to be castrating implements. I spit at the eyes of the 
enemies? [sic] They close in on me in a ring'. ${ }^{1}$ These adversaries are perhaps the product of his teenage experiences of alienation and bullying, culminating in the possibility of being called before a Military Service Board and sentenced to internment. These experiences, coupled with Baxter's belief in the creative fertility which follows sacrifice, might explain the otherwise exaggerated description of similar 'very valuable' experiences of bullying in 'Notes': 'I could compare them perhaps with the experiences of a Jewish boy growing up in an anti-Semitic neighbourhood. They created a gap in which the poems were able to grow' (12324).

Despite the other horrors presented in this sequence, it is the fourth part which is 'the dream most horrible to me'.

I am sitting with $\left[{ }^{2}\right]$, on a bed, and her face takes on the expression of a she-devil. A face of malignant hostility. She says that she is "dead sick of me", will have nothing more to do with me. Her eyes are green, she seems full of energy and hostile toward me.

Here the girlfriend has transformed from an object of desire to a figure who invokes terror. The horror is perhaps so striking because these two extremes are contained in one form. Judging by the very similar dream recounted at the end of Horse ${ }^{3}$, this

\footnotetext{
${ }^{1}$ See Horse 120: 'In the third dream [Horse] and Peter [a criminal acquaintance] were being hunted by the cops ... the cops captured them and took them to a building which resembled a cellar or the cavernous crypt of a church. When Horse looked round at the circle of cops, he saw that they were extremely ugly men with tough stubbled faces, but with the confidence possessed by those who represent a crude justice'.

${ }^{2}$ Baxter explains that this woman is his girlfriend.

3 'In the first dream he was sitting on one end of a bed and Fern was sitting on the other. He tried to approach her and embrace her. But she changed into a demoness with a black face whose eyes spouted flame. The demoness said to him, 'You must love me with a Christian love'. This surprised
} 
may relate to Baxter's troubled relationship with Jane Aylward, though what is significant is that this figure is a textbook example of the archetypal anima, who initiates the male into a new realm of understanding. It is the hope of a 'secret order' through Jungian interpretation that informs Baxter's approach to this manifestation of the anima, which takes its form from a familiar figure at the centre of his own emotional life. The real woman is transformed into the terrifying archetypal image which communicates a message that assists the hero on his quest towards self-knowledge. After this encounter, Baxter dreams that he returns to find his girlfriend 'in a mummified condition, long dead'. This evokes a 'great sense of loss and tragedy'. Within the dream, he makes the interpretation that he has 'destroyed her' by 'trying to found on sensation what should be founded on emotion'. Along with the need to balance these two Jungian 'faculties', the dreamer's guilt is perhaps connected to the role of sex in Baxter's 'world-view' and creative process, as represented later in Horse. Once this personal message is deciphered and accepted, she 'revives ... promising to be my friend, as I have now chosen the Christian rather than the pagan view'. ${ }^{4}$ This suggests a transition towards the position demonstrated two years later in 'Why Writers Stop Writing' (27).

With his world-view 'adjusted', the dreamer embarks on the next stage of the quest, which dominates the remainder of the sequence: 'I am determined to find out Why the central horror? [sic]'. This horror is 'recognisably the same in all my threatening dreams and in times of waking depression', underlying all of his fears and doubts. This sense of the same negative characteristics underlying a wide range of experiences is a precursor to the unity which notions of 'the gap' provide twenty

Horse, since Fern had never been a Christian. He retreated to his own end of the bed, and she became Fern again ...' (119).

${ }^{4}$ See chapter 5 . 
years later in 'Notes'. The same horror can be identified 'behind' all of the threatening experiences of these dreams, recognisable through heightened emotion. The images in these dreams are thus only the surface materials which reveal archetypal patterns, providing an opening to the centre. From this perspective, the relevant questions are therefore: what is the origin, significance and purpose of this horror? The dreamer's quest is presented as a visceral, emotive experience, though one which is endured with courage and hope: 'Though sick with fear, I am not helpless, but return again and again to the danger-point.' There is a recognition that the answer must be found, no matter what the danger. Like the hero Odin, Baxter stays staring into the terrifying abyss in the hope of finding the wisdom that he seeks.

In the eighth part of the sequence the dream-self descends further to 'a childhood layer (the ground-floor or basement of a house)'. Here he finds 'the Authorities who direct the series', who are 'upset as people would be if the automaton in a puppet show suddenly demanded to know what the play was about'. The dreamer has in a sense 'woken up' and now seems to face these authorities with the combined forces of the conscious and unconscious mind, as in Jung's theory of the 'transcendent function'. The presence of these 'Authorities' is related to a very specific personal issue:

Doctor Johnson (one of them) appears and tells I should go on with academic work. [sic] He is irritated with my pressing. I say, How can I work without first finding out what I need to know so urgently - the nature of the central horror. 
Here Baxter revisits the issue of the two types of learning, which had come to a head in early 1945 when he told his parents that he would not be returning to Otago University for a second year. ${ }^{5}$ Perhaps the scholarly figure of Doctor Johnson suggests the sort of respected 'man of letters' that Baxter believed his mother wanted him to be, more akin to Millicent's father, the distinguished academic John Macmillan Brown. ${ }^{6}$ Baxter believed that this emphasis on secular, rational learning and the 'thinking' faculty separated him from the sacred and could not help him to deal with the 'central horror'.

In 1947 Baxter (then 21) was still based at his parent's house in Brighton and struggling to balance his desire for independence with competing attachments and obligations. ${ }^{7}$ In the dream, this issue is resolved, and having passed another test and asserted his independence and the objective value of his subjective quest, Baxter encounters another figure:

A Young Man with a dark shiny face, powerful and helpful says to me that They could not possibly allow any of this to happen if I were not able to analyse the dreams as I dreamt them.

This figure appears to be a particularly benevolent manifestation of the 'Prisoner', Baxter's version of 'the Shadow'. This wise young man helps the dreamer to understand that 'the Authorities existed in their own right', their dream forms being representations of the institutions which sustained the status quo of 'secular Calvinism'. This objective reality was in contrast to the provisional, fluid nature of

\footnotetext{
${ }^{5}$ See Horse 8-11 and 'To My Father' in chapter 5.

${ }^{6}$ See 'Essay on the Higher Learning' 61 and Millar in Muse 42-45.

${ }^{7}$ See 'Alligator' 2.
} 
'the dream symbols in which each problem was presented, like a nut which I had to crack until the kernel was presented as a new nut'. The 'problems' of Baxter's own psyche are wrapped up in these archetypal symbols, which must be cracked open again and again so that their true meaning can be discovered.

It was these 'shock tactics' - utilising tools to find order within the disorder - that 'went against the grain of the dreams and even of the Authorities'. In light of this heroic, rebellious questioning, the 'Young Man' recognises Baxter's dream-self as a worthy ally and 'makes again and again statements which I have to comprehend i.e. make a semi-conscious synthesis of them. His remarks are always unexpected and lucid'. The intoxicating power of interpretation, the ability to discern the cosmos in the chaos, rests with the dreamer, in alliance with his shadow-self - the combination of these two selves produces 'the third', the mythologising self. It is the ability to crack open the symbols and decipher the meaning of the code which sets him apart. Having collaborated with this wise Young Man and absorbed further wisdom, Baxter's dream-self is helped by a non-threatening form of the anima: ${ }^{8}$ 'the Guiding Woman ... gives me the words Red Lamp or Red Lights as a clue or key to the next compartment which I enter alone'. With this new 'nut' of knowledge, he prepares to enter what he imagines may be a brothel. ${ }^{9}$ He stands outside a door, 'as in dreams which I used to have at about 5 years old.' Opening this door again requires overcoming intense fear of the unknown. Inside the door a 'big angry pale Scottish Highlander' waits in the dusk, a figure from Baxter's 'readymade myth': 'my ancestors were Highlanders, hence he is highly primitive', a tribal version of natural man. This ancestral figure seems to be an enduring presence in Baxter's mind, as

\footnotetext{
${ }^{8}$ See 'Archetypes', $C W$ Vol 9, Part 1, 32.

9 'The centre of our dreaming is the cave / That the world translates as brothel' ('Autumn Testament' 39, 1972, CP 560).
} 
demonstrated by Chennor, the intimidating Highlander who interrogates Baxter in 'Conversation with an Ancestor' nearly twenty years later. ${ }^{10}$ Again, Baxter's dreamself musters his courage and like Odin journeys onwards as if "pressing up a stream to its source', reaffirming this as a quest for the origins of creation.

The dreamer next finds himself 'with head and shoulders wedged inside a red-lit cave, my body from below the waist still outside'. This is clearly some form of reentry to the womb of the 'earth mother', connecting to an important thread of symbolism in Baxter's mythology. As indicated by Baxter's earlier confused response to the 'Guiding Woman', there is undoubtedly a sexual aspect here, prefigured by the concern over sexual relationships and perhaps signified by the presence of 'red velvet'. Yet the rather passive position of the dreamer suggests the broader sense of a healing union with the source which he has been seeking, a passage to the hollow place and the 'rock of knowledge'. A Jungian might see this as a symbolic return to the ancestral 'womb' of the 'collective unconscious', as in Baxter's comment to Ginn two years earlier: 'The Sea is the symbol of the collective unconscious. It appeals to all of us to sink into its depths' (Spark 406). Having reached this 'primitive layer' Baxter finally feels that he has made satisfactory progress: 'this seems the end of the search, and I have a feeling of having partially achieved my object'. Thus Baxter's own interpretation here would suggest that an 'inward search', quarrying within the 'abyss', has been rewarded with a vision of the archetypal 'spring of life'.

The characteristic urgency driving this quest is partially resolved by the meaning and healing offered by this version of the anima. In Jung's terms, 'an archetype that up till then had lain hidden behind the meaningful nonsense played out by the ${ }^{10}$ Courtesy of Geoffrey Miles. 
anima. This is the archetype of meaning, just as the anima is the archetype of life itself ('Archetypes', 32). Respite from this urgency indicates that the desired sense of meaning and healing has been secured: 'I return to the Guiding Woman, who tells me I must wait. I press her to find out more, but the feeling of urgency has lessened greatly'. The Guiding Woman finally tells him that 'she will find out what I want to know from the Theatre later on'. This reinforces the sense of an ongoing internal 'psychodrama' in which patterns and plots can communicate the 'crises, violations and reconciliations' of the spiritual life. The 'danger point' which Baxter returns to again and again thus relates variously to many of the recurring features in his writing: separation and alienation; fear and sacrifice; sex and romantic relationships; religion; art and intellectual pursuits; ways of 'learning' (and Baxter's choice of career); suffering; guilt; death and loss; social and cultural forces; internal divisions and the 'prisoner' in the cellblock of the mind; disconnection from a tribe; ancestors; regression to the womb; and the lessons of the 'theatre'. Baxter gets part of the way towards connecting these images and resolves the immediate pressing issues of his relationships, perhaps the reason why he makes it 'halfway' out of or into the womb.

In the dream notes, as in Baxter's poetry, the feeling evoked by symbols is of primary importance; the images only exist in order to convey their messages. The pathways to the centre are linked by a network of symbols and figures which merely 'clothe' the 'empty space electrically charged', the 'central horror' of the lifeless abyss which becomes the life-giving womb when the symbols and messages are deciphered and the 'relationship between parts' is established. This 'central horror' is the chaos which precedes personal cosmos. It is both 'empty space' and potent matter, the source of suffering as well as understanding and creativity. 
Baxter affirms that the archetypal images are not themselves 'the horror' but merely 'the empty space electrically charged which they clothe', demonstrating the dual nature of chaos as emptiness and form. The images are mere forms which emerge from apparent 'emptiness' of the fluid space-matter at the centre, presenting the possibility of reconstructing meaning out of fragmentary intuition. Passing through each door is to enter the gap and encounter the central horror behind each symbol or figure, the core of the 'nut', the dreamer becomes the master of this inner world of symbols and absorbs each lesson before progressing towards the source.

As in Jung's interpretation of the dream material cited earlier, in this sequence Baxter journeys to the centre through a landscape of symbols towards the fluid core, where chaos is transformed to cosmos. Thus like the poet the dreamer aimed, in Jung's terms, to gain 'possession' of the energy which was in the wrong place, ${ }^{11}$ or in Baxter's own later terms to find the message within the 'kernel of experience' and thus crack 'open, like a nut, the causal universe' ('World' 185) and momentarily reach the source of meaning and harmony. One could choose to follow a 'Jungian' interpretation of Baxter's personal mythology and argue that as a whole it follows the process described here, spiralling around the 'central horror' of the gap which connects a diverse range of content to the same underlying characteristics. Like Odin staring into the abyss, the 'shapeless, nameless ills' threatening the tree of life take form one after another, becoming the symbols and patterns which Baxter utilises. Thus in Baxter's poetry the symbolism of the gap becomes increasingly prominent over the course of thirty years as he continually repeats the circuitous quest to renew meaning and harmony through dissolution and regeneration.

11 'The Transcendent Function' 82. 
Beyond this 'ideal' reading, which follows Baxter's own representation of this material, what is striking is his determination to establish and maintain authority over the inner and outer worlds. The malevolent 'Authorities' are to be resisted by waking up from the 'sleep' which is man's ordinary condition. Similarly, the dreamer retains authority over the inner world of symbols and patterns, and though Baxter engaged in a brief course of analysis the following year, he seems to have done most of the 'analysis' himself, telling his mother that he and the analyst 'agreed that I had found a certain balance that I had lacked before' and that he

... had to do most of the thinking and working out myself, as she never tried to push anything on me. The analysis was valuable: though it did little to solve my many problems, it gave me something of a sense of responsibility, and a self-confidence that I needed. ${ }^{12}$

The need for reassurance may have driven him to engage in analysis, but the desire for personal authority over the realm of the psyche is perhaps another reason why Baxter did not persist long with this process, noting in another dream sequence ${ }^{13}$ recorded while seeing the analyst - that 'you are helpful but don't know all the dangers'. This dream sequence can be seen as a response from the depths which 'answers' key questions at the time and affirms Baxter's special role as one set apart by a quest to confront the 'central horror'. The purposeful use of this psychological ordering to 'storm Heaven' is consistent with Baxter's attitude to other systems of knowledge and belief. He uses Jung's ordering tools to affirm the objective value of the personal myth and thus the authority of the mythologising self. Through his pre-

\footnotetext{
${ }^{12}$ Letter to Millicent Baxter, June 1948, Baxter family papers, Hocken Library.

${ }^{13}$ Hocken MS 0975 / 151.
} 
emptive interpretation, authority over this inner world could remain with the mythologising self. Baxter continued to interpret his own dreams - often publicly according to the subjective imperatives of desire, most notably in the 'Jerusalem' vision/dream. ${ }^{14}$

\section{Pig Island Letters}

Having established the chaos-ordering-cosmos framework as an effective means to interpreting Baxter's poetry, we can return to the 'Pig Island Letters' sequence discussed in chapter one. The private letter Baxter sent to Shadbolt with the first poem presents further confirmation of the central role of the gap in Baxter's personal mythology.

Talking of the gap - I think I had to be prepared to tear off the bandages, not use the poems as bandages, admit the hollow centre to which writing or psychoanalysis inevitably leads one, and make an act of trust in ... something, someone, quite unknown whose image is the wound and the darkness itself - the Higher Power of A.A., or the Crucified One - but still in a sense unknowable. I mean, very roughly - The ikons had to go ... ${ }^{15}$ it is a shift away from the aesthetic patterning, so dangerous to artists because it leads to idolatry of the work ... The gap is the place where a new self is able to be born. All one can do is to avoid hindering the growth of this strange embryo.

\footnotetext{
${ }^{14}$ See chapter 8 .

${ }^{15}$ Ellipses in original.
} 
In Baxter's mind, these diverse experiences are linked by notions of the gap, as demonstrated by the dream sequence and 'Pig Island Letters'. As with the 'central horror' in the dream sequence, here the gap links Baxter's thoughts on creativity, psychology, spirituality, religion, art and personal development. The common element is the 'hollow centre' with the potential to bring forth 'a new self' if one is able to 'make an act of trust'. The 'ikons' are obstacles to this spiritual and artistic process, much as the 'hoardings' were earlier on a cultural level and as were the dream images which had to be 'broken open'. The mysterious force 'whose image is the wound and the darkness itself' seems to apply equally to art and religion, birth and death, and to transcend any name or image given to it. In Baxter's mind the disparate and paradoxical qualities associated with this hollow centre seem to have all been suitably addressed using a single, shape-shifting term: this is all 'talking of the gap'.

I have demonstrated the ways in which, for Baxter, writing and psychoanalysis both revealed the chaotic centre of human experience which was simultaneously threatening and fertile. In 'Cosmos' the mythologising self approached apotheosis by transcending the world in an act of the will - in the dream sequence, the dreamer must face the central horror behind his fears and dig deep rather than escape into the ether. In this letter and the sequence of poems which follows, however, Baxter suggests that rather than 'storming Heaven' he had to learn how to pass through the low door of dissolution and perform the act of faith; a ritual pattern which is central to both the first and last poems in the sequence. The creative 'act of trust' here opens the possibility that new life will come from 'the wound', 'the darkness', from the gaps of absence, alienation and dissolution. 
This sequence of poems was composed over a short space of time - no more than two months - yet the notebooks show that the poems were not written in sequence, with other poems written in between. This suggests that the overarching links only occurred to Baxter after some of the poems had been written. Baxter described this sequence as 'the blood-from-the-wound type-of-thing', a step forward in authenticity through exposing experiences of the gap. The sequence reshapes past experience in a manner which makes it meaningful according to the imperatives of the present. As with the dream sequence, there is the same sense of a progression towards a resolution, a mythopoeic response to the 'gaps' which precipitate the poems when the centre is reached and the meaning and harmony of cosmos are (however momentary) experienced.

In 'Pig Island Letters' 1 (CP 276-77), archetypal experiences of sex, death and birth are evident in the movement from sterility and death towards the fruitfulness and rebirth of the mythologising self in the final lines.

The gap you speak of - yes, I find it so,

The menopause of the mind. I think of it

As a little death, practising for the greater,

For the undertaker who won't have read

Your stories or my verse ...

... In the Otago storms

Carrying spray to salt the landward farms 
The wind is a drunkard. Whoever can listen

Long enough will write again.

Death, sex and birth are all evident in the poem, though they are given 'mythological names'. Thus the poem voices the processes which led to its own 'birth' and the tools which give it mythical shape. Baxter advises Shadbolt that the place he 'starts from' is the awareness that 'man is a walking grave'. The exchange of personal experience for the 'shape of myth' could only occur when this starting point had been accessed. The horrific burden of mortality and the fear of death could be utilised as a way to negate the false world and gain entrance to the creative state of chaos. This openness to facing the gap is the secret to transforming chaos from a threatening to a fruitful realm. The 'strange embryo' is the mythologising self, the mysterious, godlike entity that creates and is created by the mythopoeic process. To make an 'act of trust' in the darkness is in effect to hand authority to this 'other' self, a self that is, however, shaped by the imperatives of desire.

While the poem ends with the confident prediction of a future rebirth, Baxter's familiarity with the pattern is already implied by the description of creative 'menopause' as a 'winter'. Baxter shares with Shadbolt his own familiarity with 'the gap you speak of' and the place which this experience has taken in his mythology: 'I think of it / As a little death, practising for the greater'. It is a preparation for the unknown day that will bring the implacable 'undertaker who won't have read / Your stories or my verse'. This death will bring a meaning and completion which lies beyond the mythologising of writers, while the practise death allows the cycle to move forward. 
The imagery of the sacred pattern of fertility is thus represented by the "crinkled labia of blossom' on the trees beside the waters that flow over the weir - carrying a typically unsubtle Baxterian suggestion of pro/creative regeneration. This example of natural creative energy had been a precious consolation for the Promethean self who otherwise tried to escape from the meaningless endurance of time, self and the 'iron pyramid' of a loveless society through poetry, sex and alcohol. Thus Baxter told Shadbolt in the accompanying letter that the 'easy dishonesties we all have in the twenties' were eventually 'drilled out by pain'. The experience of suffering led to a greater honesty and, through a deeper understanding of the significance of the gap familiar since childhood, a greater faith in the value of loss, division and dissolution. Thus the 'strange new embryo' could emerge unhindered from the abyss and the wounds of suffering. As in 'The Cold Hub'16 the suffering of the 'climbing boy, the book-bred one' lying upside down at 'a party on a cold night' is transformed into a spiritual initiation in which God makes 'room for Himself' and communicates with the mythologising self.

Baxter then returns to the process of mythologising itself: 'And this, the moment of art, can never stay', it can only ever be a momentary and fragmentary ordering of experience, the brief exaltation and satisfaction of meaning and harmony which cannot transform the objective world. The artist distances himself from the "wives in the kitchen' who 'cease to smile' as the writer goes 'into the gap itself, the solid night / Where poor drunks fear the icy firmament'. This apparently necessary act is both a response to, and a cause of, separation, creating 'the condition of solitude essential for the performance of a ritual act' ('Symbolism' 63). Going 'into the gap' creates distance and disconnection, thus allowing room for 'poems to grow'. Baxter

\footnotetext{
${ }^{16}$ See chapter 7 .
} 
told Shadbolt that one must follow the path to the extreme edge in order to confront chaos directly:

It is my deepest lack that I fail to commit myself to the point of no return one has already passed the point, but pretends - or allow myself to be dismembered by others - one is already dismembered but chooses to ignore it.

The entry into a realm of destitution, 'moral chaos' and suffering leads to an honesty which is the foundation of authentic creativity: 'Man is a walking grave, / That is where I start from.' By entering the gap the writer has space to contemplate and create; the extra tension which this initiates in 'his' personal relationships is simply further confirmation of the special status of the writer and the need for space and creative tension. The creative voice emerges out of the gap of 'menopause' and the 'starting point' of the grave. It is the attitude of 'listening' which encourages the voice of the 'daimon' to emerge again from out of the gap.

Baxter mentions another friend who helped create space, a man whose humanity and openness is related to the fact that he is 'aware of / The albatross'. Baxter glosses this as 'the Ancient Mariner's albatross, the sign of guilt', as well as 'a genuine Christ-image and the bird that outrides the endless storms south of Cape Horn', explaining that the albatross, at home flying through both storm and calm, signifies this new understanding of the 'mystical code' which explains suffering and destitution: 
at a certain point (a secret point no one else can determine) any guilt ceases to be the sign of alienation from God and becomes the sign of dereliction, of the state of being-broken, the despair that is not despair because God is hidden in it ...

In his letter Baxter tells Shadbolt that Dunedin is the perfect place to confront the gap and the voice of the inmost self. It is '(more or less) ... a hell of a place to be in, but perhaps we are most ourselves in the jaws of death and hell'. Through kenosis and the 'practising' of death the 'menopause of the mind' will pass, the 'strange new embryo' - the mythologising self and the poem it brings with it - will emerge from this gap for 'whoever can listen / Long enough'. Thus Baxter closes by advising Shadbolt to listen to 'the Otago storms' because 'that profoundly negative fury symbolized in the coastal weather' is another manifestation of 'the dark face of God' - the chaos preceding creation which 'can move me when nothing else can'. Dunedin and the Otago coast thus provide the landscape for a sequence of poems which present a mythologised account of the poet's progress towards selfknowledge, a repeated process which takes him from out of the hellish chaos into momentary cosmos and back again. The movement of the remainder of the sequence draws a range of gaps together through symbol and pattern as Baxter imaginatively explores his home territory - his own inner life, his past, the landscape and culture of 'Pig Island' - with each poem arising out of a 'gap' and finding a response in the shape of myth, as the sequence moves through the pattern of the hero's quest.

In the second letter, the poet's 'malady' rises out of a gap of absence, and from the space between self and other which is both local and pervasive throughout 'Pig 
Island' where 'love is not valued much'. This is the 'central horror' which threads through this sequence, the lack which results from disconnection from the creative love which in Baxter's view is man's 'destiny'. The poem presents Baxter's vision of a typical New Zealand family divided from within and spiritually malnourished from without. The mother of the household is a 'brisk gaunt woman', a secular Calvinist devoted to the 'kitchen god' as a protection against an 'antique horn-red Satan'. She is admired as the bastion of family life, yet her version of love is a 'walking parody', where a puritanical fear, loathing and judgement set the tone for the whole family. Her husband is 'much baffled' and retreats to the womb-like refuge of the pub to retain some semblance of personal authority, though here the talk is dry and similarly sterile. Their daughter is in the process of becoming a faithful servant of 'Caesar'. She 'goes to Training College / Will vote on the side of the Bosses', and fills her head with the 'advertising view' of life, reading her 'catalogue of dresses'. Typically, the son is 'moodier', internally divided though outwardly still fulfilling his role. He is troubled by the pervasive, half-buried deathwish which for Baxter permeates a 'deeply death-centred society' ('Shots' 5). In the mind of the teenager this underlying desire for transformation takes the distorted form of an apocalyptic 'angel with a sword ... Just waiting for the word / To overturn the cities and the rivers / And split the house like a rotten totara log'. The mythologising self remains separated from this scene, the social prophet standing outside the frame and trying to talk 'to the masters of Pig Island / About the love they dread'. This is the meaningful and creative love that lies beneath the surface, beyond the 'walking parody' of kitchen and pub, within the 'wound, the darkness'. The task is hopeless, the poet only 'plaits ropes of sand'. Yet however much he fights against the pattern he presents here, he must remain connected to these points 
of conflict, many taken from his own upbringing. He acknowledges that he can never escape from Pig Island: 'I was born among them / And will lie some day with their dead'.

In the third letter Baxter presents his own adolescent apocalyptic vision, a personal version of the myth of the flood: 'In Calvin's town / At seventeen I thought I might see / Not fire but water rise // From the shelves of surf beyond St Clair / To clang the dry bell.' This destructive desire is a reflection of the same apocalyptic 'Calvinism' which influenced 'that other Baxter the Sectarian' ${ }^{17}$ in his vision of the overthrow of earth: 'the bodies of the damned will burn / Like stubble thrown into a red-hot oven / On Judgement Day'. His earlier response to the weight of judgement was to turn away from one extreme towards another, making 'a mother of the keg' so that he could split the town 'open like an owl's egg' and break down the ladders of meaningless secular advancement. This disobedience led to 'the winter of beginning' and the lessons of suffering which eventually revealed the hollow centre. This quest is retrospectively seen as justifying the teenager's rebellion. In his search for the sacred there is 'nothing to explain it in the books' but instead 'In the bed of a girl with long plaits / I found the point of entry, / The place where father Adam died'. Under the tutelage of the snake-haired muse of sex and death he was led 'through a low doorway to the only earthly paradise' (Horse 50). This experience mythically links birth, knowing and the 'little death', as the poet's innocence is lost forever - just as Adam and Eve's disobedient act of taking the fruit of 'knowledge' caused the gap between God and man and led to the disconnection, division and disinheritance which define the 'human condition'. This moment of initiation is paired with the memory of seeing 'pillars of rain move on

${ }^{17}$ English Puritan Richard Baxter (1615-1691). See Baxter's note in CP 628. 
the dark sea' from the place of revelation 'twelve paces past the cabbage tree' at the top of the 'gorse track from the sea'. This evokes the awareness of death and evil as the lack of love which informed Baxter's wartime adolescence, as well as his Pig Island version of the Tree of Knowledge of Good and Evil. ${ }^{18}$

The fourth letter demonstrates that Baxter's worst poems often reveal most clearly his dependence on familiar starting points and ordering tools. He rails against a recent decision of the Literary Advisory Board (of which he was a sitting member) to censor one of his poems. Baxter's own reshaped, mythologised, yet 'authentic' version of 'Pig Island spinning on the potter's wheel' is thus hidden from view. The poet uses the tension generated by this threat of being isolated and silenced to create an outburst of rhyming abuse, attacking a range of targets. Typically, women are attacked as moralistic hypocrites, 'young delinquent bags' who will 'graduate to grim demanding hags'. Baxter goes on to link this attack to the prejudice of the (Pakeha) elite: 'How often Remuera girls abort / Has not been mentioned in the Hunn Report // Holyoake yammering from a kauri stump - / God save us all! I need a stomach pump'. The judgmental, paternalistic attitude to Maori evident in this report is inverted in Baxter's own hierarchy of value: 'Sea-eggs, puha, pork, and kumara: / The Maori owned the land. I have a camera'. Here the poet implies that while Maori lived in accordance with natural law and retained access to the sacred through their link to the land, and through myth and ritual, Pakeha - including the poet - were divorced from this direct connection with the land - remaining behind the 'objective lens' of the camera. In this scatter-gun approach, the institution of marriage is also given a tilt; the wild horses of chaotic fertility and natural, creative vitality are bound to the plough, but ready at any moment to bolt. The poem

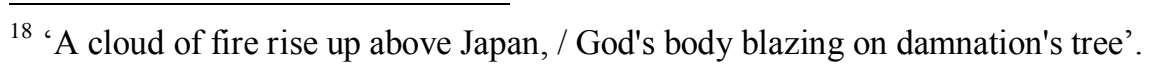


collapses in on itself as an element of self-mockery merges with the outrage, taking form in the figure of Saint Hippolytus, a conflation of a doomed mythological figure and an early martyr, who serves to represent the experience of those who are crucified, dismembered by the various social forces at work here: 'You who were pulled apart by four draught horses, / Saint Hippolytus, pray for us!'

The fifth letter reinforces what was gained through the experience of isolation and alienation. The fear of a judging 'Watcher' ${ }^{19}$ with 'the hawk's eye, the man in the sky / With his vats of poison cloud / Like Jeyes Fluid' drove the child to shelter above 'the old river', where 'the bridge was a broad mother'. There he learnt 'the tricks of water ... Hooking the fish of Maui on a pin' when 'the salt gush flowed in'. This ritual communion with water is significant throughout this sequence, as elsewhere in Baxter's work. Water can represent the fluidity of the natural order, the 'chaos' of the shapeless force and unknown depths, or the eroding power which eats at the stability and foundations of the land. Here the lesson taken is the need to 'get low', to go through a rather different 'door' of dissolution ${ }^{20}$ through emptying oneself, a process which leads to miraculous healing and new life when, like Maui, the poet drags an island world from the sea of chaos.

I make

My genuflection at an iron altar

Before the black fish rise, the weather break.

\footnotetext{
19 'Plunged early into the abyss of life / Where the tormentors move, / At war with God, the terrible Watcher, / An octopus behind a round glass window / With knives and justice, but no love. ('School Days', 1958, CP 194-95).

${ }^{20}$ See John 10:9.
} 
In the sixth letter Baxter again recalls his 'bohemian' youth and the lessons it taught. The 'hope of the body was coherent love', a harmony of body, mind and spirit, and this desire bred a 'belief in bodily truth rising / From fountains of Bohemia and the night'. This way of life reflected the distorted hope that 'the brown flagon ... the lips / Anonymously pressed in the dim light' might provide that which was lacking. The loss of this youthful 'freedom' is not to be mourned, however, as Baxter extends the message that 'Fairburn told us... "No / Words make up for what we had in youth". / For what we did not have'. It was this hunger that left 'each of us ... burnt, / Split open, grit-dry, sifting the ash of thought' and thus receptive to the message that 'whatever had condemned itself in us' was at the centre of the human condition. For Baxter, the meaning of this earlier life is now not simply 'loss', but a confirmation that, through suffering, this 'hunger' showed the way back to Eden via the cross.

Thus in the seventh letter Baxter considers the ways in which the creative love which is for him the nature of God shared by man - is thwarted by man's misdirected desire and the effects of the Fall on his will, intellect and passions. It is the frustration of this basic purpose which is the 'source of our grief', though few are willing to hear what the 'love that heals like a crooked limb... Could tell us if we cared to listen'. Baxter sees this grief behind the rebellion of adolescents, the alter egos whose 'angers mask their love', through their efforts to 'unwind the bandages / That hide in each the hope of joy'. This act of opening requires courage and wisdom which is otherwise lacking through 'long evasion, politics and art, / And speech that is a kind of contraception'. Against this sterility Baxter evokes the fluidity of the weirs, the place where 'bodies in the shade' can hear 'the voice / Of 
time from the grave of water speaking to / Those who are lucky to be sad' and thus learn the valuable lessons about the true nature of life.

In the eighth letter Baxter considers his father's legacy and reaffirms his distance from formal political affiliations. Baxter begins by 'humorously' presenting his own family credentials as a revolutionary: 'When I was only semen in a gland / Or less than that, my father hung / From a torture post at Mud Farm / Because he would not kill'. The poet is a creative product of this heroic figure and shares the same belief in the 'brotherhood of man'. Yet in the forty-five intervening years the hope of a political manifestation of this brotherhood had faded like Baxter's father, still the principled natural man but 'old now in his apple garden'. Having recently left the civil service himself, Baxter mourns the 'strong Antaeus ${ }^{21}$ of socialist brotherhood, which has lost contact with the soil it sprang from and died 'in the glass castle of the bureaucracies'. Like the creative love that is twisted by human ignorance, there is a gap between the intention and the action: 'Political action in its source is pure, / Human, direct, but in its civil function / Becomes the jail it laboured to destroy'. Thus Baxter simultaneously affirms a connection with rebellion and the integrity of distance from the mainstream, while rejecting the authority of political movements and institutions.

The ninth letter returns to the self and divisions within modern man, separating and contrasting 'the poet as family man, / Head between thumbs at mass' and 'the other / Convict self, incorrigible, scarred ... '. Neither of these half-selves are able to survive without the other, since the orderly, domesticated family man 'gets all his meat from the skull-faced twin ... struggling to speak through the gags of a poem'. Thus the task of integration is to bring these two together and momentarily revive

${ }^{21}$ See Muse 271. 
the mythologising self. In the words of the poem which echo Jung: 'When both can make a third my work is done' and the poem becomes a space of reconciliation, restoration and harmony. This delicate process is assisted by friends who 'held the door / And gave us space for art, / Time for the re-shaping of the heart'. Such fraternal love is necessary for isolated artists who need 'Companions to the manbeast, / One man in many, touching the flayed hide gently, / A brother to the artist and a nurse'. These male midwives provide the poet the space in which to create, and thus manifest the 'strange embryo'. The vision of the 'other self' lying in bed trapped in the sterility of the gap and walking 'the bridge of dread' is the contrast to this ideal. To avoid the fate of this schizophrenic whose vitality is smothered by the 'day nurse', the authentic poem must be 'a plank laid over the lion's den', spanning the central horror and linking the divided selves in the necessary work of personal integration.

In the tenth letter 'Marsyas the manbeast' - the satyr who challenged Apollo to a musical contest - is 'Hung up and flayed on a fir tree', a necessary sacrifice because ‘the mystery requires / A victim'. This mystery of redemption is demanded by the intolerable imperfection of both self and world and the need for creative love. Baxter's fear of 'being trapped in domesticity' and enduring 'a death by inches' draws him towards the illusion of freedom. Yet here a retreat to the wilderness of 'Idyllic Man' - 'a corrugated shack ... Beside a bay somewhere ... While cloud and green trees like sisters keep / The last door for natural man' - would not overcome the division within the self, being only another attempt to recreate on earth what has always been 'lost'. Rather than a retreat to a childhood Eden in nature, the poet's true place now is at the middle of life, the time when Jung believed that man urgently needed to redirect his attention and make death the 'goal' of the second 
half of life. ${ }^{22}$ In the eleventh letter Baxter is therefore torn by a separation from the imaginary realm inhabited by his son who 'makes ... a world of creatures / To populate paradise'. The middle-aged poet cannot accept 'the key of entry' to this creative paradise, 'because the journey has begun / Into the land where the sun is silent / And no one may enter the tree house / That hides the bones of a child in the forest of a man'. Thus in the twelfth letter the poet faces 'the dark wood Dante wrote of', the 'wandering gulf / That calls itself a man, seen / Through the dark prism of self-love'. The task is now to pierce through self-deception, the subconscious 'dishonesties of our twenties' and the desire to cover the gap with poems as 'bandages'. The attachment to these ikons and other selfish 'loves have tied us to the wheel / From which it is death to be unbound, yet in facing the necessary acceptance of death 'unexpected, unpredictable' moments of grace arrive 'like speckled rain that falls on a wave'. Attachment brings the pain of loss and death, and detachment offers the fluidity of chaos which miraculously leads to healing. The poet implies that the healing of these 'light fingers on the wound' is better than any 'bandaging' poem. Thus it is through an openness to death that the Pig Island poet finds his version of the 'face of Beatrice', in the cultural space 'where the marae meets the cattle hill'. ${ }^{23}$ From the reshaping of personal myth the possibility of a wider healing is now presented.

In the thirteenth letter Baxter starts by contemplating the 'hour of death', the same starting point noted in the first letter. This drives him from complacency to seek the protection and intercession of the 'Great Mother of God' whom Catholics call upon to guide them in their final moments when confronting death and seeking access to

\footnotetext{
${ }^{22}$ See chapter 7.

${ }^{23}$ See chapters 6 and 7.
} 
paradise. The dialogue which follows resembles an encounter between a disappointed yet forgiving mother and a wilful, manipulative child:

'God's grace has need of man's apology.'

'Your face is my theology.'

'Yes; but I gave you a jewel to bring.'

'In the thick gorse of the gully

I lost your signet ring.'

As an 'ikon' Mary represents the redemptive value of the act of self-emptying which is also sum total of the poet-swagger's faith, his means to ordering chaos and completing the course of his personal myth. He tells Mary that he has become like Christ on 'Skull Hill', with 'only the words, I thirst'. In response to this faith and humility, the compassionate guiding woman tells the sinner: 'You may come in.'

For Baxter this act of trust transcends rational argument because it leads one to an experience which is symbolised by the fountain of life springing up from the depths of the sea of chaos. The rock of knowledge is found as the centre is approached, yet one cannot approach the centre and remain one's ordinary self. The poet steps back from the aesthetic or 'dogmatic' representation of a Beatific Vision to describe 
instead a familiar image which symbolises the experience of cosmos where agency, identity and authority are blurred:

Is it like that? At least I know no better;

After a night of argument

Mythical, theological, political,

Somebody has the sense to get a boat

And row out towards the crayfish rocks

Where, diving deep, the downward swimmer

Finds fresh water rising up,

A mounded water breast, a fountain,

An invisible tree whose roots cannot be found;

As that wild nymph of water rises

So does the God in man.

Like Odin, the swimmer finds the roots of the tree of life within the depths of chaos; like 'the dolphin' he seems to be 'debased or drowned', yet rises from the danger point with the link between man and God renewed through the ordering of the mythologising self. A comment from 'Further Notes', written in the same year, confirms the link in Baxter's mind between this image of the spring/tree of life, the 'God in man' rising, and the production of poems: 
... Beyond the island at Waimarama ... there is a river that rises from the bottom of the sea... with such pressure that it forms a mound of fresh water on the surface of the sea. It is a tree of water rising from the sea bottom. ... It is beyond the reach of the Tourist and Publicity Department which kills every blade of grass on which it focuses its lenses. I think of that river sometimes when I am falling asleep. While it goes on rising it will be possible to write poems in this country.

Thus the final poem of the sequence brings to completion the cycle from the sterility of 'menopause' to the fertility of the spring of life, passing through the stages of loss and separation, initiation and suffering, dissolution and descent. Like Baxter's creative process the sequence begins and ends with a gap which leads to meaningful mythology.

This extended reading of the 'Pig Island Letters' sequence demonstrates the ubiquity and centrality of notions of the gap in Baxter's work. These notions were fundamental to Baxter's poetry as both 'starting point' for mythologising and as the structuring patterns which ordered chaos. Throughout this sequence Baxter's consistent use of symbol and myth links otherwise diverse material, from government reports to Calvinist theology, Maui to Beatrice, atomic bombs and satyrs. These are all symbolic components connected in a momentary 'cosmos' which charts the poet's evolving 'world-view', while also being an affirmation of the process of mythologising and the authority of the godlike creator. The 'tricks of water' which the poet gradually learns from his childhood fishing, his natural contemplation beside the weirs in Dunedin and from the wild seas of the Otago coast provide the knowledge that the final answer is to enter the sea of chaos and be 
restored by the spring of life. This 'act of trust' in 'someone, something ... unknown' is presented as the answer to the lack of love which is also central to the sequence. The negative experiences mythologised here provide the tools with which to shape meaningful mythology out of the gaps and cosmos out of chaos.

The 'big single poem' Baxter continues to write 'to let God know I still exist' is the mythology which is shaped and linked 'underwater' by the consistent starting points and the application of ordering tools utilised by the 'greater I' that continually reemerges from the centre. In the following chapters I trace the evolution of Baxter's personal mythology throughout more than thirty years of writing, demonstrating the connection between mythologising and the gap, chaos and ordering, which are fundamental to Baxter's work. The poetry which is the product of these shaping factors represents Baxter's attempt to create a 'personal unified cosmos' which would meet the demand for meaning, healing and identity. Thus I show the links between aspects of Baxter's poetry, demonstrating that this underlying project was at the heart of his poetic. This work shows the strengths and weaknesses of Baxter's mythologising method, which is addressed to social and cultural as well as personal objectives. In analysing a selection of poems from each period, I demonstrate the chaos-ordering-cosmos dynamic at work, as well as the way in which symbols, myths, figures and concepts are connected 'underwater' in the service of elaborating the 'sacred patterns' which were revealed by the gaps in experience. 


\section{Chapter Five: 'Why the Central Horror?'}

Fracturing the stolid hours of midnight

Saw I the ghost of one loved since as a child;

And knew, by the ragged wounds wherewith he was wealed

That he was among the dead of whom we speak not.

'Friend,' thought I - for thought alone seemed audible -

'What is the eternal refreshment we are seeking

And finding not - the life we long for, unspeaking,

Vainly, though ghosts and guns are terrible?'

('That the World May Know It', 1943, CP 14-15)

This chapter covers the period of Baxter's poetry from the early 1940s up until he moved to Wellington at the end of 1948. During this time Baxter's world expanded in tandem with his writing, as he evolved from the lonely schoolboy feverishly writing poems in his 'fuggy room at the top of the stairs' into a young man of twenty-two with two collections of published poetry. Along the way he had studied for a year at Otago University, explored high country stations and the night life of the city, and worked a wide range of jobs in Dunedin, Christchurch and Central Otago. He also experienced his first love affair and later became engaged to 
Jacquie. The personal mythology Baxter constructed in the poems of this period reflects the centrality of the ubiquitous notions of the gap in both interpreting and directing this personal experience in opposition to the 'vain', 'unspeaking' and meaningless life he perceived 'beyond the palisade'.

'That the World May Know It' is typical of the poetry of this period in that Baxter is actively searching for answers to his questions, and looking to 'the night' and 'the dead' for the wisdom which seems absent. The veil is raised for the poet who engages on this urgent quest, as the lifeless, 'stolid hours of midnight' are fractured and transformed by the appearance of the older, wiser 'friend', just as in the dream sequence where the shadowy 'Young Man' appears to provide guidance through the underworld of the psyche. The mythopoeic world created by the adolescent poet reflects the habit of self-reading and self-listening, and the desire to populate the empty landscape, the deserted space which had opened up 'between myself and other people'.

Baxter's pen-friendship with Noel Ginn played an important part in bridging this gap and fostering his development as a poet during the years 1942-44. In this time Baxter developed from an isolated teenager whose poems were only read by his parents, to a published author feted as the future of New Zealand literature. As Millar's Spark to a Waiting Fuse reveals, Baxter's lengthy critical dialogue with Ginn helped him to develop a sense of a potential audience and the confidence to create a distinctive poetic voice. This poetic voice emerged out of the intensive study and imitation of a wide range of poetic styles and influences, documented throughout this dialogue. The desire for connection with and affirmation from a wise 'friend' is thus one of the defining features of this period. Yet while Baxter sought guidance from Archie and Noel Ginn in particular, the dream sequence 
suggests the abiding desire to preserve authority for the mythologising self. Both of these relationships were eventually challenged, and Millar perceptively notes this as an example of the distancing which is characteristic of Baxter's close relationships (Spark 127-28).

In pursuit of 'freedom' Baxter cultivated 'a rather sour determination to go my own way by doubt and not by Authority of person, state, religion, or convention; to work out my own position and make no promises (to Ginn, 21/07/1946, Spark 424-25). His own quest was for a 'free heart and mind' and the space to grow: 'But this is the land of Authorities: Government, Church, Monopoly, Democracy, Every-DecentMan. So he is likely to seem a rebel (Poetry in New Zealand', 1946, 111). The threat of future internment as a conscientious objector had earlier hung over Baxter's head, constantly brought to his attention through contact with Ginn and Terence, who were both detained in 'defaulter's camps' from 1940-46. Baxter told Ginn that 'You, Terry, and indeed all the rest of them being shut up is a sore spot in my mind when I think of it' $(15 / 11 / 1943$, Spark 280). Later he wrote that the terrors of his adolescence were too overwhelming to face directly, so he had to look 'sideways' at them in order to cope ('Notes' 125). The 'sore spot' provided a reliable source of inspiration, a gap through which creative energy and material could be accessed and shaped, yet the poems were at times bandages covering over this wound, masking the threatening chaos with 'aesthetic patterning'. 'Thoughts by a Conchie Camp' (1944, Spark 487-87), one of the rare references to the circumstances of Terence and Noel Ginn's internment, returns quickly to the familiar symbolic patterning of enclosure and escape, rock and water, with the emphasis on thawing the frozen river of Time. 
Baxter wrote well over 1000 notebook poems during this period, a torrent which reflects the urgent need for healing and to construct mythical meaning out of the chaos of experience. ${ }^{1}$ The notebooks present a wide range of poetic styles and, while the repetition of themes, symbols and settings is striking, over the course of these poems the adolescent Baxter also covers a wide range of 'content'. Aside from the significant technical advancement made through this early practice, the most enduring result was the development of a language of symbol and myth which could transform the experiences - 'spiritual' and otherwise - which threatened to overwhelm him. This desire to write poems also encouraged the development of a focus on certain negative aspects of experience which seemed to consistently lead to poems; in other words, the conditions preceding creation, which then brought forth the poetic voice and the authority of the mythologising self.

Baxter's method of 'shaping and reshaping' poems, 'not to a standard, but till an intuitional dissatisfaction is satisfied' (03/06/1944, Spark 361) reflects the inner quest to find satisfactory answers to the questions which plagued him, as he developed his understanding of the 'central horror'. Another cause for this 'dissatisfaction' may also be indicated by a pithy comment Baxter made to his mother the following year: '.. am not writing just now, no poems, since no need of self-justification. Also it's when they're finished growing for the year that trees make flowers' (01/10/1945, McKay 87). For his practical-minded mother Baxter initially presents the poems dismissively as merely a form of neurotic inner discourse. Yet they are in the same breath likened to 'flowers' indicating an inner growth, as suggested in 'Letter to Noel Ginn' (I) by the image of the 'lion-skin' that is shed after the heart has been 'skewered' by experience, left for 'dullards to

\footnotetext{
${ }^{1}$ See Spark to a Waiting Fuse 72-81 for a discussion of Baxter's notebook poems.
} 
admire' (1944, CP 27-29). The poems are valued to the extent that they are the product of a vital process of death and rebirth. However, a confusion between the various purposes of his art, whether for aesthetic appreciation or to communicate 'understanding', may explain Baxter's persistently ambivalent attitude to his own writing and his unease at this tendency towards 'self-justification', to bandaging over the gaps and harvesting 'flowers' for the admiration of others.

While Baxter's life changed considerably during this period, he continued to utilise the sense of a gap between himself and other people, a space of isolation which was poetically fruitful as well as painful. This distance preserved the elevated barricade of the mythologising self, remaining aloof from the world beyond the palisade, looking inward and backwards:

From this high window I can see the swells

Roll in with their incessant cannonade

Upon that shore where once, a lonely child, I made

My own mythology of weeds and shells

And dreamed I heard from the green water shade

The pealing of sea drowned cathedral bells.

('Letter to Noel Ginn II', 1946-48, CP 70-72)

The sense of isolation, threat and loss continue to coalesce within Baxter's personal mythology, and over time increasingly reflect the sense of despair that no new paradise will emerge to replace the childhood world which has sunk beneath the sea of chaos. Baxter told Ginn of his inclinations towards nihilism, 'a reality in a 
crumbling world where moral and spiritual values often disintegrate under pressure of disruptive brute force' (11/08/1943, Spark 246). In the terms of the mythology, beyond the childhood world of simple innocent joy was merely a 'jewelled dead space of a world awoken' ('Of the Fountain', 1942, Spark 163-64). In reaction to this perceived lack of meaning, he turned increasingly towards the quest for 'eternal refreshment' and a way out of the 'desert' of the solitary adolescent world which seemed to both shield and smother him:

... I, who cannot break

To the well-head I seek, Am closed in the desert-dream ...

During this period of personal and poetic growth Baxter moves through a catalogue of myths and 'figures of the self' in the quest to break out of the desert by reordering and reinterpreting experience. Heroic figures are adapted from classical mythology, with many (such as Aeneas) discarded while other, more ambiguous figures such as Odysseus and Prometheus, become important elements in Baxter's personal mythology. ${ }^{2}$ The pervasive and amorphous 'sense of grief' and the attachment to the notion of 'loss' as a source of creativity, eventually leads to a more explicit and conscious application of the myth of the Fall as an explanation for all ills, the abysmal 'central horror' which in the earlier dream sequence threatened the dreamer with destitution, dissolution and death. Once adopted, this mythic template provided a consistent plot which could be set against experience -giving a

\footnotetext{
${ }^{2}$ See The Snake-Haired Muse, especially chapter two, for Baxter's mythological 'figures of the self'.
} 
mythological meaning to the pervasive grief over the loss of that which 'never was'. Baxter's use of this mythic template began with, and retained, a close association with the seasonal cycle of death and regeneration. Thus the redemptive figure of 'The Lord' gradually emerges as an icon of the centre, leading the way through loss, alienation and dissolution towards rebirth. While this figure is clearly connected to traditional Christian belief, during this period Baxter generally retains a sceptical distance from a formal adherence to Christian mythology, putting 'pale Persephone' ('Resurrection', 1944, Spark 483-86) on par with Christ as one showing the way from a hellish frozen underworld to a spring of renewal.

The emphasis on this mythic paradigm is a reflection that the poems are increasingly seen as the product of 'the night', the dark chaotic world beneath the illusory world of 'perpetual day'. Even within what is nominally a love poem, the emphasis on the process of reforging through dissolution and regeneration is central:

Each man who looks on the night creates or destroys creates and destroys himself therein.

Yet Baxter's engagement with the darkness and chaos remained charged with fear. The gaps tend to remain subordinate to the authority of the mythologising self, with the ordering, poem-writing mind claiming mastery over the depths. The appeal of this sense of authority is demonstrated in Baxter's attitude to both religion and 
psychology, which became tools for the affirmation of the poet's unique insight and status. While working as a farmhand Baxter reported to his mother that he had used his spare time to psychoanalyse himself: 'remembered things that happened before I was 3; even recovered some beautiful bits of fantasy. It is marvellous what comes to the surface when you set off the depth-charges' (15/10/1945, McKay 87).

Another response to this sense of loss is the urgent search for the sacred space of the centre, the mythic place where the fountain of life flows freely. Numerous poems document the unbidden, spontaneous experience of inspiration or transcendence: 'Yet when the rigid sky is rolled / To north or south, sudden and strange is seen / Space fathomless, prayerful' ('Age', 1943, CP 16). Baxter told Ginn that 'my knowledge of God is fundamental for my well-being' (Spark 132). The desire to enter this prayerful space becomes an urgent necessity as 'the capacity for pain increases', and thus the poet's 'knowledge of God' is charted by mapping the mythic territory of experience using the language of religion adapted to the contours of personal mythology. Thus 'The Lord' in 'Of the Fountain' is the answer to the 'desert-dream', a redemptive figure pointing from sterility to the waters of life. This figure can also be seen as an icon of the mythologising self, the wise, godlike creator who is also a 'friend' and saviour guiding the ordinary self towards the 'life we seek', the 'eternal refreshment' which comes forth from the gap in when the sacrificial exchange is made:

Stay! There is a way: by day-sun have I seen it.

Without a word spoke of song, of sonnet,

Stay, the wavering, the earth-known way 
Breaks to heart of all folk;

Slakes fountain-seeking thirst of buried men

Again, again. Where, then?

Without word

Of heart below spider, sun, snow,

The Lord.

In the readings that follow I trace the development of Baxter's personal mythology in relation to the starting points and ordering tools which shape the poems. This process transforms an increasingly broad range of experience from meaningless chaos into meaningful mythology, therefore affirming the authority of the mythologising self.

\section{'Doctrine of Philosophy'}

'Doctrine of Philosophy' (Spark 158-61), which Baxter sent to Noel Ginn in late 1942, mythologises a quest for spiritual renewal which begins with a rejection of prevailing forms of order, clearing space for a return to a more animistic or 'poetic' mode of seeing and being. The urgent need for a 'doctrine' which is both personal and universal leads the poet to mythologise an experience of the centre. However, the notes which Baxter sent to Ginn reveal the extent of the division between writer and (potential) reader, with the poem's instructive intentions smothered in the dense symbolism and tortured syntax which reflect the 'deep obscurity' Ginn had noted in Baxter's poetry. 
The ironic title suggests the inversion of the prevailing hierarchy Baxter identified, which placed logos above mythos. The former mode is dismissed in 'The Closed Picture' (Spark 479-80) because it constructs 'A lawful-lawless cosmos / And irredeemably dead'. This 'dead' cosmos must be brought to life by the vitality shared by the poet, the 'primitive' and the child. Baxter's response to 'our intellectual heritage' and the chaos caused by this way of seeing is thus to 'resolve one's mental and emotional anarchy to anarchism, before attempting to resolve objective anarchy' (Spark 393-94). Baxter told Ginn that

it is no use trying to analyse the incalculable - as best expressed in poetry intellectually ... We analyze the fruit in our crucible and then complain that it is ashes in our mouths: perhaps this is a part of the 'blight' curable even now.

(Spark 394)

Baxter's 'doctrine' is thus derived not from intellectual sources but from the search for magical healing spelled out in the acrostic 'code':

Note: The initial letters of the lines of "Doctrine of Philosophy" spell out this-THERE IS NO HEART IN TIME SAVE SUCH AS WE BID BEAT. This is, in a sense, a key to the poem. ... does give to my somewhat childish mind something of mystery, of discovery.

(Spark 158) 
The 'secret' conveyed by this code was "that "love of life", "joy in living", is the important foundation of existence. No inertly miserable man has ever written good poetry. But this joie-de-vivre is not to be obtained by consciously looking for it. The poems will tell you more than I can' (ibid).

The 'heart in time' must be actively bid to beat through the creative will which echoes 'in time' the shaping will of the creator God outside of time. Though the emphasis here is on the 'joy' which is sought rather than 'horror' or debasement, the quest for a 'foundation of existence' links this early effort at a poetic 'doctrine' to later notions of the centre and source.

The first stanza 'concerns religion in its old forms' and is an attack on the formalism and the 'stone and marble' rigidity of institutional forms of order. Yet the churches who have maintained a separation between earth and 'eternity' are not condemned, rather, these old forms are to be seen as the expression of what the notes call 'a shapeless myth which will eventually be overwhelmed by time - a seadrowned city'.

The second stanza concerns 'the intricacy of science, and the need for greater simplicity'. Rejecting the old forms of spirituality, the modern man is then forced to 'reconcile' the creative and destructive possibilities presented by 'Einstein or radioactive billowing'. These are similarly cast off because of the desire to 'return to the black $\operatorname{tarn}^{3}$ of being', an instinctive rejection which expresses the authority of the fluid depths of inner being and natural instinct over the 'granite rock, intolerant' convictions of the scientist. Faced with the two elaborate systems of knowledge and ordering sketched in these stanzas, Baxter asserts that 'the simpler faith is better'.

\footnotetext{
3 'A small mountain lake, having no significant tributaries' $(O E D)$.
} 
In the third stanza - which 'very much concerns itself with the present day' Baxter mythologises the contemporary world as an arena of chaos. The 'innately restless' modern man overthrows tradition only to find himself left with the 'bare bones of stars that fall upon us' - the skeletal remains of a discarded cosmos: 'we seem to see the universe as a bare and overwhelming waste dwarfing our human concepts'. Thus 'We, the complex ones, are saved by the thought of he (meaning myself) who turns from these spaces to the heart of life'. The slippage of pronouns between the poem and notes here reveals the overlapping of a longed for tribal identity ('we') and the role of prophet ('myself') whose insight is maintained by the gap of isolation. The entire modern world is 'crystallised' into a ship of lost souls who are 'saved by the maxim of the landward sailor' - the desperate plea for salvation which is answered by the secret knowledge of the poet-prophet. The path to renewal is revealed by natural contemplation: 'our old defences are gone, we cannot find solace in a bare universe - let us turn to Nature'.

Thus the transformation of the modern world from chaos into cosmos is only made possible by 'moving with poetical perception', the natural contemplation which looks 'among volcanic rock for a green patch of life'. Meaning and healing are found within the 'lode-rock of a new mission', this discovery is 'something new and marvellous'; all the more so because this space - the 'heart of life' - is 'there to be found all the time', despite the 'storm (war etc.) which threatens our civilization'. This discovery lifts the poet above the world of discord to a godlike perspective, from which the living centre is identified, the 'single lake / Broken where holy martyrs died and Christ was crucified', which Baxter glosses: 'I find momentarily the source of all life - that, perhaps, by a fuller knowledge of which Christ and the holy martyrs were impelled'. This sacred knowledge is the 
foundation of the poet's authority, transforming him into a prophet and saviour: 'Even so would I lead ye, O sea-drowned men!' ${ }^{4}$ The poet's task is now 'to lead those who find themselves in a bare universe to this source of life. For on earth we may find it'. In this disorderly landscape of symbols this involves finding 'the glass wherein is seen / The goal of spirit unseeking, in soul the hill-crowning cairn'. The search is not for the far reaches of the 'atomic' or subatomic universe, but to find the 'lens' which will reveal the sacred within ordinary life.

This poem embodies Baxter's adolescent rejection of the systematic ordering of conventional religion or science in favour of a poetic 'animism'. While he later dismissed this world-view as an illusion, at the time of the poem 'joie-de-vivre' is the explicit goal of his quest. The 'source of life' is discovered here by returning to land rather than diving deep into dissolution. The telescopic lens of natural contemplation allows the poet the privilege of spying from afar and avoiding the need to 'dissolve' in the sea. The poet as redeemer digs until the 'black tarn of being' is merged with the 'single lake' at the still centre of creation. In contrast to the 'Pig Island Letters' sequence, here it is the secret knowledge of the mythologising self, rather than an act of faith in an ostensibly external 'ikon' such as Mary or Christ, which provides access to healing and redemption. By dismissing the old cosmos of conventional religion and rejecting the scattered possibilities of science and rational humanism Baxter creates the space in which to reorder the dead cosmos through 'poetical perception'. This repeatable process is the source of Baxter's messianic fervour; by discovering this connection between natural contemplation and that which is most desired, the poet finds meaning, healing and

\footnotetext{
${ }^{4}$ See also drowned figures in 'Prometheus' ( $C P$ 35), 'Odysseus' (42), 'Winter Morning' (43), 'Evening Ode' (47), 'Poem in Naseby Graveyard' (48-49), 'Songs of the Desert', 4 (56), 10 (59), 11 (60), and 'Virginia Lake' (74).
} 
identity as the one who has uncovered the mystery of how to 'bid the heart to beat' and brought the dead cosmos back to life himself.

\section{'The Mountains'}

The tension surrounding notions of 'integrity' which shapes poems such as 'Beyond the Palisade' (1942, CP 4) is also symbolised by the gap between the rugged, mysterious, threatening inland 'wilderness' and the unjust city. Baxter later told Ginn that 'The Mountains' refers to 'the landscape around Naseby, Central Otago' (16/01/1943, Spark 180), an abandoned gold-mining town. The Baxter family made numerous trips to this area, which made a significant impact on the young poet's imagination, providing the inspiration for several other poems regarding death and integrity, such as 'Poem at Naseby Graveyard'. ${ }^{5}$ In 'What shall we seek for', the heroic poet' has broken free 'from the cave of day', 'burst the globe of reverie / And found the ultimate that is / Beyond a final precipice' (1942, CP 7). 'The Mountains' presents a greater degree of ambivalence in dealing with the 'ultimate', the extreme spiritual and moral considerations which were central to Baxter's poetic vision, suggesting a developing awareness of the internal division which became a reliable source of poetic inspiration. As the severe implications of his quest loom nearer and larger on the horizon the poet (at least theoretically) rejects the high mountains of solitary, romantic exploration in favour of a life lived amongst his fellow men.

\footnotetext{
${ }^{5}$ The poem contains another contemplation of the poet's own memorial: 'For me no sold or rented grave ... Nor false memorial on the spot ... But rather my spent ashes charge / To mingle with the wind at large / Or coffinless, without a name / In the deep sea whence first I came' (1946, CP 4849).
} 
The men alone in the mountain wilderness, 'shut within a whelming bowl of hills / Grow strange', unaccustomed to the world beyond, divided from those 'by the sea' who can only imagine the mountains 'hid vaguely out of sight'. These high-country men are captive to the grandeur and terror of the ageless mountains that 'crouch like tigers' or 'wait / As women wait'. The visitor to this landscape is diminished and challenged even as he seems to be uplifted:

But $\mathrm{O}$ the heart leaps to behold them loom!

A sense as of vast fate rings in the blood. No refuge,

No refuge is there from the flame that reaches

Among familiar things and makes them seem

Trivial, vain.

Amongst the romantic exclamations a sense of unease grows, as the ordinary world of the city is reduced to a charred ruin of insignificant, meaningless 'things'. The mythologising self is here positioned on the other side of this threshold or palisade. The lure of the peaks draws him towards the death of desire, and these heights are emphasised over the depths as the poet's godlike eye 'glances across a gorge to further crags'. Yet the implicit threat of the descent is heard in the stream and the avalanches that 'speak' forcefully. The promised end of desire ${ }^{6}$ is 'a death dearer than freedom or freedom's flags' but one which demands the sacrifice of everything that is known. Thus the poem turns away from the far reaches after these few

${ }^{6}$ See O'Sullivan 13 . 
moments of vision. Rather than retreating from the 'trivial' city to these lofty heights the conflicted poet must 'go to the coastline and mingle with men' since he whom the mountains 'lay their spell upon / Leaves home, leaves kindred' and this is a gap of separation which cannot yet be faced. This characteristic, paradoxical wish to end desire by clutching at the 'outermost fields of vision' is tempered by what the 'range of the telescope's eye' reveals. In this case contemplation appears to take one not to the 'source of life' but simply to its extremities. The threat of what is found means that the poet turns back with a desire to return to the land of the lost and 'drown myself in humanity'. The resolution found by the mythologising self stands in contrast to earlier stances as the 'sea-drowned' city of 'malice manifold' is here a refuge of sorts.

This ongoing internal drama has been transplanted to an external landscape which makes the notions of isolation, retreat, spiritual transcendence and human desire comparatively substantial. The admission of an apparent failure of nerve perhaps also suggests an unease with the earlier disembodied romantic extremism and an implicit statement of independence. McKay notes that 'Baxter glossed his own copy of Beyond the Palisade: "Mountains are mothers"'(83), though later he reappraised this stance in 'At Naseby' $\left(1967, C P\right.$ 388-89). ${ }^{7}$ The mountains as barrier suggests a secondary level of symbolism in which the 'cold threshold land' of the Maniototo is a bare space between two imposing realities - the wilderness of the mountains is in another sense representative of the cold 'heights' of lofty, principled spiritual isolation which loomed ahead. For the divided self this prospect was both appealing and threatening, and here the reality of the challenge is faced with an increased self-

\footnotetext{
7 “"Mountains are mothers" - I wrote / those three words in an MS. / book, beside a new poem, / long ago ... / ... when / the earth and I were much less / compatible / ... I must have been mad! / There are no / mountains here ...'
} 
honesty. The city was 'seadrowned', the place of illusion and triviality, but also the space where a different kind of learning might take place. In this sense, 'The Mountains' points towards the later tension between the desire for romantic retreat and the need to engage with society and be part of a 'tribe'.

\section{'In City Night'}

The 'sad cretin" ${ }^{8}$ who walks the streets of the 'rotten towns' is in contrast to the mythic figure of the 'strong man' in 'Psalm of the Defeated', the one 'whose heart faileth not' in 'the desolate streets of Babylon' though 'the mountains are turned to flame; though the great deep be troubled' (CP 13-14). This man of integrity 'shall abide in faith, and take his path nor rejoicing nor weeping through the night of chaos'. This strength is denied to the inhabitants who 'cry in the streets of our desolate city', clinging to their 'idols', 'broken in the clash of the years' and 'stricken by the snakes of time'. By contrast, 'In City Night' (1944, CP 20-21) suggests what Baxter was searching for as he began to turn towards 'the city' for inspiration as well as 'Nature'. Baxter told Ginn that the poem gives 'traces of things to come' and accordingly in a review of Beyond the Palisade, Ginn praised the poem for its 'sense of the country, an imaginative vision of the community as a whole extending through the range of ordinary experience' (Spark 413-15). Yet the city landscape of this poem is also curiously unpeopled, and Baxter approaches this 'range of ordinary experience' through a series of images and experiences which emphasise the superficiality and fragility of what lies on the surface and the threat

\footnotetext{
8 'Prelude New Zealand' (1943, CP 16-17): ‘...for here / Even our fear, / Our love loses its focus ... unPolynesian, our deaths are near...'. McKay suggests that Maori 'had played little part in the thinking and writing of the earlier Baxter for the simple reason that until his late teens he had never met a Maori' (152).
} 
and promise of what lies beneath. The poem moves from the focus on the individual gap of the first lines - 'this loneliness from lesser loneliness / Sprang' - to the universal plight of the city-dwellers who 'crouch' within the womb / tomb of 'our soul, the City'.

The 'rotten heart' of the town is evident in the trashy market-stalls and the artlessness of the street-entertainments, contrasted with the depth and significance of the natural world. At a distance from the city ('jogging home' afterwards), the poet soothes himself with natural contemplation and is able to redeem and reinterpret these trivialities so that 'they did not carry doom upon their backs':

Ditches and owls and nightglow, broom and briar (As always) symbols making smooth like wax

Vacant mind-surface; then with tongues of fire

Reiterating myth, and amplitude

Of earth for herbal healing of desire.

Nature is here ordered into an arrangement of familiar 'symbols' which provides healing and reaffirms meaning through the sacred pattern of dissolution and regeneration, and thus confirms the authority of the mythologising self. The emptied mind is receptive to inspiration and the message received is the answer the poet craves: that healing is possible and the 'beauty of the earth is sufficient'. This process is threatened by the materialistic philosophy that has been passed down to the younger generation, so that 'floral solitude' is less appealing than 'jazz-bands 
and smart-houses'. Yet the 'slick and gay are not at the foundations'; nor do those who 'desire the quiet meal and fire-light; / And wander in the iron wilderness' make the poet's descent to the depths, dreaming instead of a god to break their night.

Uncharacteristically, here 'forgetting' and ignoring 'sorrow' is the necessary act, the new landscape perhaps inspiring hope for a new start with the sorrows of adolescence left behind. This subjective imprint is suggested by the mountainous figure which must be rejected by the voiceless tribe: if 'we could forget the sorrow, and forget / The parent-god of childhood conversations' then 'were reflected love in the city night'. Thus, the poem suggests, the magical 'joie-de-vivre' could be found within the city as well, so that creative love transforms 'each tower [into] a negress swaying thighs of jet'. This seductive and threatening 'other' makes clear the dual nature of chaos. The feared and desired goddess of sex and death could initiate a transformation, becoming a source of love rather than a figure of apocalyptic fear, and leading the trapped city-dwellers out of their 'limbo havenless'. Baxter has now come to see his own adolescent 'desert' as an intimation of a prevailing modern condition; the personal has become prophetic, and the 'city' is here mythologised as a landscape in which to discover the source of life. Thus the symbols of the night life of the city are gradually incorporated into Baxter's mythology, and a few years after telling Ginn that as a 'colony' New Zealand was not likely to produce poets ${ }^{9}$ he advised any would-be New Zealand writer that 'the deserts and oases of the night life of the town are there for any man to walk in', believing that in this arena could be revealed the fundamental nature of man ( New Zealand Yearbook of the Arts 1946, in Essential 27). This poem provides the first example of the word 'gap' in Baxter's published work: 'the generations, / Too wide

\footnotetext{
${ }^{9}$ See Spark 157.
} 
a gap for surgery to splay'. However Baxter's usage of 'splay' here seems probably unintentionally - to suggest an awareness that all such gaps are created.

\section{'Was it as children?'}

The mythological paradigm of the 'lost land' is prevalent throughout Baxter's notebook poems, where Atlantis and Avalon are as common as Eden, and where Scotland is also the poet's ancient home. ${ }^{10}$ Increasingly, however, it is the 'childhood paradise' which is the subject of grief, a loss which affirms the significance of the Fall. The loss of the 'true Heavens' experience by the child leaves the cosmos a 'jewelled dead world'. The inability to let go of this childhood paradise led to a fixation with the figure of the 'lost child'. As in 'Pig Island Letters (11)', in 'Christmas Poem (for Mrs Hurst Seager)' (1945, CP 36-37) the child is lost in the 'forest' of the adult life, longing for a return to the 'day'

Pray for the children lost

Within a haunted forest

No path for turning back:

Each man and woman.

In searching for re-entry to the child's kingdom, the 'wild lost city of a mother's love', ${ }^{11}$ the poet rejects the concrete present in favour of the sheltered space which once gave the illusion of unity. The notebook poem beginning 'was it as children'

\footnotetext{
${ }^{10}$ Examples of Atlantis are found in 'Resurrection' (1944, Spark 483-86) and 'Letter to Noel Ginn II' (notebook version, Spark 508-10). See also Tennyson's lost land of 'Lyonesse' in 'Tunnel Beach'.

11 'Earth Does at Length' (1946, CP 41).
} 
(1945, Spark 410) condenses this pattern of the imagery, starting from this point of loss which is presented as a universal experience:

Was it as children that we found a cave

In those green fields, and lost our way for ever

From the straight poplar paths that led us home

To childish rest and the child's night of peace?

'Like children lost' the fallen can only grieve 'in iron earth concealed, where the cold river / Of underworld regret runs loud as doom / Mocking with pain the day's remembered face'. These memories are the source of suffering as well as potential illumination, the 'mad mnemonic crows' that torment the Titan Prometheus chained to the rock of the past and unable to face the future. ${ }^{12}$

The recurring symbolism of the underworld river here suggests the Styx, the river that cannot be crossed twice, thus the remembered world is no longer a paradise, but a frozen lifeless underworld. In this poem there is no resolution to this impasse and the dream 'of that rich land' is dismissed as 'childish, vain / Intolerable'; the possibility of transforming 'the stone heart' to the 'rose of peace' is denied. This difficulty in abandoning the 'childhood paradise' could be considered a sign of Baxter's reluctance to leave behind a familiar and reliable source of inspiration. The gap of loss and the emotional impetus of grief had produced hundreds of poems and during this time the nature of merely personal loss had been transformed to a universal truth of human experience. The loss of 'the bay' is now merely an

\footnotetext{
${ }^{12}$ See Muse 58-61.
} 
indication of the greater loss, all the many roads of experience led eventually to 'the bay that never was' $(1946, C P$ 44-45). McKay writes that during this phase of his life Baxter's concentration on the Fall 'rather than on a readily available salvation' led to the development of 'a tragic conception of human nature as flawed. This emphasis, congenial to his temperament, reinforced the melancholy present in his poetry from the beginning' (116). Thus the Christian myth of the Fall was creatively useful in expanding and supporting the significance of the 'grief' which Baxter claimed had always been with him. It seems that the extreme form of this view - that there was 'no meaning but loss' - could not be sustained for long without a balancing hope for restoration. The question driving the poems becomes not why the central horror, but where and how to transform it. Thus the sacred pattern of dissolution and regeneration becomes even more central during the period 1945-48. Rather than an emphasis on the search for vitality and 'joie-de-vivre', the mythologising self affirms the way forward out of the dream and into the adult world through suffering and initiation:

After the long day of hunger

And the night of wrath

I am man, child no longer

And I accept my death.

('Snow', 1945, CP 33-34) 
Contemplation of death becomes a reliable entry point into the state of chaos, where the silencing of the ordinary self leads to the sacred speech of the mythologising self:

Eyes hold like mirrors, ears are hollow shells

Till the wind of annihilation blow upon

Ear and eye, make sorrow plain

The death of speech, the unendurable pain.

('Annales', Spark 481-82)

Thus the poet now has the heroic voyager Odysseus mouth words born out of painful experience: 'Death is more deep than love, death is my spirit now'. This is not an entirely new element in Baxter's work but a shifting in emphasis, so that the 'starting point' for poems is comparatively less often an 'inert' and passive grief and more often an 'act of faith' utilising ordering tools developed through the confrontation with chaos.

\section{'Songs of the Desert'}

'Songs of the Desert' 1 (1946, CP 54) considers the possibility of hope, faith, love, death and peace in turn, finding each to be intricately bound to and transformed by 'the breaking centre' - a pivotal term here, a year before the dream sequence which revolves around the 'central horror'. As in that dream sequence, in this poem the gaps are interpreted as channels for growth, as the means of access to the 
redemptive centre. Throughout this sequence Baxter mythologises the experience of his first significant ongoing relationship. The intensity of the experience and its enduring significance within Baxter's mythology are reflected in the fact that Baxter had the sequence published a decade later in 1957, adding a concluding tribute to the ghost of 'Pyrrha, / Girl of plaited wheat, first / Mentor of love revealed in dying' (CP 62). In that later poem the mythologising self is able with the distance of time to see that the chaos of the 'lion's jaws' devoured his lover too: 'You cried once, "I am drifting, drifting." / Self-pitying, too often drunk, / I did not see your need of comforting'. ${ }^{13}$ In this first poem, however, written eleven years earlier, the significance of the nascent relationship is subordinate to the focus on the 'breaking centre' which brings renewal out of dissolution. This chaotic centre is evocative of Yeats's millennial vision of a centre which 'cannot hold' as well as Eliade's 'rites of the centre'.

In the first stanza, the speaker is isolated from 'my fathers' who 'stare in stone' on the 'blood drenched arena'. The events which engender the poem are given further tension by this sense of being judged by these ancestors watching 'from the amphitheatre of a thousand years'. Baxter's ancestors are mythologised as dour, silent figures who challenge and threaten his identity while reminding him of his calling. The 'arena' may be drenched in blood due to thoughts as well as acts, since this phrase echoes a comment Baxter made to Ginn regarding Hopkins' phrase the 'blight man was born for'

\footnotetext{
${ }^{13}$ The second song begins 'Your heart is the spring / where my army drink / the long feud forgotten/ of the wounded desert' (CP 54-55).
} 
I used to think it was caused by modern living conditions: I begin to think it may be our intellectual heritage. Still, one can with luck sink into a sort of physical placidity, stop thinking, with sex as guiding star. But mind reenters the arena, never content with the purely physical.

(06/01/1945, Spark 393)

Sex and death are placed in opposition in this equation, as are intellection and physical sensation, perennially at odds within the world of fallen experience. These oppositions continued to create tension for Baxter throughout his life, but in this early period of sexual activity they seem to have been connected to the guilt and grief' which he experienced despite attempts to be a 'happy pagan'. The 'blood drenched arena' also suggests the bull-ring in which the Dionysian poet battles with the experiences of life, getting close to chaos in order to bring the vitality of his wounds. In this battle is found the 'spot in the arena', the intersecting space between Heaven, Earth and Hell, a gap which is opened up through the experience of suffering and dissolution. In the very depths of this guilt, grief, suffering and confusion the will is abandoned and at the point of despair is found the response to chaos: 'there is no hope but in the breaking centre'.

In the second stanza the sacred structure of the cathedral is similarly broken, 'rent' by the upheavals noted in 'Doctrine of Philosophy'. Yet in the abandoned ruins of this space of ritual the mythologising self finds a message in the 'carrion on the altar / And paved mosaic where the sea devours. / There is no faith but in the breaking centre'. The gap of transformation is opened where the formal tradition seems absent - what remains is the primitive essence of religion based on access to the sacred centre. 
The third stanza considers the possibility of love which seems to be denied by the weight of grief and suffering. Again the answer is found in the descent to the depths where the centre renews life and transforms death, the sacred pattern embodied by Christ's miraculous love which raises Lazarus

Who shall lead Lazarus from the iron womb of winter

Or raise mansorrow sunk in stony tears?

There is no love but in the breaking centre.

Thus the fourth stanza presents a transformed meaning for death if the act of faith becomes a chosen a way of life.

The tender palm is pierced, the groaning heart a cinder

From which must rise the phoenix crowned with fires.

There is no death but in the breaking centre.

This sacrificial death of the will, an exchange mirroring Christ's self-emptying, is the only death which has meaning. This act grants access to the centre, in which faults are transformed to strengths and blindness to insight:

O broken hands are strong to grasp the thunder.

Blind eyes find out the secret door to enter. 
Sea, earth and sun, lie as the first day found.

There is no peace but in the breaking centre.

The poem builds from the personal context of the first stanza to the prophetic pronouncements which spiral around the 'breaking centre'. All the poet's pressing concerns are here answered by the 'central horror' which becomes the source of meaning, healing and identity, through the role of the prophet who leads the 'seadrowned men' to the 'source of life' but who must himself be broken and sacrificed. That Baxter included this poem as the first of the sequence suggests a conscious attempt to link the experiences of his relationship with a larger mythological perspective. The primacy of the 'breaking centre', established here, suggests that the lessons learnt from the 'first mentor of love revealed in dying' were not limited to romantic relationships. Each of these gaps leads to the centre where transformation may occur, at the expense of the ordinary self. Finding ways back to the lost land did not always involve self-denial, however, and the experience of dissolution and regeneration took many forms. The notion of 'resurrection' in Baxter's mythopoeic thought which goes well beyond narrowly religious connotations to include the quest for sexual initiation and satisfaction. In Baxter's later commentary on 'The Unicorn' (1943, CP 10-11, commentary in Spark 535-39), ${ }^{14}$ he presents a pivotal moment which demonstrates the urgency of this search for escape, placing the muzzle of his father's rifle in his mouth,

having nothing to lose. Then an idea occurred ... "You have never yet loved

${ }^{14}$ See also Muse 61-63. 
a woman. Wait till then, and see if the world changes." So he replaced the gun in its hiding place.

While in this account hope emerged out of the depths of despair, within the terms of the mythology it had typically first arisen from the sea, a transition of allegiance from the gods of childhood to 'Venus', the goddess of erotic love. ${ }^{15}$ Like Odin, the unicorn is driven towards a mysterious and uncertain rebirth, a 'deeper death return beyond the womb', finally reaching the place of transformation:

$\ldots$ see

From the cold surf's futurity

Aphrodite Anadyamone

Arise in birth thou would'st extinction deem:

Arise and bind thee to an iron dream.

Millar notes the correspondences between Baxter's attitudes to sex and death which are both central to 'the search for a way out of the arid adolescent years' (Spark 54).. In this sense, within Baxter's mythology during this period 'women' come to signify the possibility of transformation, through a sexual union of flesh and spirit. This path of 'coherent love' would simultaneously overcome the gap of isolation and heal the gap of alienation by engendering a new life. In 'Let Time be Still' (1946, CP 52-53) the body of the lover provides access to paradise, through an

\footnotetext{
${ }^{15}$ See 'Song of the Years' (1958, CP 158-59) and 'Winter River' (1966, CP 377-78). For a detailed consideration of the significance of Venus, see Muse 68-92.
} 
ecstasy where time and death seem to momentarily be transcended and an alternative Edenic cosmos instituted:

Your mouth was the sun

And green earth under

The rose of your body flowering

Asking and tender

In the timelost season

Of perpetual summer.

In 1968 Baxter wrote of this phase of his life: 'The happy pagan ... is a desperate man, with his head full of fantasies, and his mind and body full of hungers; for his actions do not in fact satisfy his needs. When I ceased to try to be a happy pagan, the problem became different' ('The Pleasures of Middle Age', FC 170-71). Yet 'Tunnel Beach' (1946, CP 53) demonstrates that this 'happy pagan' phase seems to have been questioned from the start. Here sex is associated with death, horror and loss, revealing the truth of the Fall rather than a hope for new life.

... the boughs of flame were seen

Of the first garden and the root

Of graves in your salt mouth and the forehead branded fire.

The trysting lovers achieve only a momentary escape from the hound of 'Time', their reprieve heavily tainted with a renewed awareness of death. Where once he 
had waited for 'an ocean revelation' ('Evening Ode', 1946, CP 47) bringing the possibility of ecstasy, initiation, death and rebirth, in 'Tunnel Beach' the poet finds 'the hour of the hawk, not the hour of the dove'. ${ }^{16}$ As The Snake-Haired Muse indicates (78-80), rather than permanent escape, here Time is only waiting to be 'unleashed', replacing the momentary ecstatic vision that 'drew down the cirrus sky' with desolation, 'no dove' of Venus but the sea of chaos once again breaking on the shore.

\section{'Morning and Evening Calm'}

In 'Morning and Evening Calm' (1947, CP 64-65) the imagery of the sacred centre is more explicitly Christian as Baxter moves further towards a commitment to Christian faith, however rhetorical, using the poem to create out of absence a God worthy of following. This 'knowledge of God' is found in the green Edenic space made fruitful by a 'world-sustaining Will'. This is the centre where 'the Lord' speaks, the space where the unknown God takes form as the inversion of earthly absence and deficiency. This knowledge brings prophetic vision when suffering and sacrifice are accepted: 'O tenderly by Him the heart is broken // and Bartimaeus finds in the All-Seeing / his eyes again, grown younger for his pains'. The blind man healed by Jesus is, like the 'swagger' debating with Mary in the $13^{\text {th }}$ of the 'Pig Island Letters', a destitute figure with an urgent desire for transformation. ${ }^{17}$ In Mark's gospel, Bartimaeus loudly hails Christ and somewhat shamelessly demands a miracle - yet the clarity of his faith leads to the desired response. With these new eyes the mythologising self can see this centre as the source, that 'disparate Love,

\footnotetext{
${ }^{16}$ Horse 51.

${ }^{17}$ Mark 10:46-52.
} 
that else were iron grains / draws meaning from the magnet of His Being'. The poem, which dates from the same period as the dream sequence in chapter four, also presents a spiralling around a mysterious centre. As this mysterious centre of 'meaning', a rhetorically or mythopoeically posited God may also take to 'Himself' the various discordant or 'disparate materials' of personal experience and produce for the faithful a vision of harmony, a crystallisation of one's personal story into a series of interconnected sacred patterns, meeting the imperatives of desire which drive Baxter's quest.

The larger suffering, love and vision revealed in the centre denies the poet's habitual 'self-pity', the purely personal meaning of 'my sorrow and my hunger' is reordered 'with voice of wounds'. The suffering of Christ as the meeting point between man and God is always crucial to Baxter's faith and this is the most common meaning of Christ as an 'ikon' in his mythology. ${ }^{18}$ This suffering provides meaning for the 'bleeding' which preceded this calm when one is 'content in Him to crave no longer'. The 'terrible compassion' of this suffering Christ takes away the blind life which existed beforehand. Thus the mythologising self provides a vision of a God who could claim the space at the centre while remaining defined by the mythologising self - as 'the Lord' presiding over the green garden of Eden and sustaining the world through an ongoing act of creation, as the healer who restores full sight, as the source of love and meaning, and as the sacrificial lamb who gives meaning to human suffering.

The fertile ground of 'destitution' was at the centre of Baxter's movement towards a formal commitment to Christianity as well as his attraction to a 'bohemian'

\footnotetext{
${ }^{18}$ See 'Easter Sonnet' (1945, Spark 505) and 'Credo under the lion-throated sun' (1946, CP 44).
} 
lifestyle. In 'Resurrection' Baxter beseeches Christ to provide the salvation which once the poet felt was his destined role:

Storm devouring storm

In cloudy limbo;

Bodies by steel are torn

Spirits are smoored in snow.

O Christ come thou!

The mythic paradigm of dissolution and regeneration is now explicitly linked to the need for salvation and redemption, an escape from the underworld which is not possible through the heroic will. This 'sickness' belongs to the world as well, crying out for 'the bread of blessing in thy healing hand'. Yet while Baxter becomes increasingly comfortable with the language and symbolism of Christianity, it is the paradigm of dissolution and regeneration which remains the primary reality, above and beyond any early sense of devotion to an 'ikon'. Thus the cry 'from hell' is directed to two figures who both represent this sacred pattern, showing the way to 'make new with leaf and fruit / A green land':

O Christ, as from the crucificial tomb

Come thou; with pale Persephone come ... 


\section{'To My Father'}

In the 1960s Baxter introduced 'To My Father' (1947, CP 65-66) as a poem about 'that split with a parent whom one loves' and 'the wish not to hurt by becoming oneself' when one finally 'leaves home, leaves kindred'. ${ }^{19}$ As shown in the dream material and suggested by similar scenes in Horse (7-10), by 1947 Baxter's relationship with his parents had become strained. This poem represents Baxter's desire to find the space to 'put into words the shape of the world inside me' ('Notes' 150) by severing the 'invincible umbilical cord' (McKay 118) of parental influence which impinged on his sense of personal authority.

The poem begins and ends with an affirmation of a common familial objective, with the gap created by an act of severance inserted between assurances of unity and loyalty. The starting point is the act of contemplation while the poet looks 'at the flowering peach, / The island off the shore and waves that break / Quiet upon the rocks'. This suggests to the younger man that 'we must join forces, you and I, remake / The harbour silted and the city bombed / And all our hopes that lie now fire-entombed'. The task of healing the dismembered spirit and creating a new world is left to poets and pacifists. Yet Baxter goes on to suggest the different paths that they must take towards this goal, contrasting his father's 'country childhood' which helped to make him 'strong, / Ploughing at twelve', with his own upbringing, 'more sheltered and too long / In love with my disease'. Yet Baxter claims that 'illness can / Impart by dint of pain a different kind / Of toughness to the predatory mind', thus suggesting that like Archie he has also been initiated into wisdom through suffering.

19 'Interviews and Readings from James K. Baxter', c.1960s, Stout Centre Literary Archive, (SCRLA); 110. 
The poem emerges out of the tension between Baxter's instincts towards tribal unity and individual freedom and is an act of independence in establishing not only distance but also difference between father and son. Baxter evidently felt that his attachment to his beloved figure had become a hindrance to growth and change. One might further suggest that Baxter's turbulent 'bohemian' lifestyle and the attendant guilt associated with his burgeoning alcoholism are behind this urge for self-justification. The poet implicitly and explicitly contrasts his own weakness with the presence of the mountainous, morally upright figure of his father, hardened and humbled by his suffering, who maintained 'behind slow speech and quiet eye / The rock of passionate integrity'. Archie was a 'poet whom the time betrayed / To action' having apparently 'prayed / That [he] might have a poet for a son'. Baxter's characteristic fierce independence is thus conflicted - as the 'answer' to this prayer he feels responsibility to a man in whom he can find 'no fault', thus being 'tempted / To stay your child'. Yet even the 'light and sympathetic yoke' of a supportive father must now be shaken off if the heroic quest is to progress: 'It is in me that your own true mettle shows; / Nor can we thus be friends till we are foes'.

This distancing is further explained by the admission of the following stanza

This you know well, but it will bear repeating -

Almost you are at times a second self;

Almost at times I feel your heart beating

In my own breast as if there were no gulf

To sever us. And you have seemed then rather

An out-of-time twin brother than a father. 
This is particularly revealing in the light of Baxter's much later comment about a 'second self' contrasted with the perfection of Christ. The high moral and spiritual standards which Baxter seemed to demand of himself are undoubtedly linked to the mountainous significance of Archie as an almost Christ-like icon of integrity, strength and spiritual insight. The figure of the 'twin' - elsewhere used to mythologise an internal division which is both troublesome and fruitful - here suggests a somewhat stifling closeness between father and son.

The younger man has, however, developed ways of seeing and being which differ from his father. Baxter was in revolt against the 'authorities' and in search of a 'free heart and mind', something which required sufficient space and time. As an 'authority' on poetry, spirituality, politics and the struggle for integrity and freedom, Archie was thus himself an obstacle to the poet's growth. From this point Baxter continues to associate his father with the failed dreams of a socialist utopia which marked a major difference between their generations. ${ }^{20}$ Through close contact with labouring men and disillusionment with the state of politics in 1940s New Zealand, Baxter had essentially rejected any earlier hopes for a working man's paradise, as suggested in the words addressed to Noel Ginn:

... it was my dearly held delusion once

That labouring men were better than their betters

And needed only to throw off their fetters

For Eden to return to Adam's sons.

Since then I've worked with them; and they're go-getters

${ }^{20}$ For example 'Elegy at the Year's End' (1953, CP 135) and 'A Family Photograph 1939'. 
Just like the Rev. Fraser ...

('Letter to Noel Ginn II', 1948, CP 70-72)

The weight of his father's past on the poet's own story is perhaps one reason why he has felt the desire to 'cut the past out, like a cancer' and create a gap in which new poems could grow. In this personal mythology, room is needed for the primary figure, the self who both stands above the mythopoeic world and also occupies the central space in the 'arena'. So the poet presents a series of images as a way to remember and preserve the lessons of this other self. Here Archie is the romantic natural man, 'tickling trout', 'quoting Burns and Byron', 'breaking quartz until the mica glistened' and showing the way in to the rock of knowledge. These images are retained as 'changeless' icons 'while my life changes', cementing Archie's mythological meaning as a man 'rooted like a tree in the land's love' and thus isolated from the contemporary urban world which the poet seeks out.

The distance now opened up enables the poet to go beyond, to where his father could not travel:

I shall compare you to the bended bow,

Myself the arrow launched upon the hollow

Resounding air. And I must go

In time, my friend, to where you cannot follow.

It is not love would hope to keep me young,

The arrow rusted and the bow unstrung. 
In their discussion of the figure of Odysseus in Baxter's poetry, Miles, Millar and Davidson point out the recurring image of 'bending the bow'. In this case, the great work of strength and the mark of character belongs to Archie, yet the bow remains poised, waiting for the poetic flight which leaves behind the 'slow', rooted figure (Muse 174-75). The necessary 'chaotic' freedom of this flight of poetic expression is the cause of the gap which the mythologising self creates, just as later the "wives in the kitchen' must be left behind.

Having established just cause for his separation from the 'second self', the poem returns to the unity with which it opened:

We have one aim: to set men free

From fear and custom and the incessant war

Of self with self and city against city -

So they may know the peace that they were born for

And find the earth sufficient ...

Thus the prophetic role of leading the 'seadrowned' to the 'source of life' is yet again affirmed. The fruitfulness which may come from this freedom is associated also with the continuity of the Baxter clan and thus the 'hopes that now lie fireentombed' are to be restored through myth, memory and the single vision which is communicated from father to son: 
And you grandchildren yet to tell

Old tales despite the anger of the guns:

Leisure to stroll and see Him unafraid

Who walked with Adam once in the green shade.

In his desire to continue developing, Baxter increasingly turned from the mountains to the 'near death' in the city, remembering 'the tired faces in the pub / The children who have never grown' ('Haast Pass', 1946, CP 62-63). Thus in contrast to the earnest affirmations of spiritual integrity which buttress 'Beyond the Palisade', the sheltering space and 'spot in the arena' is now often the pub. The lofty aspirations of the mountains can be set aside within the frame of the poem, where the 'green inn' can be either church or tavern, cave or doll's house. In 'Sea Noon' the pub is the object of the quest: 'Where is a house with windows open to the afternoon?' Within this sacred space

One would accept all fates, and even the gold

Melancholy leaves of late autumn

Would seem as natural as a child's toy.

(1946, CP 46)

The thirst for life and the search for the sacred continued to take the poet in new directions while affirming the same underlying patterns shaped by the gaps of loss, alienation and dissolution. The response to these gaps were, however, dependent on that attitude to the 'exchange' which transformed the ordinary self. This internal 
division became creatively fruitful for the poet, either through the use of mythic figures or social 'types' who embodied the fear and resistance of the ordinary self who refuses to face the 'sore spot', denying both the horror and the possibility of the centre.

When Baxter begins to mythologise the 'typical New Zealand products', it is the gaps which he finds, and figures such as the 'Farmhand' (1948, CP 70) and 'Returned Soldier' (1946, CP 42-43) reflect the same experiences of 'wounds' and the confrontation with the horror at 'maelstrom centre'. These New Zealanders have failed to find a way to connect to the living centre positively, and thus they echo the failures of their forefathers, among them Baxter's grandfather, mourned in an 'Elegy for My Father's Father' (1946, CP 51). The title may suggest a deference to Archie's more direct claim to grief, or a similar distancing from the sad figure who 'knew in the hour he died / That his heart had never spoken / In eighty years of days'. In the elevated position of the mythologising self, Baxter provides a redemption for this lost soul, leading him down the familiar path to the source of both life and death.

And the naked thought fell back

To a house by the waterside

And the leaves the wind had shaken

Then for a child's sake:

To the waves all night awake

With the dark mouths of the dead. 
The tongues of water spoke

And his heart was unafraid.

'Song for an Old Soak' (1946-48, CP 76) marks the development of the recurring figure of the aging alcoholic outcast, isolated by this way of life, searching for the spring of life within a landscape of rock and sand. This stubborn man alone begins with an assertion of independence and a questioning of belief in redemption: 'For why should I remember / The unimagined good / The promise of September ...' Yet after a catalogue of loss and suffering comes an admission of the inability to escape from the abyss where 'in the same pit lie / Love, grief, and memory'. Thus the freedom to 'choose' a redemptive vision over one of pointless, self-contained suffering, is implicit in the childish simplicity of the old soak's plea for entrance to the sacred space and a way out of the desert-dream:

Jesus and Mary, make

The springtime come again

Somewhere sometime, or take

The burden of my pain.

I seek the green inn

Where life and death begin.

This is the same landscape of rock and water which defined the early quest poems such as 'Of the Fountain' and 'Doctrine of Philosophy'. Yet the object of desire has 
changed from 'joy in living' to the breaking centre, source of both life and death. On these terms the poet's quest is now for a shelter within the breaking centre.

The 'dramatic role' of the alcoholic poet who 'wore in all weathers a long overcoat buttoned up to the neck' (McKay 98) was an overt expression of Baxter's desire to access the creativity of chaos. Yet increasingly Baxter saw his own drinking as connected to a stubborn refusal to face chaos directly. This tension between various roles, and their relation to his creative and personal needs, persisted throughout the following decade, and beyond. Throughout the external shifts Baxter's quest remained an expression of the underlying creative process which depended on the confrontation with chaos and the application of ordering tools. Thus while the circumstances of his life continued to change, the 'anarchic' freedom and authority of the mythologising self remained integral to this quest. In 1948 Baxter playfully posed for a photograph in front of Christchurch Cathedral with his infamous overcoat turned inside out. ${ }^{21}$ This gesture embodies the attitude which shaped Baxter's engagement with forms of order over the next decade. At the same time as he moves towards 'the city' - now Wellington - and becomes an orthodox Christian, he also continues to affirm his distance from authority and the freedom of the mythologising self. During the course of the next decade, Baxter became an Anglican, a married man, a major figure in New Zealand literature, an educator and a civil servant. Within the terms of his own mythology, however, these various forms of 'authority' continue to be a source of tension and division, incorporated and interpreted in relation to 'the gap'. The poet set on confrontation with chaos remained loyal first and foremost to his own path which required utilising these gap in experience so as to access the conditions preceding creation.

${ }^{21}$ See McKay, 37. 


\section{Chapter Six: 'The time of turning darkness to sober light'}

... night increased under the signal stars.

In the dark bows, facing the flat sea,

Stood one I had not expected, yet knew without surprise

As the Janus made formidable by loveless years.

'Well met,' he said, 'on the terrestrial journey

From chaos into light - what light it is

Contains our peril and purpose, history has not revealed.'

('Crossing Cook Strait', 1947-56, CP 159-60)

This chapter covers the decade from late 1948 to late 1958, when Baxter left New Zealand to travel and live in Asia. During this tumultuous period Baxter struggled with the onset of alcoholism and associated domestic difficulties while engaging in numerous literary endeavours (and conflicts) and publishing two major new collections, The Fallen House (1953) and In Fires of No Return (1958). These titles suggest the shift in Baxter's personal mythology from an emphasis on loss and grief to suffering as an initiation into new life. Yet, having established his literary position with his first two collections, the poems of this period represent a confusion of therapeutic, prophetic and instrumental purposes, and the divided aims 
of the poet, towards both freedom and integrity. In the words of 'the Janus', 'the light' of order would not be revealed through 'history', suggesting Baxter's ongoing search for a mythic 'doctrine' to guide himself through the waters of chaos. During the middle of this period Baxter entered A.A., which marks one of the major turning points of his life. Through the second half of this period his interest in Catholicism deepened, culminating in his conversion in 1958, a period in which he was estranged from his wife for a year.

In a 1954 letter to his mother Baxter inverts the weighted psychological polarities found in Horse, complaining of 'having 2 minds - the one careful, considerate and awake to necessary obligations; the other egotistical, erratic and much at the mercy of feelings'. He lists a number of difficulties, presenting each in mythologised form along the lines of an oppositional split:

... It is difficult to whittle down egotism when one's line of country in art requires a close, even solitary preoccupation with one's own feelings. It is difficult to keep the rules, even the basic ones, when one is concerned often so much more with the 'feel of things' than with the rules. To want to be a good man is one thing; to want to be a good poet is another. I hope they are not incompatible, for if so I may well not make the grade.

(McKay 142)

The 'Janus' Baxter encounters while crossing Cook Strait is the god of doorways, a spirit of the space between, here signifying the difficulty in shutting one door and facing the future. ${ }^{1}$ While much has been made of Baxter's 'Path to Rome',

${ }^{1}$ See Muse 61-65. 
culminating in his conversion to Catholicism at the end of this period, this development can be seen as part of the ongoing evolution of the mythology of the gap where the quest for meaning, healing and identity are driven by an insistent emphasis on absence, division and the threat of dissolution and the mythologising self speaks with the voice of saviour as well as sinner. Conflicting urges - towards freedom and order, Dionysian darkness and sober light - mark this period, yet behind the apparent duplicity, the one consistent factor is the need to transform or escape from the 'ordinary' into another realm or state of being. While the stances of the mythologising self shift notably during this period - often occupying what seem to be conflicting positions from poem to poem - the use of starting points or doors of entry remained consistent, and the journey 'from chaos into light' continued to draw the poet towards 'peril' as well as 'purpose'.

Despite claiming the space of the centre for the honest poet in 'Recent Trends', Baxter continued to distance himself from various authorities, moving towards a more familiar position at the margins. As he had earlier felt the need to create a gap between himself and Archie, during this period Baxter distanced himself from literary 'father figures', especially his erstwhile benefactor Curnow. The 'newer' writers, especially those in the so-called 'Wellington group', engaged in a battle with these elders for critical authority throughout the 1950s. Looking back in 1967, Baxter emphasised the need to reject the mantle laid at his feet and follow his own path:

... I had given a talk at a Writer's Conference in Christchurch; and I remember Curnow congratulating me ... with a paternal warmth that both

${ }^{2}$ See McKay 151-65. 
pleased and troubled me. I felt like an ungrateful Elisha to whom Elijah was trying to donate his prophet's cloak; I had to dodge the offering, even at the cost of ingratitude, because Curnow's road and mine would always be different (in my case, could only remain real by being different); and the close parallel to the difficulties of a father-son relationship can hardly be ignored ... Many of the newer writers, myself included, may have felt too near to Curnow for them to feel safe when treading in his foot-prints. It was psychologically necessary ... to follow an entirely different track ... we have ... cleared a space to develop our own intuitions and our own literary idioms.

('The Broadeners' 5)

During this period the movement towards the margins in often mythologised through the use of the figure of the swagger, hermit, alcoholic or thief, an outsider who is able to perceive both the horror and the possibility within the 'tragic view'. The great thirst of the alcoholic drives him towards the dry creekbed, the desert centre under which the fountain of eternal life, the Lord, waits for his heart to break open. This is a recurring pattern throughout the poetry of these years, which assumes simultaneously the characteristics of personal destitution and abasement and the position of spiritual and moral authority which interprets and advises the fallen man.

The close links between sex and death, death and birth, and the notion of the 'womb' as both prison and refuge continued to define the mythological 'meaning' of Baxter's mythopoeic women as a threatening and fertile 'other'. In 'Crossing Cook Strait' the mysterious spirit appears after the poet fails to conjure a consoling vision of Venus from the waters of the night. Baxter's 'battles with Venus' continued, justified creatively by his belief that the wounds of sexual desire kept him in contact with the snake-haired muse. Baxter's growing devotion to Mary as an 
exemplar and icon of compassion, self-emptying, refuge and intercession extended the existing division of women within his mythology into two basic types.

The emphasis on suffering as the door to redemption is particularly prominent during this period, during which Baxter continued to develop a personal mythic framework utilising Christian forms. The figures of Christ and Mary are either placed alongside or in opposition to the earlier 'pagan' presences, as Baxter attempted to develop a 'unified personal cosmos' which incorporated, but was not limited to, a traditional Christian framework. While Baxter revered Mary in a Christian - and from 1958, specifically Catholic - context, within his mythology she also retained a broader 'archetypal' significance, as the 'Dei Genetrix / goddess prefigured by Isis and Semele' ('Traveller's Litany', 1954, CP 143). In this role as 'birth-giver of God' she is the mother who brings forth new life, the womb of redemption. As the compassionate intercessor for sinners, she is the one who 'dost bruise under thy heel the serpent', diminishing suffering and standing against the poisonous effects of the Fall.

Entry into A.A. was a definitive moment in Baxter's life as well as his mythology ${ }^{3}$. In his own later view, his 'recovery only began when I acquired a total trust in the love of God' ('The Church and the Alcoholic' 20), since

the basis of A.A. spirituality is the recognition of a common destitution that waits for God to transform it into fertile love. Our badges are wounds; our language, ordinary, sincere ... conceals many chasms of light and darkness. Our central belief is that we know at last who we are - alcoholics - people

\footnotetext{
${ }^{3}$ See McKay for a fittingly 'mythic' account of Baxter's cry for help, which included an 'extraordinary' performance of 'The Hound of Heaven' (145-46).
} 
who were created to come to God by the direct road of accepted humiliations. We are able to be joyful.

However there is little evidence of this joy in the poetry of the time, which consistently turns on the need for atonement, to impose judgement or beg for mercy from the God or 'higher power' created to meet the imperatives of desire.

The 'Traveller's Litany' sequence (1954 CP 139-45) demonstrates the recurrent theme of transition. The quest now is not for the source of 'joie-de-vivre', but for deliverance and healing by steering a course between the rocky extremes, guided by icons of spiritual order such as Mary, the beacon in the chaos of the icy firmament, 'stella maris / Star of the tired sailor'.

It is the time of turning

Darkness to sober light

From Scylla's yelping pride

Charybdis' cave of ruin

Equally from the betraying joy

As from the malice of self-loathing

From the lion's mouth, Lord,

Now is the time of turning. 
Yet this ideal of the middle way between extremes, sailing a course which brings together opposites in a harmonious union, is at odds with the well-established habits of the creative process. The framing of these extremes makes clear that the poems continue to emerge out of gaps, from the charged space between rather than the still waters of harmony. The poems, like the life, continue to swing between extremes rather than steering a steady path between them.

\section{'Wellington'}

In 'Wellington'(1949, CP 76-77), one of the first poems Baxter wrote after moving to the capital, the mythologising self holds the city out at arm's length and passes judgement from a familiar perspective. The mythologising process feeds from the negative aspects of this new environment, selecting suitably gloomy details to crystallise a landscape fit for disillusionment and despair rather than the promise of a prodigious noon. ${ }^{4}$ Wellington is condemned as the centre where 'power breeds on power in labyrinthine hives', a fruitless industry which brings forth no new life: ' $O$ sterile whore of a thousand bureaucrats!' The mythologising self is drawn to confront the threat which this new city presents, gaining authority through interpretation, and creating and preserving a gap of dissociation which maintains the poet's cherished sense of 'integrity'. By accentuating these gaps the poet reveals:

... a chasm of sadness behind

\footnotetext{
${ }^{4}$ See the 1962 poem of the same title (CP 263) for a different perspective which simultaneously challenges and reinforces this sense of sterility.
} 
Your formal giggle, when the moon opens

Cold doors in space.

Thus the mythologising self turns to the message communicated from 'the dark hill / Above your broken lights', where 'no crucifix / Entreats, but the gun emplacements overgrown / And the radio masts' huge harp of the wind's grief'. These are signs of a fallen world where chaos prevails behind the facade of a social order and where there is little room for faith.

\section{'Poem in the Matukituki Valley'}

In 'Recent Trends' Baxter demonstrates the split between the city and the wilderness by quoting from 'Poem in the Matukituki Valley' (1949, CP 86-87). Here a retreat from the abysmal drudgery of the city to the spiritual purity of the 'wilderness' remains a tantalising prospect as the poem extends the significance of the mountains as a landscape of threat and possibility. As in 'The Mountains' written five years earlier - the 'half-aware' outsider is gradually filled with awe by this sublime and hostile environment. In this space the land is revealed as 'matrix and destroyer' drawing the natural man to the centre where life and death meet with 'sunset omens' and 'low words heard in branches'. This intimation of death and rebirth leads to the fire of spiritual initiation: 'Do they not, clay in that unearthly furnace, / Endure the hermit's peace / And mindless ecstasy?' This unsettling 'peace' is dependent on the displacement and self-emptying which is implied by the term 'ecstasy'. These intuitions are conveyed through symbolism, the mythologising self inducing the ordinary self into the depths: 


\section{... Blue-lipped crevasse}

And smooth rock chimney straddling - a communion

With what eludes our net - Leviathan

Stirring to ocean birth our inland waters?

Entering this space is an act of faith which provides the possibility of 'communion' as the strange embryo is once again born out of the deep waters of chaos. Thus the mountainous landscape is the 'flawed mirror' of the unknown creator God 'who gave the mountain strength / And dwells in holy calm, undying freshness'. The 'world-sustaining will' at the centre of this creative process is in a limited way available to those who can give themselves to the 'deathly summits', sacrificing the ordinary self. Yet because of the threat involved in this process God's challenge seems sinister, death hidden in the avalanche which 'shakes the rough moraine with giant laughter'. As in 'The Mountains' this poem concludes with a denial of this terrifying invocation, though now the poet's broader focus presents the denial as a sign of universal human weakness in the face of the ultimate: 'Therefore we turn, hiding our soul's dullness / From that too blinding glass'. The imagery of the 'glass' is here symbolic of a burning clarity at the centre of man's existence, where the depths of being share ground with the creator. ${ }^{5}$ Rather than facing this brightness, 'we' turn to

... the gentle

Dark of the human daydream, child and wife,

\footnotetext{
${ }^{5}$ See 'The Glass Door' (1950, CP 96-97).
} 
... the lawful city

Where man may live, and no wild trespass

Of what's eternal shake his grave of time.

In this poem, the 'romantic' retreat again serves to heighten the sense of division between the city and the wilderness, the natural man and the 'bourgeois family man' Baxter feared he could become now that he was one of those 'in the lawful city' with 'child and wife'. Within his poetry, at least, Baxter seems to have responded to this division by developing the figure of the hermit, the unsophisticated swagger or loner on the outskirts of society who suffers the gap of alienation as the price of some primal crime or as the necessary sacrifice in exchange for 'what's eternal'.

Baxter's fear of a 'deathly' life in the city contributed to his ongoing fascination and identification with this figure. In 'The Hermit' (1949, CP 80), the man alone on his deathbed faces the mystery of the self and the possibility of God in the space cleared by retreat to the wilderness. In this hollowed out state, he returns to the 'worn bible page' telling the familiar story of Lazarus. This ordinary man is bid to come forth from the grave so that others may know that Christ is 'the Resurrection and the Life'; the doorway to eternity. In this dismembered and deathly state, the hermit's 'heart like wax in God's meridian blaze / His body shaken like a burnt-out husk - / Praises that Love who wakened him to weep' with Lazarus 'drawn vertiginous' from the grave. Implicit in this death is the quest for the 'eternal refreshment' of the fountain of life. In 'The Ballad of Lazarus' (1949, CP 78-79), which precedes this poem, Lazarus is brought forth from 'paradise' not for himself 
'but for the sake of men to see ... My heavenly Father dwells in me'. This is the exercise of 'choice of belief' which is able to bring forth that which is lacking in the world, the eternal refreshment promised by Christ who says that those who believe 'will live, even though they die'.

In the ballad, Lazarus is analogous to the family man who buries himself within the 'human daydream', reluctant to face the call of another life beyond the 'veil' and become a walking testament to Christ's power over spiritual death. The abandonment to this other life is, however, accepted by the hollowed out hermit, already edging through the door and willing to go with the wind and water "when a wave takes him' or the 'cold / March gales' blow him through the gateway of the grave, his soul released 'to that river where none grow old'. The outsider on the fringes of society remained for Baxter uniquely able to occupy the fruitful space between the alternating values of life and death.

\section{'Wild Bees'}

The gap of loss remains the predominant feature of Baxter's mythology during this phase, as the new life in the city fails to match the perfection imagined through the mythic screen of memory. In 'Wild Bees' (1941-49, CP 82-83) the memory of a comically inept attempt at 'smoking out' a hive is used to highlight the universal significance of personal loss. The bees are symbols of 'passionless industry', a natural fruitfulness shared by the boy 'drifting / In a rented boat' in a summer world, feeding from the secret messages communicated by the bees 'clustering black at the crevice/ Of a rotten cabbage tree, where their hive was hidden low'. The search for an external source of 'gold' marks a transition, a turning point when 
the 'city of instinctive wisdom' is exchanged for a misguided and fruitless quest. Thus the attack on the hive - a 'job well botched', the boys stung and the 'maimed bees groaning' left dead or homeless - is a betrayal as well as a failure: 'little enough their gold, and slight our joy'. There is an undertone of Baxterian humour in the sense of a mock tragedy - in reworking the 'gauche' version written at fifteen ${ }^{6}$ Baxter distances himself somewhat from the melodramatic tone of the original: ' $O$ it was Carthage under the Roman torches, / Or loud with flames and falling timber, Troy!' Yet the essential message is unchanged, and in this rewritten version the twenty-three-year-old poet shapes towards the 'perfect round', drawing out and hammering home the lesson which is now consistently the starting point for his poems: that 'loss' is fundamental to human experience and the centre of human meaning. The 'loss' is equated with that which is desired, the ordinary experience of loss becomes an indicator of the 'larger loss':

Fallen then the city of instinctive wisdom.

Tragedy is written distinct and small:

A hive burned on a cool night in summer.

But loss is a precious stone to me, a nectar

Distilled in time, preaching the truth of winter

To the fallen heart that does not cease to fall.

\footnotetext{
${ }^{6}$ See 'The Bees' (Spark 302-03). Baxter told Ginn in 1943 that the earlier poem was 'not bad, rather gauche maybe' (301).
} 
The messages are 'written' for those who are able to perceive the pattern through the lenses of myth and memory and stamped thoroughly onto the final shape of the poem.

\section{'The Fallen House'}

The search for a space which could be secured and maintained was driven by the pervasive sense of grief at that which had been lost and the irrevocable and ongoing effects of the Fall. In 'The Fallen House' (1950, CP 97-98) the journey in search of meaning and healing - and therefore poems - takes the poet up 'the clay track leading / From Black Bridge to Duffy's farm', the area once the site of Baxter's great grand-uncle Duncan McColl's farm (Jones 68). This rural arcadia is also the setting for 'The First Forgotten' (1944, CP 30-31) and 'The Doll' (1950, CP 91), where a 'certain ageing man of my own blood' listens to 'the sound of bees / Contented' and ponders 'his near death' with 'that tale of Samson's youth' in mind, 'when the dead lion's bone brought honey forth'. This gentle soul - also reminiscent of Archie - is stirred by some mysterious 'fond myth, ancestral memory' to place a carved doll as a 'guard' and 'visible sign of mana' on a post by 'the garden orchard ... now ruinous with bramble'. In 'The Fallen House', however, the poet is careful to maintain distance and proceed on a different path, 'in no forefather's footmark treading', with the hope of remaining 'free ... from any harm' which might come from time's warping of 'a once-fair steading'. In a storm he finds a sheltering space 'in a grove ... of gums ... whose roots had drained the turf / Of life till a starved soil sickened'. Beyond any tribal fault or modern lack, however, 'an older grief spoke plainly' here of a larger loss. This 'voice' issues 'from the green mound' and the 'sprawled stones fire-blackened', the space where 
once the ancestral 'house stood / Stands ragged thistle only'. The 'wraith of dead joy haunted' this place, a refuge once where 'the murk was cloven / By hearthlight fondly flaring within: / Adamant seemed their hope and haven'. Even this simple vision is unable to endure and thus the 'precious stone' of loss is woken again, reminding the mythologising self of another 'ancestral memory' and the home that never was.

This disinheritance plot shapes past experience in 'Never No More' (1952, CP 12122), where the truth of 'winter' is gradually revealed and the summer world of childhood is forever lost

A hamstrung heart and no way back:

Like a toi-toi arrow shot in the air

Never no more never no more.

Baxter attempts to translate this masculine experience of 'disinheritance' to the figure of the 'Mill Girl' (1952 CP 120-21) 'fresh as paint in the flower of her sixteenth year'. Her desire for transformation is both child-like and piteously humble, she waits for 'Mr Right' to lead her 'into a world lovely as fishes, / Secret as starlight', from the 'stagnant slum ... to a table at the Grand'. Yet this passage into adulthood involves another form of 'disgrace' as she 'loses what none can keep'. This passive and voiceless female figure is all too obviously a mere tool for Baxter's own mythos, the 'meaning' of her life strictly controlled by the ordering of the mythologising self. In this plot there is no possibility of reversing the pattern, only escaping into a different landscape of loss. In 'The Homecoming' (1952, CP 
121) a modern Odysseus comes 'home, to the gully farm' and 'his mother, grief's Penelope'. This place is also a prison, 'the sour ground that nurtured a boy's / Dream of freedom'. This enclosed space offers no refuge, 'the quiet maelstrom spinning / In the circle of their days' holds them together in a desperate bind. This typical Baxterian mother has nothing else to live for but a childish dream of innocence, still wishing to carry her son

... folded within her, shut from the wild and many

Voices of life's combat, in the cage of beginning;

She counts it natural that he should never marry.

Like the earlier returned soldier figures, this man bends his will to the horrific normality epitomised by 'the bleating ewe' and the 'sale day drink', taking the 'smell of saddle leather' as his 'sacrament', a submission of the will to an unloved rider. Against this false order however, Odysseus 'yet hears beyond sparse fields / On reef and cave the sea's hexameter beating' and the siren call of another 'womb'. Now, however, the sea of chaos and rebirth offers no release, in time only returning him to this prison.

\section{'The Dark Side'}

Baxter's address to the 1951 Writers' Conference reframed the parameters of his mythopoeic quest in terms of integrity, authority and healing. He told the gathered writers that 
We are ... in the midst of great calamity, physical and spiritual. The ... writer who turns his eyes from the fact of human suffering is involved in selfbetrayal. We have greater need of prophets than we have of mechanics. Yet to submit one's mind to an inadequate doctrine of morals and politics is equally maiming.

'The Dark Side' (1951, CP 117-18) reflects the urgency of this quest for an adequate doctrine or world-view within which one might also maintain integrity and freedom. The poem mythologises a lifelong battle against 'impassive chaos', which sees the hapless subject shifting through a range of positions and perspectives without being able to overcome the enduring, shapeless 'horror' that is 'learnt early'. The 'child lying / Awake in heavy darkness' is able to discern the moment when an ordinary object changes from 'thing to daemon' and the mind torments itself, the 'electric charge' of chaos reshaping the ordinary into a threatening horror. Rather than disappearing with the acquisition of the rational lens, this struggle merely evolves over time:

Later his mind, a matchstick Hamlet, makes

A verbal barricade, a cold prism

That love alone or the brute nightmare breaks -

Upon the grave of savage animism

He builds that glassy tower not flawed by schism

That Science loves ... 
The 'cold prism' of this rational ordering is not able to effectively replace the primitive ordering of 'savage animism', and the 'verbal barricade' is a palisade always susceptible to the threatening forces of love and the 'brute nightmare' of life's recurring horrors. The knowledge attained in 'that glassy tower' provides the sense of solidity and a rational mythos which seems to offer a mastery over the mysterious energies of creation, drawing 'lightning down to fill a Leyden jar'. However, this artificial order inevitably fails, 'the fabric frays' and once again threatens to reveal the horror lurking beneath the surface. Turning to theology, he 'sees the hostile night outside / His lighted window' and embraces 'an antique cosmology'. Finally he gives up his struggle: 'Thought fails: the grave is wide; / Impassive Chaos claims him as a bride'. At this point his only remaining strategy is to abandon 'the mask of civil day' entirely under the threat of the 'ghostly enemy ... Mahu, strangler of souls', desperately praying to the Lord for help out of the fertile ground of destitution.

This poem presents a characteristic rejection of various 'objective' modes of ordering, which effectively leaves space the reassertion of personal authority. While the religious aspects of Baxter's quest for transformative ordering led to a renewed interest in finding an adequate doctrine, this search seems to have been continually halted by the need to preserve this space, in which the poet could 'make a free and entire response to the world in which he lives' ('Mask' 50). The search continued for an effective mythos which did not depend on a stifling logos, and for the means to balance freedom and order also informed his creative approach. ${ }^{7}$

'Bar Room Elegy' (1951 CP 119) demonstrates the association between the 'inn' and the chaos of the ginungagap, reflecting the conflicting personal and poetic ${ }^{7}$ See 'The Book of Hours'(1952, CP 122-23) and 'Letter to Piers Plowman' (1952, CP 125-26). 
imperatives characteristic of this period. The poet utilises the pub as the starting point, the cave of birth and death which allows him the opportunity to face chaos and return to the ordinary world with mythopoeic order reaffirmed. To enter the pub is to step into 'the heart's cage / Ornamented with wishes', where man's desires are distorted and grief and horror seem momentarily absent. Yet the divided and haunted self cannot be transformed and no 'Bacchic rite delivers / Us ... from the white tooth of the dog'. In this arena where the 'twelve great rivers' flow out of Eden (as from the ginungagap), the 'Flaming and the Oblivious are best known'; the rivers of underworld suffering and forgetfulness. Here the ‘wise barman' avoids the poet's mirror where the image of 'Disgrace' threatens the lone sailor riding the waves of chaos. In this underworld the hypocritical 'literati live as parrots caw / With brandy voices while love's colours fade' with no sign of Christ, 'the one beloved Face'. This limbo is a womb which cannot bring forth new life, a shelter where the tiger of suffering still prowls despite his 'wounded paw'. The meaning of this place is also 'loss', a 'garden' claimed by the 'evergrowing brambles' in which 'Anthropoid Adam mourns his lost estate'.

In 'The World of the Creative Artist' (1955) Baxter wrote that he had abandoned the earlier, childish belief in the magical effect of poetry:

... there is no magic, only the look of recognition between living creatures in their weakness and suffering, and the voice of intercession which speaks for all men through the mouth of one man ... 
Thus the poet expresses the 'destructive forces at work in the microcosm of personality and the macrocosm of collective civilisation' and brings forth 'not only the destructive but also the healing powers' of the fallen self (184). In this effort to 'make a free and entire response to the world in which he lives' however, the 'demonic' aspect of freedom continued to open the doorway to a 'tragic' destiny'. This problem of freedom and order continued to plague Baxter, and in 1971 he looked back at his 'tragic' difficulties with the perspective created by time:

At a certain point for one's own personal benefit one may have to smash the mirror. I remember when I was coming off the grog - it was in third-stage alcoholism - and I was writing some very, very good poems, I knew, which were of a negative, death-seeking kind (there were one or two that were really good, 'Lament for Barney Flanagan', I think, is one of them...) but I realised that if I came off the grog and made a change in my life-style then my poetic mirrors would be shattered. And it did happen. For three or four years I was writing bad verse ... because I was reforming my life. But I think the life morally has to have priority over the work

('Interview' 244)

In 'Lament for Barney Flanagan' (1953 CP 136-37) Baxter's romantic view of the Irish Catholic alcoholic ${ }^{8}$ shapes the figure of the wise barman into an exemplary figure. In the figure of Flanagan - based on Baxter's recently deceased friend 'Fitz' - the poet mythologises a counterpoint to the fearful Andrew Crummock, with his severe and loveless 'Thoughts of a Dying Calvinist' (1950 CP 94-95). As the

\footnotetext{
${ }^{8}$ See 'Literature and Belief' 45.

${ }^{9}$ See 'Song of Tinbum Kelly' (1954, CP 137), 'Pig Island Letters' 9 (1963, CP 282) and 'Fitz Drives Home the Spigot' (1966, CP 375).
} 
guardian of the pub who holds the door open, Flanagan is loved by all who enter this masculine refuge, and the poet responds to his passing by shaping this mythic account of a deeply flawed hero whose death unites every sector of society. In contrast to the Calvinist, this flawed yet honest man will gain entrance into paradise (after 'a hundred masses') because in this cosmos the Lord, like the mythologising self, must not 'despise ... the work of Thine own hands'.

\section{'Perseus'}

'Perseus' (1952 CP 129-30) details a different type of struggle in the depths, a reshaping of the heroic quest as an affirmation of the poet's 'mirror-work'. The half-mortal hero gladly leaves the 'children of the Sun' behind, disdainful of 'their perpetual / Unwearying dance about the ancient Tree' of custom. Baxter focuses on the final stage of Perseus's quest, overlooking the arduous process of acquiring the tools to confront Medusa, the 'child of derisive Chaos / And hateful Night, whom no man may / Look on and live'. As the mythologising self already has these tools at his disposal, the hero enters 'the stone kingdom where no life / Started, but brackish water fell / Like tears'. In this realm of darkness the hero approaches the central horror, found 'by the final cleft precipitous / At a blind gorge's end' where he waits to trap the gorgon. With his 'shield of art' acting as mirror and protection, Perseus is able to face this chaos at one remove, striking a death blow to this snakegarlanded 'image of the soul's despair'. Once this target is struck there remains only an empty cave, a pitiful and monstrous corpse and the uneventful return with 'pouched Despair at his girdle hanging'. Having returned from the centre and the moment of art which staves off chaos, the hero, like the poet, renders back to the gods their borrowed tools, becoming a mere mortal again in the ordinary world. The 
'snake-haired Muse' of chaos is 'defeated' by the artful ordering of the heroic poet who gets as close as possible to the central horror.

\section{'Questions Propounded by the Blind'}

The desire to do away with the ordinary or sinful self continued to drive the extremities within Baxter's poems. During this period the hope for a moral transformation remained strong, even as the poem-writing habit continued to feed off the chaotic experiences and emotions produced by the 'rumbustious', and rebellious elements in his personality. In 'Thief and Samaritan' (1954 CP 138) one who is 'fallen among thieves' is addressed by another figure, a 'friend' giving voice to the mythologising self standing above the chaos of this life and offering 'hope of a bright inn, Love's oil and wine'. ${ }^{11}$ The self-deception, the easy dishonesties and the evasiveness of the thief are challenged, 'always we say another hand drives / Home the knife'. The wise friend shares 'one greasy cloth of comfort ... Nailed at the crossroad' from his own struggle: that suffering is universal and 'Your night I too could not endure'. Suffering provides an entrance, an initiation into the truth of dissolution and a gateway to the 'greater I' when the thief is stripped of 'the doublebreasted suit / That left no cold out', finding the personal apocalypse which is the doorway to the paradise promised by Christ on the cross. The pub becomes a sacred space when 'by falling stars' Love comes, 'with ointment for our deadly wound' and carries him 'up the steep inn stairs'. The mythologising self advises the thief against repaying this merciful love with theft, remembering the code which has been revealed, and that as there is no escape from this 'divine justice'.

\footnotetext{
${ }^{10}$ See 'The Bad Young Man' (1951 CP 118-19).

${ }^{11}$ 'We are the robbers [in our] retreat from Divine Justice' (CP 626).
} 
Search well the wound, friend: know to the quick

What pain is. Thieves are taught only by pain.

And when, no longer sick,

You sit at table in the bright inn,

Remembering that pain you may sing small, dine

On a little bread, less wine.

These poems dramatising the divided self reveal the difficulty the mythologising poet faces in accepting the position of humility and releasing authority over this personal 'plot'. The extreme internal divisions highlighted during the 'drying out' process at times gave rise to a hysterical tone, reflected in the chaotic notebook version of 'Canticle of the Desert' (1954, N 17.98), ${ }^{12}$ which is initially addressed to the 'idiot' self who asks the questions

... propounded by the blind

To ease their blindness:

Are we indeed ourselves?

Can we choose other than we choose?

Love, why hast thou forsaken us?

The poem is a striking example of the process of internal dialogue, revealing the tensions between the creative, therapeutic and spiritual imperatives which drive

${ }^{12}$ Also in Poetry Yearbook, 1955. 
Baxter's mythologising. In the wilderness of this desert, the ordering process descends into a tortuous and often incoherent argument between competing voices, embodying the 'infinite ... search / For maimed identity'. The mythologising self tries to gain dominance over a chaotic chorus, asking the voices 'of those in ruined Babel': 'Now shall there be speech between us?' In this tower of pride and grief is heard 'one true word, Alas!'. With no ordering centre 'The sleek believers and the makebelievers / The god-makers and the god-breakers' overwhelm the mythologising self: 'Till we have learned the silence / How shall we learn speech?' Yet clearly silence, acceptance and the acknowledgement of weakness did not come easily for Baxter. These personal experiences are continually universalised as gaps encountered by all: the shared 'delusion ... of the thirsty'; the young walking 'in terror and desire / A wild and fruitful garden. Now, however, the voice of the mythologising self seeks to break open even the sanctuary of the poem-writing habit:

Fellow-demoniac.

I will be plain with you.

These bandages can heal no wound.

The mythologising self attempts to create distance from the false self, the 'young man of talent and no assigned income', lured by 'the security of the Civil Service', who 'Obsessed by matters of the utmost gravity / Between the pub and lecture room, / Will dream of prophecy'. Instead of prophetic truth, however, this guiding voice tells the chaotic cast that 'we are come to the desert ... To be healed of a false 
heart and a lying tongue'. This is the road of purgation that brings one to the horrifying centre where 'the soul must meet / That face behind the manifold delusion', the 'minotaur ... with lion's jaws ... the Questioner'. This is the dark face of God, the horror at the centre of the ordinary self's nightmare, a terrifying beast with a 'worn chaotic face' who 'Questions by silence with a dusty yawn':

'Are you indeed yourself?

What choice is meaningful?

Have you the right to speak in love's name? ...

This (rather confused) oracle states that 'you are myth', though it will 'grant you your status' as a 'meaningful' myth because 'the vertigo of will / And terror of imagined adversaries' gives emotional truth. This voice occupies the space between chaos and mythos, where the wisdom of the underworld is translated into the true speech through symbol and myth:

'I do not speak from knowledge, for I am the Void

Between the stars, the night of history.

These truths I gather from the dog Anubis

Between the ebb and rising of the tide'. 
The layers of voice and visionary authority here suggest Baxter's difficulties in attempting to reconcile the long-established function of his poetry as self-guidance (and 'self-justification') with the burgeoning desire for a more meaningful spiritual authority and effective ordering tools. Yet always the poet retained the urge to translate the silence so that 'love's voices' could speak 'darkly and obscurely' from out of the depths of the secret 'recess'. The penitential poet, attempting to correct himself of old habits, cannot bring himself to believe that silence is the answer. Rather, the mythologising habit is presented as a lesser, yet still meaningful form of truth and authority:

All that I have done and said

All I have said and done

Is to hold up at day's first light

A smoking candle to the sun.

\section{'At Akitio'}

'At Akitio' (1957, CP 184-85) dates from Baxter's period of separation from Jacquie, which his verse only looks at 'sideways'. ${ }^{13}$ The specific experience of loss and tension is made 'universal' through the mythic paradigm of dissolution and regeneration, thus providing that which is most urgently needed - in this case, hope. The voice of the mythologising self urges those 'who have lost / Lover or friend' to 'consider this barbarian coast' in their search for consolation. In such moments of

13 'The Watch' (1963, CP 274-75) mentions events 'that bad year when we were both apart'. 
grief, a bare coast such as Akitio can seem a place which 'has never made / Anything out of anything', a barren wilderness where one must draw from 'bitter springs'. The poet must dig deeper to find what is desired, much like the woman 'fishing at river mouth' who uses 'the sea-drilled stone her mother used / For sinker'. This stone has been worn by nature, time and use until - like the poet's tool of natural contemplation - it provides nourishment 'as big kahawai come' while 'tides press upward to time's source'. This 'native' ability to follow the tides of time and nature is contrasted with the landowner who once 'built / An ethos of the leisured life', striving to bridge the gap from the homeland through the outward forms of 'Lawn, antlered hall and billiard room, / Glass candelabra brought from Paris'. This vain endeavour brought forth nothing but ruin, 'unhorsed' these lost men now 'sleep' having passed on nothing, 'the homestead foundered among fields'. Awareness of death and loss saves the traveller from a similar fate, and the voice of the mythologising self swells with the knowledge of the fruitful night, the fountain now suggesting the path Baxter would forge in his last years:

\author{
As tributary of a greater stream \\ Your single grief enlarges now \\ The voice of night in kumara gardens, \\ Prayer of the bush pigeon.
}

The world thus reshaped, the traveller may finally drink 'at these pure springs'. This consolation, however, relies upon an awareness of the ongoing 'threat' of chaos, staying close to the wound and the darkness and remembering 'the early strength / 
Of bull-voiced water' which can destroy the cherished 'shapes of man, / Emblems of our short fever'. Despair and separation are translated into spiritual sustenance, a hard-won knowledge which has come through the processes of art and contemplation on the path to the spring of life:

Pluck then from ledges of the sea

Crayfish for the sack. Not now but later

Think what you were born for. Drink,

Child, at the springs of sleep.

\section{'The Breadboard'}

The fear of literary 'self-betrayal' may explain the series of mildly irreverent parodies of other New Zealand poets which Baxter wrote in 1956, while still struggling to twist the Muse's arm. He did not spare himself from this mockery in 'The Breadboard' ( $C P$ 173), giving, as McKay says, 'a fair inventory of his preoccupations up to 1957: ancestors, Original Sin, death, sex, grief, and the need for love' (155). Here Baxter mimics the orotund voice of ponderous rhetoric which had become his poetic signature. The preaching tendency is skewered by the hypocrisy of the poet - 'love alone / Can soothe' loss, though this is easily confused with sex 'when warm in bed' lies his lover and 'her breadboard thighs'. Drink, like sex or 'even porridge scarcely has the power / To fill the void within, the spirit's hunger'. The habitual strains of loss and longing overtake the romantic poet and overwhelm what Curnow would have called the 'local and specific' reality prior to the poem: 
Perhaps I should have written somewhat more

About the breadboard, but my heart is sore

For other reasons; and I save my breath

To blow my porridge cool, though in the gates of death.

In mocking the excesses of his own rhetorical style, Baxter is suggesting that other poets and their poetry are also best taken, like porridge, with a few grains of salt. While the rhetorical excess remained a feature of Baxter's poems, his intention moved towards a more grounded approach which stayed close to the wound, the darkness, and the testaments of rock and sand. Despite the admission of 'subconscious dishonesties' here, one might argue that this parody also represents an attempt to retain authority over his poetry by standing above it and taking up this critical position himself.

\section{'Song of the Years'}

In 'Song of the Years' (1958, CP 188-89) Baxter attempts to reframe the voice of the mythologising self as an instrument of praise, relinquishing authority to the King. This simple plot charts a pilgrim's progress towards the triumphant conclusion which marks entry into a new eternal life. Yet the 'glory' of the conclusion is dependent on the structured negation of the self, with the mythologising self seemingly wrestling itself into submission to make space for a new 'king'.

The song begins with another mythical account of birth and a wry acknowledgement that from the beginning 'Disputandum was my name'. This born 
outsider could not accept any other authority, but 'Weeping hoping threatening / Beyond myself I had no king'. The misguided child is drawn further away from the centre towards desire and pride: 'When my childhood days were spent / To Venus I grew suppliant'. This proud thief was in thrall to 'created beauty' while 'singing on the gallows cart'. ${ }^{14}$ The true self remained locked in a prison of the spirit by the aardvark's hunger and the onager's stubbornness, ${ }^{15}$ unable to escape despite the 'tremors' which 'woke and died / Within the mountain of my pride'. Release from this prison is mythologised as a sudden turning, rather than the gradual evolution documented in the poems of the previous decade. Within 'that deep den the King of bliss / Broke my heart and gave me his'. The tomb becomes a womb of rebirth when the cry of despair brings forth redemption, the broken centre becomes the green inn. The rebirth of the child is a transformation which comes through the silencing of the ordinary self, rather than the magical authority of the mythologising self, and the new life is marked by an uncharacteristic joy inspired by the Lord: 'This for your doom and penance take / Be merry always for My sake'. This suggests a transformation of identity in a remade world: 'He gave me a white stone to bear / With my true name written there'. The stone of loss has been wakened to love, and the new identity has displaced the old divided self in an ecstatic transformation. The pilgrim's progress seems complete, as the new identity of child/nobody takes over, apparently free from pride, desire and attachment to 'created beauty' and looking only to offer a song of praise: 'Laus tibi, Domine!'. ${ }^{16}$ This is a consoling personal myth of redemption made possible by the rejection of one's weak and lowly self. The thief is the ordinary self, the 'prisoner' is the

\footnotetext{
${ }^{14}$ See also 'Seraphion' (1952 CP 126-27).

15 A division presented in the children's parable 'The Aardvark and the Onager' (Undated) MS $1136 / 007$.

16 'Praise to thee, O Lord, king of eternal glory'. From the Masses for the Dead said during Lent.
} 
suffering natural man freed by symbol, myth and ritual. In this momentary ecstasy of conversion, the integrity of the 'cell' seemed to have been secured by the overpowering embrace of God.

In 1958 Baxter wrote of abandoning this other personality, with the help of the A.A. programme, for the sake of a 'functional' life:

The core of the whole matter seems to me to be that when boozed or recovering from booze I was Jamie(2) a very pathological deadbeat whereas without booze I am Jamie(1) no beauty but functionally sound. As long as I took Jamie(2) seriously as a possible life-form I remained a long way up the beanstalk; only when I realized that Jamie(1) was me, not half-me but all me, did life begin to fall into place. Booze turns us into schizophrenics ... split men.

(McKay 145)

In this view the anarchic 'prisoner' cannot be set free, and his very reality is denied. Baxter's hope that he had found a partial resolution of his problems of identity is revealed in a letter to Roderick Finlayson, written soon after he became a Catholic:

The gas has come out of my air-balloon and I am back on the dry solid earth. This longing to be a somebody has deep roots in my nature: it is a cancer, not a plant. But now the longing to be a nobody, to be lost among the mountains and rivers of the Mass, stands beside it, planted by God - and the two may well wrestle till I die, when, as Yeats tells us, at stroke of midnight God will win ... He made me a Catholic ... [because] ... without conscious continual contact with Him I'd be a lost man; and He knows this 
and will not let me go even when I struggle like a child that wants to leave its mother's arms.

$(12 / 02 / 58$, McKay 161)

The child's resistance to the imprisoning shelter of its 'mother's arms' still threatens the life-giving connection, yet this also remained a fruitful tension in the following years. The paradoxical desire to be 'nobody' became a central focus and a reliable source of poems - over the final years of Baxter's life. This was a 'choice of belief' engendered by urgent necessity rather than certainty. However, despite the longing to be a 'nobody', the mythologising self's desire to be a 'somebody' means that these tools are effectively incorporated into the personal mythology which meets the creator's imperatives of desire. Alcohol could no longer be 'justified' as an effective way to confront chaos, and the dissolution offered by the 'mountains of rivers of the Mass' is framed as a primitive ordering which takes the natural man back 'home'. The insistence on the urgent need for God is a restatement of the fundamental need for 'knowledge of God' proclaimed by the eighteen-year-old, yet added to art and contemplation now are the 'objective' instruments of this knowledge; the traditional rites and rituals of Catholicism. Thus the poet hopes that God is no longer a distant, malevolent force buried in the mountain avalanche, but the Lord of the broken centre whose healing springs from the rituals which embody the sacred patterns. These are terms under which Baxter presents his 'conversion', bowing to the authority of the Church as a means to overcoming an unbearable uncertainty and the horrors of the 'dark side'. In the next phase of his life, however, the habitual dependence on the gaps continued to create tension rather than leading to the protective tranquillity of a 'mother's arms'. 


\title{
Chapter Seven: 'The Cold Hub'
}

\author{
And something bust inside me, like a winter clod \\ Cracked open by the frost. A sense of being at \\ The absolute unmoving hub \\ From which, to which, the intricate roads went.
}

('The Cold Hub' (1961-1962, CP 256-57)

In September 1958 Baxter set off for Asia as the recipient of a UNESCO grant. During the next six months he travelled to Japan, Thailand and India, reuniting with his family while based in Delhi. The introduction to Howrah Bridge (1961) suggests the process of taking stock which followed Baxter's time in India. $\mathrm{He}$ writes that the first part of the book 'was written some time ago by a man who thought he was a New Zealander; the second part, lately, in the past two or three years by a man who had become almost unawares, a member of a bigger, rougher family' (McKay 176).

Baxter continued to work for School Publications on returning to New Zealand, until leaving in 1962 to work as a postman. He published two major collections during this period (Howrah Bridge and Pig Island Letters, 1966) as well as many poems published elsewhere, accounting for over a third of the Collected Poems. 
This creative fertility suggests Baxter's persistent need for the mythologising process 'despite' a more settled personal life.

Baxter took up the Burns Fellowship for 1966 and the family stayed in Dunedin for three years, during which time he wrote a large number of poems as well as numerous plays, articles and lectures. Yet his restlessness and desire for fluidity remained a constant throughout this period, and at the beginning of 1968 a dream triggered the turn towards Jerusalem, which Jacquie later attributed directly to his experiences in India. ${ }^{1}$

Baxter's ongoing sense of a 'dilemma' over his position as a servant of 'Caesar', informed his work on returning to 'exile' in New Zealand. The same patterns of absence and grief, division and conflicting opposites can be found in the poems dealing with social and political matters. ${ }^{3}$ Typically, Baxter's involvement in the 'soap-powder lockout' ${ }^{4}$ is shaped by his own favoured mythic paradigms; the alienation from the means of production is simply an updated version of fallen man's 'dispossession' (McKay 195). In a private note to himself on returning from India, Baxter had written that his own greatest desire was for the spiritual consolations of poverty and a shedding of earthly possessions to make 'space' for God:

to be self-stripped of goods, books, people's approval - these things seem to burn and stifle my soul - chiefly (I believe) in order to give Him greater access to my soul. But He, having implanted this desire (the most powerful I

\footnotetext{
${ }^{1}$ See Millar, 'James K. Baxter's Indian Poems'.

${ }^{2}$ See McKay 191.

3 See 'Spring Song of a Civil Servant' (1959, CP 206), 'Election 1960' (1960, CP 224-25), 'On Reading Yevtushenko' (1962, CP 261), 'The Bureaucrats', (1962, CP 249).

${ }^{4}$ See 'The Strike' (1965, CP 328).
} 
have) forbids me to accomplish it but surrounds me with things to use and people to try to look after. This is where the deepest pain lies. Blessed be His Name!'

('Some Points of Difficulty')

Baxter's stance towards the city, the suburbs and the 'labyrinth' of state continued to reflect such personal imperatives, which provided starting points for poems which rage at the absence of an 'impossible harmony'. In 'Words and Money' (1961, CP 236) the gap is an artificial 'space between' which becomes the site of suffering:

There is a crime. I do not know its name.

A man's work becomes a Persian wheel

Where he goes round and round like a blind camel.

A woman's house becomes her cage

Where she sits barren, plagued by the noonday demon.

Words were made to stand for things

And relations between things,

Where you are a thing and I am a thing and God comes to be called a thing,

Because the words are true. 
These are the chaotic 'western processes of thought' ${ }^{5}$ through which, in Baxter's view:

Words divided from things, money divided from things,

Have made a gap between us and the world

And in that gap our intellects are crucified.

For Baxter, this way of thinking is a further separation mirroring and renewing the effects of the Fall: 'And so we wander like sparks on soot / At the back of the kitchen fire of creation', transformed into 'Small heartless stinging flies / Crucified by words and money'. This awareness requires a new mode to emerge out of the gaps in experience: 'It is a new crime. I don't know what to call it'. Baxter's response to this secular crucifixion was to willingly take up the practice of selfemptying or kenosis as a means to bringing the mythologising self back from the dead. Having 'swallowed the Church's anchor' ('Fellowship' 244), however, Baxter soon found that he did not enter a harmonious sanctuary free from the challenges of ordinary life or the ongoing effects of the Fall. The desire to change the song persisted as 'the hour of death', the opposition to a 'progressively more meaningless' culture, the competing claims of 'the city' and 'the wilderness', and the struggle to be a 'nobody' rather than a 'somebody' all directed the further evolution of the mythology of the gap.

${ }^{5}$ See McKay 167. 


\section{'Howrah Bridge'}

In 'Howrah Bridge' (1958 CP 194) the ubiquitous, visible suffering of 'the huddled bundles lying / In doorways' of the Kolkatta slums brings perspective to the inner torment of the poet 'in the unsleeping night'. The poem is dedicated to Jacquie who is far away 'in Delhi' but who will 'Enter the same room by another door', an acknowledgement that this experience of maelstrom centre is not unique. There is little hope for the poor who 'implore a Marxist cage' to replace the anarchic trampling of the 'rupee god'. The weight of human suffering and desperation embodied by 'Tout and owl-eyed whore' are for the visitor 'Angels of Judgement', icons that 'husk the soul / Till pity, pity only stays'. This awareness of suffering and the shared sense of empathy bridges the gap between the married couple, giving meaning and purpose to past suffering by waking the stone of loss to attempt love: 'Out of my wounds they have made stars: / Each is an eye that looks on you'.

'The Carvers' (1958 CP 195-96) reveals the connection between the search for poetic inspiration and the Holy Spirit that provides 'light in the dark room'. In an Indian town 'of boulders / Under the palmyra trees' the 'patient carvers ... taught us what to be', shaping meaningful forms of 'hewn cloud' and 'blown water' from the unshaped chaos of raw matter. Thus the mythologising self implores the carvers' 'instructor', the 'Dark Spirit ... / For whom our sleepless hungers burn' to 'Shine in the casual labyrinth, / Explode the debris of our lives'. Millar sees the reference to ‘villages of fish and oxen' as symbolising the Christian and Hindu faiths which were both then at the foreground of his thinking, though here 'Baxter continues on past these communities of organised belief until his journey has become a solitary pilgrimage, by a 'steep path and dangerous' to 'the silence of the daimon' ('Baxter's Indian Poems'). This daimon is the dark spirit of the gap, the instructor bringing 
order to the soul through the shaping forces of suffering, like the carver planing away until chaos becomes cosmos. The questions raised by Baxter's interest in Hinduism are formed around these notions of suffering, transformation and dissolution. He goes on to ask whether the 'throne of waiting' taken up by the sadhu 'among the mango-breasted' goddesses is 'ours', or instead the 'great midnight of Aquinas / Lighted by the rivers of the stars?' As Millar suggests, this quest continues beyond cultural forms to the enlightened and elevated position - 'the lion-pillared / Temple pyramid and burnt-out pharos' - from which inspiration can come forth, in exchange for the dissolution experienced while looking at the image of 'Vishnu in his square sea chamber / (Cradle and coffin of the soul)'. In 'Madras' (1958, CP 197) this scene is revisited, where the daimon of inspiration is more decisively spiritual and flavoured by the presence of the Apostle Thomas, the one who doubted Christ, who by local legend is buried nearby:

Always You come without procession,

Dark Spirit sought and found,

Breeze, Tongue and Cloud,

For Whom my barefoot heart hiding

In the mountains of transgression

Thirsts and waits, O royal One,

More-than-Brahma, Light beyond the sun.

On the sea road from Madras You found me,

Led me to the doubting cave, 
The Sitio of true belief,

Wounds not my own imprinted there,

Rain like arrows piercing the grass roofs

By the Apostle's mount and open grave.

This dark spirit emerges to answer 'the Sitio' - Christ's cry of 'I thirst' on the cross. In this severe spiritual landscape, destitution is the both the central horror and the centre of redemption. Thus in 'The Carvers' the mythologising self again takes up a stance of abdication, beseeching the authority from the depths for instruction at all costs: 'Dark Spirit of our disenthronement, / Punish and speak. Our deaths expect you'.

In 'The Ballad of Calvary Street' (1960, CP 213-14) two 'typical New Zealand products' are set in opposition to one another and both found to be overlooking the 'source' of creative love. The poem arises out the gap between the poet and the status quo, the prevailing tension generated by Baxter's hopes for a domestic harmony and his sense of 'the intense inner solitude of the urban New Zealander, mocked by material comfort in a community where most spiritual roads turn out to be blind alleys' (Aspects 41). The poem is constructed around the wholly separated and conflicting opposites which Baxter routinely identifies in New Zealand society. The facade of the suburban idyll where 'bright as blood the roses bloom' is revealed as a thin veil covering over the sense of loss, division and lack of meaning which Baxter habitually locates in the lives of his nameless suburbanites. Here the emblems of the status quo, 'National Mum and Labour Dad' 'go slowly mad', each claiming their own sacred space - the kitchen and 'Grunt Grotto' - and silently 
resenting the other. Typically Baxter, having recently converted to Catholicism, makes this couple Catholic as a way to assert that no external 'objective' order is the answer to the chaos at the centre of man's world.

'Dad' is an unsympathetic yet somewhat peripheral character, gleefully 'going to town' in anger at his grandson, 'Mum' is presented more thoroughly as a bastion of Calvinism. Once a 'goddess in a tartan skirt' she is now humourless, bitter and given over to a sterile illusion of moral purity:

... wisdom, age and mothercraft

Have rubbed it home that men like dirt:

Five children and a fallen womb,

A golden crown beyond the tomb.

Here a stifling 'objective' morality rules, rather than creative love. Mum's refusal to forgive an affair 'thirty years ago' is suggested as the source of their shared anguish; Dad's part is less thoroughly examined. Their domestic dysfunction is a manifestation of the lack of love which the poet considers an inevitable effect of the Fall, merely exaggerated by these social divisions:

The love they kill won't let them rest,

Two birds that peck in one fouled nest.

... Habit, habit clogs them dumb.

The Sacred Heart above the range 
Will bleed and burn till Kingdom Come,

But Yin and Yang won't ever meet

In Calvary Street, in Calvary Street.

\section{The Flowers of the Abyss}

The encounter with a Thai prostitute described in 'Air Flight to Delhi' (1958, CP 193) tempted Baxter with the 'old ideograph of peace' through sexual love. The 'ambition of that savage empty boy' - to 'Be Happy in Bed' (1958-1959, CP 199200) - remained a source of tension. This hope for 'one landscape, many women' still brought the poet, imaginatively at least, to the 'Boathouses on the edge of Nowhere'. In 'Mandrakes for Supper' (1959, CP 200-01) he returns to this underworld to review the instructions received

.....mooching there

Like Dante's ghost, among a faceless nation.

The white antarctic Gorgon was my mentor:

... her eyes of desolation

Sisterly gazing from the whirlwind's centre,

Received, embraced my naked intuition.

The town of Nilburg too I shrank to enter

(If memory serves me right) and wept contrition 
For indistinct all-but-committed crimes

In gelding-rooms and caves of parturition.

Earlier Baxter had written of 'Dante's [Hell] of phantasmagoria and pain', the 'causal nightmare' where 'we are always what we have been' ('World' 182). Without the possibility of transformation and a progression in the plot, these memories would merely be a torment. Yet while a 'part of our nature belongs to' this Hellish city, now the poet revisits the 'whirlwind's centre' not to slaughter the gorgon but to reaffirm the lessons of dissolution learnt at her feet. In the "cellars of Nilburg' the poet 'grew / Into an adult mandrake', a self-made creation eventually sacrificed in the 'cave of parturition'. The meaning of thirst is transformed by sacrifice and separation when from the nightmarish world of Nowhere and his underworld companions he 'woke ... left you, travelling light by mountain roads / To Elsewhere; drank at desert wells; gained strength'.

This mythologising account of temptation overcome and lessons learnt is one which Baxter continually revisits as he struggles with conflicting attitudes towards sex, love and relationships between men and women. 'The Tempter' (1957-1959, CP 205) offers Odysseus the ambivalent ocean wanderer a tantalising vision of his past indulgences in 'the cave / Of the summer nymph'. This is the familiar siren 'voice of sensual nostalgia which is strongest in the winter of the soul'. ${ }^{6}$ The tempter's voice emerges out of absence and longing, in attempt to reach 'one who has sailed beyond the reach', the anima as destructive seductress

\footnotetext{
${ }^{6}$ From Baxter's notes for ‘Traveller's Litany', CP 626.
} 
wheedles one

Whose mind aches in dispossession,

Whose limbs are fastened to the rock ...

With one door closed, another not yet open, the self is again destitute and thirsty, yet now has the tools to set down 'a pedlar's maxim' as a bridge between thought and action 'for thefts of being words will never cure'. The heroic quest is reduced to a simple test of temperance and the restraint of the self from 'mortal sins ${ }^{7}$ in order to experience the eternal refreshment: 'Thirst, obey, endure'.

In the 'The Apple Tree' (1960 CP 220-21), however, the lover brings release and joy 'from that high apple-tree ... That somehow bent in Eden' when 'I, time's prisoner' found entrance to paradise and the 'poor man's treasure', the gap of access to a place where body and mind are reconciled and love reclaims the innocent joy of the first couple: 'Bread newly baked in God's great oven'. 'On the Death of Her Body' (1960, CP 224), written soon afterwards, shifts perspective to take as its starting point the future loss of this 'treasure'. The contemplation of this loss is a grief laid over the loss of Eden, since the body of the lover was an instrument of transformation

that led me to the mountains beyond pleasure where each is not gross body or blank soul but a strong harp the wind of genesis makes music in ...

\footnotetext{
${ }^{7}$ See 'Some Points of Difficulty', Hocken MS - 0739 / 019.
} 
Entering through this low doorway of sexual dissolution recreates the song of creation where fruitful chaos is ordered by love and creative beauty emerges out of the gap

... such resonant music

That I was Adam, loosened by your kiss

From time's hard bond, and you,

My love, in the world's first summer stood

Plucking the flowers of the abyss.

\section{'The Flood'}

The sense of loss and alienation from God provides a starting point for poems such as 'The Flood' (1962, CP 263), which returns to the time of Baxter's solitary adolescence in Brighton, and

... those long walks I took

... to Scroggs Hill

Or some other standing-place

From which the farms were bare and small,

Houses not even visible. 
The need to put distance between himself and the 'acquisitive town' and to find a 'standing-place' of integrity and authority led to the search for 'my soul's hidden face'. This solitary quest for 'Joy, glory, primitive charisma' introduced him to the dark face of God: 'Welcoming as truth's dimension / The fury of the sky father'. The desire to be something or someone else was the common response to this personal version of the Fall, the 'brown flood' which buried his childhood paradise like the deluge which 'covered paddocks, sheds and fences' on the Taieri plain. Here retrospective mythologising traces over the child's impressions, clarifying the message taken from the experience of separation and loss. Standing above and beyond the town, and now separated from the world of childhood, the voice of the 'inward guardian' emerges from the gap to provide meaning and plot: 'All / Knowledge, my son, is knowledge of the Fall'.

The more expansive poem 'The Town Under the Sea' (1962, CP 252-53) revises this familiar trope ${ }^{8}$. Here the age of innocence is accessed only via mythic ordering, crossing a divide which crystallises childhood experiences into a handful of images: creek, bridge, beach, sky, schoolroom and the battles of Mars played out with 'bows and arrows'. The underlying meaning of these images is now revealed through the lens of the Fall:

... The difference, looking back,

Was that we did not see our own

Death in an oil-fouled seagull's death,

${ }^{8}$ See the prose piece 'The Town Under the Sea' (1956) and 'At Serrières' (1962, CP 250). 
And the copulation of dogs did not

Remind us of ourselves.

This childhood land of innocence was drowned 'At puberty, / Or the first deadly sin', when 'the sea rose up in one // Pounding night and swallowed the land'. Since then 'Shark / And octopus triumph in the dark / Doors of the human breath, / And the spider-crab is strong'. These are icons of the Fall and the competing hungers and drives which seek 'rule' over fallen man. ${ }^{9}$ The tokens of sheltered innocence now 'lie inaccessible, deep / Among the bivalves'. Rather than merely voicing grief, the mythologising self responds to this loss by reinforcing the need for faith. The final stanza presents a vision of hope emerging out of loss, dismemberment and dissolution:

Yet some have said (not fools, not ruled by money)

Beyond this dying world and the prison house

Of Purgatory, a land lies

Lovely for human eyes, where smashed love, broken vows,

Are healed again. Water must

Exist (they say) to answer thirst;

Our thirst is great. That second Paradise

We measure by the first.

\footnotetext{
${ }^{9}$ See 'The Waves' (1963, CP 286-88).
} 
Here the relentless 'thirst' which has directed Baxter's quest is paradoxically a source of reassurance, the degree of dissatisfaction with the fallen world is commensurate to the satisfaction of the Paradise to come.

\section{'The Cold Hub'}

In middle age Baxter's tendency to revisit early experiences is accentuated as well as challenged. In 'The Tree' (1962, CP 244) he considers the childhood paradise centred around the tree of life and death, where innocence is exchanged for knowledge:

Nothing was evil then. The editing came later.

Thirty years back, down time's rock shaft, I see,

Too early for the heart-and-arrow sign,

A tree of vulvas oozing golden resin ...

This sight 'invoked the gross maternal mystery', the living centre which sustained life. The 'mystery' which calls to the child poet is translated by the 'editing', the sense of knowing which informs his mythologising. The burden of this knowing is the awareness of death and separation from God. 'The Cold Hub' presents another pivotal point in Baxter's mythology, as the stance towards emptiness and dissolution, and the experiences of sex and death associated with the third type of gap, shift through the three versions of the poem. Here Baxter revisits another instructive moment in his personal mythology to reshape the meaning of his despairing delinquency. He suggests that it was his awareness of the gap which 
made the mystery meaningful even as it demanded that he strip himself of all attachment to comfort. The poem went through at least three draft versions - 'The Fifty Acre Bedroom' (22.10), 'The Hub' (22.12) in 1961, and the final version (23.35) written the following year. The poem thus demonstrates the 'editing' process of constantly remythologising the past in the light of present preoccupations. However the shaping of this poem also provides an example of the 'intuitional dissatisfaction' which drove the poem-writing process, as the notebooks reveal that the definitive feature of the 'hub' originally had the polar opposite characteristics of extreme heat rather than cold.

The eighteen year old poet lies on a bench in the town belt on a freezing cold Dunedin night, carefully arranging his own stage so that the current role may be acted out (O'Sullivan 50). He creates a gap of separation by placing himself on the margins of society, drunk and 'homeless' near the town belt, rejecting the cosy domesticity represented by home fires and warm coats. This 'spiritual Houdini' searches blindly for escape from the winter of suffering into the Edenic summer of pleasure, from the meaningless march of time towards death, and from his craving for alcohol, companionship and sex towards some other, more dependable form of sustenance and support.

In 'The Fifty Acre Bedroom' what is 'learnt' from the following breakthrough is a reinforcement of the quest for vitality. This young hero 'didn't want a fifty acre bedroom' in which to sleep through life comfortably. Instead he wanted 'Simply to be / As near as I could get to the hot centre'. 
Where matches are struck, fires lit, predators lolling

And a woman as well, or even a couple of women

To wrap themselves around with hot eyes,

Hot thighs. Hot ...

The desire to be near the 'hot centre' of vitality and passion seems to be in direct contrast to the resigned acceptance of the 'cold hub' in the published version. How did the 'meaning of cold, of time, of waiting' change for the poet in the short space of time between the writing of these two drafts? One answer is that this poem represents the multiple mediations of a subjective experience remembered, reinterpreted and recounted eighteen years later. The poet's claim to have 'sorted out what he wanted' from life seems unconvincing if the desire for 'hot thighs' is comparable to the list of synonyms for ' $n a d a$ ' in the later version, with its emphasis on coldness, destitution, detachment and emptiness. The 'meaning' of this memory was quickly reworked in the notebook to emphasise what - on the surface, at least appears to be a rather different meaning.

And something happened, not a change of heart,

A sense, rather, of being at

The absolute unmoving hub

From which, to which the intricate roads went.

[a recognition of death perhaps?] 
I was a single winter clod

Cracked open...

In Horse, a similar scenario ends with the 'psychologically damned' young hero, having reached rock bottom after a 'long and gruelling bash', finding in his girlfriend's bed 'the gates of that paradise from which runs the great river Euphrates' (57-58). In 'The Cold Hub', however, it is the separation from his girlfriend - and thus access to 'that paradise' - which provides entry into another realm. Here the negation of comfort and desire and the failure of love between the fallen create a burden of suffering which leads the way back through the eye of the needle to 'nada'. Entering this space is 'the beginning of knowledge', a lesson in the threat and promise of death, where all of the 'intricate roads' of desire inevitably lead.

This 'recognition of death' behind the concluding lines of this second version of the poem links it to the published version. The intuitional dissatisfaction is worked through until the key image of the 'hot centre' is entirely inverted to become the 'cold hub', at which point a string of synonyms is unleashed:

And something bust inside me, like a winter clod

Cracked open by the frost. A sense of being at

The absolute unmoving hub

From which, to which, the intricate roads went. 
Like Hemingway, I call it nada: ${ }^{10}$

Nada, the Spanish word for nothing.

Nada; the belly of the whale; nada;

Nada; the little hub of the great wheel;

Nada; the drink inside the empty bottle.

You can't get there unless you are there.

The hole in my pants where the money falls out,

That's the beginning of knowledge; nada.

It didn't last for long; it never left me.

I knew that I was nada ...

For Saint John of the Cross the term ' $n a d a$ ' is a tool on the path of absolute negation, the via negativa which leads through the 'dark night of the soul' towards union with the unknown God. O'Sullivan suggests that this nada is 'the terminal point of Baxter's thought, where all aspects of his writing converge ... Baxter now locates despondency and illumination in the same place' (51). The mythologising hero moves away from the false world and self, suffers alienation and dismemberment, and finally accepts the descent to the depths, discovering the

\footnotetext{
${ }^{10}$ See Hemingway's short story 'A Clean, Well-Lighted Place'.
} 
spring of life at the centre where opposites come together, life and death meet, chaos becomes cosmos.

The conflicting attitudes to sexuality and spirituality which had remained at the centre of Baxter's personal mythology are played out in the transition of the central image of the 'hub' and what it was that the poet 'figured out'. In moving towards the 'spiritual' interpretation, which connects Baxter's bohemian past to his enduring interest in the kenotic mysticism of Saint John of the Cross, he reflects the experience of 'closing one door' and waiting for the other to open, of crossing the gap into middle age, and points towards the emphasis on detachment and emptying which became key features of his later writing.

The first versions rehearse stances towards the experience of the younger self, finally affirming a version in which the younger self shows the way. Leaving behind the passionate heat of 'vitality' for the steely cold of detachment was a challenge which fitted not only with his new spiritual values but also his long-held creative practices - in returning to the struggle between fire and ice the conditions of the ginungagap were continually recreated. From the 'nothing' which is surrounded by poles of fire and ice comes the creative regeneration which was always Baxter's primary motivation, whether poetic or spiritual. Although the spiritual quest of Baxter's final decade may at times seem an inversion of the hot pursuit of his youth, the underlying desire for transformation remains, as the ordinary self is directed along these 'signposts' towards the regenerative centre. O’Sullivan writes of Baxter's evolving use of opposites in this regard: 
... the desire simply to be free of existence has become for him the expression for union with God. The fullness of God is also the emptiness of nada. Negation of self, and the new Eden, are now one and the same.

Despite the apparent profundity of this breakthrough, the poem ends with the suggestion that - on the surface at least - little had changed.

That night, drunk again, I slept much better

At the bus station, in a broom cupboard.

Typically the wisdom of ' $n a d a$ ' is available to drunks, those who travel the road of humiliations' which leads 'directly' to God, and denied to those who sleep safely in suburban beds.

\section{'East Coast Journey'}

Baxter's gradual exposure to Maori culture and mythology through his wife and his own reading and friendships had started to make the 'integration'11 of cultures increasingly desirable. ${ }^{12}$ This process was strongly shaped by Baxter's sense of the inadequacy of Pakeha culture and spirituality, particularly with regards sex and death. In one sense, 'East Coast Journey' (1962-63, CP 273) demonstrates this gradual movement towards a creative engagement with Maori mythology and beliefs, interpreted through the lens of his own prevailing preoccupations. However,

\footnotetext{
11 'Symbolism' 55.

${ }^{12}$ See Muse 26.
} 
this poem also reveals an enduring link between the threat and promise of sexual dissolution and Baxter's problem of identity. In 'The Betrayal' (1961-1962, CP 25455), Baxter recounts a dream which took him back to the central horror of the 1947 sequence. Finding himself back in bed with Pyrrha, he again confronts the central horror where life and death meet, a chaotic space which is now presented as his true home:

'Where have you been?' he said;

'The hypocrite words, the frost, the waiting,

Made me imagine a world where you were dead.

This is the only place where I am I.'

Her head rolled sideways. She

Looked at him with a yellow corpse's eye.

Time had now opened up the space in which to acknowledge the emotional consequences of what had happened, and in front of Pyrrha's flat - now boarded up - he could concede that what happened was 'not your fault - to love, hate, die, / Is natural'. Now 'death looks to me like the only love affair / Worth having' because 'Death is the one door out of the labyrinth!'.

The later search for a Maori teacher or elder brother is prefigured in the scene at 'the whitewashed pub', from 'East Coast Journey' where 'one of the drinkers round packing cases had / The worn face of a kumara god, / Or so it struck me.' The notion of the 'kumara god' recurs in Horse, where the protagonist encounters 'a 
Maori who had seated himself on a full beer carton ... Horse saw him as a stone kumara god, the true master of life. "You are my brother", he said' (25-26). In Baxter's mythology, the kumara came to signify 'the Maori, who needed his land to live, just as a potato cannot live without soil' ('Poetry and Education', 3 ). ${ }^{13}$

In Horse, the romantic mythologising of the drunken young hero is deflated when the man in question tells Horse's friends that 'He's not right in the head ... I don't want any Pakeha telling me I'm his brother'. This is a form of awakening, since Horse narrowly escapes 'a clout on the ear' but nevertheless 'the imagined piledriving fist of the Maori had knocked a hole in his private world'. The gap between the drunken, sentimental hope for brotherhood and the complex reality is rammed home. After this illusion is shattered, Horse looks ahead to 'the unknown evening, his stomach grew uneasy, and he sank like a man in a lift down, down towards the centre of the earth' (26). What appeared to be a 'revelation' of the 'master of life' turns out to be an experience of dissociation and disillusionment. Yet in 'East Coast Journey' the same mythologised vision of the 'kumara god' is only slightly qualified: 'or so it struck me'. In this mythologising vein, the poet's 'great dryness of mind' - the gap as menopause - brings forth the response of 'the voice of the sea', and then the pattern becomes 'plot':

... As a man

Grows older he does not want beer, bread, or the prancing flesh,

But the arms of the eater of life, Hine-nui-te-po,

${ }^{13}$ See also 'Fellowship', 245, and 'Christchurch 1948' (1960, CP 215-16). 
With teeth of obsidian and hair like kelp

Flashing and glimmering at the edge of the horizon.

In this mythic formulation Baxter's preoccupations with sex and death are brought together in the powerful image of Hine-nui-te-po, the goddess of the night. ${ }^{14}$ The figure of Hine-nui-te-po is integrated into Baxter's mythology as an icon signifying heroic dissolution and the transformation of the gap of death into the womb of rebirth. Hine-nui-te-po was probably best known to Baxter as the figure who finally defeated Maui the trickster, when he tried to win immortality by entering her body and re-emerging unscathed from the 'house of death'. ${ }^{15}$ Maui is the hero who confronts this terrifying centre, seeking to win immortality one way or another.

In the last section of 'Notes' Baxter writes that

When Venus leaves us to ourselves, her uncle Hades enters the door of the heart. Perhaps now, bare and empty, with only the stone of grief in my belly binding me to the centre of the earth, I am a little nearer to that community of the living and the dead which I have looked for all my life.

\footnotetext{
${ }^{14}$ See Muse 242.

${ }^{15}$ In Horse Grummet recites a poem on the relationship between love and death:
}

"“It is ... a poem about the female pudenda. The house of death ... That is the phrase the Maoris used for it. Life can be difficult. One has to get down low. Down low'.

Mr Grummet smiled sadly, drooped his head, coughed, crumpled, and sat on the floor" (87). 
Baxter suggests that the battles of Venus had lost some of their allure and no longer provided the germinal seeds of poetry. Thus death becomes Baxter's most consistent source of inspiration and it is to the goddess of death, rather than love or mercy, that the poet opens his arms. Miles note the links between Hine-nui-te-po and Persephone, seeing in this poem a reiteration of the relationship between Venus and 'her uncle Hades in terms of Maori myth (and in death-imagery of the sea rather than the earth)' (Muse 242). Behind her allure is the final 'transformation' offered by this deathly figure. Her body is an entrance to another realm, which must in Baxter's mythology be contrasted with the essentially 'meaningless' lesser desires of the flesh which (he hopefully suggests) fall away with age. The 'hour of death' is now one of the most consistently fruitful spots in the arena, aligned with the shift in the form of desire from the temporary thirsts of the body to an urge towards dissolution and death as the gateway to another realm.

\section{'The Ballad of Grady's Dream'}

In 'The Ballad of Grady's Dream' (1965 CP 239-40) the destitute outsider remembers his way home to paradise. In Baxter's words, the alcoholic Grady's dream is: 'the Divine Comedy ... Hell and Purgatory and Heaven'. Grady's dream is recounted on a 'clink black night in June' looking out 'through the harbour fog' as 'the guts of Wellington / Glowed like a great morgue'. In this marginal space, Grady presents a vision of deliverance after destitution. Emerging from hibernation as 'a white bird' the dreamer is caught by a gale and thrown north till 'There was nothing left standing / On the bare-arsed earth'. This journey towards the heart of darkness takes Grady through an encounter with the ghostly forms of guilt that still 
haunt the ex-soldier. In the face of this horror he lets 'the winds carry / Me out past Kapiti / In the belly of the storm above / A thousand miles of sea'. In this spiritual maelstrom he finds the gap which is the only way to deliverance, the 'hollow place' in a sea cliff 'deep as the cunning of Hell / And high as the trouble of man' with

One gap in it

Where only a bird could fly;

I said the Hail Mary

And threaded the needle's eye ...

Here the act of faith is the only hope for deliverance. Passing through the eye of the needle, Grady reverses the Fall and enters 'a green garden' which presents a uniquely earthy vision of Paradise, concluding with 'a bullock wagon' carrying 'The Host Itself with seven nuns, / And one of them had the face / Of Rose O'Rourke when she was young'. This mixture of the profane and the sacred presents the various desires which haunt Grady and his companion Jack Flynn. Alcohol, sex and the sacraments are all gaps of a sort which promise fulfilment or the momentary cessation of desire. As Millar notes, this is 'a particularly Baxterian theology, in which good works don't get this pilgrim into heaven, instead faith, courage and suffering, leading to a kenotic self-emptying, are what it takes for Grady to pass through the narrow gate and find paradise among the brides of Christ ('Tutua'). The two alcoholics are not 'reformed' here, yet the poem implies that Grady's passage through the needle's eye is a transformation which is unlikely to occur for those shut within the 'great morgue' below. 


\section{Easter Poems}

The series of Easter poems written throughout the early 1960s reveal the deeply embedded significance of the 'pattern of the passion' in Baxter's mythology. In these poems the ordinary self is crucified as the unrepentant thief, while the mythologising self effectively takes a secondary position next to Christ, in the position of Dismas, whose faith is rewarded with Christ's promise of entry to paradise. In 'The Pain of God' (1961-62, CP 247-48) the sinner is a 'blind beast' reluctant to move towards 'that Jerusalem we have not seen' but impelled by 'the fiery goad that You have planted / In the soul's cloven rock'. Despite the 'sparks of pain' sown in the depths of man's fallen and divided nature the mythologising self begs that the Lord does 'not render / Consolation, if that pain is nearer / The springs of light than any joy could be'. Thus

... Beauty is hideous

Compared to Golgotha where we stand

Without excuse and gaze on the murderous

Meaning of the world. The meaning of

Our night is seen in Your dismembered love,

And we will thirst till morning is at hand

Now that the pain of God belongs to us.

This harsh vision is considered necessary because 'under the cavernous / Night of truce that You have given us / I and my elder brothers dream of love / Without a cross'. This ignorance and disobedience is 'the night, the dream ... cloths that bind 
Your body in the grave'. Only an act of faith and a choice of creative love brings back the source of love. 'Easter Sunday' (1962, CP 249-50) marks this moment of restoration, when 'By a silent lightning flash // All things are made' through the spiritual fertility of the "phallic candle whose name is Christ / Three times dipped in the womb of water', which bursts 'the gates of Hell, begetting sons'. The mythologising self eagerly offers as a sacrificial victim the stubborn self who refuses the cross of Dismas:

... In pain I stood

There, torn, and watched the light flicker,

Dry-shod beyond the walls of Red Sea water,

And saw my Pharaoh who had feared to die

Dragged into the deep. The Pharaoh I

Is dead. Today I watch begin

The endless prodigies of the sun.

The ongoing confusion of purposes evident in Baxter's mythologising is demonstrated by 'Easter Testament' (1965, CP 319-20), where he resists such elaborate posturing in favour of a stance which echoes his Jerusalem poetry. Paradoxically, the poet begins by claiming that he will remain silent and not mention the 'quarrel of meanings in / the red-and-black-backed notebook' where he 
tries to make meaning out of the chaos of experience. Instead, 'not / expecting martyrdom' now his humble aim is to be instructed by the ritual of 'this excellent Friday'. The process of detachment and dissolution is begun 'at the church door' where he hangs 'my balls and car-coat' so that he might 'go up / to swap saliva on those metal feet that touch the lip'. In this silent exchange comes the meaning that evades the poet's pages and - by implication - his previous attempts at Easter poems:

... What He

offers, what I ask Him, won't

ever hit the quarterly

magazines, because the thud

of lead-weighted scourges can't

make light verse, and if it could,

that's not my job.

Instead the poet is instructed by the pattern of the passion embodied in the rituals of dismemberment which peel another skin

... Off

the onion - heart, head, either

useless - leaving me just one 
ploy, to let the hair shirt chafe

till the earth speaks through the man.

The apparent abandonment of 'ploys' in favour of this stripped back and earthbound voice of authority is a mortification in keeping with Baxter's earlier comment to Shadbolt, that he had to leave the poems as open 'wounds' rather than dressing them with aesthetic bandages. ${ }^{16}$

\section{'The Maori Jesus'}

In a number of poems written during this period, the messenger who appears to bring life to the abyss of suburban existence ${ }^{17}$ comes from the fringes and inverts the meaningless order of the suburban wilderness. 'The Maori Jesus' (1966 CP 34748) brings together the social and religious preoccupations of this period. ${ }^{18}$ The figure of 'the Maori' is elevated to the position of the resurrected Christ, walking the chaotic waters of the harbour and entering the city to find himself crucified by the cruelty meted out to those on the margins of New Zealand society. The dualism of Baxter's later attitude to Maori pits spiritual and cultural strength against the material, political and economic dominance of the Pakeha 'status quo'. The ministry of the Maori Jesus brings together a tribe of the dispossessed, weakened by a lack of love and fallen into addiction and self-betrayal. These misfits are the destitute of society, the ones who are wounded and thus remain open to the healing

\footnotetext{
${ }^{16}$ See also 'Ballad of Nine Jobs' (1965, CP 319).

17 'The Postman' (1950-1965, CP 312-13).

${ }^{18}$ See 'A Bucket of Blood for a Dollar' (1965, CP 320-22) and 'The Gunner's Lament' (1965, CP 323-24), which speaks for a marginalised Maori soldier sent as a sacrificial victim 'like a bullock to the abattoirs / In the name of liberty' to where 'the Yanks and the Reds [take] turns / At murdering the poor'.
} 
message brought by an unfamiliar spiritual authority. This figure seems uncannily familiar, a prototype of Baxter's own 'Hemi' persona, a profane prophet who is thoroughly schooled in the suffering of the principled outsider: arrested, beaten, charged, imprisoned and sent to an asylum for 'telling a screw the sun would stop rising'.

The bluntness of these mythological facts - his 'arrest for being a Maori' - are typical of Baxter's oppositional rhetoric. However the horror suggested by the 'fifth day' of this passion which 'lasted seven years / While he worked in the asylum laundry / Never out of the steam' reflects the poet's own fear of the 'underworld' state of seasonless limbo. The significance of prisons, cells and asylums in Baxter's mythology was augmented by his many visits to Mount Crawford prison, while his fascination with mental illness drew from his lifelong sense that he was effectively a 'schizophrene' or prone to the 'manic depressive cycle'. ${ }^{19}$ Though the Maori Jesus does no harm, his very otherness means that his message is ignored and he is destroyed by Caesar because the rational mind of 'the head doctor' cannot comprehend the sacred vision:

The sixth day he told the head doctor,

'I am the Light in the Void;

I am who I am.'

The seventh day he was lobotomized;

The brain of God was cut in half.

\footnotetext{
${ }^{19}$ Baxter wrote at this time that the example of Robert Lowell had taught him 'to use words as a straight-jacket to contain the violent experiences of the manic-depressive cycle' (Critic 210). Later he explained this dark humour: 'when you get near to this chaotic centre it's best expressed in jokes often, and the poems may be jokes - quite serious jokes' ('Interview' 245).
} 
On the eighth day the sun did not rise.

It didn't rise the day after.

God was neither alive nor dead.

The 'brain of God', contained within the mind of man, is butchered by the forces of $\operatorname{order}^{20}$. In the aftermath of this division, the process of creation cannot spur new acts of love or art, the plot remains stuck in limbo:

The darkness of the Void,

Mountainous, mile-deep, civilized darkness

Sat on the earth from then till now.

\section{'Tangi'}

In 'Man You Will be Dust' (1966, CP 374-75) reflection upon the hour of death is the doorway to a rebirth which seems to come with a new identity attached:

Death is a kind of life

As the Maori understood it,

And you who struggled all your life against it

Become a Maori - Stilt-walking

Pakeha, without words or money

20 'Shots' (7-13) suggests that Baxter's association with Janet Frame during this period may also have influenced this poem. 
You die, man!

McKay misreads the tangled syntax as suggesting that Baxter was struggling against 'becoming a Maori' (225). Yet in urging himself to give up the fearful attitude of the 'Stilt-walking Pakeha' who tries to remain above the inevitable reality of the grave, Baxter is 'becoming Maori' by adopting his own personal version of the 'Maori view'. In this view death poverty and destitution preserve an openness to the living centre and the primitive ordering of myth and ritual make connection to this centre possible.

The emptiness and disconnection of 'a culture that has ceased to understand itself' ('Notes' 153) and the ongoing effort to come to terms with death provide a background for the ecstatic revelation in 'Tangi' (1967 CP 400). Death serves to 'bridge' this gap of 'real separation between Maori and European' ('The Maori View of life and Death', FC 54) and provide the poet with the sense of a new beginning anchored in tradition. Baxter prefaces his discussion of this Maori view by noting a gap which engenders the increasing desire for 'spiritual security' in the face of approaching death: ' ... as men come nearer to God, so they also become more aware of the distance between themselves and God, and the differences between the Divine Nature and human nature'. However this need for certainty cannot be met, and can only be indirectly addressed by finding 'the means to reach Heaven', the tools for working out 'in experience the kind of living relationship to Him which will make those means effectual' (61). The poem and later article demonstrate how a personalised and simplified version of 'the Maori view' is incorporated into Baxter's ordering tools: 
Recently I had the privilege of attending a Maori tangi ... Afterwards, meditating on the occasion, it occurred to me like a belated thunderclap what the main difference is between Maori and European society. Maori society has accepted death as the centre of life, as a source both of grief and of communal transformation ...

The ritual of the tangi serves to take the poet through the door of dissolution, joining body, mind and earth in a way which seems to explicitly address Baxter's own desires. He typically emphasises the disconnection between Maori and Pakeha, the women who cry out in grief are simplified as 'the voice of those / Who have accepted death' and the assumed Pakeha reader is put in their place:

$\ldots$ inside the door

(A thing unacceptable to the world we inhabit, in which

No one is allowed to speak of death)

The dead man was conqueror!

This message is communicated on the level where opposites can be brought together through symbol and ritual, and thus the cultural gap is miraculously bridged: 'I knew for the first time the meaning of / The yellow woven tukutuku panels, / The shark's tooth, the flounder, the tears of the albatross'. The poet's mythologising perspective connects these icons to a pattern and plot which is in fact firmly entrenched in his own mind. Despite Baxter's apparent awareness of the harmful influence of 'positive and negative idealizations', he proceeds to reinforce 
his own version of 'the mythical attitudes held by any individual towards his own and other races ...'

... We (I speak of the New Zealanders of European descent) should ... avoid any nuance of unconscious arrogance, and ... develop the kind of humility that may enable us to see ourselves as learners rather than as teachers. The Maori is the elder brother; the European is the younger one at least in the matter of a grasp of communal values.

Despite the need to learn and listen, the iconography Baxter describes is integrated by relating it to the familiar gaps and sacred patterns of his own mythology, ${ }^{21}$ it is 'understandable only when death is accepted / As the centre of life - The opening of a million doors! / The rush of canoes that carry through breaking waves / The dead and the living!' In contrast to this mythologised representation of an entirely unexpected ecstatic revelation, the shift in view implied here involved a slowlydawning perspective which would come to shape the last years of Baxter's life.

\section{'Before Battle'}

In 1968 Baxter looked back at his two years as Burns Fellow and decided that there was in fact 'too much death' in his mind at the time ('Fellowship' 246). In casting aside the familiar ghosts of the past and attempting to 'inhabit the empty ground' the absence of a 'road ahead' seemed threatening. In 'Before Battle' (1967, CP 402)

${ }^{21}$ See 'The Maori View of Life and Death' 54-66. 
the loss of youth presents the stark choice between regression to old ways or an embrace of death which may not bring forth anything:

Now that we have lost those early ikons,

The selves we wore when young -

A full glass of gin, the smell of green hay

Carried from the barns on our clothing,

Fascination locked in the bodies of women,

... now that those things have gone

Like water under the sand, what is there

To fight about!

Empty sea and earth.

We are half-buried statues of ourselves ...

The problem of identity continued to plague him, the comfort afforded by these 'ikons' of the self is now lost, and ahead seems only a precarious, perhaps selfdestructive path:

Should we pray - 'Lord, forgive us

For ceasing to be human' -

Or take the sheep track round the cliff's face

Hoping it will not hold the weight of our feet? 
If 'The Doctrine' of hope (1967, CP 413-14), which had occupied such a vital place in Baxter's life, was to be abandoned, then it seemed that something would need to emerge to replace it. But Baxter believed that the ability to perceive messages from the depths had become compromised - and his own acceptance of the Burns Fellowship was a mark of his wrong turn towards comfort and the bargain with the 'kitchen god'. 'Safety' (1967 CP 395) presents the image of an 'old wattled Adam / Back in the garden; behind the safe stone gate', having given up the ladders and doors of escape, the gaps 'in the high stone wall / That constitutes life'. In response to this stifling domestic order, 'The Fear of Change' (1967 CP 404) considers the prospect of being 'woken suddenly / By the drums of Revolution in the street' or 'the door shot open' to reveal 'Upright and singing a young bullfighter', the master of chaos, 'offering to each of us / Death, sex, hope' or the hint of disaster 'calling us loudly to consider God'. From this perspective the bullfighter is the threatening other, rather than an image of the self. Thus the mythologising self sourly states that 'we are not that kind of people; / We have learnt to weigh each word like an ounce of butter; / Our talent is for anger and monotony'. This sense of the rejection of the vitality of the bullfighter for the sleep of the spirit in a bourgeois world of words and money seems to spur Baxter's transformation. Here the bitter accusation is aimed at the mirror and the one who fears he has embraced 'safety' as he enters his forties. Thus the urge towards simplicity and a 'primitive' perspective re-emerges:

Lately it seemed to me that God was trying to say something to me. It is hard to hear through the static of frost and cigarettes and Tablet articles and TV documentaries. But it seems to say something like this: 'You poor old sod! I meant you to be a primitive, not a civilized talker at Women's Social Evenings. You've balled it up. Remember your clan motto: don't die till 
you're dead. I know you believe in Me; but that's not quite enough to believe in. Try growing kumaras for a change. I make very few primitives and I like to see them survive. The Fellowship was a conditional mistake. You knew that all along. Why don't you use your radar? I'm not angry about it; I'm only sorry...'

Something like that. The Fellowship hadn't exactly done me in. But my asbestos suit had worn through in a few places.

('Fellowship' 246)

\section{'Letter from the Mountains'}

'Letter from the Mountains' (1968, CP 415-16) gives a sense of the desire for change which had been building momentum during Baxter's time in Dunedin and provides an example of chaos as the means to remythologising. The mythologising self's position, writing back to a friend in the city, mirrors the position of the Jerusalem Sonnets, written the following year. The poem uses the starting point of loss and separation, ultimately using the identified gap to reinforce the 'message': a belief in the meaning and purpose of suffering. Only in the mountains could the primitive, natural man clearly hear God's message, obscured in the city where the quest for love has apparently died.

The poem opens with an admission of having lost his way through life's journey: 'There was a message. I have forgotten it. / There was a journey to make. It did not come to anything'. The familiar retreat to the wilderness leads to purgation and a renewal of the quest. The gap of separation is opened up between the space of purgation, the 'nights ... under the iron roof / Of this old rabbiters' hut' and the spiritual desert of 'the city, all that other life / In which we crept sadly like animals / 
Through thickets of dark thorns, haunted by the moisture of women / And the rock of barren friendship'. In his chosen wilderness, the speaker feels 'strangely at ease', and rediscovers access to the meaningful material buried within the chaos: 'The true dreams, those longed-for strangers, / Begin to come to me through the gates of horn'. From this perspective, and in contrast to this vision, the 'other life' in the city is remythologised and begins to take on 'another shape'. A memory of conflict between partners at a party becomes a sign of separation and the failure of love, while the poet's friend loses the mask of civility and is transmogrified into a mythic figure rising from the depths 'like a Triton' to 'shout as if drowning'.

Triton, the messenger of the sea, rises from the profound depths of this interpersonal chaos, bringing a message which transforms meaning, with the speaker interpreting this as a recognition of the 'fundamental anarchy' in man's heart which leads to both suffering and regeneration:

Despair is the only gift;

When it is shared, it becomes a different thing; like rock, like water; And so you also can share this emptiness with me.

The 'letter' thus makes connections between the personal 'retreat' into the mountains and the common experiences of conflict and the failures of love in the city. The 'tears from faces of stone' are 'our own tears', as suffering clarifies the nature of the gap and its centrality in human experience The wilderness of the 'mountain' is simply a way to assist with this process of emptying oneself of 
attachments and opening to suffering and the 'true dreams' underneath the false dreams of the earthly paradise:

Even if I had forgotten them

The mountain that has taken my being to itself

Would still hang over this hut, with the dead and the living

Twined in its crevasses. My door has forgotten how to shut.

\section{'The Bargain'}

'The Bargain' (1968, CP 421-22) addresses again the issue of the divided self and the sense of a 'lost message' or an abandoned 'journey'. The orderly suburban idyll symbolised by the neighbour's 'rows of pea-plants' glistening with dew and the path that runs underneath the forgotten tree of life: 'some kind of tree / Whose leaves topple in green waterfalls' 'very likely' leads 'to a car-park or a junk-yard'. This path is 'able to be thought of' (or mythologised) as 'the wandering track // That goes to a place where Brother Ass can bray / Without burdens'. This marks an early appearance of 'Brother Ass' in Baxter's poetry, a lowly figure representing the stubborn self reluctantly carrying the Christ within towards both birth and death. In living the secure and successful life of the poet as family man he has 'accepted God's bribe. // To be content with not being dead, / His singing eunuch'. As opposed to this 'kitchen god', the 'true' God who is the source of meaning and the ultimate destination of the path must also be offered a sacrifice, which means that the rebellious self within cannot be allowed to die: 
... if the prisoner ceased one day to sweat and rage

In his cell of jumping nerves and layered muscle,

Dreaming of wild women and guerrilla battles ...

I would not be I, and the bargain useless,

For He would be cheated of the aroma of bitter blood

Spilt on the cross-tree, and I would have become

Simply the dead man hanging, the abdicated Jesus.

Not only is this prisoner the mouthpiece of creativity who keeps alive the connection with the underworld of inspiration, he is also the suffering 'thief' who dies next to Christ, the sacrificial victim and scapegoat who must take on the weight of tribal guilt rather than live a half-life in comfort. Baxter's resistance to the good life thus resurfaces in the following 'Poem Against Comfort' $(C P$ 422) where the mythologising self urges the move 'away from the mother's knees' because:

any comfort is the cold blanket

Of a drunk in the dark. We have to strip

To the bone and beyond before the gate can open

And our silence be united both to what we leave

And to the dark centre of the sun. 
'The Bargain' is the last poem entered into the series of notebooks which recorded Baxter's evolution as a poet from the age of seven. The break with this habit may have occurred at around the same time as the dream which provided him with a vision of the 'road ahead', a vision which had been formulating not just over the past decade, but ever since he first encountered the gap. Within the terms of Baxter's own mythology, the journey now takes him towards 'the dark centre of the sun', a path of silence which strips all comfort, including, Baxter believed, the bandaging comfort of poetry.

Baxter wrote that he had applied for the Burns Fellowship because 'Thirty-nine was a stopping place: a place to sit down and think about the road ahead'. After two years in the university environment he asked himself 'what'll you do when you have to get out of this Old Man's Home ... and contend directly with whatever wad of rubbish society can deposit on your doorstep?' Despite the persistent efforts to come to terms with being middle aged, ${ }^{22}$ the desire for the fruitful chaos of youth remained, as did the wish to inhabit a dramatic role in a living myth:

... In some ways I am sorry that I did not receive the Fellowship while I was still an active alcoholic. To spend a year roaring drunk ... would have truly honoured the Muse, who likes a rumpus ... and it would have left a hairy legend of the Abominable Snowman to gladden the hearts of the young and offend the nostrils of the old. But I am myself too old to sleep out on park benches ...

('Fellowship' 245)

${ }^{22}$ See for example 'Notes' 153-54. 
Baxter's return to the city of his youth may have marked the completion of a cycle, though it was typically transformed into a radical new beginning when at the age of forty-two he had the 'vision' which brought together the lessons and challenges of his time in India with the chaos he found in his own country. 


\section{Chapter Eight: 'To go forward like a man in the dark'}

To go forward like a man in the dark

Is the meaning of this dark vocation ...

('Te Whiore o te Kuri' ${ }^{1}$ 7, 1972, CP 568)

In late March 1968 Baxter found an answer to his desire for transformation in a prophetic dream which provided a vision that shaped the final years of his life. McKay writes that, in a 'state very close to despair, Baxter had prayed to God for a solution to his difficulties' (236-37). Baxter reported on the result a fortnight later:

... when I woke in the morning the first thought in my mind - was 'Jerusalem' ... the mission station on the Wanganui River. And either immediately or very shortly after a linked thought came into consciousness - that I should go to Jerusalem without money or books, there learn the spoken Maori from a man who God would provide for me - whose name might or might not be Matiu - and then (God willing) proceed quietly and slowly to form the nucleus of a community where the people, both Maori and Pakeha, would try to live without money or books, worship God and work the land.

(McKay 237)

1 'The Tail of the Dog'. 
This experience can be seen in the context of Baxter's lifelong habit of drawing 'mythological' meaning from his dreams. The content of the vision provided an 'answer' to a number of pressing difficulties and brought together concerns which had been occupying his mind for years. ${ }^{2}$ There are a number of different accounts of Baxter's dream / vision which appear to have been modified according to his audience. Weir later presented a slightly different account of this vision: 'God the Father appeared to him in a dream, holding the globe of the world in His hands. At the apex of the globe was a shrouded cross. In his dream, Baxter parted the shroud and saw a Maori Christ. Then he heard the words, "Go to Jerusalem!" ('James K. Baxter, a Voice for the Living'). At the centre of this vision is the Christ who is neither dead nor alive, but must be made manifest by going to Jerusalem and thus making one's world 'turn around the Cross'. One might argue from a Jungian perspective that this figure of the Maori Christ - whom the dreamer is called to imitate - is connected to the young man with the 'dark shining face' from Baxter's 1947 dream. Baxter himself questioned to what extent he was he was afflicted with 'the male menopause in a particularly virulent form' (qtd in Newton, 23). Regardless of the origins of this message, Baxter sprang into action and took this message from the depths to be a genuine communication, and an antidote to the 'death-seeking' had come to dominate his thoughts. ${ }^{3}$

From this point onwards, Baxter's life was effectively incorporated into the mythology of the gap, as he renounced suburban 'comfort' in exchange for the

\footnotetext{
${ }^{2}$ See McKay 237.

${ }^{3}$ The spectre of suicide and a fear of the underworld seems to have haunted Baxter's thoughts during this period. See for example 'The Searchers' (1968 CP 418-19), 'Epilogue for Ian' (1968, CP 42526), 'Seances', (1968, CP 426), 'At Goat Island', (1968, CP 426), 'The Bohemians', (1968 CP 428), 'Memento', (1968, CP 428).
} 
perfection of plot and the paradoxical dramatic role of Hemi te tutua, thus taking up the challenge of 'middle age' which he had laid out in prose:

We do not, I think, become ourselves, here on earth, in any real sense, until we begin to enter into the atmosphere of the Passion from which the meaning of life and death is conveyed to us...

... And in that atmosphere all the signs are changed, so that pain is joy, and loss is gain, and death itself is everlasting life. We should envy those to whom God has begun to give Himself by means of the Cross.

('Middle Age' 173-74)

As with the dream sequence in 1947, the transformative change that Baxter desired came forth from the gap. Baxter seems to have taken up the message, and the offer of a special role, with relish: 'James K. Baxter must die. He has served his purpose; but this no longer seems to be God's purpose' (McKay 237). Baxter sprang into action and chose to take this message from the depths as a 'genuine' communication, and a call to occupy the space between:

... Two central ideas were linked - poverty (somewhat of the Franciscan kind) and aroha, which then seemed to me to be the Humanity of Our Lord, dismembered among the Pakehas, in process of being dismembered among the Maoris.

The Lord (I speak as if the communication were a genuine one) indicated to me that He had in this country, as it were, two faces on one Head, a Maori face and a Pakeha face, that the Maori face was being mangled and hurt by our civilisation, and that $\mathrm{He}$ desired me to begin the labour of washing and 
cleaning it. I was to learn spoken Maori, and assume as far as possible a Maori identity ...

Baxter's great desire for a homecoming, to return to the original state, becomes an increasingly dominant imperative, driving the desire to journey through the dark night, to openly embrace chaos and the grave. In this final stage of his mythologising, the extreme terms of Baxter's new 'bargain' drive what seems at times to be a total rejection of the ordinary world and self in favour of a living mythology. Notions of exile, destitution and loss also remain pervasive, as various forms of homecoming or reunion continually provide the starting point for the mythologising which reaches outwards. Before arriving at Jerusalem, however, Baxter spent a further nine months with his family, during which time his fear of self-betrayal and desire for rebirth engendered the gaps evident in bleak poems such as the 'Ballad of Dives and Lazarus' (1968, CP 434-35), in which Baxter occupies the locus of tension between these two modes of being. ${ }^{4}$ Thus God - through the mythologising self - tells Dives to 'Go back and learn from Lazarus' until his 'crippled soul' is healed. ${ }^{5}$

'Letter to Sam Hunt' (1968 CP 429-31) prefigures the impending transformation from Jim to Hemi by opening space between the mythologising self and the self who has accepted the terms of the 'bargain'. He thanks Hunt for a letter and poem which are 'much better / To look at than the dreary words / I day by day excrete like turds / To help the Catholic bourgeoisie / To bear their own insanity'. The

\footnotetext{
4 'Two men lived in the same street / But they were poles apart / For Lazarus had crippled bones / But dives a crippled heart / That made him stare both night and day / At a production chart.'

${ }^{5}$ See also ‘Two Songs for Lazarus' (1971, CP 520-22).
} 
bourgeois self who made and accepted the bargain is transformed into a 'weta' 'with snapping jaws, / A Hitler who has lost his cause' - to be pitied and released: 'Don't hit it with a shovel - No, / Christen it JIM and let it go'.

As he set out on his mission Baxter marked the occasion with a 'Song' in which the mythologising self revels in the new role as a pilgrim who has accepted the terms of Christ's bargain: 'I have left my books and my bed and my house, / To follow him till I die' ( $C P$ 477). Yet the mythologising habit would not leave, and Baxter told his friend Colin Durning that despite his best intentions, the words crawled up his back ('Road to Jerusalem'). To Weir, Baxter claimed that

the prophet will not be troubled whether his poem is good or not; but the poet will be troubled whether his poem's good or not. And one can't make a poem prophetic.

Yet this prophetic role sits uneasily with the desire to be a 'nobody', and there is a constant deflation of the status of the poet.

I do write, yes, from time to time, when I have leisure and when there seems some imperative reason. Sometimes my poems are instrumental ... the 'Ballad of the Junkies and the Fuzz' ... is social poetry to some extent, poetry of community, perhaps. I would not be so desperately concerned with how well the poem is made as I once would have been. 
While he endeavoured to find a tuakana or elder brother to learn from, ${ }^{6}$ Baxter was more comfortable with the role of counsellor and mentor which he took on at the crashpad in Boyle Crescent in Auckland, where two adjoining houses became a loosely organised 'urban commune' housing drug addicts and dropouts. ${ }^{7}$ Baxter's time at Boyle Crescent was interpreted in familiar terms:

People use junk because the lack of love is too hard for them to bear. They get love as well as junk from their friend. But junk bridges the gap when the love wears thin.

('Elegy for Boyle Crescent’ 112)

These young refugees constituted a tribe of 'lost children'. ${ }^{8}$ Baxter writes of the 'young refugees' who escaped from 'the demon of acedia' and went in search of 'a magic somewhere that would get him off their backs'. Through these familiar patterns and figures the shape of Baxter's own personal mythology determines his reading of this new situation and its wider social context:

They did not get away from him. He is a hard demon to dislodge. The death ship of our culture moves on darkly between the junkie id and the cop shop super-ego. Whirlpool or cliff. Neither is an answer.

\footnotetext{
6 'For Hone' (1969, CP 439).

${ }^{7}$ See The Double Rainbow, 40-43 for a description of Boyle Crescent and a summary of this phase of Baxter's life.

8 25/06/1969, McKay 242-43.
} 
'The Ballad of the Junkies and the Fuzz' (1969 CP 442-47) reveals the conflicting purposes of Baxter's verse. The 'therapeutic' approach seeks to bring about healing on a personal and social level by bringing to the surface the fears and desires buried below. The prophetic voice arises out of divisions and a sense of alienation, and relies on the elaboration of these divisions for its own authority, thus Baxter's need to continually recreate the 'space between' often leads to rhetorical posturing, depending on the intended audience. In contrast to a letter to his mother where Baxter acknowledges that the police must be seen as 'persons (which they are) instead of life characters out of a horror comic' (McKay 243), in the ballad the 'fuzz' are nightmarish comic-book villains in their blind opposition to the 'junkies'. McKay writes that in this poem 'Baxter adopted the stance of Counsel for the Defence, and spoke for those who had no one else to defend them against a society that holds all the cards. No lawyer in such circumstances would make concessions that could damage his case' (244). In this role righteous indignation often overwhelms the concrete details of real lives and real places which provided the starting point for the poem. The mythologising self separates the various groups of characters - the police, the supporters of the social order and the junkies - so that it can reassert the familiar message that regardless of these division and oppositions, the common, underlying 'pain is greater than word or drug can cover', and that 'each are persons and capable of love'. The junkie house becomes a theatre for a communal nightmare, which aligns with Baxter's description of the theatre as an arena 'which gives a shape to communal mind of the audience', a space where collective myths are projected and embodied (1968, 'Some Notes on Drama', 21). The oppositional drama played out in the rest of the poem is (at least initially) grounded in Baxter's typical emphasis on universal destitution, and the gap between 
these two groups is man-made. In this gap, the junkies are crucified while the ordinary citizens simply hope to ward off suffering:

It was necessary of course to invent the fuzz

To fence off the area of civilized coma

From the forces of revolt and lamentation

That rise around it, male and female

Ikons weeping tears of blood.

Following this experimental phase, Baxter departed for Jerusalem, where numerous social and sacred strands of his personal mythology were crystallised through the attempt to create a sanctuary. As John Newton makes clear in The Double Rainbow, the full story of the Jerusalem commune has also been obscured by the Baxter myth. While Baxter's two stints at Jerusalem are undoubtedly a significant part of his life story, during this last four years of his life - the 'Jerusalem' phase - Baxter actually spent more time away from this community in the 'wilderness'. He constantly travelled back to the city to inhabit his public role as a walking symbol, inverting cultural values and, as 'Hemi te tutua', becoming a conspicuously prominent 'nobody'. As Millar observes, during this phase of his mythology Baxter gradually 'personalises what was once an impersonal construct' and the gap is presented in the place of a conventional identity ('Tutua'). 
Baxter's 'theology of kenosis', ${ }^{9}$ which brings personal experience into alignment with the pattern of the passion, is the definitive ordering feature of this period. In Jerusalem Daybook he claims that:

Through a theology of kenosis Buddhist and Catholic stand on the same ground. Kenosis means self-emptying, always with the proviso that one hopes to make more room for God and one's neighbour.

Along with the 'kenotic' example of Christian mystics such as Saint John of the Cross, during these years Baxter studied and practiced other forms of contemplation, such as Buddhist meditation. Yet it is typical of Baxter's crosscultural borrowing that he seizes on specific correspondences, seeing attitudes to death as the link between these traditions: 'underneath the surface contradiction, there are secret similarities. Christian and Buddhist both recognise that one has to die in order to live' (Six Faces, 'Love and Suffering'). ${ }^{10}$ In terms of Baxter's mythology, the significance of the theology of kenosis is that it puts the selfemptying and self-sacrificing Christ at the centre of human meaning, the essence of the mythos which is revealed by the gaps: 'You are the heart and the meaning of all meaning' (AT 58). When the self is 'emptied' to make room for God and for others, the space within is pervaded by this meaning which flows from the 'gap behind all appearances' ('Elegy for Boyle Crescent', 114). Baxter makes frequent and increasingly direct reference to the gap, which through this pattern becomes

9 'Self-emptying'. The term derives from Paul's second letter to the Philippians.

${ }^{10}$ Baxter's somewhat simplistic understanding of Buddhism is evident in 'Letter to John Weir' (1969, CP 482-83), 'Poem for Colin' 8 and 26 (1969, CP 458, 467) and Six Faces, 'Love and Suffering'. 
synonymous with God: 'The Christian churches teach that God is the Reality behind all created phenomena' (Six Faces, 'Love and Suffering'). Thus God and the gap are equated, and God the Father increasingly becomes the distance and unknowable 'source' of that which 'fills the gap', providing healing, meaning, identity and creation. ${ }^{11}$

Reliance on, or faith in God is thus a statement about the efficacy of the man-made ‘ikons' of collective or personal mythology: 'All our fables blow away like smoke before we come to God' ( $J D$ 7). The ikons have fallen, and what is left instead is absence, silence, darkness - which become themselves the indication of the 'reality behind' man-made order and creation. The direct emphasis on the 'heart of meaning', interpreted in relation to the pattern of Christ's life and death, brings Baxter's mythologising to an impasse where the paradoxes inherent in his conflicting roles as poet, prophet, protestor and penitent pilgrim can only be resolved by resorting to the dissolution of the gap, the void. While continuing to mythologise the experiences of the 'I', Baxter's writings during this period reflect a desire to release the 'ikons' that had defined his identity and bound him to the limitations of his own mythology. Despite his repeated emphasis on submission and the end of mythologising, Baxter's relentless pursuit of a self-defined, sacred dissolution often shares characteristics with Joseph Campbell's version of the last stages of the journey of the hero. In this extreme - 'perfectionist' - form of the myth, the greatest sacrifices are made with as much bravado as humility, using the instruments of

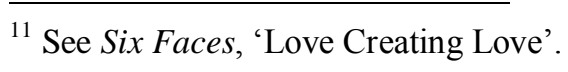


Art, literature, myth and cult, philosophy, and ascetic disciplines ... to help the individual past his limiting horizons into spheres of ever-expanding realization. As he crosses threshold after threshold ... the stature of the divinity that he summons to his highest wish increases, until it subsumes the cosmos. Finally, the mind breaks the bounding sphere of the cosmos to a realization transcending all experiences of form - all symbolizations, all divinities: a realization of the ineluctable void.

(The Hero with a Thousand Faces 163)

Baxter's journey to the place where 'even one's name means "this gap inside a coat" ("The Ikons') is punctuated by barriers and trials which simultaneously affirm the authority of the mythologising self while sacrificing the ignorant, stubborn 'idiot twin' who refuses to accept the underlying meaning of the 'pattern'. This is a reflection of the 'extremist' potential of mythological thought, which is able to reduce the matter of life to either meaningful myth or a meaningless void. In the period prior to his departure for Jerusalem, the mythologising self continually lays down the gauntlet to follow the terms of a new bargain. Following the pattern of Christ's life and death becomes the sole defining purpose of life and 'we cannot object to following where He has gone already' ('Middle Age', 173) . Destitution and death are seen as the necessary conditions for fulfilling the 'plot' man was born for:

To love means in the long run to die for one's friends. There are no exceptions to this rule. The seed has to die in order that the plant may grow. I do not quarrel with that destiny. 
On the whole, Baxter wrote as much during this last $4 \frac{1}{2}$ years of his life as during any other period, producing a large volume of prose as well as two major sequences, Jerusalem Sonnets and Autumn Testament. Many of the later poems are striking attempts to enact or enforce some form of 'surrender' of the mythologising authority to the dimension of 'silence, 12 and 'darkness' which Baxter continually refers to. Yet the poems which are alternately mental exercises, a chance to vent, or a way to stave off loneliness, continue to emerge out of the gaps, regardless of the poet's stated intentions.

\section{Jerusalem Sonnets}

Baxter's commune at Jerusalem can be seen as a culmination of his quest to create a sacred space which would allow the alignment of the inner and outer life:

If that Jerusalem which is unshakeable friendship with God has not first been established in the heart, how can the objective Jerusalem of communal charity be built so as not to fall?

$(C P$ 453)

The sequence of epistolary poems which were published as the 'Jerusalem Sonnets' (1969, CP 455-76) were sent to Baxter's friend Colin Durning before the commune was active, while the 'ex-poet' was still in the process of setting a trap 'to catch a tribe' ('Poem for Colin' 35). While Baxter had written considerably fewer poems during the first half of 1969, his attempt to 'give up books' and stop writing altogether was a battle which was never won. This sequence of sonnets addresses

\footnotetext{
${ }^{12}$ See for example 'He Waiata mo Tana' (1970, CP 492).
} 
various gaps, responding to a sense of loss and concerns about his mission, staving off the loneliness which had always caused him to 'reach out' in his writing, and reaffirming his unique position as outcast, prophet and 'nobody'. Thus he advised Durning:

Keep these 'sonnets' I send you - I'll have no copies here, or not likely and just at the minute I mean to go on writing a few more, to get myself mentally settled in - so keep them, stack them away somewhere - I asked the Lord about it and He said He didn't mind - I guess it doesn't come under the 'No books' heading ... Those poems I have sent you - good or bad, who cares? - spring from my sense of a spiritual cable between us - and you will see how nevertheless they are all "I" poems! I think we don't have to be ashamed of "I" - the thing is, what does a man know except his own experience? - which includes experience of such bonds - the ship knows only the ends of the ropes that moor her to the wharf, nevertheless they have other ends.

(McKay 258)

The poems are seen as the product of a connection which links fellow travellers in the gap, a 'spiritual cable' which affirms a common purpose and direction within the uncertainty of his new life. Later in Autumn Testament Baxter again affirmed this 'spiritual cable' of friendship with Durning, as a response to exile in the gap: 'After leaving the varsity job, and losing the borstal job, I knew you were travelling in a gap of uncertainty where no one can be fully at peace' (53).

In 'Poem for Colin' 1, the poet presages his difficulties in following a simple spiritual life without being swallowed up by his own mythologising. Thus he makes a 'serious joke' at the expense of the image of the bearded holy man. The louse 
which nests in his beard is not transformed into 'a pearl of God' by the grateful and wise hermit but rather remains 'a fiery tormentor' which goads him awake. Baxter's spiritual quest remains a struggle, a wrestling match between the 'idiot twin' and 'the other I was born to be', or alternatively, the longing to be somebody and the longing to be nobody. The movement into the night and the entrance to the holy space is a repeated pattern in these poems. Here he crosses the 'thick grass // Wet with rain, feet cold, to kneel / For an hour or two in front of the red flickering // Tabernacle light'. The comfort of his cottage is exchanged for the Tabernacle, the 'little house' emitting its sacred light, a sign of Christ's presence. This act of submission should take him through the doorway of dissolution, yet the mythologising self remains aware of the chaos within his 'meandering mind', sharing a joke at the expense of the other self, the 'madman ... nobody ... raconteur'.

In light of the renewed emphasis on exile and homecoming, this symbolism of the 'house' evolves further during these years. While houses remain ambivalent, in this period the ideal house evolves into the 'meeting house' where room is cleared for 'God and one's neighbours'. After leaving behind his own family home Baxter spent the last three years of his life in a succession of more or less 'communal' houses - these places were shared with the drug addicts at Boyle Crescent, with commune members and visitors at Jerusalem, with squatters and protestors in Wellington and elsewhere. These experiences seem to have filtered through into this evolution of the symbol. Now the house suggests openness, possibility and 'availability', just as Baxter came to prefer poems that are not 'closed in on themselves' but rather 'like a house with all its doors open. Anything could happen, you know' ('Interview' 245). The new house represents the possibility of 
communal, creative love. It is not the poet himself but 'the love of friends / Plants the tentpole, builds the walls of the house', ${ }^{13}$ or in the wider scheme:

God builds the house. I do not build it. I am its unimportant caretaker. Only God can build with living timber ... He builds with souls, and our own doubtful souls have a place somewhere in his unknowable design.

Baxter read his own existence prior to his escape as a time of torment in the 'Kingdom of Anxiety' 14 of the family home as a degradation of fertility. The antidote to this sterility is thus the ideal of the communal centre:

There has to be, I think, some shelter,

A home, an all-but-God, an all-but-mother

In time and place, not just the abstract void

Of I looking for me. Around these walls

They dipped their hands in paint and left their handprints

As on the walls of caves the Magdalenian hunters.

\footnotetext{
13 'Song to the Holy Spirit' (1972, CP 572).

14 'Song for Sakyamuni' (1971, CP 500-02).
} 
This is a space of fertility, education, ${ }^{15}$ protective love and a ('primitive') communal creativity. The communal house is thus the destination of the 'path', the 'green lane' leading to the 'secret house' of 'Poem by the Clock Tower, Sumner' is now found down the river road. In the sacred place where life and death, Maori and Pakeha worlds are brought together 'the dark song of welcome / Will rise in the meeting house' ('The Dark Welcome', 1972, CP 587).

In 'Poem for Colin' 2, the promise of spiritual fertility is suggested by the bees 'singing with what seems a virile joy / In the apple tree whose reddish blossoms fall // At the centre of the paddock'. This spiritual renewal lifts the poem towards familiar metaphorical excess, though this temptation is resisted. The 'old springcart' which is found nearby might be 'Elijah's chariot', however this fertility comes not from the poet's own authority but by 'thinking of the woman who is like a tree / Whom I need not name' as he clumsily grips his rosary beads and moves towards the centre. In 'Poem for Colin' 3 this access to grace is immediately challenged, and there is a distancing from the attempt to 'hack down the wall of God' through flagellation. The mythologising self takes up the voice of the priest to tell this penitent that this 'reunion' can be made 'by love alone'. The poet dreams of crossing the 'black gale-thrashed sea' of chaos in a 'shaky aeroplane', uncertain of his spiritual vehicle and the new bargain he has made. The wilful nature of this heroic or foolhardy action suggests the 'master of all who is never himself' ('Poem for Colin' 4). The demands of this quest are thus revealed as an uprooting of ingrained human habits and desires, even the building of a basic 'outdoor lavatory' is compared cynically to 'the gardens of Babylon', a structure which traps him 'in

\footnotetext{
${ }^{15}$ See 'Sestina to Frank McKay’ (1972, CP 583-84).
} 
the ditch of ownership' and leaves him exposed, in fear of 'the next gale at night' ('Poem for Colin' 5).

In 'Poem for Colin' 6, Baxter resists the journey into the 'middle of the Maori night', symbolised by 'te whare kehua', the house of ghosts. For someone with Baxter's temperament and interests, one of the attractions of 'the Maori culture, so spiritually vigorous', was the sense that it 'is loaded with preternatural elements dream, omen, kehua, taniwha' ('Things and Idols' 26). He later looked back at

... my first six months at Jerusalem, when I lived there as a hermit, I used to go step by step up a certain dusty dark road - moving my feet very slowly as if they were in deep sand - towards an old ... house smothered in bramble which my anima told me was haunted - possibly by the anima itself, since that part of one's soul is often experienced as a destructive power.

I would force myself to go in through the bramble, alone, at midnight, right into the dark door of the house - my heart pounding, sweat running off my body. To retreat to the area of the animus - to cast aside the experience of fear as being irrational - this would have been madness to me, because to transcend my culture, to make a journey to the Maori side of the fence, I had to go beyond rational concepts, into the preternatural area.

This process of initiation and dissolution was of course not new to Baxter, and his attempts at 'learning from the other side of the fence' were inevitably shaped by his previous experience and impressions of this 'night life'. It seems that while Baxter received sporadic advice and guidance from Maori on these matters, on the whole 
he retained his habitual position of having 'no spiritual director', ${ }^{16}$ largely giving up his search for an 'elder brother'. Through this self-directed journey into 'the Maori unconscious' he combined his own spiritual imperatives with the desire to take on the role of the father to his budding tribe:

The ordeal was necessary to diminish my fears, what good would I be as a father to a fearful tribe ... if I could not myself go against the fears that tended to swallow them up. Those early ordeals - of which there were many - did pay off ...

I have had to get to know the preternatural area of my own soul - to be, if you like, more familiar with the dead than the living - in Jerusalem which is a village of graveyards. Perhaps this is to be a good tohunga. ${ }^{17}$ One has to cease ... to fear death or the dead or the dark abyss of one's own soul. Curiously, one's sensual temptations then tend to diminish. Perhaps they always included a desire to huddle in the warmth of one's mother's arms as the cold night came on.

In 'Poem for Colin' 6 however, the reluctant self cannot yet take 'those hard steps' that 'lead out of all protection'. The house is over the hill's edge, away at a distance in the darkness of a haunted night, and the space between the poet and this threatening place represents the 'inward journey' of kenosis, the path to Calvary signified by the 'three posts conveniently placed'. On that path death is the doorway to new life:

\footnotetext{
16 'Some Points of Difficulty'.

17 'Tohunga' can refer to a master in a number of fields; Baxter probably means this as 'priest' or master of the spiritual world.
} 
... even a crucifix

Held in the palm of the hand will not fend off

Precisely that hour when the moon is a spirit

And the wounds of the soul open - to be is to die

The death of others, having loosened the safe coat of becoming.

In the seventh sonnet Baxter reports that the fragile community centred on the 'Junkie' house at Boyle Crescent has succumbed to the wind of chaos, the 'house of wood and straw / Is gone in smoke'. The tribe of lost children have once again scattered and the absent father wants 'to hold them', yet he is also drawn to the memory of that place because there he 'was a king / For a little while'. 'Poem for Colin' 8 affirms that this new Jerusalem is not based on the 'educated rational approach' that 'any priest in town' might be qualified to recommend, but the qualities of simplicity, discipline and intuition as found in the Zen Buddhist tradition:

'Live sparely; laugh at money;

Follow uphill the track of the bull -

Can a snowflake exist in a raging fire?

Here are the footprints of the patriarchs.' 
Yet the desire for discipline is undermined by the 'crabs' which are pestilential examples of anarchic, communal freedom: 'they have no Pope or King, Colin; / Anarchist, acephalous; they've got me stuffed!' ('Poem for Colin' 9). From this humorous position the sequence re-enters the space of the 'dark night'. In this dimension the 'thoughts of God' seem too cold, their transformative ordering demanding too much of the self who remains like the cows 'slow to move outside the gate / Where they sleep at night' ('Poem for Colin' 10). Yet the poet finds himself 'as it were by accident' entering the church again to kneel 'in front of the tabernacle, // His fortress'. For this act of faith he is once again rewarded with a sacred fire which is taken 'under my breastbone' back 'to my own house'.

'Poem for Colin' 11 returns to the temptations which obstruct entrance through 'the gate'. The ego is tempted by a letter from an admirer, which transforms the 'magpie chatter in the paddock' into 'the image of Hatana' (Satan) who 'bashes at the windows / In idiot spite, shouting - "Pakeha! You can be / The country's leading poet"'. For the Pakeha 'fog-eater' the solution is to take up the humbling task of learning Maori. The poet 'murmurs' Tena koe to 'the oldest woman' at Mass, and she replies in turn, yet this simple exchange is a reminder that 'the red book is shut from which I should learn Maori / And these daft English words meander on, // How dark a light!' The failure to measure up to the terms of his new bargain leaves the poet 'on the rack of the middle world', in the gap between the old life and the new, still holding on to his own language and his life as a poet: 'and from my grave at length / A muddy spring of poems will gush out'. The poems are now presented as the products of failure rather than mastery.

From this admission of sin 'Poem for Colin' 12 turns to an external (Pakeha) target and an argument with the ghost of 'Mother Mary Joseph Aubert'. Baxter told Weir 
that in this poem 'she would represent part of my own mind - perhaps the rather housewifely figure of the Church speaking - very much a Pakeha figure, of course. But I'm speaking on behalf of something else - the Maori pa, perhaps, or rather the multiple world of experience' ('Interview' 243). The 'pa is all but empty' where she fought for the well-being of local Maori, and Hemi te tutua takes up the role of selfappointed advocate, searching for a new solution for 'the converts' greatgrandchildren / Who need drugs to sleep at night'. This links with Baxter's experience in Grafton, where in 'Poem for Colin' 13 he nevertheless claims to have slept well 'Under the delicate Japanese image // Of the man whose dying arms embrace the night'. This embrace of the night, of death, of chaos as the void is the path through suffering to the 'great freedom / Of a river that runs in the dark towards its mouth'. ${ }^{18}$ This is the prophet's implicit solution, since this embrace of chaos and of one another at Grafton brought 'the sleep of children' in the 'breathing space', 'with our weapons thrown down'. Conversely, in 'Poem for Colin' 14, the poet is called from his sleep by God to once again 'go across the wet paddock / And burgle the dark church'. The role of the 'thief' is again adopted, here timidly unbolting the side door and entering where 'red light, moonlight / Mix together' in the sacred space. This sonnet brings together the network of symbols employed throughout the sequence - the ghosts of 'the Maori dead', the bee that 'wakes up and buzzes' and the crabs that torment the poet and display his distance from the antiseptic comforts of suburbia. The private act of lying 'down cruciform / On the cold linoleum' is shared with Durning, a violation of 'God's decorum' which situates the self in Christ's space, humbling himself before the Father in the process

\footnotetext{
${ }^{18}$ See also 'He Waiata mo take Tangi' (1971, CP 505-13), where a prolonged meditation on death and the sacrificial role focuses on the healing quality of rivers and the freedom granted when one becomes 'a gap in a wall'.
} 
of exchange. Thus he hears a voice correcting him - 'More stupid than a stone, what do you know // Of love? Can you carry the weight of my Passion, / You old crab farmer?"' Once again, the temptation to imagine an exalted role is revealed and mocked, a necessary deflation which allows him to go 'back home in peace'.

In 'Poem for Colin' 15 Baxter considers the nature of absence and the desire for a cigarette despite his attempts at detachment and 'virtue', yet 'Poem for Colin' 16 offers the consolation that he has escaped the net of the 'death blind world / Howling on all fours'. The reports from this imaginary world come through the newspaper, and the 'half sane' poet on the fringes of this world gathers enough material from these fragments to confirm his status as an outsider. Rather than enduring the chaos of the city he is a friend to that world's 'imaginary half brother, the great water lizard'. However even the refuge of Jerusalem, the home of the taniwha, is threatened by the 'earthquake god' of progress, 'represented by / Two young Maoris with a cunning bulldozer' who rip up everything surrounding 'te whare kehua', the poet's beloved space of instruction ('Poem for Colin' 17). The issue of obedience is further explored in 'Poem for Colin' 19, where the 'bullock bleeds' on the stone which lies 'at the centre of my mind'. Baxter's feelings about his abandonment of 'Te Kare' are the source of suffering. ${ }^{19}$ He can no longer turn to the rock of real knowledge but must instead return to the 'rock of unknowing' and offer himself 'to the knife of love' as a sacrifice. In his uncertainty he abandons his will and sacrifices his uncertain self to the 'wave of the sea / On which the Dove moved before the world began'. Thus 'by doing nothing I will do / What you desire', thus aligning or conflating personal experience with the will of God. The

\footnotetext{
${ }^{19}$ In 'He Waiata mo Te Kare' 4 (1972, CP 537), the poet hopes that 'Te Atua [God the father] will have pity on the two whom he has divided'. See Baxter's letter to Weir 09/04/1968, qtd in The Double Rainbow 34, in which he reveals the same 'pattern' in distancing himself from his wife as he had earlier with his father in the 1940s and from Curnow's literary project in the 1950s.
} 
conflicting affiliations are further elaborated in 'Poem for Colin' 20, which considers the different symbolic permutations of a ring bearing the image of intertwined fish. From one perspective, there are 'Two fishes for Te Kare and myself, / The love of the One to the One which is the hook in our guts', the 'anchor, te aroha'. Yet the call of the love of 'the Many, the cross of Te Ariki' ${ }^{20}$ exerts a stronger pull. This love is inextricably linked to

...the Maori fish

Who twists on after Him in poverty and darkness, And I must go with them upstream to the heart of the cross.

The mythologising momentum is with this tide of transformation, and 'Poem for Colin' 21 again reveals the image of the 'poor donkey', Brother Ass who must carry Christ 'into Hiruharama'. The battle for authority continues as the 'idiot twin' resists the knife of loving transformation:

Let the Maker of rainbows and mountains do what He wishes

With this poor idiot, this crab in His beard

Who will not be dislodged - becoming, as it were,

Available is all my science,

${ }^{20}$ Christ. 
And what He will do He will do - the problem is

Not our existence, Colin, but our arrogance

That wants to run the party ...

('Poem for Colin' 22)

The antidote to this obstructive arrogance is humility and self-emptying. Baxter continually refers to the processes of the body and the everyday indignities of his chosen life of poverty, secretly nourishing' potatoes 'with my own dung ... That is one job I can do / While he lets me do it'. This 'availability' and desire for humility is synonymous with Baxter's 'Franciscan' notions of poverty:

Poverty is availability. It is to be that void, that nothing, on which Te Wairua Tapu moved at the beginning of the world, and still does move. I am incapable of being good - my soul is a mass of faults and contradictions - but when I know I am nothing, then through the eye of that needle God can do what he wants to do. It is when I think I am something that my life backfires on me.

$(J D$ 16)

This desire for the creative power which proceeds from poverty engenders further tension and distancing in 'Poem for Colin' 23: 'don't be proud that you are poor!' Poverty is seen as the earth from which the seed of renewal will spring, yet he has to 'strip the sods off' and 'shake them / To get the earth loose'. In 'Poem for Colin' 24 he remembers the response of the children in Auckland to his appearance: 
“"Jesus!” / Or, "Hullo, Moses!"” As a walking icon, a prophet set against the status quo, his message is one of the inversion: 'money and prestige are worse drugs than morphine'. 'Poem for Colin' 25 ponders the 'brown river, te taniwha' which 'could even be on my side', yet the wait for 'the taniwha in the heart to rise' is an anxious one - 'when will that happen? / Is He dead or alive?' - and meanwhile the river itself is threatened by the culture of 'money and prestige' in the form of a car, a moving icon 'with an enormous slogan advertising / Rides for tourists on the jetboat at Pipiriki'. In 'Poem for Colin' 26 Baxter again considers the strenuous efforts towards self-emptying which are constantly reinforced (and threatened) by this mythologising process. He pictures imaginary adversaries who call him an 'ascetic hedonist'. The mythologising self must ward off the rational 'theologians' who represent another part of Brother Ass's resistance to the rider. The earthiness is no mere affectation, he claims, it is the only way to 'fight' the necessary spiritual battle:

...how do they fight

The world and the flesh in their universities?

The naked Master who hangs above my door

Gave up, like old Milarepa, ${ }^{21}$ His bones to the bonfire.

${ }^{21}$ A Tibetan Buddhist adept and poet. 
'Poem for Colin' 27 connects Baxter's interest in Buddhist meditation to the common mythic pattern of death and rebirth. The 'three dark buds' he finds in his jacket remind him of meditating next to a mysterious 'girl':

She would hold a blue flower at the centre of the bullring

While the twigs on the tree became black

And then slowly green again - she was young - if I had said,

'Have my coat; have my money' -

She would have gone away; but because I gave her nothing

She came again and again to share that nothing

Like a bird that nests in the open hand.

This female figure engenders peace, harmony and renewal in return for the sharing of nada. Even in the apparent tranquillity of Jerusalem this experience is necessary because of the continual return of the bullock to that centre where the knife causes suffering, as in 'Poem for Colin' 28 where the poet battles against 'the noonday demon ... the hermit's familiar'. The divided self remains an impetus for poetry even (or particularly) when the poet claims to be 'nobody'. The voice of this demon fills the gap of solitude: 
What does he say? - something

Like this - "You should be somewhere else, brother,

Anywhere else; this stagnant life is bad,

Much too limited for a bloke of your talents

Such as - well, you name them!"

The yawning gap of isolation and uncertainty threatens to engulf him, as the demon voices his fears and desires: "“as for that notion of yours of founding a tribe, / Hell, you're on your own here!'”. As with the poet's desiccated 'bourgeois' self in 'Letter to Sam Hunt', this ego-demon is squashed 'like a weta with a shovel'. 'Poem for Colin' 29 begins by noting that 'Our Lady shifted the demons; no need to talk about it'. Yet conflicting thoughts about the ability to exercise authority over his own life continued to cause confusion. Baxter suggests that an appropriate epitaph would be: 'He was too much troubled / By his own absurdity'. ${ }^{22}$ In 'Poem for Colin' 30 this absurdity is highlighted by the contrast between the simple, quiet life he has been leading at Jerusalem and the grand vision of the prophet:

... when the sun rises my delusion hears him shout

Above the river fog - 'This is the hill fort

\footnotetext{
${ }^{22}$ He continues: 'though I'd prefer - "Hemi” - // And nothing else'. Baxter's gravestone at Jerusalem reads: 'Hemi / James Keir Baxter / i whanau 1926 / i mate 1972'.
} 
Of our God; it is called Hiruharama!

'The goat and the opossum will find a home

Among the rocks, and the river of joy will flow from it!'

In 'Poem for Colin' 31 it is Father Te Awhitu who becomes 'the Maori angel' and puts the poet back in his place, gently directing his thoughts away from such grandeur. Yet on the whole Baxter remains his own spiritual director, and in 'Poem for Colin' 32 he returns to the habitual practice of 'tormenting myself with a moral inventory' and searching for a therapeutic healing. In this case, he agonises over 'my two illegitimate children // And how they will judge me when they come of age'. He moves from fear of this judgement to self-justification by referring to the familiar fertility trope, suggesting that, having been 'saddled with' these women, his only option was to love them 'whatever way he can // Till his guts drop out?' This mythologising voice wins out over the 'Lutheran' objection: 'the women used no rubber plugs or pills / Because they wanted to have my children'. ${ }^{23}$

In 'Poem for Colin' 34 Baxter takes on the role of the sacrificial victim in the new context of Pakeha restitution for the destructive wind which 'blew for a century / levelling by the musket and the law // Ten thousand meeting houses'. At Jerusalem he interprets the two disused marae at the pa as evidence of the (near) 'fatal impact' of Pakeha colonisation. In response to the apparent hopeless of this situation - and his own position of a Pakeha outsider in a largely Maori community - he asks 'What can this Pakeha fog-eater do? / Nothing; nothing!' Yet he offers to this 'tribe

${ }^{23}$ For the ongoing effort at 'self-justification' in this regard, see also 'Brother I am like a dead man' (1971, CP 494-95). 
of the wind' his 'flesh for kai, my blood to drink' in a unique attempt to shed his own guilt and at the same time affirm a positive identity as a (nearly) Maori (nearly) Jesus. The extremity of his self-directed 'sacrifice' is central to his plans to 'catch a tribe'. By letting himself be broken and 'emptied' of his Pakeha identity and his attachment to comfort he will be the 'rotten egg in the creek' which attracts the eels: 'And Te Ariki must crack me open / If the fish are to be drawn in at all' ('Poem for Colin' 35).

This brings the sequence back to 'Brother Ass' who the mythologising self hounds in 'Poem for Colin' 36: 'you are full of fancies, / You want this and that ... and now you complain of the weight of the Rider // Who will set you free to gallop in the light of the sun!'. There is an echo of 'Song of the Years' in the claim that 'long ago, long ago, // The battle was fought and the issue decided / As to who would be King'. This familiar poetic position of distance and authority places the mythologising self above the 'little donkey // Saddled and bridled by the Master of the world' and struggling to take 'His true weight' on the dark path towards Calvary. Here Baxter turns again to address his friend:

Colin, you can tell my words are crippled now;

The bright coat of art He has taken away from me

And like the snail I crushed at the church door

My song is my stupidity ...

('Poem for Colin' 37) 
The 'stupidity' of the song is perhaps a reflection of the absurdity of the mythologising self's position here - paradoxically affirming the inexpressibility of the experience and the inability to write while crafting a sonnet. The description of this emptying is another example of the poet's mythologising coming into awkward conflict with the obvious facts. The poem states that as well as his 'home and bed' God has taken away prayers and songs of praise - all of which would otherwise seem to be the product of Baxter's own choices. The mythologising self remains, however, to record the results of this kenosis:

As blind men meet and touch each other's faces

So He is kind to my infirmity;

As the cross is lifted and the day goes dark

Rule over myself He has taken away from me.

Perhaps in response to this resistance to silence, in 'Poem for Colin' 38 he sings 'the song of the thief who hangs upon the tree'. The opening of the poem is borrowed from Saint John of the Cross: 'I am dying now because I do not die'. ${ }^{24}$ Like the Spanish mystic and poet, Baxter writes of the pain which comes from having moved away from an old life of living 'in himself' without yet having achieved union - or 'marriage' - with God. The agony of this wait in the gap is the cross which he takes up, and the undead mythologising self is the one who sings the song of the humbled thief, unable even to turn towards the other one "who hangs

${ }^{24}$ See also 'The Song of the One' (1971, CP 522-23). 
beside me on the other tree'. Instead he is once again reliant on the mercy of Mary, 'the woman who is standing down below', whose prayers of intercession are his only hope.

In this position Baxter ends the sequence at thirty-nine, each sonnet a lash which takes him closer to a death both craved and feared. If Boyle Crescent, where he was 'king' had been 'the twelve days garland' - a glorious birth - now he had arrived at 'the apex and the clean flint knife', in readiness for the sacrifice which will transform him into 'Hemi te tutua' ('Poem for Colin' 39).

\section{Autumn Testament}

The 'Autumn Testament' sequence of poems (1972, CP 541-64) is anchored in the same geographical place as the 'Jerusalem Sonnets', though the movement of time and the events of the intervening years contribute to a comparably sombre tone. The sequence continually weaves between hope and despair, certainty and unknowing. A sense of leave-taking begins to dominate the sequence as Baxter gradually releases himself from the Jerusalem dream and looks to enter a new, as yet undefined chapter of his life. The previous year Baxter had told Weir that accessing the gap more fully and effectively could mean that he no longer needed to write.

Baxter: $\quad$ I find that my own mind more and more gravitates towards this silence, death, eternity, whatever you like - the point of peace actually ... To be there, in that gap! And the poems will come from there at times like water out of the rock. 
Weir: $\quad$ On the other hand that need, that want, may lead you to refrain from writing?

Baxter: $\quad$ Yes, yes, blessedly one might refrain from writing.

('Interview' 250)

This 'silence, death, eternity' is synonymous with the creative void later referred to as 'Wahi Ngaro', a term which carries connotations of the 'missing portion', or of something precious which is lost or hidden. In Autumn Testament Baxter explains the relationship of Wahi Ngaro to his spiritual practice and the theology of kenosis. Wahi Ngaro is 'the void out of which all things come. That is my point of beginning. That is where I find my peace' (AT 9). In The Double Rainbow John Newton suggests that 'the autumn of 1972 brought about a major acceleration' in Baxter's creative output (83). The absence of his earlier role as shepherd of a chaotic community, and the gap of uncertainty over 'God's purpose' for him typically became the starting point for a creative outpouring, in which he crafted his final major sequence of poems.

'Autumn Testament' 1 revisits the familiar symbolic landscape of Jerusalem, yet rather than the fervour and hope of the earlier sequence, the mythologising self now servant asks his master for guidance and pity: 'What would you have me do, / King Jesus? Your games with me have turned me into a boulder'. In 'Autumn Testament' 2, Baxter considers those who are absent:

Two thousand perhaps in the tribe of nga mokai Scattered like seeds now ... 
Inside the spider-cage of a common dream,

Drugs, work, money.

These are the 'woven spider-cages' the labyrinths of the mind ('a civilization in each') which emerge out of 'Wahi Ngaro, the void from which all life comes'. The first half of 'Autumn Testament' 4 elaborates on 'Wahi Ngaro' and the sense of loss, lack and longing which it engenders, leading up to a submission to the gap and the transformative experience which follows. After this the poem turns to describe the renewal of life which follows from this abandonment of the will. Wahi Ngaro is 'the gap from which our prayers / Fall back like the toi-toi arrows // Children shoot upwards'. The darkness and unknowable nature of the lost or hidden God is 'the limitless, the silent, the black night sky // From which the church huddles like a woman / On her hillock of ground'. This is a God reduced to the simplest terms, to a black hole which draws everything towards it, leaving only the experience of union with the gap, the void: 'into your wide arms // Travelling, I forget the name of God'. Here the gap and God are fully merged, as chaos and cosmos become one. This experience of a spiritual death is immediately turned to rebirth, where each of the senses brings back news of renewal: 'Yet I can hear the flies roam through the rooms ... feel the wind that flutters ... see / The orange flowers ... / Taste my tobacco phlegm, touch ... the great bronze Christ'. It is typical of the later poetry that the mystical experience of dissolution and implied union with God is immediately brought back to earth, in this case by flies, flowers and phlegm. 
'Autumn Testament' 5 again begins with the words 'Wahi Ngaro', detailing the experience of momentary union, when 'the ego like a sentry / At the gate of the soul closes its eyelids'. In response to this experience the mythologising self forgets the prevailing grief of Adam in his fallen world and thinks 'There need be no other Heaven / Than this world'. In this imaginative Eden, however, he soon hides from the rain 'under / The willow leaves and bramble, as Adam did / Once from the Father'. Thus brought back to the simple needs of communal living, he remembers to bring back 'a sprig of wild wet mint' for the next day's potatoes. In 'Autumn Testament' 6 the 'darkness of oneself' haunts him in the empty house. Those who are absent by distance or death become threatening ghosts in the solitary space which is claimed by the ego and its shadow: 'the darkness of oneself / Comes from knowing that nothing can be possessed'. Accordingly, in 'Autumn Testament' 7 the poet wakes 'with a back sore from the hard mattress / In a borrowed sleeping bag'. This kindness is emblematic of the 'heart' of nga mokai, which is 'enough to nourish the dead world'. In this sequence Baxter more consistently emphasises the actions of others who have taken on, in their own way, his mission to live out the 'Love of the Many'. Whereas once the lone poet would search in secret places for an insight or a role which could bring the world to life, now he claims to be happy to have the burden shared with others because

... to wake is to lift up

Again on one's shoulder this curious world 
Whose secret cannot be known by any of us

Until we enter Te Whiro's kingdom.

The entrance to this kingdom of death is one of the preoccupations of Baxter's final volume. In 'Autumn Testament' 8 he tells the 'pa people' that he misses the sea and 'the rock my father fished from' and is told that 'you have the sea as well if you have this river'. The image of the river, which has continually served as a symbol of the 'underworld', is in this last phase of the mythology also a symbol for the theology of kenosis which joins the self to God. Thus in 'Autumn Testament' 9 he lists the sea-creatures whose

$\ldots$ images rise in sleep

Through the waters of my soul -

As if I had been carried as a foetus

On the breast of Tangaroa, ${ }^{25}$

And held in my heart an old hunger

To be dissolved and swallowed up by the waters.

This desire for dissolution is a reflection of the enduring sense of grief and suffering which drives one 'to the grass of the graveyard or a woman's breast ... for absolution' ('Autumn Testament' 10). Death and sex offers ways of responding to a ${ }^{25}$ See also 'Ode to Auckland' (1972, CP 597-600). 
pain which - in this sonnet, at least - cannot be provided by the 'mossgrown haloed cross' and the old ways of 'Mother Aubert and the Catholic Mission'. This severe love is 'too bleak for the mind of old Odysseus // Coming home to his table of rock' or 'the mind of Maui, who climbed inside the body / Of his ancestress and died there'. In the comparative space and silence of his second spell at Jerusalem, he had more time to 'walk beside the budding figtree / Or on the round stones by the river'. This is the ideal place to encounter 'the face of my dead father', with whom he had once hoped to find the 'Leisure to stroll and see Him unafraid / who walked with Adam once in the green shade' ('To My Father'). Baxter typically takes the opportunity to question the dead, and in this case he also expresses his enduring sense of unworthiness in comparison to his father's integrity: 'Is there a chance your son will ever join you // 'In the kingdom of the summer stars?' Having journeyed to the underworld through the gate of natural contemplation he must return without an answer, yet this encounter with death leaves the world renewed: 'like a touch behind him, // Greener the bulge of fruit among the figleaves, / Hotter the bright eye of the noonday sun'.

The hopefulness of this conclusion is instantly challenged in 'Autumn Testament' 12: 'the wish to climb a ladder to the loft of God dies hard in us'. Rather, the answer formulated here is to let the bramble grow till the fruit have ripened' and forget 'the ladder-climbing game'. The fruitful approach is instead to 'love God, to serve man' yet accept even the possibility of 'damnation by loneliness'. In contrast to this resignation, in 'Autumn Testament' 13 the gap of loneliness and absence drives him towards a vision of connection and fullness. Walking 'on the bulldozed clay' cleared three years earlier, he considers those 'Pharisees' like pine trees who 'shove their solemn tough-barked crowns to Heaven / But nothing grows under 
them'. This brings him to an opposing vision of the regeneration of this empty space:

... One day on that ripped hill,

If God desires it, there will be a house

With Maori rafters, and over its doorway painted these words:

'Te Wairua o Te Kare o Nga Wai'. ${ }^{26}$

This resistance, in its mythic vagueness both spiritual and socio-political, again brings to mind the image of Archie, in the painting which 'shows him as the Iron Duke ... Now in my mother's house // The picture is an ikon' (14). To this ikon Baxter addresses the pressing question which plagues him to write: 'Father, is it easier to fight / The military machine, or the maggots of one's own heart?'

'Autumn Testament' 15 expresses the grief that the early promises of Jerusalem seem to have come to nothing. In the sacred space of shared communal life nga mokai and the Church came together, briefly, which brought a sense of 'new skin under wounds, the Church becoming human', yet this brief hope faded and now 'the Church can count her losses in Pharisaic peace'. Similarly, the struggle with 'Caesar' now seems too much to face: 'Nobody can win that kind of battle, / I don't try it' (16). The 'dark angel of the town' (17) is no longer an instructive spirit but the voice of acedia and despair. In 'Autumn Testament' 18 the two elements of Baxter's project are further separated when he mourns the loss of 'Father Lenin'

\footnotetext{
${ }^{26}$ The spirit of Te Kare of the waters.
} 
whose 'bones in the Red Square / Are clothed in roubles till the Resurrection'. No economic system will bring redemption, and 'the mask of money // Hides too well the wound we cannot touch'.

'Autumn Testament' 21 describes the familiar pattern of tension and reconciliation: 'King Jesus, after a day or a week of bitching / I come back always to your bread and salt, // Because no other man, no other God, / Suffered our pains with us minute by minute // And asked us to die with him'. This is the path of suffering in which the abyss must be faced again and again:

To pray for an easy heart is no prayer at all

Because the heart itself is the creaking bridge

On which we cross these Himalayan gorges

From bluff to bluff. To sweat out the soul's blood

Midnight after midnight is the ministry of Jacob,

And Jacob will be healed.

Thus in ignorance and faith rather than wisdom the mythologising self offers the body which 
Was made to hang like a sack on its thief's cross,

Counting it better than bread to say the words of Christ, 'Eli! Eli!' ...

Brother thief,

You who are lodged in my ribcage, do not rail at

The only gate we have to paradise.

Yet the search for 'the delicate pure invisible light I have not / Seen since I left Grafton' continues, and the answer to this desire for transcendence is to once again 'kneel under the knife-edged moon' praying to Mary to intercede on behalf of the tribe who want to be free. This compassionate mother knows and accepts the tribe as her children waiting to be born into new life: 'I see no sin. My secret is / I hold the Child I was given to hold' (33). As the star of the sea as well as Te Whaea - the void-mother - her messages reminds the mythologising self that "Without God our boat will sink, // And that is the way it should be' (35).

Yet increasingly, Baxter sees Jerusalem as a thing of the past. The sacred space of refuge where 'the hernias of the mind retract themselves' will no longer be filled with the 'ones who used to come here // Like divers to a decompression chamber ... I have to say, "So be it", (41). In the absence of a new direction, the sacred pattern of death and rebirth provides reassurance that 'fidelity to death' will eventually bring forth new life: 'Today when Father Te Awhitu / Put on the black gown with 
the silver cross, // It was the same story'. This death must come first because 'The hard rind of the ego / Won't ever crack except to the teeth of Te Whiro, ${ }^{27} / /$ That thin man who'll eat the stars. I can't say / It pleases me'. In this process of kenosis, faith is continually threatened by the malevolent voice of the ego who resists the exchange, like the 'whining mason fly' who 'tells me, / "Your Christianity won't put an end to death"' (42). The contemplation of death once again brings the hero to the confrontation with ginungagap, ${ }^{28}$ the place of extremes and absence where life and death meet:

Heaven is light

And Hell is darkness, so the Christmen say,

But this dark is the belly of the whale

In which I, Jonah, have to make my journey

Till the fear has gone.

Out of the darkness and fear has come the Love of the Many, and thus with the tribe beginning to stand without the help of their 'father', the way is cleared for the repetition of the familiar pattern:

${ }^{27}$ God of sickness and death.

${ }^{28}$ See also “'In Times of Trouble Among Nations' (1972 CP 593) where the central horror of the gap, and the extremes it reveals, are horrendous: 'The sun goes down / And leaves a gap of darkness / Too fiery and cold for any man to live in'. 
The chorus of their chaos becomes a possible Christ

When the light behind the face begins to shine ...

I go south tomorrow with the river

And leave no lock on my door.

With the door open to the process of transformation, the mythologising self once again comes to the centre of the labyrinth and the death which brings forth the strange embryo. In 'The Labyrinth' (1970, CP 488-89) the erstwhile hero, stripped of everything on the journey to the very centre of the labyrinth, ${ }^{29}$ accepts the terrifying embrace which is the doorway to the harmony of cosmos:

$$
\text { I tell you, brother, }
$$

When I throw my arms around the Minotaur

Our silence will be pure as gold.

In embracing this horror he reaches the 'centre of the cross' and the shots of the marksman are transformed into expressions of love, messages from Christ who is 'my peace, my terror, my joy, my sorry, my life, my death, but not my security' ( $J D$ $15)^{30}$

\footnotetext{
${ }^{29}$ See Muse 151-53.

${ }^{30}$ See O'Sullivan 45-46.
} 
Thus in the final sonnet, the terrifying goddess of sex and death, 'Kehua, vampire, eight-eyed watcher / At the gate of the dead', is transformed into a 'little Arachne', the horror at the centre of the self now seemingly loved and accepted (48). The webs woven by Wahi Ngaro pose no threat here, because despite the nets of fear and the 'aerial castle' which each person constructs:

Fear is the only enemy.

Therefore when I die,

And you wait for my soul, you hefty as a king crab

At the door of the underworld, let me pass in peace.

In 'Te Whiore o te Kuri (7)' Baxter lays out a simple approach to rediscovering paradise which represents a crystallisation of the mythic quest for 'the heart of life' which was at the centre of 'Doctrine of Philosophy'. The same concerns preoccupy the poet thirty years later - the 'simple' way, the 'heart', the 'spring', and the desire to lead others to the sacred place. The experience of the hollow place which was central to the earlier poem encouraged Baxter to believe that he was called to 'lead others those who find themselves in a bare universe to this source of life. For on earth we may find it'. Thirty years later the poet the poet still 'turns to Nature', yet what he finds there is now almost as 'bare' as the chaotic world which the teenage poet rejected. Whereas the younger poet believed that it was man's creative insight which could bid the 'heart in time' to beat, the older poet gives the same message 
with a slight adjustment - the heart of life beats to the extent that man enters the gap and thus allows God to 'be'.

Thus the mythologising self continued to go forward into the dark, guiding - or goading - the 'idiot twin' towards the place of sacrifice, dissolution and regeneration. This is the 'meaning' of Baxter's 'dark vocation':

So simple, tree, star, the bare cup of the hills,

The lifelong grave of waiting

As indeed it has to be. To ask for Jacob's ladder

Would be to mistake oneself and the dark Master,

Yet at times the road comes down to a place

Where water runs and horses gallop

Behind a hedge. There it is possible to sit,

Light a cigarette, and rub

Your bruised heels on the cold grass. Always because

A man's body is a meeting house,

Ribs, arms, for the tribe to gather under,

And the heart must be their spring of water. 


\section{Conclusion}

There was a man who lived at Jerusalem,

He had an old coat ...

... why couldn't he live

In the Kingdom of Anxiety like any other man

And go into his house like a rabbit to its burrow?

God was his problem; God and the universe;

He had, let us say, a problem of identity -

('Song for Sakyamuni', 1971, CP 500-02)

Baxter died of a heart attack in Auckland on the $22^{\text {nd }}$ of October, 1972. Since that moment, the 'meaning' of his life and works have been beyond the influence of the mythologising self. The poet who proclaimed himself a 'nothing', a 'gap', has become a larger than life mythic figure, and thus problems of identity have continued to define Baxter's mythology in the years since his death.

In retrospect one can suggest that Baxter eventually sets out to live out the dream he describes in 'Shots Around the Target': to be 'carried, lifted' by 'his people', to take on the role of representative, spokesman, talisman, prophet, 'voice'. In his own 
terms, he does this by breaking away from 'the narrow sense' of the role of the artist. The stream of his life is united with the tide of myth and follows the momentum of this tide towards his 'destiny'. The 'man who lived at Jerusalem' is now 'out of the picture' and Baxter has in many ways become a ghost or an 'ikon', the myth sealed by the 'moment in history' represented by his death and tangi. Yet it is only through his early death that Baxter's mythology has remained associated so strongly with this final phase of his life and his resting place at Jerusalem. In the months before his death Baxter had moved around without a clear sense of direction, perhaps waiting for further instructions to 'emerge' from out of the gap.

In this thesis I have established a critical framework for reading Baxter's writing as a whole, providing a selection of readings which account for the breadth of Baxter's work, while identifying its underlying consistencies. In the introduction I suggested that various competing mythologies have shaped the critical response to Baxter's work, often focusing on the 'icon' at the centre of the mythology. In chapter one I outlined Baxter's own view of his mythologising process as a necessary creative response to universal 'gaps' in experience. Yet Baxter's 'gaps' are also the product of the mythologising habit, and at the centre of this creative process is the 'mythologising self' who momentarily accesses and records the experience of a 'cosmos' which is shaped by the imperatives of desire. In chapter two I compared the use of gaps to the heroic journey to the 'centre', where the exchange of the ordinary self for the mythologising self can occur. Baxter consistently utilised three types of gap - loss and absence, division and dismemberment, and dissolution - as starting points, through a range of stances and methods which allow him to create the distance and space in which poems could 'grow'. In chapter three I showed that Baxter's mythologising was an ordering process which utilised myth, symbol and 
metaphor to transform 'chaos into cosmos', thus allowing for the repetition of the creative act which points the way back to the centre. In chapter four I gave an example of two extended sequences in which this journey to the centre is clearly evident, as various troubling experiences are eventually connected and resolved through mythologising the gaps. In the final four chapters I constructed readings of Baxter's poems using my framework, demonstrating the underlying consistencies in his work on the level of 'origins' as well as myth and symbol. In this work I show that 'ubiquitous notions of the gap' are pervasive and fundamental to Baxter's work across the range of his poetry. These readings also trace the journey of the mythologising self, as the relationship to the gap evolved to the point where the poet proclaims that 'even one's name is a way of saying - "This gap inside a coat". This framework provides tools for reading Baxter's method as well as his material, and thus offers an approach which can be utilised as a tool for comparison in future readings of the poet's work.

The conclusions drawn in this thesis also point outwards beyond the field of Baxter criticism and New Zealand literature. Baxter's mythology was undoubtedly informed by local social, cultural and geographical features, some of which are unique to New Zealand. Yet the most enduring and influential features of his work - particularly his mythologising and use of gaps - transcend national boundaries, linking the poet to other models and traditions. In particular, Baxter's work points to larger issues around writing, inspiration, identity, agency and personal authority. Much of the critical response to Baxter's work suggests a desire to locate within the author the fixed message of the text, which is then taken to reflect shared or rejected values. Yet Baxter's writing emerges out of the problems of identity and the gaps which the mythologising self effectively relies on for a momentary sense of 
authority. The desire to be a somebody and a nobody remained with the poet, and the critical response has generally overlooked the significance of the latter in favour of more biographical responses. The creative process traced in this thesis challenges the notion of a singular, fixed identity as the source of the author's work. While the content of Baxter's 'social' poetry and prose may be dated in terms of detail, these questions asked in relation to personal experience seem enduringly relevant. The three types of gap Baxter continually returns to are indeed - in their broadest application - prevailing 'subjective' conditions of human experience.

There is a sense in which the question of identity is at the hub of Baxter's life and work, challenging and reshaping the mythology in response to experience. In this sense, alongside his 'perfectionist' tendencies, Baxter's openness to other traditions reflects a countervailing desire to go beyond form and notions of 'logos' towards a greater acceptance of mystery and uncertainty. In 1971 Baxter told Weir that

Buddha Sakyamuni went out and took his robe from the bodies of the dead ... and said 'The ego is a hole in the ground; it is a gap' ... people would be scandalized, wouldn't they ... But this was truth. Truth is hard to put a name to, isn't it? And they want a name, and they want a fixed position because they want their own fixed identity which does not exist.

('Interview' 246-47)

The place Baxter reached through his engagement with the gap at times seemed to suggest a freedom from the labyrinth of his own mythologising - yet the harsh terms of the Jerusalem 'bargain' seem to have contributed to the fulfilment of that earlier prophetic wish to be joined to the myth and to follow it to its conclusion. 
Baxter's mythologising moves back and forth between perfection and possibility, and perhaps in the critical response to his work these positions are also continually tested.

Baxter told Shadbolt that both psychology and writing led to a 'hollow centre'. Given the place at which his story came to rest, Baxter's mythology can easily be interpreted along the lines of the process of integration Jung describes in 'Dream Symbolism in Relation to Alchemy'. In summarising the dreamer's journey to the centre, Jung writes:

it seems as if all the personal entanglements and dramatic changes of fortune that go to make up the intensity of life were nothing but hesitations ... manufactured to avoid facing the finality of this strange or uncanny process of crystallisation. Often one has the impression that the personal psyche is running around this central point like a shy animal, at once fascinated and frightened, always in flight, and yet steadily drawing near.

(CW 12, Part 1, 325)

This notion of a journey to the centre illuminates Baxter's patterns of symbolism, and his mythology can be read as a progression towards a final acceptance of the 'uncanny process of crystallisation', especially its ending in a 'sacrificial' death. Yet an alternative story emerges from Baxter's mythologising, which can be set alongside this Jungian reading. This other narrative has at its centre an unconvinced and divided individual who continually makes the decision to privilege mythos over logos, rejecting the 'ordinary' self and world, continually reinforcing a choice of belief in sacred patterns through the process of exchanging experience for myth. 
This process discards, repudiates and rejects in order to transform experience into mythology. Behind this process lie further mysterious machinations of self-reading and writing, in the space where agency and identity are blurred and fluid.

The sense of the 'uncanny' often enters into Baxter's mythologising process, where the 'infinite search for maimed identity' which is at the heart of poems such as 'Canticle of the Desert' reflects a concurrent sense of knowing and uncertainty, authority and ignorance, and a doubling of the self which seems simultaneously the subject and object at the centre of the story. In 1955, Baxter wrote that he was haunted by the

man I see in the shaving mirror - who has come a good way and knows less than when he began. The most dangerous time for him is the day he first uses the word 'adolescent' to describe the thing he does not like; when he rejects half of his universe to make the other half safe.

('Outlook for Poetry', Essential 7)

In Horse, however, this type of rejection leads to the blurring of identity and agency evident in the scene where the writer's two alter egos stare at each other in the mirror. Just as in Norse mythology Odin sacrifices 'himself to himself', so in the mind of Horse, the writer places a vision of self-destruction or suicide:

He shaved slowly in the narrow bathroom at the bottom of the stairs. His twin and incubus, Timothy Harold Glass ... stared back at him from the loony mirror. Pud-puller! He whispered bitterly to his reflection. A sniper's rifle cracked soundlessly from outer space. Two bullets ... entered his cranium ... It was a cold day for the funeral. 
... A high shrill music sounded above the wandering clouds. Six feet underground a young man's bones lay quiet until the ending of the world.

Having attended his own funeral, Horse moved gingerly through the house on stockinged feet ...

In this mock suicide/murder the mythologising self seems to occupy a range of positions simultaneously, as worthy victim, unsympathetic observer and the divine marksman ${ }^{1}$ dispensing justice. The phases in Baxter's work, and life, are intricately tied to the mythology of the gap, the need to destroy the old gods, or icons, and to shake off the deathly state of stasis in an exchange which brings forth new life at the expense of the old self, as the 'god' is sacrificed to be reborn. In this mode, the journey to the centre is further complicated by the sense in which self-reading and self-writing are implicitly or explicitly played out in front of an audience.

Baxter's mythology of the gap reflects the persistent desire for the possibility of meaning, healing and identity which was both threatened and reinforced by the creative process. In his reaching out towards mythological 'certainty', he often repudiated and rejected the ordinary world and the self who inhabited it, thus arguably negating creative possibilities through this tendency towards 'perfectionism'. In blurring the line between personal mythology, poetry and 'prophetic' wisdom, Baxter consistently reinforces the authority of the mythologising self, the momentarily godlike creator who divines and establishes order. The rejection of the 'ordinary' self and the world it inhabits in favour of a momentary, more or less illusory self, seems in this version of the creative process

\footnotetext{
${ }^{1}$ See also the parable of the 'marksman', $J D$ 2-3.
} 
to be both a necessary part of the poet's work and a source of ongoing tension and suffering. The desire to escape 'elsewhere' can never satisfy on any terms other than through the 'moment of art'. Thus I see Baxter's mythologising as instructive where the questions of identity, authority and the capacity to decipher or construct meaning are all constantly addressed and obscured by the presence of the self who shifts in and out of the 'empty frame'.

Typically, Baxter seems to have anticipated those who might make the trip down the winding river road to Jerusalem in search of an icon, a 'kiwi hero' to place at the centre of a story, enabling a momentary exchange of the 'Kingdom of Anxiety' for the world of myth. Yet what is revealed at the end of a journey is dependent on the imperatives of desire which inform it, and the name Baxter can also frame a question. Rather than driving the seeker towards the rejection of 'what is' in favour of the fixed plot of prophetic perfectionism, this questioning path might lead to the window of possibility and the freshness of 'ordinary' experience:

Now, if you go to the valley of Jerusalem,

You'll find that the silence is like any other silence,

You'll find that the river is like any other river,

You'll find that the rain is like any other rain,

But the old man has gone out of the picture,

Leaving an empty picture frame. 


\section{Bibliography}

\section{Works by James K. Baxter}

\section{(a) Books}

Baxter, James K. Recent Trends in New Zealand Poetry. Christchurch: The Caxton Press, 1951.

- The Fire and the Anvil: Notes on Modern Poetry. Wellington: New Zealand University Press, 1955.

- Howrah Bridge and other Poems. Wellington: Oxford University Press, 1961.

—. Pig Island Letters. London: Oxford University Press, 1966.

—. Aspects of Poetry in New Zealand. Christchurch: Caxton Press, 1967.

—. The Man on the Horse. Dunedin: Otago University Press, 1967.

—. The Flowering Cross. Dunedin: New Zealand Tablet, 1969.

- Jerusalem Sonnets: Poems for Colin Durning. Dunedin: Bibliography Room, University of Otago, 1970.

—. Jerusalem Daybook. Wellington: Price Milburn, 1971.

—. Autumn Testament. Wellington: Price Milburn, 1972.

—. Six Faces of Love. Wellington: Futuna Press, 1972.

—. Thoughts about the Holy Spirit. Wellington: Futuna Press, 1973.

- The Bone Chanter: Unpublished Poems 1945-72. Ed. J. E. Weir. Wellington: Oxford University Press, 1976. 
- James K. Baxter as Critic: A Selection from his Literary Criticism by Frank McKay. Auckland: Heinemann Educational Books, 1978.

- Collected Plays. Ed. Howard McNaughton. Auckland: Oxford University Press, 1982.

—. Horse. Auckland: Oxford University Press, 1985.

- Cold Spring: Baxter's Unpublished Early Collection. Ed. Paul Millar. Auckland: Oxford University Press, 1996.

—. New Selected Poems. Ed. Paul Millar. Auckland: Oxford University Press, 2001.

- Collected Poems. Ed. J. E. Weir. Auckland: Oxford University Press, 2003.

—. Selected Poems. Ed. Paul Millar. Auckland: Auckland University Press, 2010.

\section{(b) Shorter texts}

'When the Wind Blows'. Canta. 7/7/48.

'Saturnalia'. Canta. 5/5/48.

'Choice of Belief in Modern Society.' Critic 28.1, 6 March 1952: 1, 7.

'Essay on the Higher Learning.' Spike 1961: 61-64.

'Further Notes on New Zealand Poetry.' Unpublished typescript. Hocken MS 975/119.

Review of Man Alone by John Mulgan. Landfall 3 (1949): 374.

'On the Burns Fellowship.' Landfall 22 (1968).

'Some Notes on Drama.' Act 1.3 (July/Sept 1967): 20. 
'Why Writers Stop Writing.' Hilltop I.3 (Sept. 1949): 26-27.

'The Town That Sank Under the Sea.' Otago Daily Times 28 Jan. 1956: 4.

'Essay on the Higher Learning.' Spike (1961): 61-64.

'Shots Around the Target.' Chaff XVIV.2 (Sep. 1966). See also Eikon 2 (Dec. 1966): 16.

'Baxter: The Human Being is Object and Subject.' Critic XLIII.12 (5 Sep. 1967): 21.

'Poetry in New Zealand.' Yearbook of the Arts in New Zealand 2 (1946): 111-14.

'The Furies.' Canta XIX.8 (7 July 1948): 4.

'To Accidie.' Canta XIX.8 (7 July 1948): 4.

‘Salvation Army Aesthete.' Canta XIX.9 (21 July 1948): 4.

'Desert Song.' Canta XIX.11 (18 Aug. 1948): 4.

'The Idea of Progress' NZ Monthly Review 63 (Dec 1965-Jan 1966) 63, 13-14.

'The Advantages of Not Being Educated', Listener 24/12/1959, 8.

‘On Returning to Dunedin', Otago Daily Times, 22/09/1966, 4.

'Correspondence' [Teilhard de Chardin debate] Hocken MS - 0739/023.

'Things and Idols', Hocken MS- 0975/160.

'Elegy for Boyle Crescent', James K. Baxter, 1926-1972: A Memorial Volume. Wellington:, 1972. Alistair Taylor Publishing. Ed. Alistair Taylor.

\section{(c) Unpublished material}

All of the unpublished material is sourced from the Baxter archive in the Hocken Library (ARC-0027), with the exception of Baxter's letter to Shadbolt, the original 
of which is held in the Frank McKay archive in the Beaglehole Room, Victoria University of Wellington. Thanks to Paul Millar for access to this letter.

\section{Secondary Works}

Adcock, Fleur. 'Wielding the Jawbone of an Ass.' New Zealand Books. 4.2 (August 1994): 1,11-12.

Altizer, Thomas. Mircea Eliade and the Dialectic of the Sacred. Westport, Connecticut: Greenwood Press, 1975.

Auden, W. H. 'Yeats as Example', The Kenyon Review, 10.2 (Spring 1948): 187-95.

Aristotle. Poetics. New York: W.W. Norton, 1982.

Baxter, Archibald. We Will Not Cease. Whatamongo Bay: Cape Catley, 1980.

Baxter, Millicent. The Memoirs of Millicent Baxter. Whatamongo Bay: Cape Catley, 1981.

Beard, Tom. 'More than the Myth he became.' New Zealand Books. 4.2 (August 1994): 9-10.

Berger, John. 'The Hour of Poetry'. Selected Essays. Ed Geoff Dyer. London: Bloomsbury, 2001. 445-52.

Burke, Kenneth. Language as Symbolic Action: Essays on Life, Literature, and Method. Berkeley: University of California Press, 1966.

Bertram, James. 'Two New Zealand Poets.' Education. 2.4 (September 1949): 59-61.

—. 'Poet of Extremes.' Listener. 71.1724 (20/11/1972): 8-9.

Bornholdt, Jenny, Gregory O’Brien, Mark Williams. Eds. An Anthology of New Zealand Poetry in English. Auckland: Oxford University Press, 1997. 
Brasch, Charles. 'Phrases and Poems.' Review of Pig Island Letters. New Zealand Monthly Review. 74 (December 1966): 22-23.

Brown, Danielle. 'James K. Baxter : the identification of "poet" and the authority of the "prophet".' Journal of New Zealand Literature (JNZL) 13 (1995): $133-42$.

Broughton, William. 'Troubled by his own absurdity? an examination of some of the last sonnets of Baxter.' JNZL. 13 (1995): 143-56.

Bruner, Jerome. 'Life As Narrative.' Social Research. 71.3 (Fall 2004): 691-710.

Campbell, Alistair. 'Impressions of the Earlier Baxter.' Landfall 27 (September 1973): 179-84.

Campbell, Joseph. The Hero with a Thousand Faces. Princeton: Princeton University Press, 1949.

—. The Masks of God: Occidental Mythology. New York: Viking, 1964.

- The Inner Reaches of Outer Space: Metaphor as Myth and as Religion. New York: Harper \& Row, 1988.

Chan, Stephen. 'A Godly dissidence: In Memoriam, James K. Baxter 19261972.' New Zealand Monthly Review. 280 (September 1985): 18-20.

Clark, Timothy. 'Contradictory Passion: Inspiration in Blanchot's The Space of Literature.' SubStance. 25.1 .79 (1996) 46-61.

—. The Theory of Inspiration: Composition As a Crisis of Subjectivity in Romantic and Post-Romantic Writing. Manchester: Manchester University Press, 1997.

Cleary, Farrell. 'Baxter's plays: the search for life before death.' (JNZL) 13. (1995): 121-32.

Coupe, Laurence. Kenneth Burke on Myth: An Introduction. New York: Routledge, 2005.

M. Myth. $2^{\text {nd }}$ ed. Abdingdon: Routledge, 2009. 
Cupitt, Don. Mysticism After Modernity. Oxford: Blackwell, 1998.

Curnow, Allen. Ed. A Book of New Zealand Verse, 1923-45. Christchurch: Caxton Press, 1945.

-. Ed. Penguin Book of New Zealand Verse. Harmondsworth: Penguin, 1960.

- Ed. The Penguin Book of New Zealand Verse: Edited and introduced Allen Curnow. Auckland: Blackwood and Janet Paul, 1966.

Davidson, John. 'James K. Baxter and the Classics.' Islands.4 (Summer 1975): 451-64.

—. 'Catullus, Horace and Baxter.' Islands 5 (Autumn 1976): 86-94.

—. 'Philoctetes Down Under.' AUMLA: Journal of the Australasian Universities Language and Literature Association. 47 (1978): 49-56.

—. 'Odysseus, Baxter and New Zealand poetry.' Landfall. 34 (June 1980) 107-19.

—. 'James K. Baxter at Colonus.' AUMLA: Journal of the Australasian Universities Language and Literature Association. 83 (May 1995): 43-54.

Dennison, John. "Truth that is shared": James K. Baxter's Cross-cultural Metaphors and Pakeha Identity.' Stimulus: the New Zealand Journal of Christian Thought and Practice (Stimulus). 11.1 (February 2003): 42-47.

—. 'Ko teina te Pakeha: Baxter's Cross-Cultural Poetry'. JNZL. 23.2 (2005): 36-46.

_. 'Myth-Eaten: JKB's Habits of Mind', The Landfall Review Online. (December 2011). 18 ${ }^{\text {th }}$ October 2012. http://landfallreviewonline.blogsp ot.co.nz/2011/12/myth-eaten-jkbs-habits-of-mind.html\#!/2011/12/mytheaten-jkbs-habits-of-mind.html.

Doyle, Charles. James K. Baxter. Boston: Twayne, 1976 (Twayne's World Authors Series). 
Eliade, Mircea. The Sacred and the Profane; the Nature of Religion. New York: Harcourt Brace, 1959.

—. The Quest: History and Meaning in Religion. London: Harvill Press, 1961.

—. Images and Symbols: Studies in Religious Symbolism. London: Harvill Press, 1961.

- Myth and reality. New York: Harper \& Row 1963.

—. Man and the Sacred: A Thematic Source Book of the History of Religions. New York: Harper \& Row, 1974.

. A Critical Reader. Ed. Bryan Rennie. London: Equinox Publishing, 2006.

Eliot, T.S. Selected Prose of T.S. Eliot. London: Faber and Faber, 1975.

Feder, Lilian, Ancient Myth in Modern Poetry. Princeton: Princeton University Press, 1971.

Frye, Northrop. Anatomy of Criticism: Four Essays. Princeton: Princeton University Press, 1957.

—. Blake: A Collection of Critical Essays (Ed.). Englewood Cliffs, New Jersey: Prentice Hall, 1966.

- The Double Vision: Language and Meaning in Religion. Toronto: University of Toronto Press, 1991.

Glover, Denis. 'James K. Baxter.' James K. Baxter 1926-1972, A Memorial Volume. Ed. Alistair Taylor. Wellington: Alistair Taylor Publishing, 1972. 125.

Harkiman. 'The poetry of death: a thematic study of the verse of James K. Baxter and Chairil Anwar.' Thesis, MA. Victoria University of Wellington, 1993.

Hawes, Tara. 'A Tribesman cut off from his Tribe: Baxter and the Family.' JNZL. 13 (1995): 39-45.

Hughes, Ted, 'Myth and Education' in Winter Pollen: Occasional Prose. Ed. William Scammell. London: Faber, 1994. 136-53. 
Ireland, Kevin, Review of 'Pig Island Letters.' The Journal of Commonwealth Literature 4 (1969): 139.

Isichei, Elizabeth. 'James K. Baxter: Religious Sensibility and a changing Church.' JNZL. 13 (1995): 235-56.

Jackson, Anna. 'An Appealing Excess: A New Edition of James K. Baxter.' Review of New Selected Poems. JNZL. 18/19 (2001): 205-06.

James, Trevor. 'Poetry in the Labyrinth: the Poetry of James K. Baxter.' World Literature Written in English 22: (Autumn 1983): 342-51.

—. 'Baxter's "two-horned" Poetry and its Critics.' Landfall 38: 459-66; December 1984.

Jensen, Kai. 'The Drunkard and the Hag: James K. Baxter's use of Jung.' JNZL. 13 (1995): 211-34.

- Whole Men: The Masculine Tradition in New Zealand Literature. Auckland: Auckland University Press, 1996.

Jones, Lawrence. 'The Mythology of Place: James K. Baxter's Otago Worlds.' JNZL. 13 (1995): 65-96.

Jung, C. G. Modern Man in Search of a Soul. London: Routledge \& Kegan Paul, 1933.

— The Collected Works of C.G. Jung. Eds. Herbert Read, Michael Fordham, Gerhard Adler. 20 volumes. London: Routledge; Princeton: Princeton University Press, 1953-79.

— Jung, C.G., Aniela Jaffé. Memories, Dreams, Reflections. New York: Vintage Books, 1965.

Keary, A. \& E. The Heroes of Asgard: Tales from Scandinavian Mythology. London: Macmillan and Co, 1893, 1906, 1930, Introduction taken from 1906 version). 
King, Michael. 'Jerusalem 25 October 1972', James K. Baxter 1926-1972: A Memorial Volume. Ed. Alistair Taylor. Wellington: Alistair Taylor Publishing, 1972. 44-51.

Land Jones. James. Adam's Dream: Mythic Consciousness in Keats and Yeats. Athens, Georgia: University of Georgia Press, 1975.

Lane, Allister. 'The Christian Symbolism of Nigel Brown/' Stimulus. 17.1 (February 2009): 2-8.

Lawlor, P. The Two Baxters: Diary Notes: with an Essay by Vincent O'Sullivan. Wellington: Millwood Press, 1979.

Leeming, Owen. 'And the Clay Man? Reflections on The Rock Woman: Selected Poems by James K. Baxter.' Landfall. 25 (1971): 9-19.

Maio, Samuel. Creating Another Self: Voice in Modern American Personal Poetry. $2^{\text {nd }}$ edition. Kirksville, Missouri: Truman State University Press, 2005.

Mansfield, Nick. Subjectivity: Theories of the Self from Freud to Haraway. Sydney: Allen \& Unwin, 2000.

McKay, Frank. 'Baxter's Jerusalem poetry.' Landfall. 35 (March 1981): 66-76.

—. The Life of James K. Baxter. Auckland: Oxford University Press, 1990.

McNaughton, Howard. 'Baxter's Strong Ghost.' Landfall. 35 (March 1981): 62-66.

McNeill, Dougal. 'Baxter's Burns'. Ka Mate Ka Ora: A New Zealand Journal of Poetry and Poetics (Ka Mate). 8 (September 2009). 18 ${ }^{\text {th }}$ October 2012. http://www.nzepc.auckland.ac.nz/kmko/08/ka_mate08_mcneill.pdf.

Manhire, Bill. 'Stranger at the Ranchslider.' JNZL. 13 (1995): 11-22.

- 'World Famous in New Zealand.' Poetry London. Summer 10. $16^{\text {th }}$ October 2012. http://www.poetrylondon.co.uk/magazines/66/article/worldfamous-in-new-zealand.

Matthews, Richard. 'James K. Baxter and Kopua.' JNZL. 13 (1995): 257-65. 
Miles, Geoffrey. Classical Mythology in English Literature: A Critical Anthology. London: Routledge, 1999.

- 'Baxter as Icon.' In View: Works from the VUW Art Collection. Wellington: Adam Art Gallery, 2006: 6-7.

—. 'Three Calypsos: Baxter's Variations on a Mythic Theme.' Still Shines When You Think of It: A Festschrift for Vincent O'Sullivan. Eds. Bill Manhire, Peter Whiteford. Wellington: Victoria University Press, 2007: 234-48.

—. "My Troubles began with an Apple": Baxter and the Hercules Myth.' Running Writing Robinson. Eds. David Carnegie, Paul Millar, David Norton, Harry Ricketts. Wellington: Victoria University Press, 2011.

—. 'Baling the Golden Fleece: Baxter's Jason.' Kotare: New Zealand Notes and Queries. Special Issue: Essays in New Zealand Literary Biography Series Three: 'The Early Poets', 2008. October 19 2012. http://nzetc.victoria.ac.nz/tm/scholarly/tei-MilBali.html.

Miles, Geoffrey, John Davidson, Paul Millar. The Snake-Haired Muse: James K. Baxter and Classical Myth. Wellington: Victoria University Press, 2011.

Millar, Paul. 'The “tension of belief': some Remarks on the Criticism of James K. Baxter's Poetry.' Span. 45 (October 1997): 103-08.

—. "He who would be a poet": James K Baxter's Early Poetry Manuscript Books.' Kotare: New Zealand Notes \& Queries. 2.2 (November 1999): 28-43.

- Spark to a Waiting Fuse: James K. Baxter's Correspondence with Noel Ginn, 1942-46. Wellington: Victoria University Press, 2001.

—. "Hemi te Tutua/ Jim the Nobody: the "gap" and the "void" in the Poetry of James K Baxter.' Stimulus. 11.1 ( February 2003): 9-16.

—. 'Baxter, James Keir 1926-1972.' Dictionary of New Zealand Biography, updated 7 April 2006 URL: http://www.dnzb.govt.nz/. 
—_. 'James K. Baxter's Indian Poems.' Ka Mate. 3 (March 2007).

Newton, John, "'By Writing and Example”: The Baxter Effect.' Ka Mate. 1 (December 2005).

- The Double Rainbow: James K. Baxter, Ngati Hau and the Jerusalem Commune. Wellington: Victoria University Press, 2009.

de Nicholas, Antonio T. St. John of the Cross: Alchemist of the Soul: His Life, His Poetry (Bilingual), His Prose. New York: Paragon House, 1989.

O'Brien, Gregory. 'After Bathing at Baxter's.' After Bathing at Baxter's: Essays and Notebooks. Wellington: Victoria University Press, 2002. (17-45).

—. 'No dream but life: James K. Baxter's Spark to a Waiting Fuse and Peter Jackson's Lord of the Rings: a notebook, 19 December 2001.' Sport. 28 (2002): 95-108.

O'Donoghue, Heather. From Asgard to Valhalla: The Remarkable History of the Norse Myths. London: I.B. Tauris, 2007.

Oliver, W. James K. Baxter: A Portrait. Wellington: Port Nicholson Press, 1983.

—. 'The Virtue of Defeat.' New Zealand Books 4.2 (August 1994): 11-12.

O'Sullivan, Vince. 'After Culloden: remarks on the early and middle poetry of James K. Baxter.' Islands. 2 (Autumn 1973): 19-30.

—. James K. Baxter. Wellington: Oxford University Press, 1976.

—. 'The Sore Thumb of the Tribe.' Review of Collected Poems by James K. Baxter. New Zealand Listener. (25 Oct. 1980): 84-85.

- 'James K. Baxter.' In Poetry of the Pacific Region: proceedings of the RNLE/SPACLALS Conference, Adelaide, 1983. Edited by Paul Sharrad, Adelaide : Centre for Research in the New Literatures in English, 1984. 
—. 'Urgently creating a past: remarks on James K. Baxter.' In The writer's sense of the past: essays on Southeast Asian and Australian literature, edited by Kirpal Singh. Singapore : Singapore University Press, 1987. 94101.

—. An Anthology of Twentieth Century New Zealand Poetry. $3^{\text {rd }}$ edition. London: Oxford University Press, 1987.

Paparoa Holman, Jeffrey. "Reason not the need": John Newton and James K. Baxter's Double Rainbow', Ka Mate. 8 (September 2009).

Parr, C. Introducing James K. Baxter. Auckland: Longman Paul, 1983.

Pearson, Bill, and Peter Olds. 'Two personal memories of James K. Baxter.' Islands 2 (Autumn 1973): 2-7.

Pease, Donald E. 'The Author'. Critical Terms for Literary Study, $2^{\text {nd }}$ ed. Eds. Lentricchia, Frank and McLaughlin, Thomas. Chicago: The University of Chicago Press, 1995.

Phillips, Russell. 'James K. Baxter: a dialogue with his later theological and philosophical thought in the context of Aotearoa/New Zealand.' JNZL. 13. (1995): 267-84.

Porte, Rebecca, 'The Passion of James K. Baxter', Contemporary Poetry Review, 2008.

Riach, Alan. 'James K. Baxter and the dialect of the tribe.' New Literatures Review. 20 (Winter 1990): 12-18. Reprinted in Opening the Book: New Essays on New Zealand Writing. Edited by Mark Williams and Michele Leggott. Auckland: Auckland University Press, 1995. 105-22

Ricketts, Harry. Talking About Ourselves: Twelve New Zealand Poets in Conversation with Harry Ricketts. Wellington: Mallinson Rendel, 1986.

Ricoeur, Paul. Time and Narrative. Chicago: University of Chicago Press, 1984. A Ricoeur Reader: Reflection and Imagination. Ed. Mario J Valdes. New York and London: Harvester/Wheatsheaf, 1991. 
Riddell, Michael. Jerusalem, Jerusalem. Dunedin: Bucket Press, 2003.

—. 'A poet for our Christ? The myth of James K Baxter.' Stimulus. 11.1 (Feb 2003): $35-41$.

Russell, Keith. Reviews Journal. 2 (December 1984): 74-77.

—. 'Kenosis in Baxter's Pig Island Letters.' JNZL. 13 (1995): 109-20.

Segal, Robert A. Jung on Mythology: Selected and Introduced by Robert A. Segal. Princeton, New Jersey: Princeton University Press, 1998.

—. Myth: A Very Short Introduction. Oxford: Oxford University Press, 2004.

Shadbolt, Maurice. 'Letter to Jim Baxter', James K. Baxter 1926-1972, A Memorial Volume. Ed. Alistair Taylor. Wellington: Alistair Taylor Publishing, 1972, 28-40.

- 'James K. Baxter.' In Love and Legend: some 20th century New Zealanders. Auckland: Hodder \& Stoughton, 1976.

Sharp, Iain. More 53: 275-77; Nov 1987.

—. 'Interview with Les Murray', Landfall, 42.2 (166), 1988, 150-68.

—. 'My Grudge against Baxter.' Quote Unquote. 14 (August 1994): 12-14.

Stead, C.K. 'Towards Jerusalem: the Later Poetry of James K. Baxter.' Islands 2 (Autumn 1973): 7-18. Reprinted in Kin of Place : Essays on $20 \mathrm{New}$ Zealand Writers. Auckland: Auckland University Press, 2002.

—. 'James K. Baxter : a Loss of Direction.' In Kin of Place: Essays on 20 New Zealand Writers. Auckland: Auckland University Press, 2002.

Steer, Philip. 'The Jerusalem theology of James K Baxter.' Stimulus. 11.1 (February 2003): 9-16.

Stollenwork, Daniel. 'Void, gap, nada: St John of the Cross' "Dark Night of the Soul” in James K. Baxter's Jerusalem Works', Stimulus. 14.2 (May 2006): 24-32. 
Strelka, Joseph P. (ed.), Literary Criticism and Myth: Yearbook of Comparative Criticism, vol. 9. University Park, Pennsylvania: Pennsylvania State University Press, 1980.

Taylor, Alister (ed), James K. Baxter, 1926-1972: A Memorial Volume. Wellington: Alistair Taylor Publishing, 1972.

Teilhard de Chardin, Pierre. The Phenomenon of Man. London: William Collins Sons, 1959.

—. Le Divin Milieu. London: William Collins Sons, 1960.

Turner, Brian. 'The Forest of a Man: James Keir Baxter, 1926-72.' Lipsync 2 (December 1972):1-3.

Underhill, Evelyn. The Essentials of Mysticism: and other Essays. New York: Dutton, 1960.

Vice, Samantha. 'Literature and the Narrative Self.' Philosophy. 78 (2003): 93-107.

Wedde, Ian. Introduction, The Penguin Book of New Zealand Verse, ed. Ian Wedde and Harvey McQueen (Auckland: Penguin, 1985), 44.

Weir, J.E. 'Man without a Mask: a Study of the Poetry of James K. Baxter.' Thesis, MA. University of Canterbury, 1968.

- The Poetry of James K. Baxter. Wellington: Oxford University Press, 1970.

—. 'An interview with James K. Baxter.' Landfall. 28 (1974): 241-250.

—. 'A Man went on a Search: the Life and Writings of James K. Baxter.' In From Dante to Solzhenitsyn: essays on Christianity and literature. Edited by Robert M. Yule. Wellington: Tertiary Christian Studies Programme, Victoria University of Wellington, 1978.

—. 'James K. Baxter: a Voice for the living.' New Zealandia 4 (August 1989): $19-22$. 
- The Essential Baxter: Selected and Introduced by John Weir. Auckland: Oxford University Press, 1994.

Weir, John and Barbara Lyon. A Preliminary Bibliography of Works by and Works about James K. Baxter. Christchurch: University of Canterbury, 1979.

Whiteford, Peter. 'He Waiata o Hemi : an unpublished poem by James K. Baxter.' Kotare: New Zealand Notes \& Queries. 2.1 (May 1999): 8-13.

Williams, Mark. 'Introduction.' Opening the Book: New Essays on New Zealand Writing. Eds Mark Williams and Michelle Leggott. Auckland: Auckland University Press, 1995.

—. 'James K. Baxter.' The Literary Encyclopedia. (7/11/2002). Accessed 25/8/2011. http://www.litencyc.com/php/speople.php?rec=true \&UID=303.

Wilson, Godfrey. 'Sermon on the death of JKB', James K. Baxter, 1926-1972: A Memorial Volume. Wellington: Alister Taylor Publications, 1972.

Wilson, Janet. 'Archie, Millicent and James: the Baxter autobiographies.' JNZL. 13 (1995): 47-64.

Wu, Duncan. Ed. Romanticism: An Anthology. $2^{\text {nd }}$ edition. Oxford: Blackwell, 1994.

\section{Audio and audiovisual material}

Bland, Peter. 'Interview with James K. Baxter', recorded mid-1960s, Stout Research Centre Literary Archive, ref: 111. Audio

Gilbertson, Elizabeth. 'In their Own Words - New Zealand Writers', interview recorded 13 December 1964.

The Road to Jerusalem. Dir. Bruce Morrison. Morrison Grieve, 1997. Film. 